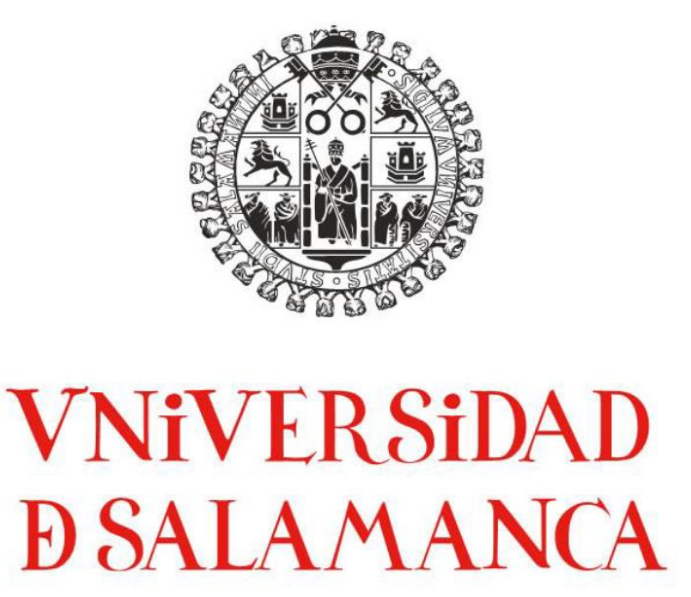

UNIVERSIDAD DE SALAMANCA

ESCUELA DE DOCTORADO

PROGRAMA DE DOCTORADO EN CIENCIAS SOCIALES

TESIS DOCTORAL

\title{
LA COOPERACIÓN SUR-SUR EN AMÉRICA LATINA EN LOS ALBORES DEL SIGLO XXI: EL CASO DE ECUADOR 2000-2015
}

Doctoranda:

Director:

Tutor:
Sandra Elizabeth Zapata Mafla

Rafael Domínguez Martín

Miguel Carrera Troyano

Junio 2020 


\section{Dedicatoria}

\section{A Maura y Ramiro:}

por ser fuente de amor infinito y regalarme alas para volar libre.

\section{A Ximena:}

por los vientos y mares que hemos recorrido juntas y por los que vendrán.

\section{A Cristhian:}

por la ilusión de un futuro resplandeciente y lleno de notas musicales.

\section{A Santiago:}

por estar en mi vida a tiempo y destiempo.

\section{A las Pepas:}

por la infinidad de recuerdos que siempre revivo para ser feliz.

A mi familia:

por las palabras de aliento, la ternura y los abrazos. 


\section{Agradecimientos}

Este proyecto de investigación concluye una etapa de muchas horas de trabajo de doctorado, por lo que resulta imposible no detenerse a pensar en el camino recorrido y recapitular lo andado. Tengo la certeza de que nada de esto hubiese sido posible sin el respaldo, la guía y consejos de todos quienes me acompañaron en esta aventura académica.

Agradezco a la Universidad de Salamanca y a la Facultad de Ciencias Sociales, por abrirme las puertas a una fuente inconmensurable de conocimientos y cultura, y por otorgarme la beca USAL-Santander que me ha permitido mudarme a esta ciudad y descubrir nuevos senderos. De manera particular agradezco el apoyo de mi director de tesis Rafael Domínguez, por su pensamiento crítico, disponibilidad y agilidad para comentar mis avances a lo largo de estos años. También, al departamento de Ciencias Políticas de la USAL, especialmente a Manuel Alcántara por ser un gran mentor y acogerme en el área durante toda mi estadía en Salamanca.

Esta tesis ha salido adelante gracias a las estancias de investigación y participación en congresos internacionales que han sido fuente de enriquecedores intercambios. Agradezco al German Institute of Global and Area Studies -GIGA, en Hamburgo, particularmente a Detlef Nolte quien cada año me brindó las facilidades para para investigar, atender seminarios y discutir mis propuestas. A FLACSO Ecuador, por ser mi alma mater y a donde siempre regreso por ideas frescas y novedosas. Gracias a los programas de ayudas financieras de movilidad, especialmente a la Oficina de Cooperación de la USAL, por la beca para proyectos de Cooperación para el Desarrollo realizada en República Dominicana que me ha permitido mantener al Sur Global en mi horizonte inmediato.

Agradezco a todos los compañeros de FIASCO, por las conversaciones en el jardín, los encuentros en el reloj de la Plaza Mayor, las incontables tazas de café, pero sobre todo por jtantas risas compartidas! A Paloma, por los sabores que evocan nuestras tantas tertulias juntas. Por todos ustedes, los años que viví bajo 
el Cielo de Salamanca adquieren sentido, despiertan una infinidad de buenos recuerdos y ahora saben a dulce nostalgia.

Cuando vuelvo mi mirada al sendero andado, redescubro en lo más íntimo que mi familia ha sido mi refugio y mi fuente de inspiración. Gracias por enseñarme que los pequeños esfuerzos repetidos día a día son pócimas de felicidad y por no soltar mi mano en cada nuevo comienzo, en cada nueva aventura y en cada nuevo horizonte. 


\section{INDICE}

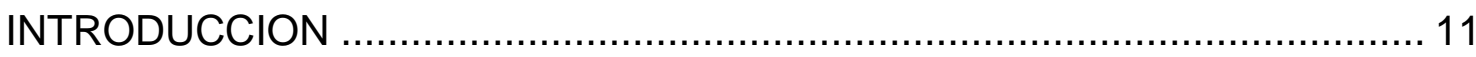

1. Delimitación del objeto de estudio .................................................. 11

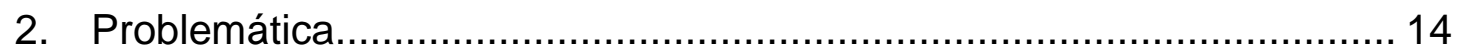

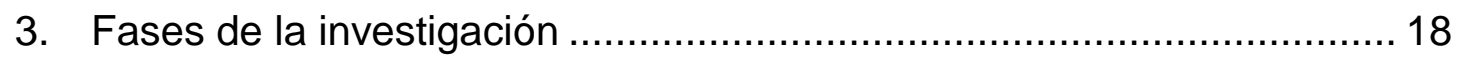

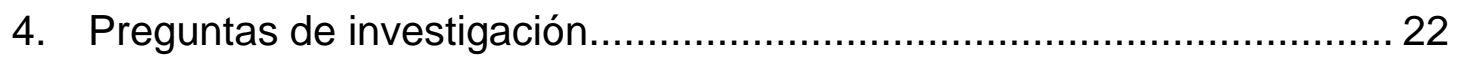

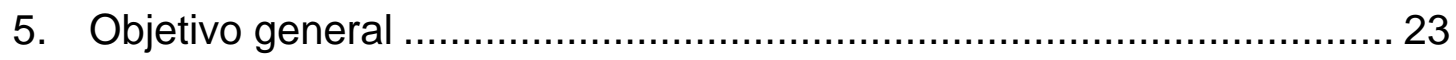

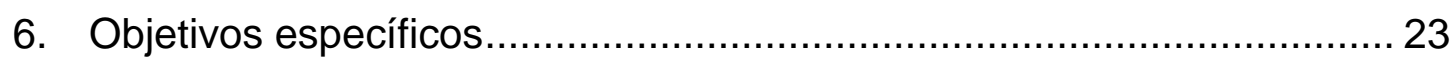

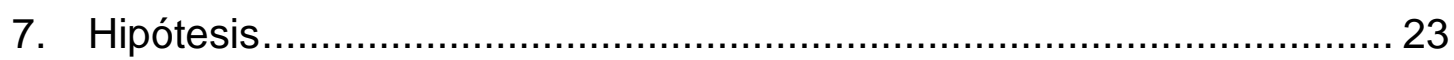

8. Metodología y técnicas de investigación .............................................. 26

9. Fuentes de análisis y construcción de base de datos ............................29

10. Alcances y limitaciones de la propuesta teórico-metodológica ............ 31

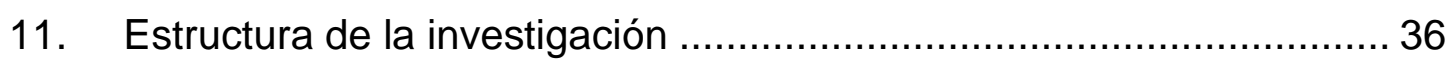

CAPÍTULO I: DESDE DONDE ENTENDER LA COOPERACIÓN SUR-SUR: ANTECEDENTES, CONCEPTOS Y PREMISAS ......................................... 40

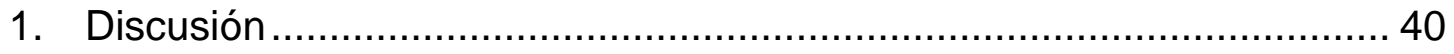

2. La cooperación y el desarrollo en el orden internacional asimétrico ...... 41

3. El Sur en el orden internacional: ¿Qué es la Cooperación Sur-Sur?...... 49

4. Conceptos y abordaje de la Cooperación Sur-Sur ................................. 54

5. Factores de cambio y transformaciones en la estructura internacional .. 59

6. La reemergencia de la Cooperación Sur-Sur en el siglo XXI .................62 62

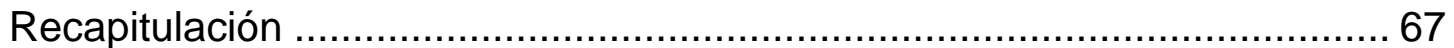

CAPÍTULO II: DINÁMICAS DE LA COOPERACIÓN SUR-SUR EN AMÉRICA LATINA EN LOS ALBORES DEL SIGLO XXI ............................................ 70

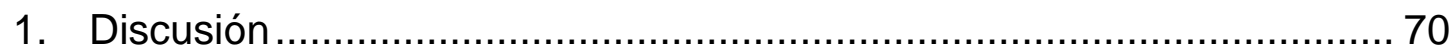

2. Influencia china en el resurgimiento de la CSS en América Latina ........ 70

3. Cooperación Sur-Sur: dimensión económica vs cooperación técnica .... 80

4. Cooperación Sur-Sur: dimensión regional ............................................ 87

4.1 La Alternativa Bolivariana para los Pueblos de Nuestra América Tratado de Comercio de los Pueblos (ALBA-TCP) .................................. 92

4.2 Unión de Naciones Suramericanas -UNASUR …............................ 96

4.3 Comunidad de Estados Latinoamericanos y Caribeños -CELAC .... 99

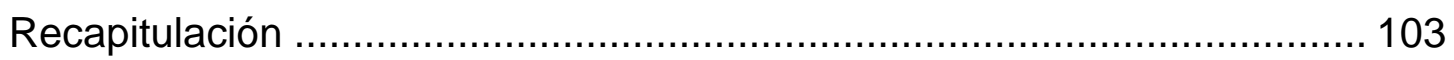

CAPÍTULO III. COOPERACIÓN SUR-SUR Y POLÍTICA EXTERIOR EN LA PERIFERIA: FUNDAMENTOS TEÓRICOS Y METODOLOGÍA. ................... 106 
1. Discusión 106

2. La política exterior en el pensamiento latinoamericano: Realismo Periférico y autonomía 107

3. Abordajes teóricos sobre la autonomía 111

3.1 La autonomía en el pensamiento de Juan Carlos Puig. 113

3.2 La autonomía neoconservadora: el aporte de Escudé.................... 115

3.3 Autonomía relacional y la escuela socio histórica.......................... 118

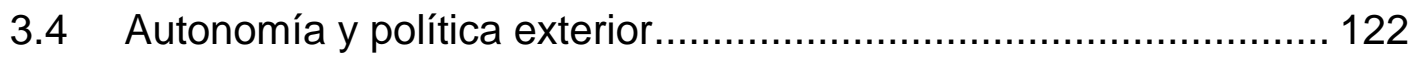

4. Delimitación de principales postulados teóricos e hipótesis .................. 124

5. El método estructural sistémico: variables estructurales y de agencia. 129

5.1 Fase I. Modelo explicativo: variables e indicadores 131

5.2 Fase II: Estudio de caso. La CSS en la política exterior del Ecuador 135

Recapitulación 141

CAPÍTULO IV: LA POLÍTICA EXTERIOR EN AMÉRICA LATINA ANTE LA POTENCIA HEGEMÓNICA DE ESTADOS UNIDOS Y LA POTENCIA EMERGENTE DE CHINA

1. Discusión

2. ¿Qué factores influencian la política exterior en América Latina?

Principales hipótesis 147

3. Alineamiento en política exterior: variables e indicadores. 155

4. La política exterior en América Latina: factores sistémicos y factores agenciales. 158

5. Modelos explicativos 169

Recapitulación 174

CAPÍTULO V. LA COOPERACIÓN SUR-SUR EN LA POLÍTICA EXTERIOR ECUATORIANA: 2000-2015

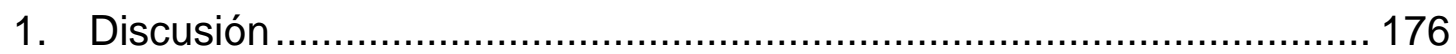

2. Ecuador en el mundo: panorama general de su política exterior .......... 178

3. Variables estructurales de la política exterior ecuatoriana ................... 179

4. Variables domésticas de la política exterior ecuatoriana ........................ 185

5. Ruptura con el centro: el ascenso de Rafael Correa ............................ 188

6. La política exterior en el marco de la Revolución Ciudadana ................ 192

7. Cooperación Sur-Sur y estructuras económicas del Ecuador ............... 193

8. El rol de China y de Estados Unidos en el panorama económico del Ecuador. 204 
9. La reprimarización de la economía ecuatoriana: índice IVCR y Balassa 208

10. Autonomía política: voto de Ecuador en NNUU ...............................213

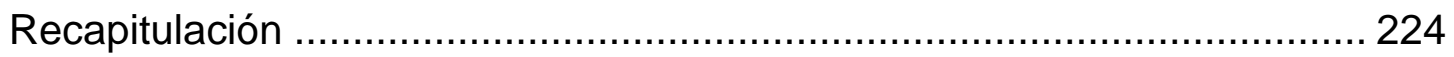

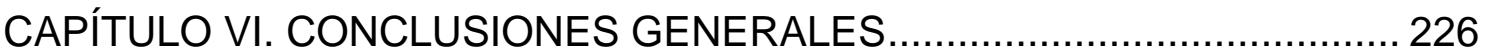

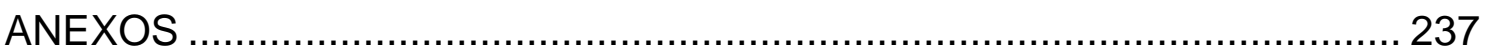

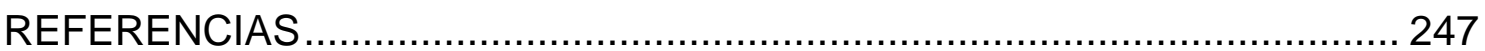

\section{ÍNDICE DE TABLAS}

Tabla 1. Modelos de análisis. Factores de alineamiento de los países latinoamericanos hacia EEUU y China (Regresión lineal múltiple). .............. 170

Tabla 2. Índice Elcano de Presencia Global Ecuador ................................... 184

Tabla 3. Importaciones y exportaciones de Ecuador. China-EEUU ................ 207

Tabla 4. IVCR Ecuador en relación con China y EEUU ................................ 210

Tabla 5. Votaciones Ecuador, China y EEUU por temas en la AGNU ............ 216

\section{ÍNDICE DE ANEXOS}

Anexo 1. Sistematización del fundamento teórico ........................................ 237

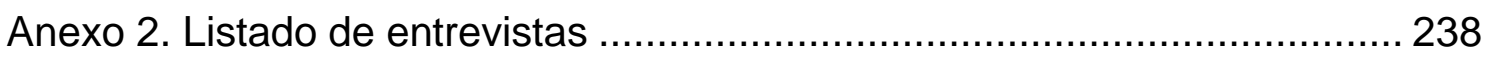

Anexo 3. Votaciones en NNUU: Temática de Derechos Humanos ................. 239

Anexo 4: IVCR normalizado en el mercado de China .................................... 241

Anexo 5: IVCR Normalizado en el mercado de EEUU .................................. 243 


\section{ÍNDICE DE GRÁFICOS}

Gráfico 1. Exportaciones de commodities desde Sudamérica al mundo.......... 75

Gráfico 2. Alineamiento de América Latina con EEUU y China (1970-2015). 159 Gráfico 3 a-b. Alineamiento de América Latina con EEUU y con China. Periodo de polaridad global 161

Gráfico 4 a-b. Alineamiento de América Latina con EEUU y con China.

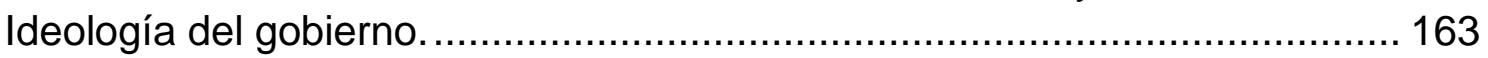

Gráfico 5 a-b. Alineamiento de América Latina con EEUU y con China.

Cualidad democrática del gobierno .

Gráfico 6 a-b. Alineamiento con EEUU y con China. Capacidad económica de

América Latina 165

Gráfico 7 a-b. Alineamiento de América Latina con EEUU y con China.

Concentración de poder 166

Gráfico 8. Efectos internos y sistémicos en el alineamiento de América Latina hacia China y EEUU. 170

Gráfico 9. Alineamiento de los países latinoamericanos hacia EEUU y China.

Análisis factorial Hj Biplot: Clusters jerárquicos............................................ 172

Gráfico 10. Promedio CINC Sudamérica.................................................. 181

Gráfico 11. CINC Sudamérica 1970-2012 ............................................... 182

Gráfico 12. Evolución CINC Sudamérica 1970-2012 ................................. 182

Gráfico 13. Evolución de las exportaciones de Ecuador ................................ 195

Gráfico 14. Composición de exportaciones de Ecuador................................. 196

Gráfico 15.Exportaciones de bienes y servicios Ecuador.............................. 199

Gráfico 16. Importaciones de bienes y servicios Ecuador ............................. 201

Gráfico 17. Componente de importaciones ecuatorianas (en \% sobre el total)

Gráfico 18. Balanza comercial de bienes y servicios (US\$ a precios actuales)

Gráfico 19. Importaciones del Ecuador (\% sobre el total de importaciones) .. 205

Gráfico 20. Exportaciones del Ecuador (Valores en miles de US\$) ............... 206

Gráfico 21. IVCR Ecuador con China y EEUU .......................................... 210

Gráfico 22. Número de resoluciones AGNU por temática. Ecuador, China y

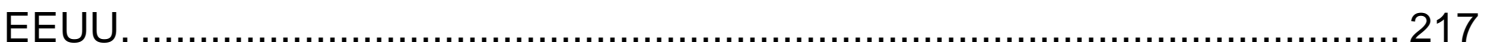

Gráfico 23. Composición temática de resoluciones discutidas en la AGNU por

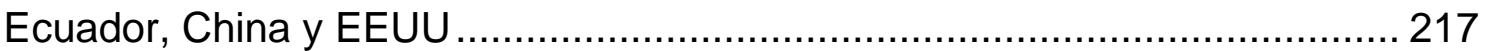

Gráfico 24. Votaciones Ecuador, China, EEUU......................................... 219

Gráfico 25. Composición por temáticas y número de resoluciones................. 220 


\section{INDICE DE ACRÓNIMOS}

AOD

AGNU

ALADI

ALBA-TCP

BCE

BM

CELAC

CEPAL

CINC

COMTRADE

CSS

CTPD

EEUU

EPI

FMI

IED

ITC

IVCR

JID

MRERPC

NNUU

MNOAL
Ayuda Oficial al Desarrollo

Asamblea General de Naciones Unidas

Asociación Latinoamericana de Integración

La Alternativa Bolivariana para los Pueblos de Nuestra América -Tratado de Comercio de los Pueblos

Banco Central del Ecuador

Banco Mundial

Comunidad de Estados Latinoamericanos y Caribeños

Comisión Económica para América Latina y el Caribe

Índice de Capacidades Materiales Nacionales

United Nations Comtrade Database

Cooperación Sur-Sur

Cooperación Técnica entre Países en Desarrollo

Estados Unidos de América

Economía Política Internacional

Fondo Monetario Internacional

Inversión Extrajera Directa

International Trade Center

Índice de Ventajas Comparativas Reveladas

Junta Interamericana de Defensa

Ministerio de Relaciones Exteriores de la RPC

Naciones Unidas

Movimiento de Países No Alineados 


$\begin{array}{ll}\text { NOEI } & \text { Nuevo Orden Económico Internacional } \\ \text { OEA } & \text { Organización de Estados Americanos } \\ \text { OEC } & \text { Observatory of Economic Complexity } \\ \text { PAIS } & \text { Patria Altiva i Soberana } \\ \text { PIB } & \text { Producto interno bruto } \\ \text { PLANEX } & \text { Plan Nacional de Política Exterior } \\ \text { PNBV } & \text { Plan Nacional para el Buen Vivir } \\ \text { RPC } & \text { República Popular China } \\ \text { SEGIB } & \text { Secretaría General lberoamericana } \\ \text { SELA } & \text { Sistema Económico Latinoamericano y del Caribe } \\ \text { SENPLADES } & \text { Secretaría Nacional de Planificación y Desarrollo } \\ \text { TIAR } & \text { Tratado Interamericano de Asistencia Recíproca } \\ \text { UE } & \text { Unión Europea } \\ \text { UNASUR } & \text { Unión de Naciones Suramericanas } \\ \text { UNCTAD } & \text { Unidad de Cooperación Económica e Integración entre } \\ \text { WITS } & \text { Países en Desarrollo } \\ \text { WTO } & \text { World Integrated Trade Solution } \\ & \text { World Trade Organization }\end{array}$




\section{INTRODUCCION}

\section{Delimitación del objeto de estudio}

La cooperación Sur-Sur (CSS) es un tema cada vez más relevante en el campo de estudio de las Relaciones Internacionales. Transmite diferentes significados vinculados a la promoción de visiones alternativas de desarrollo que reflejan los diversos intereses de los países del Sur frente al Norte Global dominante. Como categoría analítica ha sido el concepto organizador de un conjunto de prácticas que reivindican una vasta complejidad de procesos de transformación social que, sobre la base del fortalecimiento de relaciones horizontales y solidarias, debería permitir a los países en desarrollo una inserción más simétrica en el orden internacional.

Su resurgimiento en los albores del siglo XXI se encuentra estrechamente vinculado al renovado liderazgo de países emergentes, pertenecientes al Sur Global $^{1}$, que se ubican en el centro de la actual transformación del sistema internacional. Estos actores cuentan con creciente capacidad económica, financiera y técnica para incidir en el reordenamiento de las jerarquías y equilibrios mundiales de poder. Particularmente en América Latina, la CSS se revitaliza como un mecanismo de política exterior que pone en relieve el dinamismo social, económico, cultural de las relaciones entre países del Sur y recupera la narrativa reivindicativa como instrumento para posicionar alternativas de desarrollo y propuestas de acción colectiva tendientes a afianzar la autonomía política y económica de estos países.

Históricamente, la CSS dio coherencia a un conjunto de prácticas que promueven la autosuficiencia, la no interferencia y la independencia económica para la mejor inserción de los países subdesarrollados en el orden mundial establecido a raíz de la Segunda Guerra Mundial. Este enfoque de reivindicación tomó como hito la Conferencia Afroasiática de Bandung en 1955, que conformó el ideario político de colaboración entre los países del Sur, y se plasmó

\footnotetext{
${ }^{1}$ La expresión Sur Global ha adquirido un uso generalizado en las relaciones internacionales para referirse a los países emergentes y en desarrollo, ubicados en África, América Latina y el Caribe, Asia y el Pacífico (Rica \& Lockhart, 2013).
} 
posteriormente en la institucionalización de los mecanismos de concertación política y económica como el MNOAL, la creación de la UNCTAD y del Grupo 77 (G77). La CSS alcanzó su máxima expresión en la década de 1970 con la agenda del Nuevo Orden Económico Internacional (NOEI) y la Carta de Derechos y Deberes Económicos de los Estados.

Estas propuestas agruparon los postulados de los países periféricos relativas a las reglas de funcionamiento de la economía internacional y el rol asimétrico al que se encuentran sometidos estos países en sus procesos de inserción internacional. Uno de los elementos clave de la cooperación entre los países del Sur fue el cuestionamiento a la "ayuda al desarrollo" y la crítica a la visión misma de "desarrollo" enfocada únicamente en atender el crecimiento económico dejando de lado el análisis sistémico donde determinadas estructuras y orden económico perpetúan la posición de desigualdad y marginalidad de los países periféricos. Estas estructuras merman la persecución de proyectos nacionales basados en la autosuficiencia nacional colectiva para liberarse de la dependencia comercial, financiera y tecnológica que impedía la realización del derecho al desarrollo de los países recientemente independizados (Domínguez 2019: 7).

En el ámbito académico el resurgimiento de la CSS en los últimos años ha sido abordado, a grandes rasgos, desde dos enfoques principales. El primero, la entiende en el marco de lo que se conoce como "Ayuda Oficial para el Desarrollo" (AOD) y se la estudia bajo el prisma institucional de la Organización para la Cooperación y el Desarrollo Económico (OCDE), donde la CSS es una modalidad más dentro de los flujos que las agencias oficiales, incluidos los gobiernos estatales y locales, o sus agencias ejecutivas, destinan a los países en desarrollo y a las instituciones multilaterales (OECD 2020).

Desde este enfoque se realizan análisis sobre las áreas temáticas, volúmenes, regiones prioritarias de procedencia y destino de la cooperación, diseños institucionales, esquemas de financiamiento, agentes involucrados, entre otros. Bajo este prisma, la CSS se inserta en el entramado del régimen de la ayuda, en tanto dimensión de las relaciones Sur-Sur. Así, la CSS se circunscribe a aquellas 
acciones gestadas desde las unidades del gobierno y orientadas a la cooperación internacional para el desarrollo con un tercer país que pueden materializarse a través de la cooperación técnica (programas de asistencia técnica), las transferencias directas (subvenciones) y los préstamos concesionales, entre otros instrumentos (Lengyel y Malacalza 2014).

El segundo enfoque, que constituye la línea guía de esta investigación, retoma el carácter histórico de la CSS que surge como movimiento contestatario de las asimetrías en las relaciones Norte-Sur y se consolida como un mecanismo de diálogo cuya finalidad es fortalecer la capacidad de negociación colectiva de los países del Sur Global. En este aspecto, la CSS se plasma como proyecto político reivindicativo de los países periféricos para demandar cambios en las estructuras internacionales, a partir de diversos intentos de crear coaliciones para transformar el orden económico internacional en base de la cooperación política y económica. En este sentido, se retoma la CSS como parte fundamental del ejercicio de la política exterior de los países periféricos como herramienta que ayudaría a superar la estratificación sistémica internacional (Bergamaschi y Tickner 2017; Chakrabarti, 2018; Muir 2016; Domínguez 2019)

Desde este punto de partida, en este estudio se entiende a la CSS en el marco amplio de la Economía Política Internacional (EPI) y de las fuerzas sociales que avala; y, por ende, se la analiza en estrecha relación con las transformaciones tectónicas de las estructuras de poder y con los sujetos que configuran dichas relaciones. Dentro de este marco, se busca comprender a la CSS tomando como eje central el sistema internacional en su totalidad, es decir analizarla dentro del "sistema de poder que se integra en la esfera más amplia de la política internacional” (Sogge 2002). Por ello, esta investigación se remite a la teoría y práctica de las relaciones internacionales, es decir, a la estructura y dinámica de las relaciones políticas y económicas internacionales y a los sujetos y fuerzas que producen esas relaciones. Así, tanto la "cooperación", como instrumento de política exterior bilateral o multilateral, y el "desarrollo", como concepto teóricoideológico básicamente normativo, histórico y culturalmente connotado, son entendidos como la expresión de un orden internacional hegemónico determinado. 
En base a este enfoque, existe consenso en que el marco de acción contemporáneo se caracteriza por el paulatino proceso de transición hegemónica del Norte Atlántico al Asia Pacífico. Esto ubica a China como el principal eje comercial y político de la transformación sistémica y por ende principal proveedor de CSS, lo que plantea nuevas dinámicas de relacionamiento de los países periféricos en referencia a la tradicional potencia hemisférica Estados Unidos de América (EEUU). De manera más acotada, se concibe a la CSS en América Latina como eje articulador de proyectos políticos y económicos que promovieron visiones alternativas de relacionamiento entre los países en albores del siglo XXI. En este sentido, la CSS se configura como una categoría analítica útil para comprender la organización de un conjunto de prácticas y acciones emprendidas por los países del Sur para diversificar socios políticos y comerciales, fortalecer procesos de integración regional, establecer marcos institucionales, etc. -con miras a incrementar sus márgenes de autonomía internacional y a disminuir los niveles de dependencia en relación a socios tradicionales del Norte.

\section{Problemática}

La CSS se ha convertido en una herramienta de política exterior de los países latinoamericanos que ha oscilado entre un rol revisionista y un rol instrumental. En su afán de promover lógicas alternativas de desarrollo, tal herramienta parecería que no ha superado el ejercicio retórico. Su resurgimiento en los albores del siglo XXI ha traído consigo un renovado interés en su promesa histórica de transformar el orden mundial y promover desarrollo autónomo para los pueblos del Sur Global. Particularmente, en los países latinoamericanos se retomó la narrativa reivindicativa de la CSS y se la plasmó de manera pragmática en el ejercicio de la política exterior para fomentar el interés nacional en un contexto que cambia rápidamente.

Una vez inaugurado el nuevo milenio, los países latinoamericanos en mayor o menor grado, volcaron sus esfuerzos para implementar estrategias de CSS enmarcadas en el ámbito de sus políticas exteriores. Se dio énfasis al 
fortalecimiento de las relaciones con los socios del Sur Global a través de la diversificación de relaciones políticas y económicas y con el establecimiento de novedosas iniciativas e instituciones que -si bien fueron dispersas- mostraron una línea clara de la progresiva evolución de la región hacia la búsqueda de mayores márgenes de autonomía de los poderes de centro. Estas dinámicas se pueden observar en tres niveles. En el ámbito de las relaciones extra hemisféricas se optó por el fortalecimiento de las alianzas con los países de Asia Pacífico, especialmente con China, que emerge como líder que abandera la narrativa de CSS. A nivel regional, los países se abocaron al fortalecimiento de una institucionalidad propia del Sur con iniciativas de carácter autonómico como el ALBA, UNASUR, CELAC. A nivel nacional, se observó el posicionamiento de alternativas al desarrollo basadas en modelos económicos que trasciendan los modelos primario exportadores y de comercialización de materias primas.

Esto da cuenta de que se buscaron alternativas de desarrollo que ubicaron como objetivo prioritario el interés nacional y el ejercicio de una política exterior reivindicativa con miras al fortalecimiento de las relaciones con socios del Sur Global. Los países de la región buscaron en el aspecto político diversificar sus relaciones en la multipolaridad; mientras que en el económico apostaron por modelos que reduzcan su dependencia tanto de los ejes centrales de capital financiero internacional, como de modelos de desarrollo basados en la extracción de bienes primarios. Así, surgieron iniciativas como el "Socialismo del siglo XXI", Sumak Kawsay o el Buen Vivir que se contraponen a las estrategias promovidas por el Consenso de Washington.

En este sentido, varios países de la región latinoamericana, especialmente aquellos con gobiernos de corte progresista o pertenecientes a la denominada marea rosa ${ }^{2}$, recuperaron la agenda desarrollista y la relevancia de lo político

\footnotetext{
2 La marea rosa o Pink Tide es un término que fue utilizado por el reportero del New York Times Larry Rother en 2005 para expresar el hecho de que alrededor de dos tercios de los gobiernos elegidos en América Latina durante los primeros diez años del siglo se encontraban a la izquierda del espectro ideológico (Rosario Queirolo). Utilizaré esta categoría a lo largo de la investigación, ya que resulta útil para retratar el discurso y el carácter progresista que mostraron gobiernos como el de Ecuador, Bolivia, Venezuela o Brasil en América del Sur. La literatura académica también se refiere a estos gobiernos como populistas de izquierda (Carlos de la Torre), gobiernos de centro-izquierda (Jonas Wolf), gobiernos de tendencia izquierdista (Gian Luca Gardini), gobiernos progresistas (Kevin Gray, Barry Gills).
} 
sobre lo comercial, se enfatizó en el rol del Estado frente al protagonismo de las fuerzas del mercado, se crearon instituciones para una cooperación más intensa en temas de seguridad. En el nivel regional, se buscó la articulación de los mercados nacionales y la promoción de la integración física y se dio relevancia a las dimensiones sociales de la integración y al tratamiento de disparidades y asimetrías interestatales vinculando a la integración regional con los objetivos nacionales de reducción de la pobreza y desigualdad (Cienfuegos et al. 2010).

Esto refleja un cambio de prioridades, de enfoques, de concepciones, de demandas y de expectativas de los países que apuntan al fortalecimiento de las relaciones Sur-Sur en contraposición a los modelos tradicionales de desarrollo Norte-Sur. En este sentido, los países latinoamericanos recuperaron la narrativa reivindicativa de la CSS e iniciaron procesos que implicaron una nueva forma de entender lo económico y lo político. Uno de los argumentos principales para impulsar las relaciones Sur-Sur es que los países de la periferia muestran patrones similares de inserción internacional y similares desafíos que enfrentar, por lo que, sobre la base de relaciones horizontales y solidarias, se buscó proponer alternativas políticas y económicas para estimular el desarrollo. Respecto de esta concepción se derivan dos posicionamientos generales sobre la CSS.

Una visión optimista respecto del fomento de las relaciones Sur-Sur considera a este tipo de cooperación como un fenómeno con capacidad de transformar la arquitectura geopolítica y los modelos de desarrollo, especialmente porque los países del Sur asumen un nuevo rol de donantes de cooperación. Ese enfoque considera que los países ponen sus recursos, capacidades y experiencias a disposición de otros socios con similar o menor nivel de renta, cuyo principal objetivo es el establecimiento de lazos cooperativos entre los propios países en desarrollo (Santander 2011: 5). Este entusiasmo es compartido por varias instituciones, incluida la OCDE que ve en el fortalecimiento de la CSS la base para un nuevo paradigma de desarrollo que genere una "agenda de desarrollo global más inclusiva, efectiva y horizontal, si opera junto a los vínculos NorteSur" (OCDE 2010). 
En un sentido contrario a dicha visión, esta tesis retoma la corriente crítica del desarrollo y entiende a la CSS en el marco amplio de las estructuras internacionales, que se encuentran transversalizadas por desequilibrios tanto en las relaciones Norte-Sur, como en las relaciones Sur-Sur y destacan que junto a la promesa de emancipación existe el peligro de reproducir nuevas formas de intercambio desigual. Es decir, si bien en la actualidad ha surgido un nuevo espacio del Sur, éste sigue siendo jerárquico y reproduce los desequilibrios internacionales (DeHart 2012; Najam y Thrasher 2012; Carmody 2013). En esta línea, varios autores analizan el mismo auge de la CSS subsumida dentro del paradigma del desarrollo capitalista global contemporáneo que reproduce nuevas formas de centro y periferia y de desigualdades interestatales y mundiales; a la vez que se verifica un aumento en la vulnerabilidad social y ambiental (Gray y Gills 2016; Hardoon et al. 2016).

La presente investigación busca poner en contexto el resurgimiento de la CSS tomando como hilo conductor el rol cada vez más asertivo que juega la República Popular China (RPC) en la región latinoamericana. Se argumenta que si bien algunos Estados-nación pertenecientes al Sur Global pueden estar en una marea ascendente y abanderar el espíritu reivindicativo junto con países más débiles de la periferia, su ascenso y el relacionamiento que propician no escapa de las dinámicas de reproducción de desigualdades interestatales y mundiales que caracterizan al sistema internacional contemporáneo. Esto devela una doble dinámica: por un lado, se encuentra la aspiración de los países periféricos a alcanzar mayores márgenes de autonomía en su accionar internacional, que se tradujo en el impulso a un gran número de iniciativas e instituciones de orden económico y político; y, por otro, se visualizó una CSS carente de herramientas de transformación y cooptada en su ejecución práctica por las mismas dinámicas que promueve las relaciones Norte-Sur.

Esto puede ayudar a entender el hecho de que, a pesar de la retórica revisionista y la narrativa que coloca a la CSS como uno de los medios a través de los que se puede alcanzar los objetivos de desarrollo planteados a nivel nacional, en la práctica se observan varias paradojas. Así, se promovieron iniciativas de comercio, pero existió menos integración; se buscó más crecimiento económico 
pero se exacerbó la desigualdad; la retórica integracionista se concretó en acciones fragmentadoras; el discurso cooperativo se acompañó con el escalamiento de las tensiones; se realizaron diseños institucionales complejos pero con debilidades estructurales; hubo una mayor participación en el contexto internacional pero sin una posición común; y la aspiración a una mayor autonomía en el sistema internacional se pretendió sin una voz propia.

Estas paradojas resultaron especialmente relevantes en los países de corte progresista latinoamericano que a partir del año 2000 optaron, en mayor o menor grado, por el ejercicio de una política exterior reivindicativa apoyada en el fortalecimiento de las relaciones Sur-Sur, pero que, a su vez, no pudieron escapar de su posición periférica en las estructuras internacionales y a los vaivenes originados en las relaciones de poder y conflicto en el orden internacional. Con lo cual, las acciones autonómicas devinieron en retórica, a la vez que se reforzaron modelos de desarrollo tradicionales y opciones de inserción internacional acordes con el movimiento de flujos económicos y financieros internacionales, sea de socios tradicionales o de nuevos emergentes que se disputan, actualmente, la región latinoamericana.

\section{Fases de la investigación}

A lo largo de la investigación se buscó caracterizar los factores de cambio sistémicos y de tipo agencial que produjeron el resurgimiento de la CSS una vez inaugurado el siglo XXI y analizar cómo los gobiernos progresistas sudamericanos retomaron la CSS como mecanismo de política exterior para ampliar su autonomía y reducir la dependencia de potencias del Norte global. Para ello, se trató, por un lado, de comprender cómo se conjugan las dinámicas de estructura-agencia en períodos históricos específicos y, por otro, de estudiar un caso particular que ejemplifique cómo, a través del fortalecimiento de una política exterior que impulsa las relaciones Sur-Sur, se promovieron iniciativas de carácter autonómico con miras a reducir la dependencia de Estados de centro. 
A partir de la exploración y estudio de la CSS como herramienta de política internacional, la investigación trajo al centro del debate tres elementos clave que definen los cambios en el ejercicio de la política exterior de los países sudamericanos durante el período analizado, a saber:

a) El constante cuestionamiento a la globalización y la dominación económica y política del hegemón hemisférico (EEUU)

b) La búsqueda para redefinir modelos de desarrollo e inserción internacional basados en la reafirmación del interés nacional

c) La reafirmación de dinámicas de autonomía y dependencia como elementos clave de desarrollo

El contexto internacional de inicios del siglo XXI vino marcado por el declive relativo del poder de EEUU, la potencia hegemónica en el hemisferio, lo cual tuvo repercusiones directas en el dinamismo de las políticas exteriores de los países de la región latinoamericana. El auge de la CSS se configuró en contraposición al rol desempeñado por la potencia del Norte y se hizo particularmente visible en las áreas comerciales, de seguridad y en asuntos políticos. Desde finales de la década de los noventa se experimentó la pérdida de impulso de las estrategias de liberalización comercial desplegadas por el país norteamericano en la región. El ejemplo más pragmático fue el amplio movimiento político y social adoptado por diferentes instituciones, gobiernos, partidos políticos, sindicatos de toda la región para oponerse al Área de Libre Comercio de las Américas (ALCA) impulsada por EEUU y que debía entrar en vigencia en el año 2005. La tendencia clara fue la crítica a las reglas del libre comercio como eje regulador de las relaciones internacionales porque demostraron acentuar la desigualdad y la pobreza al proponer la profundización de mecanismos neoliberales de desarrollo, que resultaron poco efectivos durante la década de los ochenta y noventa en la región.

El cuestionamiento a la globalización se acentuó con la crisis financiera de 2008 que marcó un punto de inflexión porque afectó principalmente a las economías centrales de Europa y EEUU. La quiebra de uno de los principales bancos de EEUU, Lehman Brothers, propició una crisis financiera de alcance global que 
encendió el debate sobre el declive hegemónico y de las instituciones que lo representan. En la región latinoamericana esto se expresó en un creciente cuestionamiento a la institucionalidad hemisférica representada por la Organización de Estados Americanos (OEA), la Junta Interamericana de Defensa (JID) y el Tratado Interamericano de Asistencia Recíproca (TIAR) tradicionalmente impulsadas por Washington tras la post guerra mundial.

Estas tendencias se dieron a la par del incremento del peso relativo de poder de los países emergentes en la región latinoamericana, especialmente de China, que ganó influencia económica y política en el "patio trasero" de EEUU. Con el inicio del nuevo milenio se inauguró una nueva etapa respecto a la llegada del gigante asiático al continente que abrió espacios para pensar en la región del Asia Pacífico como nuevo eje de relacionamiento de América Latina. En el ámbito económico, China ya se configuró como principal socio comercial de varios países de la región en el año 2015; mientras que en el ámbito político ha logrado consolidar acuerdos de cooperación y fortalecer su presencia en áreas estratégicas en toda la región. Estos factores se convirtieron en vectores que fortalecieron las dinámicas de cooperación Sur-Sur e impulsaron la ampliación de espacios de autonomía al Sur del continente.

En el ámbito regional se dio paso a una fase de regionalismo heterogéneo, enfocado no solamente en el ámbito económico, sino particularmente en el ámbito social y de seguridad con la finalidad de resolver los problemas de la región de manera conjunta y sin interferencia de la hegemonía de EEUU. El surgimiento de mecanismos post-neoliberales ${ }^{3}$ reconfiguraron el espacio político de América Latina y apostaron al impulso de un nuevo centro de gravedad perteneciente a los países del Sur. Los esquemas más relevantes de concertación política que se crearon fueron el ALBA, UNASUR, CELAC que más allá de su heterogeneidad, diferencias de visión y enfoque político-económico de los gobiernos que los impulsaron, optaron por establecer marcos comunes de

\footnotetext{
${ }^{3}$ La calificación de la integración sudamericana como proceso post-neoliberal busca explicar la trascendencia del modelo neoliberal, con la dirección estatal en el proceso económico como dato distintivo. Su acción se orienta en pos de una mayor inclusión social y del combate a la pobreza, mitigando los efectos negativos de la integración neoliberal, de desregulación económica y excesiva permisión al mercado (Rica \& Lockhart, 2013)
} 
concertación con miras a consolidar propuestas y posicionamientos internacionales conjuntos.

En el plano de la política doméstica de los Estados latinoamericanos, el nuevo milenio coincidió con el surgimiento de líderes progresistas, quienes impulsaron ideas revisionistas y críticas del neoliberalismo, y dieron paso a la implementación de modelos económicos alternativos más regulados y proteccionistas. Se observó una tendencia a impulsar el interés nacional y agendas de desarrollo basadas en la nueva ventana de oportunidades que se abrió a través del fortalecimiento de las relaciones Sur-Sur, especialmente redinamizadas por el incremento de lazos sino-latinoamericanos, y que ubicaron a la región Asia-Pacífico en un horizonte estratégico.

Este conjunto de transformaciones a nivel internacional, regional y doméstico, configuró el marco de acción de la política exterior de los Estados latinoamericanos en los albores del siglo XXI. En el nivel sistémico estructural se encuentra el declive relativo de la potencia hegemónica de EEUU, que abrió paso a un mayor acercamiento económico y diplomático de China en la región. En el nivel de agencia, los países latinoamericanos exploraron diferentes alternativas de inserción internacional, dándose un reacomodo de prioridades en materia de política exterior y el impulso de proyectos nacionales de carácter autónomo.

Consecuentemente, se conformaron nuevos alineamientos geopolíticos que concurrieron como péndulos entre el poder dominante y las fuerzas antisistémicas, donde los países latinoamericanos tuvieron que redefinir sus estrategias de vinculación y alineamiento político. Para ello, los gobiernos tuvieron que optar entre mejorar sus relaciones con el poder en ascenso, liderado por China, sin desafiar a la tradicional potencia dominante detentada por EEUU, por medio de alternativas de alineamiento o de autonomía. De esto se deriva uno de los cuestionamientos generales que se busca responder a lo largo de la investigación, ¿cómo se alinea la política exterior de los países latinoamericanos ante la creciente presencia de la potencia emergente de China y la potencia hegemónica de EEUU? 
De igual manera, el fortalecimiento de las relaciones de cooperación con socios del Sur tanto a nivel intra regional, como con China como el principal aliado extra hemisférico, reavivó la concepción latinoamericana del desarrollo ligada al pensamiento de autonomía y de la dependencia. El primero es un concepto de carácter político que hace alusión a los márgenes de acción que un país puede tener para llevar a cabo su visión de desarrollo, por lo general, se identifican acciones autonomistas comparando posicionamientos políticos del país periférico en relación a aquellos de potencias centrales. La dependencia, por su parte, se usará para caracterizar el aspecto económico que explica la subordinación de los Estados a modelos primario exportadores de inserción internacional y se puede visualizar en el grado de diversificación de los socios comerciales y de la canasta exportadora. De ello surge otra de las preguntas de investigación, ¿en qué medida el fortalecimiento de la CSS coadyuvó a fomentar la autonomía y superar patrones de dependencia en los países latinoamericanos?

\section{Preguntas de investigación}

Sobre la base de los planteamientos expuestos en la formulación del objeto de estudio, problemática y derroteros de la investigación, se identificó una serie de preguntas que guían la investigación.

- ¿Cómo se explica el resurgimiento de la CSS como mecanismo de la política exterior de los países latinoamericanos durante el período 2000$2015 ?$

- ¿Cómo se alinea la política exterior de los países latinoamericanos ante la creciente presencia de la potencia emergente de China y la potencia hegemónica de EEUU?

- ¿En qué medida el fortalecimiento de la CSS se ha constituido, para los países latinoamericanos, en un mecanismo que apuntala la consecución de mayores márgenes de autonomía y reducción de dependencia de potencias centrales? 


\section{Objetivo general}

Caracterizar el resurgimiento de la cooperación Sur-Sur en América Latina en los albores del siglo XXI y el modo en que su fortalecimiento contribuye a establecer modelos de desarrollo más autónomos y menos dependientes de potencias centrales, tomando como caso de estudio al Ecuador desde el año 2000 al 2015.

\section{Objetivos específicos}

- Analizar el resurgimiento de la cooperación Sur-Sur en el marco de la reconfiguración de las estructuras sistémicas del orden internacional, resaltando la retórica revisionista que retoman los países periféricos latinoamericanos en el ejercicio de su política exterior en los albores del siglo XXI.

- Comprender la articulación de la cooperación Sur-Sur en las estrategias de política exterior de los gobiernos latinoamericanos relacionando los modelos de desarrollo e inserción internacional que impulsan los países periféricos, en tres dimensiones específicas a) cooperación económica, b) cooperación técnica, c) integración regional.

- Explicar el alineamiento de la política exterior de los países latinoamericanos en relación al ascenso de la cooperación China en la región y el declive relativo de la potencia hegemónica de EEUU.

- Caracterizar la política exterior ecuatoriana en lo referente a las estrategias y prácticas de cooperación Sur-Sur a la luz de las categorías analíticas de autonomía y dependencia, durante el periodo 2000-2015.

\section{Hipótesis}

La hipótesis principal que guía a esta investigación es que los países periféricos en América Latina optaron por fortalecer la CSS con una narrativa revisionista en el ejercicio de la política exterior cuya la finalidad fue proponer políticas alternativas de desarrollo; sin embargo, estos Estados no pudieron escapar a 
factores estructurales de asimetría política y dependencia económica característicos del sistema internacional actual.

Para contrastar esta hipótesis la investigación resaltó la necesidad de retomar el acervo teórico latinoamericano, específicamente en lo referente a las premisas del Realismo Periférico y los fundamentos teóricos derivados de la EPI. Estas teorías buscan explicar el esquema de vinculación de los Estados periféricos para con las grandes potencias y permiten analizar los procesos de inserción internacional y sus estrategias de política exterior. Los principales conceptos que se derivan de estos postulados teóricos son: asimetría de poder, transición, orden mundial, hegemonía, política exterior, autonomía y dependencia, que se leen como eje estructurante del pensamiento teórico y empírico a lo largo de la tesis. Si bien esos elementos no son nuevos en el ejercicio de la política exterior, se observa que su combinación es cualitativamente diferente del pasado y es una característica que marca el accionar de los países del eje progresista de la región; por lo que estas nociones capturan, reconcilian y dan sentido a la aparente divergencia en las agendas y políticas implementadas en la política exterior de los países sudamericanos.

De esta base teórica se desprenden los siguientes postulados específicos e hipótesis subordinadas que se analizan en los diferentes capítulos de la tesis:

El primer postulado que se busca analizar a lo largo de la investigación es la dinámica del fortalecimiento de las relaciones Sur-Sur en relación con los cambios en las estructuras internacionales del orden mundial. Par ello la primera hipótesis subordinada es que los factores de cambio y transformaciones en la estructura internacional, considerando a China como el hilo conductor de estos cambios, dan paso a relaciones más simétricas entre los países periféricos. En contraposición a lo que indica la doctrina subalterna de la CSS entendida en el marco de la industria de la ayuda, que considera a la CSS como intrínsecamente solidaria y horizontal, esta investigación busca probar que el eje Sur-Sur tendería a reproducir patrones similares a los de la cooperación tradicional, dado que las relaciones entre países del Sur se manejan bajo los mismos principios de libre mercado que guían el sistema económico mundial actual. 
Un segundo postulado busca dar cuenta de la emergencia de un renovado fortalecimiento del pensamiento teórico en relación a la CSS, que surge con eminente sello latinoamericano. A lo largo de la tesis se resaltan las ideas críticas que se desarrollan en la región para dar luz al entendimiento de las iniciativas de integración regional, cooperación económica y financiera que se producen durante el periodo estudiado. La segunda hipótesis subordinada que se busca probar es que el aporte teórico surgido en América Latina sigue vigente y ha demostrado su capacidad de aportar ideas originales, que permiten entender procesos de calado sistémico, especialmente, en lo referente al rol del Estado y del desarrollo vinculado a la ampliación de márgenes de autonomía y reducción de dependencia de potencias centrales.

Un tercer postulado que se busca contrastar es el peso tanto de los factores estructurales como de los factores domésticos que influencian en el ejercicio de la política exterior en la periferia. Especialmente cuando la literatura señala que, en el marco de transición hegemónica, los Estados periféricos apuestan por tendencias de alineamiento o de autonomía respecto de las potencias centrales. Por lo tanto, la tercera hipótesis subordinada es que el resurgimiento de la CSS, liderada por la presencia asertiva de China en la región latinoamericana, cambia el tablero geopolítico haciendo que los países de la periferia tiendan a fortalecer no solamente sus lazos económicos con el gigante asiático, sino también los posicionamientos políticos. Para ello, se derivan indicadores sistémicos y domésticos que dan cuenta de la dinámica de alineación de los países latinoamericanos en perspectiva triangular, China y EEUU.

Un cuarto postulado de la tesis señala que el fortalecimiento de la cooperación Sur-Sur ha abierto oportunidades para que los países periféricos impulsen formas autónomas de inserción internacional y reduzcan su dependencia económica de potencias centrales. Al respecto, la cuarta y última hipótesis subordinada es que el Ecuador adoptó una política exterior reivindicativa que buscó, en el ámbito político, diversificar sus relaciones en la multipolaridad estrechando lazos con países del Sur global, específicamente con China; mientras que, en el ámbito económico, buscó superar el modelo de desarrollo 
primario exportador apostando a que las relaciones sino-ecuatorianas promoverían términos de intercambio más horizontales.

\title{
8. Metodología y técnicas de investigación
}

Esta investigación es de naturaleza inductiva y adopta una metodología cualitativa, ya que trata de entender la dinámica del resurgimiento de la CSS y las políticas que de ésta se derivaron en los países latinoamericanos en los albores del siglo XXI. En este sentido, la tesis se basa en un planteamiento holístico de carácter interpretativo (el análisis estructural-sistémico) que se diseña a través de la selección de elementos teóricos y conceptuales como mecanismos orientativos.

La propuesta, al ser de carácter cualitativo, tuvo la finalidad de obtener nuevos conocimientos sobre la realidad social a través la observación contextualizada de un fenómeno; es decir, buscó comprender e interpretar de manera más precisa ciertas realidades teniendo en cuenta el contexto en el que se desarrollan. Como señalan Denzin y Lincoln 2000:

\begin{abstract}
la investigación cualitativa es una actividad localizada que sitúa al observador en el mundo. Consiste en un conjunto de prácticas interpretativas que hacen que el mundo sea visible. Estas prácticas transforman el mundo y lo convierten en una serie de representaciones, que incluyen apuntes de campo, entrevistas, conversaciones, grabaciones y notas propias. En este nivel, la investigación cualitativa contiene un enfoque interpretativo y naturalista del mundo. Significa que los investigadores cualitativos estudian las cosas en su ambiente natural, tratando de encontrar sentido o de interpretar los fenómenos de acuerdo con el significado que la gente les otorga (Denzin \& Lincoln, 2000).
\end{abstract}

Desde esta perspectiva, existen varias alternativas para construir un diseño metodológico, por lo que la presente investigación se circunscribe al ámbito de estudio de la Economía Política Internacional y la Cooperación Internacional; sin embargo, se recurre a los aportes conceptuales de diferentes disciplinas como la Historia, las Relaciones Internacionales, la Economía Política, para facilitar una interpretación más integradora de la temática estudiada. 
En cuanto a los métodos de estudio, se optó por el uso de métodos mixtos, cuantitativos y cualitativos dado que su complementación es factible siempre y cuando la investigación siga una misma lógica (King, Keohane y Verba 1995). De acuerdo a Lamont, un estudio cualitativo con un $N$ grande tiene el potencial de ser complementado a detalle con un estudio de caso de $n$ pequeño (Lamont 2015: 122). Para ser consecuente con el marco teórico adoptado, el estudio se basó en la metodología de análisis estructural-sistémico.

Para operacionalizar la propuesta metodológica, la tesis se dividió en dos grandes partes interconectadas entre sí, que comprenden las dos fases que tuvo la investigación. En la primera fase, se buscó contextualizar el resurgimiento de la CSS en el marco de las relaciones internacionales, por lo que, se definieron los principales conceptos, premisas y enfoque que se adoptó a lo largo de la investigación, usando los fundamentos derivados de las teorías de la EPI y del Realismo Periférico. Este marco teórico permitió caracterizar la complejidad del fenómeno de la CSS y acotar su ámbito de análisis alrededor de los aspectos comunes que de ella derivan. En este sentido, se dio relevancia a las nociones sobre la transformación de las estructuras internacionales, la asimetría de poder en el ámbito internacional, los procesos de inserción internacional de la periferia, las relaciones de autonomía y dependencia vinculadas al desarrollo, las categorías de análisis Norte-Sur y Sur-Sur. Esta etapa se corresponde con los tres primeros capítulos de la tesis.

En la segunda parte de la investigación se construyó un modelo analítico que buscó comprender la relación causal entre los factores sistémicos y domésticos que incidieron en la política exterior de los países latinoamericanos en un contexto marcado por procesos de transición hegemónica. Esto exigió que se desarrolle una definición operativa tanto de la política exterior como de los factores que la influencian y las formas de medir ambas cosas. Para ello, se recurrió al uso de variables e indicadores que permitan observar tendencias generales de los países latinoamericanos en cuanto a los factores que influencian en su comportamiento de inserción internacional. Esto permitió comprender las opciones de política exterior de los países periféricos latinoamericanos en relación a la cooperación China y a las relaciones 
tradicionales con EEUU. Esta fase se corresponde con los capítulos IV, V y VI de la tesis.

Para operacionalizar el modelo analítico, se consideró el análisis de 18 países latinoamericanos durante el periodo comprendido entre 1970 a 2015. Dado que el objetivo fue caracterizar la política exterior, ésta se convirtió en la variable dependiente, mientras que las variables independientes pasaron a ser los factores estructurales y domésticos que influyeron en el alineamiento político de los países latinoamericanos en su relacionamiento con la potencia emergente de China y con la potencia hegemónica de EEUU. Para la operacionalización de las variables se consideró relevante adoptar como proxi de la política exterior las votaciones de los países en el seno de la AGNU, por ello, se tomó como referencia un número de $\mathrm{N} 1906$ votos adoptados en esta instancia internacional. La observación analítica se hizo en tres etapas marcadas por diferentes relaciones de poder a nivel internacional: se observó el momento de bipolaridad durante la Guerra Fría (1976-1991), el de unipolaridad (1992-2002) y el de multipolaridad (2003-2015).

Adicionalmente, el modelo analítico se complementó con un estudio de caso único optando para ello el análisis del Ecuador durante el período 2000-2015. La selección de este país se justifica porque el Ecuador constituye un caso representativo de los países que conformaron el eje progresista sudamericano en los albores del nuevo milenio. El país andino es el ejemplo de un Estado débil y vulnerable en el sistema internacional, que, sin embargo, optó por impulsar una política exterior contrahegemónica desde el ascenso de Rafael Correa a la presidencia de la República en el año 2006. La elección de este caso ayudó a ejemplificar la realidad de procesos sociales complejos relativos al ejercicio de una política exterior reivindicativa basada en el fortalecimiento de las relaciones de tipo Sur-Sur. En este sentido, el país sudamericano se conviertió en un caso paradigmático que ha sido poco analizado en la literatura académica.

Particularmente, el Ecuador es un país andino que retomó la idea de fortalecer sus relaciones de cooperación Sur-Sur, con China liderando esta narrativa, a fin de aumentar sus márgenes de autonomía y reducir su dependencia de Estados 
centrales, especialmente de los EEUU. Al respecto, el estudio de caso se enfocó en comprender las estrategias de CSS, que se impulsaron como mecanismo de la política exterior de la periferia, y caracterizar cómo el país sudamericano buscó aumentar la autonomía, sobre la base de la multipolaridad, y reducir la dependencia a través de la diversificación de socios comerciales y del cambio de matriz productiva. El caso de estudio propuesto permitió ejemplificar cómo un país débil y pequeño, a pesar de la retórica revisionista y las acciones para fortalecer la CSS que adopta, se vio limitado en sus esfuerzos por su condición estructural para llevar a la práctica un modelo de desarrollo alternativo.

La operacionalización del estudio de caso contempló, por una parte, la observación empírica e interpretativa de las dinámicas entre la agencia y estructura que intervinieron en el ejercicio de la política exterior del país andino. Por otra parte, se hizo énfasis en el análisis de las categorías analíticas de autonomía y dependencia. Para ello se utilizaron las variables e indicadores derivados del fundamento teórico propuesto.

En cuanto a la dependencia, se planteó un análisis de la composición económica del comercio, las ventajas comparativas y la reprimarización de la economía ecuatoriana en perspectiva relacional (China, EEUU); para lo cual se estudió el Índice de Ventajas Comparativas Reveladas (IVCR) y el índice Balassa. En cuanto al tema de la autonomía en política exterior se tomó como proxi las votaciones en el seno de la AGNU desde el año 2000 al 2014 (período para el cual se encuentran datos actualizados) y se elaboró una base de datos tipo panel -que contempló en total 489 resoluciones, que dieron lugar a 2.916 votaciones, correspondientes desde las sesiones 55 a la 69. Se analizaron seis áreas temáticas de votaciones: conflicto palestino (ME), armas y material nuclear (NU), colonialismo (CO), derechos humanos (HR), desarrollo económico (CE), control de armas y desarme (DI).

\section{Fuentes de análisis y construcción de base de datos}

A lo largo de la investigación se recurrió al uso de bases documentales de análisis, considerando fuentes que incluyen libros, revistas indexadas, 
publicaciones especializadas, informes nacionales e internacionales, boletines de prensa en diarios, sitios web, bases de datos, entre otros. Esta información fue organizada, procesada y sistematizada, lo que ha facilitado la ejecución adecuada de la referenciación a lo largo del estudio.

Adicionalmente, se realizaron 7 entrevistas semi estructuradas en Ecuador a funcionarios públicos de alto nivel, quienes estuvieron vinculados directamente en la implementación de políticas de fortalecimiento de la CSS y política exterior durante el periodo analizado. Las entrevistas, que tienen una duración de aproximadamente una hora, fueron llevadas a cabo de manera presencial en la ciudad de Quito entre los meses de enero y febrero de 2018. Para el procesamiento de la información recolectada se hizo uso de la técnica de análisis de contenido, de tal manera que los datos recabados contribuyeron a la identificación de hallazgos relevantes durante la investigación.

En lo referente a la construcción de las bases de datos para analizar el modelo empírico que se planteó en la investigación se recurrió a operacionalizar la política exterior como variable dependiente y se definieron variables independientes relacionadas a: la distribución del poder, el rol de la ideología, el tipo de régimen político, la interdependencia comercial, factores geopolíticos. Se propuso este modelo para comprender los factores que incidieron en el alineamiento de la política exterior de los países latinoamericanos en relación con: la cooperación de socios del Sur con China como líder, así como, en relación a la potencia hemisférica tradicional de EEUU. Para ello, se recurrió a información estadística de carácter oficial, tanto para el análisis del aspecto económico como para el aspecto político.

Las fuentes que se usaron para obtener indicadores de cada una de estas variables fueron diversas. Para el análisis del poder mundial se usó el Índice de Capacidades Materiales Nacionales (CINC) del proyecto Correlates of War, para la ideología se recurrió al posicionamiento ideológico (medido en una escala de 1 a 5 , siendo 1 izquierda, 2 centro izquierda, 3 centro, 4 centro derecha y 5 derecha) de los países latinoamericanos. Para el análisis del régimen político se usó el indicador Polity IV, que es un índice que va de -10 a 10, donde -10 es el 
menor grado de democracia o de mayor autoritarismo y 10 el grado más alto de democracia, mientras que para el ámbito de comercio se usó indicadores de interdependencia comercial entre los países y las potencias analizadas. Los detalles metodológicos, variables e indicadores se explican a profundidad en el capítulo IV.

Adicionalmente, para el estudio de caso se analizó el IVCR y el índice Balassa y el alineamiento de votaciones en las seis áreas temáticas que contemplan los votos en el seno de la AGNU. En el plano económico, se recopiló información respecto del comercio, importaciones, exportaciones para relacionarlas con EEUU y China y definir características de dependencia económica. La recolección de datos se hizo a través de sitios oficiales como la United Nations Comtrade Database -COMTRADE (2018), Base de datos de ALADI, el Observatory of Economic Complexity (OEC), Banco Central del Ecuador (BCE), entre otras fuentes oficiales.

La propuesta metodológica planteada, así como el uso de fuentes empíricas, sientan una base sólida que permite entender la dinámica de CSS en la región latinoamericana, pero también permite explicar en profundidad un caso de estudio particular, como es el caso de Ecuador. Siguiendo a Ragin, esta combinación ecléctica ayuda a capturar esas lógicas de actuación, consolidación y prácticas reales de los actores objeto de estudio (Ragin 124: 2014).

\section{Alcances y limitaciones de la propuesta teórico-metodológica}

El estudio de las Relaciones Internacionales como disciplina se encuentra arraigada en el pensamiento occidental. En la década de los sesenta, Stanley Hoffman señaló que esta disciplina "nació y se desarrolló en Estados Unidos" y ha estado dominada por el país norteamericano debido a su "preeminencia política" (Hoffmann 1963). Este enfoque es el que ha prevalecido para la comprensión de las temáticas que competen a su análisis, como el área de la Política Exterior o de la Cooperación Internacional, que continúan estando fuertemente influenciadas por esta línea de pensamiento. 
A lo largo de esta tesis se abogó por la necesidad de dar relevancia a posicionamientos epistemológicos que colocan en el centro de análisis a los países periféricos del sistema internacional, considerando enfoques teóricos más precisos para comprender sus realidades. Se propuso una visión crítica respecto de la adopción de postulados tradicionales en materia de RRII, que soslayan factores como la asimetría de poder internacional, las relaciones de jerarquía y de vulnerabilidad estructural, que cuanto menos, condicionan el desarrollo de los países en la periferia. Por ello, se adoptó el enfoque del Realismo Periférico, desarrollado en base a las experiencias de los países latinoamericanos; y de la EPI porque proporciona una visión más allá del Estado, al conjugar análisis de las estructuras de poder económicas y políticas características del sistema internacional. Por esta razón, esta investigación buscó incluir puntos de vista no tradicionales y justipreciar el pensamiento autonómico y de dependencia que surge con un sello eminentemente latinoamericano.

El marco teórico propuesto presenta limitaciones al no incluir, de manera sistemática, los aportes provenientes del pensamiento chino en lo referente a teorías de RRII. Es importante hacer esta aclaración porque a medida que el gigante asiático se fortalece económicamente, políticamente y militarmente, resulta imperativo entender las "características chinas" respecto de su visión sobre las relaciones internacionales y sobre las subtemáticas que se analizan en esta investigación. Ello, en aras del fortalecimiento del pensamiento crítico, el diálogo interdisciplinario y la inclusión de visiones alternativas y no eurocéntricas respecto del desarrollo y del orden internacional. Al respecto, los debates que se abordan en esta tesis se ven limitados al no contemplar dicho alcance.

Los temas sobre los cuales gira esta investigación toman como hilo conductor el resurgimiento de la CSS liderada por China y se analiza su relación en perspectiva triangular: América Latina, Estados Unidos y China. A pesar de que se hizo referencia a autores orientales, la tesis no se fundamenta en una "visión china" de las RRII. Esto debido a que no es sino hasta hace unos pocos años que, de acuerdo a Geeraerts y Jing, "hay una generación de académicos que 
actualmente está entusiasmada en hacer aportes teóricos al área de RRII desde un enfoque chino (Geeraerts y Jing 2001: 28).

Específicamente respecto de la discusión teórica sobre la que gira esta investigación: CSS, desarrollo y política exterior, quizá las dos teorías que mayor relevancia han adquirido en los últimos años son el "Realismo Moral" (Xuetong 2014; 2016; 2019) y la "Nueva Economía Estructural" (Lin, 2012). La primera explica desde una perspectiva china el auge, la permanencia y la caída de las potencias hegemónicas, para ello considera factores relacionados al liderazgo y la capacidad de adaptación de los sistemas políticos (Xuetong 2019). La segunda, propone un marco para reformular el pensamiento sobre el desarrollo considerando que "la estructura económica de una economía es endógena a la estructura de su patrimonio factorial"; por lo que el peso de las estructuras es diferente para cada actor del sistema internacional (Lin 2011).

Los aportes de esta literatura han sido considerados de manera transversal a lo largo de esta investigación, pero no constituyen la línea de pensamiento sobre la que se fundamentan los principales argumentos de esta tesis. Esta misma lógica aplica para el entendimiento de los Derechos Humanos, que se analiza como parte de las áreas temáticas que se votan en el seno de la AGNU. En la investigación, no se alcanza a visualizar las diferencias entre la concepción china y la occidental sobre los DDHH.

Se pasa por alto, por ejemplo, el uso utilitario que se ha dado a los derechos humanos en occidente. En el caso de los EEUU, este país contempla explícitamente, dentro de su legislación, que ningún tipo de asistencia militar, económica o multilateral se proveerá a aquellos países que se enmarquen en "un patrón de comportamiento consistente en fuertes violaciones de los derechos humanos reconocidos internacionalmente" (Gonzáles-Tablas 1995: 161). Como la historia ha dejado claro, la política detrás de los derechos humanos se ha subordinado a intereses geoestratégicos de los países. Carter, hasta el año 1981, recortó ayuda a Estados como Argentina, Bolivia, El Salvador, Guatemala, Haití, Nicaragua, Paraguay y Uruguay, mientras que cuando Reagan asumió la presidencia restableció los lazos de ayuda con los aliados estratégicos de 
América del Sur. Bush subordinó los derechos humanos a la guerra de la droga en Perú, y permaneció en relaciones amistosas con los países petroleros de Oriente Medio (Gonzáles-Tablas 1995: 163).

Por su parte, China en su Libro Blanco, publicado en 1991, subraya que "a causa de las tremendas diferencias en el marco histórico, el sistema social, la tradición cultural y el desarrollo económico, los países difieren en el entendimiento y la práctica de los derechos humanos (Libro Blanco 1991). El modelo chino de ayuda se basa en la no interferencia en asuntos internos de los Estados y en la defensa de la integridad soberana; por lo que su cooperación se dirige de forma indiferente hacia países con mayores o menores cotas de respeto por los DDHH. En palabras de Luo Haocai, de la Sociedad China para el Estudio de los derechos humanos, el enfoque chino al respecto da prioridad a los derechos de subsistencia y desarrollo de sus ciudadanos, y ello es un proceso gradual, es decir:
china garantizará otros derechos humanos económicos y sociales a condición de que antes se hagan realidad estos dos derechos básicos. Desde este enfoque, los derechos humanos no sólo son individuales, sino también colectivos y constituyen una razón importante de la estabilidad china, la armonía social y la libertad del pueblo" (Haocai 2008).

Para salvar estas limitaciones, a manera de sugerencia cabe señalar que la literatura académica -relacionada con la CSS, el desarrollo y la política exteriorincluye a varios autores quienes realizan análisis críticos y contemplan los fundamentos y visiones del desarrollo desde una perspectiva oriental en sus trabajos. De manera acotada se puede resaltar los aportes de Chin 2016; Hsiang 2016; Li 2017; Lin 2017; Park 2016; Shicheng 2006 y 2016; Xing 2016; Xuetong 2014; Yahuda 1978; Yu 2015; Zhang 2017; Zhimin 2015; Yan 2018, Bräutigam y Tang 2014; Domínguez 2019, 2018, 2017, 2016; Lo Brutto 2015, 2017, Gallagher 2016; Bräutigam, D., y Tang, X. 2014, entre otros.

En lo que se refiere al aspecto metodológico, una de las limitaciones más importantes fue encontrar consenso académico, en la literatura especializada, sobre la operacionalización de la variable dependiente, es decir sobre el uso de 
las votaciones en la AGNU como proxi de la política exterior. Las críticas señalan que las resoluciones adoptadas en el seno de las NNUU no son legalmente vinculantes y carecen de fuerza legal por lo que la falta de rendición de cuentas hace que los votos se conviertan en una cuestión simbólica (Kennedy, 2006).

Sin embargo, esta investigación tomó la decisión metodológica impulsada por los autores que revalidan su uso porque son indicadores que ayudan a identificar las posiciones de los países en la arena de la política internacional, en temas multilaterales o en alineamientos regionales (Lijphart, 1963; Selcher, 1978; Marín-Bosch, 1998); y por tanto, indican la orientación general de la política exterior (Tomlin, 1985; Thacker 1999; Voeten, 2000). En el ámbito latinoamericano, Amorim (2011) es uno de los pioneros en el uso de métodos cuantitativos para entender la política exterior de Brasil usando la mencionada metodología; Neto y Malamud (2015) estudian las votaciones para definir factores que determinan a política exterior de Argentina, Brasil y México; Schenoni (2012) también revalida su uso. Para el caso específico de Ecuador, Jeanne Hey (1995) señala que:

La mayoría de los estudios que intentan generalizar los hallazgos sobre la política exterior dependiente aplican análisis estadísticos a los datos de votación de la Asamblea General de las Naciones Unidas (UNGA). El uso de los votos de la AGNU es bastante comprensible. El conjunto de datos contiene un gran número de casos fácilmente observables tanto longitudinalmente como a través de diferentes países y regiones. La desventaja de este método es, por supuesto, que el analista no contempla el proceso de política exterior o las personas que están detrás de las decisiones (Hey 1995: 2).

Finalmente, resulta relevante recalcar que esta tesis ha sido consolidada sobre la base de artículos, que fueron escritos a lo largo del periodo de realización del doctorado y son producto de las diferentes fases de la investigación doctoral y de la participación en diferentes congresos internacionales. Para la consolidación de la monografía fue necesario reconfigurar, actualizar, clasificar toda la información recabada y añadir nuevos contenidos para alcanzar 
coherencia y sentido en el conjunto de la tesis. A lo largo de los capítulos se cita de manera adecuada los trabajos ya publicados ${ }^{4}$.

\section{Estructura de la investigación}

La investigación se configura alrededor del análisis de la cooperación Sur-Sur como mecanismo de la política exterior de los países del eje progresista latinoamericano en los albores del siglo XXI. Con la finalidad de ordenar los contenidos y establecer una secuencia narrativa lógica, a lo largo de la tesis se combinan categorías analíticas, derivadas del fundamento teórico, con datos empíricos relevantes para comprender el fenómeno. La investigación se organiza en cinco capítulos interrelacionados entre sí, que se ubican inmediatamente después de esta introducción donde se establecen los lineamientos guía.

El hilo conductor de la presente tesis es como sigue: primero, se analiza la revitalización de las dinámicas de CSS considerando las trasformaciones en el orden internacional actual que se caracterizan por un proceso paulatino de transición hegemónica, que se traslada el eje Atlántico Norte al eje Asia Pacífico. Segundo, se analiza las implicaciones de estos cambios y la relación entre CSS y política exterior en América Latina en cuanto mecanismo que apuntala el diálogo político y busca la consolidación de coaliciones entre países del Sur para su mejor inserción en el orden internacional. Se consideran tres áreas específicas: integración regional, cooperación económica y cooperación técnica. Tercero, se analizan los factores estructurales y domésticos que inciden en el ejercicio de la política exterior de los países periféricos latinoamericanos, en lo referente a su relacionamiento con la potencia emergente China y la potencia hegemónica de EEUU. Finalmente, se analiza a profundidad el caso de Ecuador durante el período 2000-2015.

\footnotetext{
${ }^{4}$ Ver por ejemplo: Zapata, S. (2017). El regionalismo latinoamericano en la primera década del siglo XXI: repensando la idea de autonomía. Revista Andina de Estudios Políticos, Lima, 7(2), 67-91.

Zapata, S. (2017). ALBA en el turbulento escenario venezolano. Política Exterior. Disponible en: https://www.politicaexterior.com/la-iniciativa-alba-en-el-turbulento-escenario-venezolano/ Zapata, S. (2018). Power reconfigurations and South-South Cooperation Policies in Latin America during the first decade of the 21st century. Revista Andina de Estudios políticos, 8(1), 31-59
} 
En el primer capítulo se aborda los principales debates sobre el resurgimiento de la CSS, para lo cual se repasa los antecedentes históricos, derroteros y diferentes concepciones sobre su entendimiento hasta su configuración actual. La idea central radica en contrastar las visiones y limitaciones que ubican a la CSS dentro del marco de la AOD y sentar las bases de una propuesta que aporta con una visión histórico-crítica de la CSS. Para ello, se coloca al estudio de la CSS dentro de las corrientes de la EPI crítica y del pensamiento latinoamericano en Relaciones Internacionales, lo que permite su comprensión dentro del sistema asimétrico de poder que caracteriza al orden internacional actual. Sobre esta base, se caracteriza los cambios más evidentes que se producen en las estructuras internacionales y su repercusión en el establecimiento de mecanismos de diálogo alternativos y autónomos que emergieron con eminente sello latinoamericano.

En el segundo capítulo se coloca al estudio de la CSS dentro del contexto de la economía política de las Américas en los albores del siglo XXI. El objetivo de este apartado es abordar las principales premisas para comprender el resurgimiento de la CSS y sus implicaciones en la política exterior latinoamericana. Para ello, se analizan los espacios, agendas y políticas que se vieron fortalecidas con el resurgimiento de la CSS en la región y se retoman las acciones impulsadas en los tres ejes que históricamente promovió la CSS: a) cooperación económica, b) cooperación técnica, c) integración regional. Se propone un abordaje analítico-explicativo sobre los elementos más destacados de la economía política internacional y el vuelco de la región al fortalecimiento de las relaciones Sur-Sur.

En el tercer capítulo se establecen los fundamentos teóricos y metodológicos para entender la CSS y la política exterior en la periferia del sistema internacional. Para ello, se interpela la necesidad de retomar el acervo teórico latinoamericano para su análisis, específicamente el Realismo Periférico y el método estructural sistémico para el análisis de estrategias política exterior. Tras una revisión de literatura teórica relevante al respecto, el marco conceptual enunciado conjuga y discute los principales conceptos que giran al presente 
estudio: transición hegemónica, política exterior, autonomía, dependencia. En este apartado se detalla la adopción del método estructural sistémico para el análisis de estrategias política externa y las iniciativas de cooperación Sur-Sur que de ella derivan.

En este capítulo se propone la consolidación de un modelo analítico que toma como eje central tanto factores estructurales, como de agencia relacionados al ejercicio de la política exterior y se definen las principales premisas, postulados y variables que se analizan en la investigación. Esto permite informar sobre los procesos de transición internacional y el peso de los factores como la distribución del poder, la interdependencia económica y las fuerzas a nivel doméstico como la ideología, el perfil del gobierno en la política exterior, y el alineamiento político en materia de política exterior, en perspectiva relacional China, EEUU.

El cuarto capítulo conecta el marco teórico y metodológico con sólida evidencia empírica para explicar el alineamiento de la política exterior de los países periféricos en el marco de procesos de transición hegemónica. Se consolida el modelo analítico, las variables y fuentes utilizadas para proporcionar un estudio de carácter cuantitativo, poco común en las Relaciones Internacionales. La idea central es explicitar el peso de los factores tanto estructurales como de agencia en la adopción de alternativas de inserción internacional marcadas por el alineamiento con EEUU o por la búsqueda de alternativas autonomizantes ligadas a la cooperación China. Esto permite entender en perspectiva histórica, los factores que inciden y definen la adopción de estrategias de política exterior en virtud del posicionamiento de los Estados en una estructura determinada. Los resultados apuntan a que factores domésticos, ciclos políticos, periodos de polaridad global y condiciones económicas definen convergencias políticas más cercanas con Beijin que con EEUU.

El quinto capítulo presenta un estudio de caso único considerando al Ecuador como ejemplo paradigmático. Se analiza la política exterior ecuatoriana en lo referente a sus estrategias y prácticas de Cooperación Sur-Sur a la luz de las teorías provenientes del realismo periférico durante el período 2000-2015. Para ello, se conjuga el acervo teórico, las variables relativas a su condición de Estado 
periférico como rasgo estructural de su política externa y la evidencia empírica buscando caracterizar las estrategias de inserción internacional del país, que fluctúan entre la dependencia y la autonomía para con la potencia central. Se parte por la identificación de la retórica desarrollista impulsada por el gobierno de Rafael Correa y se contrasta dicha información con evidencia empírica sobre la diversificación de socios comerciales, la reprimarización de la economía, el alineamiento político en temáticas especificas a nivel internacional.

Este análisis permite profundizar en el entendimiento de las categorías analíticas de autonomía y dependencia y verificar la hipótesis de que la creciente presencia de China en el país ha abierto oportunidades y creado ventajas para quienes persiguen formas autónomas de inserción internacional y buscan reducir la dependencia de los países centrales.

Finalmente, la investigación ofrece un apartado que resume las principales conclusiones, hallazgos y reflexiones alrededor de la cooperación Sur-Sur, la Política Exterior, autonomía y dependencia en la periferia. De igual manera, se plasma las reflexiones sobre la aplicación teórica y metodológica y se incluyen sugerencias para futuras investigación. 


\section{CAPÍTULO I: DESDE DONDE ENTENDER LA COOPERACIÓN SUR-SUR: ANTECEDENTES, CONCEPTOS Y PREMISAS}

\section{Discusión}

La Cooperación Sur-Sur ha vuelto al centro de la discusión de la política y de la economía mundial renovando sus históricas promesas de promover mayor protagonismo de los países del Sur en el asimétrico orden internacional. Su resurgimiento se encuentra estrechamente vinculado a las transformaciones de poder y a la paulatina reconfiguración de las estructuras sistémicas del orden internacional, caracterizado por el ascenso económico-político de potencias emergentes pertenecientes al Sur Global.

La narrativa de la CSS ha ido evolucionando en el pensamiento de los académicos y en la praxis de los hacedores de políticas públicas de manera heterogénea. Las interpretaciones relativas a sus orígenes, concepción, metas son variadas; por lo que se requiere hacer una reflexión crítica y pluralista sobre su dinámica y evolución a la luz del pensamiento histórico-crítico. Para ello resulta adecuado situar su análisis en el contexto de las profundas transformaciones de la economía política internacional y de la reconfiguración de las dimensiones de poder y la naturaleza de dichos cambios.

El objetivo de este primer capítulo es repasar los antecedentes históricos, principales debates sobre el entendimiento de la CSS y los derroteros que persigue hasta su configuración actual. La idea central es analizar los más generalizados entendimientos sobre esta temática y delimitar las bases sobre la cual se abordarán los principales conceptos y premisas de esta investigación, en lo referente a la CSS. Para ello, se toma como eje estructurante, por una parte, las corrientes de la EPI que permiten caracterizar los cambios más evidentes que suceden en las estructuras internacionales para fortalecer la reemergencia de la CSS; y por otra, se retoma el acervo teórico latinoamericano, específicamente el Realismo Periférico para comprender como la CSS se constituye en herramienta de política exterior y mecanismo de dialogo alternativo de los países periféricos. 
Esta combinación permite consolidar una base epistémica integral que vincula lo sistémico con lo nacional, pero va más allá del análisis tradicional de los Estudios de Política Exterior (EPE). La propuesta enlaza los factores de cambio y la mutua influencia de factores externos o sistémicos y los elementos domésticos vinculados a la promoción de la autonomía nacional que surgen con eminente sello latinoamericano, en el marco de un orden internacional dado. Partes de este capítulo han sido publicadas en el artículo "Reconfiguraciones de poder y políticas de CSS en América Latina del siglo XXI" (Zapata 2018).

Para ello, primero, se analiza la cooperación internacional y el desarrollo en el asimétrico orden internacional. Segundo, se resalta el rol de los países del Sur y de la CSS dentro de la estructura y dinámica de las relaciones políticas y económicas internacionales. Tercero, se definen las principales premisas y postulados con los cuales se va a abordar el objeto de estudio de la investigación. Posteriormente, se señalan los factores de cambio y transformaciones en la estructura internacional que dieron paso al resurgimiento del Sur Global y finalmente, se aborda el rol de la CSS en la política exterior latinoamericana considerando a China como eje estructurante de las relaciones Sur-Sur.

\section{La cooperación y el desarrollo en el orden internacional asimétrico}

La cooperación internacional y el desarrollo ocupan un lugar destacado en el análisis de las RRII por lo que su interpretación exige un ejercicio crítico que permita entender las visiones que han dominado su comprensión a lo largo del tiempo. Un punto de partida para comprender estos conceptos es analizándolos en el más amplio "marco de acción" en el que se desarrollan en un período dado; es decir ubicando su entendimiento en el conjunto del sistema internacional, de las relaciones de poder y de las asimetrías, contradicciones, tendencias y conflictos que éste reproduce (Krippendorff, 1985; Bernal-Meza y Lavagna 2000).

Tomando como punto de partida la tesis coxiana para el entendimiento de una realidad, se pueden distinguir dos perspectivas. Un enfoque de resolución de 
problemas que "toma el mundo como lo encuentra, con las relaciones sociales y de poder prevalecientes y las instituciones en las que están organizadas, como el marco dado para la acción" (Cox, 1981); y un enfoque crítico que toma como eje de análisis el sistema internacional en su totalidad y busca entender el cambio, conflicto y desarrollo del mismo (Cox, 1981).

La primera perspectiva analiza a la cooperación internacional teniendo como objeto de estudio casi exclusivamente la denominada arquitectura de la Cooperación Internacional para el Desarrollo (CID) -incluyendo a la CSS en este entramado. Esta perspectiva imprime una visión técnica multilateral que cuantifica capacidades y estudia los actores-agentes-instituciones, volúmenesvariaciones-montos, procedencia-destino, impacto-eficacia de la "industria de la ayuda" que busca propiciar el desarrollo a sus beneficiarios.

Esta visión, dominante en los Estudios del Desarrollo, está influenciada por las aproximaciones globalistas y de la interdependencia que promueven una concepción neoliberal institucionalista, donde la cooperación es el resultado de la búsqueda del equilibro cooperativo entre naciones como única manera de ganancia e inserción internacional a través del multilateralismo, sus instituciones y regímenes internacionales (Keohane, 1984, Nye, 2005). En una línea similar, se encuentran los enfoques que tienden a la idealización de la CSS caracterizándola como intrínsecamente benéfica, horizontal, solidaria entre los actores que la impulsan y predicando principios altruistas que deberían regirla. Por su parte, desde un enfoque de la EPI crítica se retoma como eje estructurante el orden internacional en su totalidad entendiendo a la cooperación y el desarrollo como "sistema de poder que se integra en la esfera más amplia de la política internacional" (Sogge 2002: 63). Esta mirada alternativa nos remite al estudio de la estructura y dinámica de las relaciones políticas y económicas internacionales y a los sujetos que producen esas relaciones. Lo que permite identificar la configuración social de las fuerzas que lo sostienen, los modelos de desarrollo que avala, los poderes técnicos y políticos y la compleja naturaleza de este régimen de cooperación que actúa no solo como un conjunto de actores, instituciones y normas, sino también como sistema de legitimación de la hegemonía en el orden global (Cox y Sinclair 1996). 
Sobre esta base se entiende a la cooperación como instrumento de política exterior de los Estados y al desarrollo como un concepto normativo, ideológico y culturalmente connotado que emerge en un "marco de acción" específico. Desde este punto de partida, se sostiene que los análisis técnicos y de cuantificación de la cooperación y las perspectivas estratégicas que la ubican en el marco del sistema internacional pueden estar entrelazadas, pues no son incompatibles, pero lo técnico debe estar subordinado a lo estratégico.

Desde esta visión, resulta indispensable analizar las estructuras históricas que conforman un orden internacional dado y el rol de la hegemonía en su consolidación buscando entender la distribución de los costos y beneficios [de la existencia de una estructura y de unas reglas determinadas] (Cox, 1981; Strange, 1988, Krasner, 1976; 1983; 1987). ¿Por qué partir del análisis de estos temas? Porque las nociones de cooperación y desarrollo que conocemos actualmente son producto de un orden mundial determinado por la interacción de atributos materiales de poder, ideas e instituciones (Cox, 1979) y que es el reflejo de la consolidación de una determinada hegemonía, entendida como la supremacía de un grupo social que manifiesta su liderazgo económico, intelectual, político y moral y al que los subalternos otorgan consentimiento activo, usando excepcionalmente la coacción como medida disciplinaria (Gramsci y Hoare 1971).

En este marco de acción se consolidaron las relaciones internacionales contemporáneas acentuando los lazos de dominación-dependencia entre países y haciendo de la asimetría una característica estructural del sistema. Por ello, cuando se hace referencia a un país del "Sur" se hace alusión a la división entre centro y periferia; es decir, entre países o actores que poseen capacidades económicas, militares, políticas superiores en relación a las unidades de la periferia. La compresión de dichas categorías es relevante porque la reconfiguración del poder internacional ha exacerbado el "resurgimiento" del 'Sur Global' dando mayor auge a iniciativas de CSS y políticas públicas reivindicativas en los países del Sur. 
Sobre esta base de entendimiento, existe consenso en que el orden internacional contemporáneo está conformado por un conjunto de normas, reglas e instituciones consolidadas por las potencias hegemónicas tras la II Guerra Mundial y que combina aspectos políticos, económicos e ideológicos. En el ámbito político, el orden internacional se ha transformado de un paradigma EsteOeste a un escenario postguerra fría (Cox, 1981) y en los tiempos que corren se visualiza una transición del Occidente europeo y norteamericano hacia el Oriente asiático (Stengel 2017; Ash, 2017); mientras que en el ámbito económico, éste ha sido fundamentado por el Sistema de Bretton Woods que institucionalizó el orden económico internacional bajo principios neoliberales de apertura de la economía y desregulación de las finanzas (Krugman 2009; Ferguson 2009).

Este orden internacional consolidó el modelo de globalización neoliberal con una influencia homogeneizadora, que impulsa las fuerzas del mercado hacia una sociedad abierta en perspectiva lineal, instaurando el capitalismo global -la actual visión que se ha impuesto como 'globalización' y constituye el signo ideológico del capitalismo actual. Esto ha legitimado la hegemonía de los socios más poderosos en detrimento de los países periféricos que se han incorporado al sistema internacional en condiciones asimétricas (Bernal-Meza y Masera 2008).

El carácter hegemónico impreso en la consolidación del actual orden internacional deriva de las estrategias desplegadas por los beneficiarios de dicha estructura para consolidarlo y profundizarlo, lo que se puede verificar en la manera cómo las potencias han empleado sus atributos materiales de poder, ideas e instituciones (Cox y Sinclair 1996). Por ello, el carácter estructural de las desigualdades 'Norte-Sur' deriva tanto de la constitución de este orden mundial neoliberal, como de la manera en que los países beneficiarios han desplegado sus estrategias y recursos para sostenerlo y perpetuarlo.

Para captar las presunciones no explícitas en el ejercicio del poder y su vinculación con las nociones de desarrollo y cooperación que sobresalen en la literatura especializada, resulta útil adoptar una definición amplia y comprensiva 
del 'poder estructural' ${ }^{5}$ entendido como 'la capacidad de una persona o grupo de personas para influir en los resultados, de tal forma que sus preferencias tengan prioridad sobre las preferencias de los demás' (Strange 1983: 38).

El clásico texto de Lukes (1974) ofrece una visualización tridimensional del poder que incluye mecanismos coercitivos, ideacionales y de poder material. La primera categoría incluye mecanismos o procesos de tipo coercitivo o directo donde la toma de decisiones se mide con la obtención de resultados. El poder material, además de lo anterior, toma en cuenta la definición de la agenda y el análisis de la estructura de toma de decisiones en procesos formales 0 informales. Finalmente, la tercera dimensión, además de los dos anteriores, incluye la conformación de expectativas y preferencias e incluye los intereses, ideas y significados intersubjetivos que orientan dichas preferencias (Lukes 1974).

Si empezamos el análisis considerando el poder ideacional, éste se ve reflejado en la concepción misma de la noción de desarrollo contemporánea que surge, tras las dinámicas de descolonización e inicio de la Guerra Fría, como la nueva encarnación de la idea de progreso en Occidente y el mito de la modernización (Wallerstein, 2004). Siguiendo a Dussel, desde Occidente se instauró un metarelato universal según el cual:

Los pueblos deben pasar de lo primitivo a lo tradicional y luego a lo moderno, siendo la sociedad liberal europea el punto de llegada al cual las culturas deben elevarse si no quieren desaparecer. Esta historia lineal se representa en un mito por el cual la civilización moderna occidental se considera la más desarrollada y esta superioridad la obliga moralmente a llevar el desarrollo a los pueblos más primitivos, a los bárbaros. Es así que se plantea la "falacia desarrollista" según la cual los pueblos deberían seguir las etapas de desarrollo que se desenvolvieron en Europa (Dussel, 2000).

El discurso del presidente Truman en enero de 1949 y el Plan Marshall, constituyen la base ideacional con la que la historiografía tradicional da pie al

\footnotetext{
${ }^{5}$ El poder estructural define oportunidades y riesgos, establece incentivos y sanciones, y los costes de oportunidad de las opciones disponibles para cada actor, condicionando de antemano su actuación. de igual manera, permite analizar cómo se percibe y define el riesgo, se intenta mitigar, y se convierte en «coste» (Strange, 1983)
} 
juego de coordenadas Norte-Sur 6 que entiende a un 'Norte' como 'desarrollado', 'primer mundo' y un 'Sur' como 'subdesarrollado', 'tercer mundo' y sus distintas combinaciones, dependiendo de la ubicación geopolítica y factores económicos de los países (Santander 2016: 28). De acuerdo a esta particular visión e ideas, se dio paso a lo que posteriormente se conoce como "Cooperación al Desarrollo" (CID) y a las prácticas dominantes de la AOD (Sagasti y Alcalde, 1999).

El poder material de la hegemonía entró en juego a través de compartir la "receta" para el éxito económico y progreso con los países del Tercer Mundo. A partir de entonces, el desarrollo se presenta como un proceso lineal y un objetivo a alcanzar para el cual bastaba la implementación de un buen proyecto modernizador con una serie de iniciativas, impulsadas por los países desarrollados, para salir del atraso (Rist, 2008). Con la paulatina consolidación de la globalización neoliberal se dio paso a la implementación de políticas de ayuda para el desarrollo, que consisten en la transferencia de recursos monetarios, humanos y técnicos, desembolsos de créditos, donaciones, programas y proyectos que buscan propiciar el desarrollo económico y social de los países.

Sobre esta base, la ayuda y el desarrollo se presenta como un aspecto técnicoracional-objetivo, moldeado por la narrativa del CAD, que ha conformado una "industria de la ayuda" o la "industria de la solidaridad" -es decir un conjunto de intermediarios especializados en la distribución, gestión y análisis de la cooperación. En palabras de Tandón:

su éxito ha resultado asombroso. Miles de personas se encuentran involucradas en la industria de la ayuda como está definida por el discurso dominante [...]. La mentalidad dominante y las normas de la ayuda que genera dependencia han dado lugar a una increíble cantidad de falsos problemas y falsas soluciones (Tandon 2009: 204).

\footnotetext{
${ }^{6}$ Resulta inevitable adoptar las categorías Norte-Sur para analizar el auge de la cooperación SurSur y regionalismo contemporáneo. Dichas categorías agrupan desde una lógica geopolítica a los países considerados como 'desarrollados' y 'en desarrollo' por parte de los organismos internacionales.
} 
Por su parte, la hegemonía también se consolida con las instituciones, a través de normas universales y mecanismos que establecen reglas generales de comportamiento para los Estados y la sociedad civil que actúa a través de las fronteras (Cox 1983: 62). Tal es el caso de la concentración de las decisiones en organismos multilaterales fundados en los Acuerdos de Bretton Woods, que institucionalizaron la ayuda y concentraron las decisiones en organismos como el FMI, BM, OMC, OCDE -creada en 1947 para gestionar el Plan Marshall. De igual manera, se consideran las políticas condicionadas, emanadas desde las instituciones económicas internacionales que presionan a los gobiernos a aceptar sus concepciones (Cox, 1983; Gill, 1995; Linklater et al. 2005). Los organismos y normas internacionales son el vehículo que legitima un orden hegemónico particular, a través del cual se propagan sus ideas y se coopta a las élites de las naciones periféricas para que divulguen y reproduzcan dichas ideas en sus propios países (Cox, 1983).

Históricamente encontramos que el Norte ha tenido la capacidad de ejercer el poder y conformar el orden internacional actual, no solo a través de la concentración de las decisiones en organismos multilaterales creados en su seno y bajo sus reglas, sino también, a través de lógicas de colonización o uso de poder militar directo. Esto ha traído como consecuencia que las potencias tradicionales han tenido mayor capacidad para establecer determinadas narrativas, expectativas y preferencias mientras que los países del Sur se han adscrito de manera subordinada a un sistema internacional diseñado por potencias hegemónicas sus instituciones y mecanismos en marcha.

Sin embargo, no se debe confundir esta perspectiva de análisis, que toma en cuenta las estructuras del sistema mundo, con aquella que propone la lectura constructivista de las RRII que tiende a mermar la relevancia de la agencia de los actores para definir sus destinos. Parte de la literatura que tuvo mucho auge durante la primera década del siglo XXI fue la propuesta de los intelectuales del denominado "Proyecto Modernidad, Colonialidad, Descolonialidad"7 quienes

\footnotetext{
${ }^{7}$ Este grupo de académicos estudian la colonialidad del poder y del saber (eurocentrismo) y se destacan autores como Enrique Dussel, Aníbal Quijano, Walter D. Mignolo, Edgardo Lander y Fernando Coronil, entre otros.
} 
argumentan que el Sur se corresponde con la negación, con las "formas de ser no dominantes" y expresa todo aquello que ha sido prohibido decir; con lo cual la existencia misma del Sur resulta una denuncia de lo inocultable y lo soterrado; en consecuencia toma formas de subversión porque dice "lo que no está permitido" (Suraski 2014: 6).

Desde esta perspectiva, la comprensión y explicación del mundo se realiza a partir de una serie de herramientas y paradigmas que implican la ausencia de subjetividad del "otro no-europeo/occidental" (Escobar 2012: 76); en otros términos, "las áreas no europeas han sido organizadas y transformadas sistemáticamente de acuerdo con los esquemas europeos" (Idem). En este sentido, el Sur fue imaginado como "el-otro-extranjero" llevando implícita la idea de que existen otras "formas de ser" y lógicas que han sido desplazadas por la hegemonía imperante (Suraski 2014).

Un posible entendimiento de la CSS, desde el pensamiento de Quijano (2003), señalaría que siendo la modernidad y la racionalidad producto de occidente, las relaciones intersubjetivas y culturales del resto del mundo fueron codificadas en el juego de categorías: Oriente-Occidente, primitivo-civilizado, mágico/míticocientífico, irracional-racional, tradicional-moderno, Norte-Sur (Quijano 2003: 211). Por ello, el Sur no se define a priori, sino en relación al Norte, "no es una cosa en si o para sí (...) más allá de lo que pueda connotar en un momento dado, siempre señala una ubicación "excéntrica", un afuera de los países centrales" (Comaroff y Comaroff, 2013: 84).

En esta investigación se comparte, por una parte, el entendimiento de que la hegemonía occidental ha establecido, incluso a las RRII como disciplina científica, como punto de partida para entender los "sistemas de relaciones sociales internacionales y sus mecanismos intelectuales para hacerlo inteligible, y a menudo legitimarlo" (Hernández 2001: 18). Sin embargo, por otra parte, este entendimiento sin el factor agencial resulta insuficiente para captar la complejidad de las relaciones entre los actores del sistema internacional, los intereses que promueven y los factores que reivindican la esencia de la Cooperación Sur-Sur. De hecho, la CSS implica variadas formas de acción 
colectiva, capacidad de negociación internacional y acciones concretas de resistencia a un orden internacional polarizado y polarizante que va en detrimento de las economías periféricas.

\section{El Sur en el orden internacional: ¿Qué es la Cooperación Sur-Sur?}

Esta investigación se enfoca en comprender a la CSS como un fenómeno de construcción de coaliciones internacionales, cuyo eje central radica en ubicar en el centro del análisis la cooperación económica entre países en desarrollo o financiera, porque constituye el ADN de la CSS (Domínguez 2016). El ámbito económico fue la base para fundamentar los objetivos políticos de carácter autonómico y las medidas de acción colectiva emprendidas entre los países del Tercer Mundo para proponer acciones conjuntas, tendientes a cambiar las reglas del juego del comercio, como camino para indispensable para "transformar la acción política" (Muir 2016: 632; Domínguez 2016).

En el contexto de negociación y disputa por el orden mundial en los albores del siglo XX, la CSS encontró sus raíces en el ámbito político y económico. Se empieza a hablar de cooperación entre los países del Sur en los procesos de lucha por la independencia de los países asiáticos y africanos en la década de 1940 que se vieron fortalecidos por los pactos de cooperación regional como la Liga Árabe (1945) y el Plan Colombo (1950), cuya finalidad era promover el progreso social y económico de sus Estados miembros (Cabana 2014). El concepto de CSS gana fuerza y reconocimiento internacional durante Conferencia de Bandung en 1955 que sentó las bases político-ideológicas, fundamentó el ideal reivindicativo de la colaboración entre países del Sur y forjó la solidaridad en contra de los desafíos del colonialismo e imperialismo y la agresión de la Guerra Fría.

En Bandung se expresó en el compromiso de los líderes presentes de proveerse mutua asistencia "hasta el máximo posible" ${ }^{\text {y }}$ marcó el inicio de dos décadas de

\footnotetext{
${ }^{8}$ Declaración Final de la Conferencia Afro-Asiática, Capítulo A: Cooperación Económica, párrafo 2
} 
cooperación entre los países del Sur cuyo propósito fue transformar las relaciones de dependencia de los países recientemente independizados respecto a sus antiguas metrópolis y formular alternativas económicas y políticas que propiciaran el desarrollo de sus sociedades (Lechini y Morasso 2010: 2). El encuentro fue el punto de partida del tercermundismo y de los principios que debían guiar las relaciones internacionales de los integrantes del MNOAL.

La consolidación del Grupo de los 77 en 1964 en el seno de la Conferencia de las Naciones Unidas sobre Comercio y Desarrollo (UNCTAD) o la realización de "La Habana Tricontinental" en 1966, constituyeron eventos que marcaron el tinte contestatario y diametralmente opuesto a los intereses del Norte. Posteriormente, esto dio lugar a la creación de la Carta de Derechos y deberes Económicos de los Estados en 1974 cuyo objetivo declarado fue "promover el establecimiento del NOEI, basado en la equidad, la igualdad soberana, la interdependencia, el interés común y la cooperación entre todos los Estados, sin distinción de sistemas económicos y sociales"9 .

La solidaridad entre los países del Sur se siguió desarrollando para desafiar la profundización de la desigualdad global y la dependencia económica del "Tercer Mundo" y se convirtió en la base política de la CSS que posteriormente se materializó en logros, tales como la creación de coaliciones entre los países en desarrollo e impulsó el establecimiento de un Nuevo Orden Económico Internacional ${ }^{10}$. Adicionalmente, se propició una serie de planes de acción, incluida la Declaración de Kuwait sobre Cooperación Técnica entre Países en Desarrollo (CTPD) en 1977, el Plan de Acción de Buenos Aires (PABA) para promover e implementar la cooperación técnica de 1978, el Programa de Acción de Caracas sobre Cooperación Económica entre países en Desarrollo en 1981, y la Declaración sobre el derecho al desarrollo de 1986. Durante los años ochenta se creó la Comisión del Sur en el marco del NOAL (1987) y en 1989 se

\footnotetext{
${ }^{9}$ Carta de Derechos y deberes Económicos de los Estados en 1974, Resolución 3281 (XXIX) de la AGNU.

${ }^{10}$ EI NOEl debía lograrse abordando las estructuras de intercambio desigual a través de "una relación justa y equitativa" entre los bienes exportados por los países en desarrollo y los bienes importados, poniendo énfasis en la soberanía sobre los recursos naturales y el derecho a nacionalizar industrias clave.
} 
estableció el Grupo de los 15, que pese a su impulso no avanzó de manera significativa durante esta década.

Durante esta etapa primó la idea de que era necesario fortalecer la cooperación entre países que compartían similares experiencias de dependencia y desigualdad; por lo que, la cooperación entre los países del Sur debía enfocarse en aumentar las capacidades de negociación ante los países del Norte y abrir nuevas opciones para avanzar hacia un estadio superior de desarrollo (Lechini y Morasso 2010: 2). Por ello, como trasfondo siempre estuvo la reclamación de un NOEl entendido como un proceso de negociación que aporte al "imperativo construir un nuevo orden con miras a resolver los serios problemas de comercio y desarrollo que acosan al mundo, especialmente los problemas que afectan a los países en desarrollo" (Prebisch, 1963: 3).

La idea de una CSS que impulse acciones colectivas para promover una arquitectura institucional internacional que considere las preferencias de los países del Sur hizo desde sus inicios un uso intensivo de tres pilares para fomentar el desarrollo del Sur. El primer pilar fue el diálogo político en su dimensión económica y financiera, concretado en acuerdos intergubernamentales con el fin de forjar alianzas colectivas a favor de un NOEI que permitiera salir del subdesarrollo. La Declaración Conjunta de los países en desarrollo realizada al término del primer período de sesiones de la UNCTAD en 1964, reconoció a esta nueva institución "como un paso significativo en la creación de un orden económico nuevo y justo" (Boutros- Ghali 2006).

El segundo pilar lo constituyeron los acuerdos comerciales y de integración que surgieron de dicho diálogo y que tenían idéntico objetivo: el mandato de la UNCTAD (resolución 1995 de 1964) era "fomentar el comercio internacional, especialmente con miras a acelerar el desarrollo económico", mediante, entre otras medidas, "negociar y aprobar instrumentos jurídicos multilaterales en la esfera del comercio" y que también, como señala Boutros-Ghali (2006), "ninguna otra organización ha estado tan implicada, y por un período tan prolongado, en cuestiones de integración regional" (Domínguez 2016: 7-8). 
El tercer pilar fue la cooperación técnica con propósitos también desarrollistas (Domínguez 2016; Zhang et al. 2015; Besharati et al. 2015). La CSS se materializó en una amplia gama de intercambios a través de programas, proyectos, iniciativas, políticas públicas ideadas para facilitar la difusión de experiencias y estrechar la solidaridad política entre los países del Sur frente al conjunto neocolonial del Norte y los intereses privados -como lo refleja la creación del Fondo de Kuwait o el PABA. Cabe destacar que se dio un rol preeminente al Estado como "representante genuino de los intereses de los pueblos de la periferia y se localizó las relaciones de explotación en el nivel interestatal posicionando de esta manera al Estado postcolonial del Sur como la figura heroica de la liberalización económica y factor clave de la modernización y el progreso (Nandy 1992: 266).

Estas acciones e iniciativas provocaron considerables debates en el Norte Global, que, haciendo uso de su poder hegemónico (Cox 1979), apelaron a propiciar Diálogos Norte-Sur. Dichos diálogos pretendían ser un esfuerzo para contribuir al desarrollo del tercer mundo y plantear consensos sobre orden internacional en ciernes, sobre la base de la reestructuración de las relaciones a nivel mundial. Tras varias reuniones, en Cancún, se puso fin al fracasado esfuerzo del grupo de los "ocho» representantes de potencias industrializadas cuando el grupo de los «diecinueve» países en vías de desarrollo mostraron su desacuerdo con las iniciativas de los «ricos» (Vilaro, 1977). La unidad del Sur se vio mermada por el aumento de los precios del petróleo y el endeudamiento creciente que provocó una dependencia crediticia de los países en desarrollo no petroleros con respecto a los mercados financieros internacionales dominados por los bancos norteamericanos (Domínguez 2018: 44).

Si bien los años ochenta ofrecieron una oportunidad para que los países en desarrollo realicen acciones coordinadas y políticas de concertación, con el avance de las políticas del Consenso de Washington, las fragilidades económicas de los países altamente endeudados disolvieron las tentativas de la cooperación multilateral. En los noventa, con el fin de la Guerra Fría, el avance de la globalización, la implementación de las políticas neoliberales y los graves 
problemas económicos de los países en desarrollo se diluyó la acción multilateral del Sur.

El final de siglo vio el triunfo del pensamiento único -corporizado en la "globalización inevitable" del modelo de economía neoliberal, al estilo there is no alternative de Thatcher que se acompañó con los planes de ajuste estructuraly la ampliación de la democracia en las regiones, pero con un Estado que debía achicarse. Este modelo no trajo aparejado bienestar y desarrollo para los países del Sur, pues los Estados centrales organizaron el orden mundial con sus propias reglas de juego, estructuradas para su beneficio y que no tenían en cuenta los problemas ni las necesidades del conjunto de los Estados de la sociedad internacional (Lechini 2009).

Como corolario, la principal fuente para conceptualizar al Sur ha sido la variable política, donde el Sur se presenta como forma de resistencia contra el orden internacional existente. En este sentido, la CSS se convirtió en un concepto clave de la organización de un conjunto de prácticas que buscan cambios históricos promoviendo visiones alternativas que toman como elemento central la defensa de la soberanía de los países recién independizados, oposición al Norte, cambio en las relaciones de poder, autonomía e identidad común. Es decir, la cooperación entre los países del Sur tuvo como objetivo transformar las relaciones de dependencia de los países periféricos respecto de los Estados de centro.

En este sentido, el propósito de las alianzas con los países del Sur fue avanzar en la formulación de alternativas de carácter económico y político que propiciaran el desarrollo de los países de sus sociedades. En este aspecto, Prashad señala que "algunos principios básicos conferían coherencia a la idea del Sur Global, un término que [se refiere] a una concatenación de protestas contra el neoliberalismo: una distribución más justa, autonomía frente al capital privado, derecho al bienestar, justicia social" (Prashad 2013: 325).

Por ello, la CSS se revela como una forma de denunciar las relaciones de poder producto de la modernidad y proporcionó la base intelectual para contestar los 
enfoques del desarrollo capitalista impulsado por el Norte; por lo menos marcó al desarrollo como un proceso controvertido donde las luchas políticas fueron decisivas para refutar los resultados distributivos a nivel internacional (Morvaridi y Hughes 2018: 8). Además, el surgimiento de la CSS da cuenta del fracaso del orden internacional instaurado en la postguerra que no pudo abordar los legados de colonialismo y proporcionar un espacio adecuado para que los Estados poscoloniales establezcan sus propios enfoques nacionales para el desarrollo (Gray and Gills 2016: 3).

\section{Conceptos y abordaje de la Cooperación Sur-Sur}

El abordaje de la cooperación Sur-Sur es muy amplio y asume connotaciones diferenciadas dependiendo de dónde provenga el análisis. Esta investigación entiende al "Sur" en el marco más amplio del sistema internacional que hace alusión a la dualidad centro-periferia, y que marca una división entre las unidades políticas que poseen menos recursos militares, políticos y económicos respecto de las unidades de centro (Lechini y Morasso 2010: 4). Este tipo de cooperación implica no solamente una manifestación en contraposición a las estructuras asimétricas a las que los países subdesarrollados deben insertarse -y que encuentra su génesis en la Conferencia de Bandung- sino también, una crítica al proyecto neoliberal internacionalizado a partir de la década de los noventa (Lo Brutto y Reyes 2015: 5).

La conceptualización de la CSS constituye un fenómeno complejo debido a su carácter político, multidimensional y de pluralidad de significados. Por una parte, en el lenguaje de la industria de la ayuda, se considera a la CSS como una modalidad de cooperación instalada dentro de la plataforma liderada por el CAD de la OCDE y se la tiende a asociar con la CTPD. Desde esta perspectiva, la CSS resulta complementaria de la cooperación tradicional Norte-Sur, es decir, a lo que se conoce como la AOD (Lechini y Morasso 2010: 3).

Desde esta línea argumentativa, los países en desarrollo comparten conocimientos, habilidades, experiencias de desarrollo similares por lo que, a través de la identificación de buenas prácticas, de sinergias y de esfuerzos 
basados en la solidaridad común podrían alcanzar estadios mayores de bienestar. Su objetivo es la construcción de una "agenda originada en el Sur, que contribuya a una arquitectura de cooperación más efectiva e inclusiva" (Camacho, 2010). Es decir, esta perspectiva se enfoca en el aspecto técnico de cuantificar proyectos, aumentar el intercambio de experiencias entre actores con similares características y buscar soluciones a problemáticas comunes.

Por el contrario, en esta tesis se sostiene que, si bien el ámbito técnico es importante, éste debe estar atado a un análisis histórico-crítico, que tome en cuenta la perspectiva del proceso de cambio mundial y los elementos estratégicos de inserción de los países periféricos en el orden internacional actual. Por ello, se hace énfasis en la importancia de retomar su carácter reivindicativo porque es lo que dio pie a que los países del Sur se unan y adopten proyectos contestatarios encaminados a mejorar los términos de su inserción internacional.

La CSS es una categoría política basada en la tradición de autonomía y de articulación de los países del Sur para mejorar sus capacidades de maniobra y negociación en sus procesos de inserción internacional (Domínguez 2019: 27; 2017). Siguiendo la metodología de Domínguez 2019, quien realiza una historiografía de la CSS, conviene usar las definiciones y conceptos tomando en cuenta el contexto en que fueron establecidas, por ello se entiende a la CSS como:

Un fenómeno de construcción de coaliciones internacionales en el contexto de la negociación y disputa por el orden mundial (Bergamaschi y Tickner, 2017; Chakrabarti, 2018) [...] y debe medirse por el criterio funcional de construcción de identidades colectivas indispensable para transformar la acción política (Muir, 2016: 632).

En este sentido, se podría definir a la CSS como la acción conjunta entre países en desarrollo que apunta a reforzar las relaciones bilaterales $y / 0$ formar coaliciones en foros internacionales con el propósito fortalecer su capacidad de negociación con el Norte y de adquirir mayores márgenes de maniobra internacional (Lechini y Morasso 2010: 3). Esto está en sintonía con la 
conceptualización de CSS que el Grupo de los 77 (G77) acuñó a través de la UNCTAD como:

los procesos, instituciones y arreglos diseñados para promover la cooperación política, económica y técnica entre los países en desarrollo en la búsqueda de objetivos de desarrollo común [...] la CSS tiene un alcance multidimensional, que abarca la cooperación en áreas tales como comercio, finanzas, inversión, así como el intercambio de conocimientos, habilidades y experiencia técnica entre los países en desarrollo (Unctad 2010).

Por lo tanto, la CSS se constituye como una apuesta para impulsar una arquitectura internacional conforme a las preferencias de los países del Sur fundamentada en el dialogo político forjado desde Bandung. En 1975, la UNCTAD a través de la Junta de Comercio y Desarrollo señalaba dos aspectos fundamentales de la CSS, por una parte, la capacidad de actuación conjunta de los países en desarrollo para consolidar sus relaciones y su fortalecer la negociación con el resto del mundo, y, por otra, el fortalecimiento de lazos mutuos para estimular su desarrollo económico (cfr. Tomassini, 1976: 28).

En cuanto a las áreas temáticas, el PNUD señala que la CSS abarca:

Un marco amplio para la colaboración entre los países del Sur en las dimensiones política, económica, social, cultural, ambiental y técnica, que involucra dos o más países en desarrollo [...] la CSS es multifacética, cubriendo diferentes áreas, tales como el comercio, la inversión, la cooperación en Ciencia y Tecnología, las PYME, y la facilitación del comercio con el potencial de fomentar la integración regional, que es un paso importante para la integración global (UNDP, 2013 en Domínguez 2016: 11).

De este acervo documental sobre la CSS, resaltan dos conceptos fundamentales en clave emancipatoria, la idea de la autonomía y el de self-reliance o autodeterminación colectiva. La autonomía, es un concepto político relacionado a la búsqueda de cooperación internacional basada en la igualdad, la confianza mutua y la justicia que permita la "democratización de las relaciones internacionales, para una cooperación equitativa integral, para el progreso económico y social” (Domínguez 2019: 19). 
La autodeterminación colectiva implica el fortalecimiento de las capacidades de negociación de los países periféricos y tiene un doble significado. Por una parte, como una relación de unidad entre los socios del Sur hacia fuera, para reforzar el poder de negociación frente a los países desarrollados; y por otra, la unidad hacia dentro para resolver los desafíos comunes de manera colectiva (O'Neill, 1980). El principio también hacía referencia al desarrollo endógeno con cambio estructural de los países a través de la cooperación económica considerando los principios de igualdad y de mutuo beneficio (Domínguez 2019: 93).

Estas dos ideas clave implican una forma de relacionamiento diferente que pone a debate la concepción misma del desarrollo. La CSS, asociada a la capacidad de acción colectiva y autonomía para construir una arquitectura institucional internacional conforme a las preferencias de los países del Sur, implica ser más respetuoso con el interés nacional del país y con la construcción de un espacio común propicio a la refundación regional, con un amplio reconocimiento interno y externo (Sotillo, 2010).

En este sentido, varios autores coinciden en que uno de los aportes de CSS fue poner en la palestra el dilema las dos corrientes de pensamiento sobre el desarrollo que se disputaban en la época de postguerra: la disyuntiva entre "el capitalismo universal o la planificación regional” (Dale, 2016; Desai, 2016).

Por un lado, la filosofía "librecambista" y de fortalecimiento del capitalismo global impulsaba la restricción de la planificación e intervención estatal y estaba fundamentado en tres pilares: transferencia masiva de capitales (sobre todo privado), exportaciones de materias primas, y el principio de las ventajas comparativas. Este planteamiento inspiró el sistema neoliberal con pretensiones globalizadoras que surgió de Bretton Woods y que se centra en "la óptima asignación de los recursos disponibles, a través de las señales provenientes del mercado dentro de un sistema regido por el liberalismo económico" (Tomassini, 1977). La concepción de desarrollo tenía como premisa que toda planificación, al dar demasiado poder al Estado para el logro de la libertad colectiva de la necesidad, era una amenaza a la libertad individual de elección y la prosperidad (Hayek, 2001). 
En contraposición, la visión de desarrollo impulsada por los países del Sur puso en el centro a la política, la planificación, la intervención estatal en la economía, y el fortalecimiento de la producción local (Bergamaschi y Tickner 2017: 1). Es decir, una visión "intervencionista" apoyada por los países del Tercer Mundo y cuyos valores más significativos eran la "igualdad en la distribución del ingreso y la autodeterminación nacional", objetivos que sólo podían lograrse "a través de un grado considerable de regulación de los mercados", apoyándose en "el surgimiento de un proletariado externo representado por los países del Tercer Mundo", dispuestos a desbordar el orden neoliberal "cuyas reglas no contribuyeron a establecer" (Tomassini 1977: 1069-1070).

Estos planteamientos encontraron eco teórico en el pensamiento de, entre otros autores, Myrdal quien criticó los "arquetipos de desarrollo" planteados en las naciones de centro y validó el principio de "interdependencia circular" en 1956. De acuerdo con el autor, este concepto debe ser entendido como:

un proceso circular y de acumulación causativa que tiende a favorecer a aquellos que ya están beneficiados e incluso a subvertir los esfuerzos de aquellos que viven en regiones atrasadas (...) y debería constituir la hipótesis principal cuando se estudia el desarrollo y el subdesarrollo económicos (Myrdal 1956, traducción propia).

Este enfoque dialéctico revela que el modelo tradicional de desarrollo es intrínsecamente pernicioso para los países periféricos y profundiza las desigualdades en los términos de intercambio en detrimento del Sur (Morvaridi \& Hughes, 2018). Esto lleva a entender las relaciones centro-periferia y la forma paradójica en cómo se expresa la dependencia y el atraso en las regiones periféricas. Por una parte, el atraso comprende una estructura y un proceso, orientados a la desarticulación de las tendencias de crecimiento y se origina en las dos grandes estructuras de dominación: una externa, articulada a la estructura supranacional y una interna, vinculada a las clases dominantes (García 2006: 147). Por ende:

El subdesarrollo comprende una compleja trama de relaciones de dependencia y de causalidad que se establecen entre factores estructurales de diversa naturaleza y a la vez, implica la negación de 
posibilidades de desarrollo independiente ligadas a las facultades de autodeterminación nacional (García 2006: 150)

Sobre esta base de entendimiento se solventó, a nivel internacional, el debate sobre la oposición de dos visiones diametralmente opuestas: la idea del mercado autorregulado y la del desarrollo con autosuficiencia; que fue la visión que los Estados recientemente independizados propusieron (Domínguez 2019: 29). En una época donde las ideas emergentes propiciadas por los países del Sur, hacían referencia a "nuevas formas de socialismo, de capitalismo, de economías planificadas y semiplanificadas, que por su propia naturaleza son regionales", y que tenían en común "el desarrollo deliberado de nuevos instrumentos y órganos de comercio, préstamos y pagos exteriores, que constituyen la esencia de la planificación regional", siendo dichos instrumentos "incomparablemente más efectivos para los propósitos de la cooperación internacional" (Polanyi 1945 en Domínguez 2019).

\section{Factores de cambio y transformaciones en la estructura internacional}

El análisis de los factores de cambio y transformaciones en las estructuras del sistema internacional resulta especialmente relevante para los países periféricos, carentes de poder en el concierto internacional, porque la conformación de tal estructura limita su margen de autonomía y decisión. Por ende, para poder conseguir algunos de sus objetivos de política exterior, este grupo de países depende de la cooperación y concertación de alianzas, capacidad de negociación internacional, funcionamiento de foros, instituciones y regímenes internacionales (Bernal-Meza 2004: 1).

Existe consenso entre especialistas de diversas orientaciones y disciplinas de que el periodo histórico actual, denominado globalización, representa un profundo cambio en la naturaleza del orden mundial creado a finales de la Segunda Guerra Mundial y profundizado por el Consenso de Washington de los años noventa. A partir de la década de los setenta se materializa un conjunto de eventos que dan paso a un nuevo tiempo histórico que modifica el orden creado por la Pax Americana, otorgando mayor relevancia al complejo del Este Asiático, 
con el ascenso de la República Popular China (RPCh) liderando los procesos de transformación del desarrollo (Krugman, 2009; Ferguson, 2009; Nye, 2005; Ohmae, 2005; Bigsten, 2004; Dicken, 2003; Cox, 1981; Rodrik, 1997, Huntington, 1998).

Esta transición se ha articulado con la reubicación de los centros de gravedad del poder mundial del 'eje transatlántico' hacia un nuevo y dinámico 'eje transpacífico' -que se ha convertido en el área más grande de comercio mundial siendo China, India, Corea del Sur, Taiwán, los países que más se han destacado (FMI, 2019). Esto configura un panorama de paulatina transición hegemónica del Atlántico Norte con EEUU como único hegemón mundial, al Este Pacífico con China como adalid de la narrativa de CSS.

El punto clave y de mayor divergencia en el ámbito académico, radica en comprender como se dará la gestión de este cambio de eje del orden internacional. De acuerdo a Nye, las nuevas dinámicas geoeconómicas y geoestratégicas en la estructura de poder existente se reflejan en la transición de un mundo unipolar a un orden internacional donde 'el mundo no es ni unipolar, ni multipolar, ni caótico; es estas tres cosas al mismo tiempo' (Nye 2011: 213). Sin embargo, las dos alternativas predominantes al respecto debaten si estas transformaciones van a tener lugar dentro de un marco de cooperación y soft power que permita un acomodo de intereses nacionales para asegurar la coexistencia pacífica de los dos poderes dominantes (Nye, 2005) o simplemente si estos cambios darán paso a un orden mundial multipolar con menos influencia de los EEUU.

Más allá de descifrar cómo será este proceso de transición mundial, resulta necesario entender la substancia de estos cambios y las implicaciones en la reconfiguración de escenarios y tendencias. Actualmente, la región asiática se ha convertido en la zona más grande de comercio mundial siendo China, Corea del Sur y Taiwán, los países que más se han destacado (FMI, 2019). Esta zona se ha anclado al mercado internacional de manera fortalecida duplicando su participación en las exportaciones, especialmente durante los últimos 15 años del siglo XX. Los países del este asiático contienen más de la mitad de la 
población del planeta y más de tres veces la población de cualquier país desarrollado (Bigsten, 2004). Resalta el ascenso de China al puesto de segunda mayor economía del mundo, que, de continuar con sus niveles de crecimiento, podría convertirse en la principal potencia económica para el año 2030 según las proyecciones del Fondo Monetario Internacional (FMI).

La relevancia de este paulatino proceso de cambio en las estructuras mundiales descansa no solamente en los indicadores de posicionamiento internacional de los países sino más bien en la naturaleza del cambio social que esto trae aparejado como resultado de su ascenso comercial. Todo este crecimiento económico ha disparado nuevos procesos de industrialización y provocado un cambio de las estructuras sociales (ABD 2010). Esta región tiene características específicas en cuanto a factores de producción, mano de obra, capital y tierra y han centrado su crecimiento en las exportaciones de bienes industrializados por lo que el fenómeno de acumulación ha sido rápido y está fuertemente ligado con las industrias extractivistas -se demanda gran cantidad de materias primas para sostener su industria (Banco Mundial 2016).

Estos países han tomado un rumbo orientado a la economía de mercado, pero regulada por el Estado lo que ha llevado a un importante aumento del poder adquisitivo de esta población. Se estima que el promedio de la región, en cuanto a poder adquisitivo, es de un $56 \%$ del promedio mundial, lo que indica que se está consolidando una amplia clase social consumidora (ABD 2010). Un estudio realizado por el Banco Asiático de Desarrollo (ABD por sus siglas en inglés) en el 2010 confirma que, más importante que el posicionamiento internacional del Asia Pacífico, está el hecho de que sus crecientes sectores sociales de clase media, sin duda, van asumir el rol de consumidores mundiales -históricamente asumido por las clases media en los EEUU y Europa (ABD 2010).

Los cambios experimentados en el sistema internacional en las dos últimas décadas han sacado a la luz el hecho de que el mundo de la cooperación internacional, construido por el sistema de Bretton Woods y que aún muchos solo interpretan desde lo técnico, no está preparado para adaptarse y gobernar el cambio en forma pluralista por cuatro limitantes estructurales. Y al seguir así, 
sin una transformación estructural de su diseño, corre riesgo de chocar con una realidad donde el liberalismo se ve limitado ante la emergencia del pluralismo (Cox and Schechter, 2002).

Una de las principales limitantes es la cerrada toma de decisiones concentradas en un grupo de naciones del eje del Atlántico Norte y sus reglas, basadas en la lógica de mercado de las economías anglosajonas, que se aplican al comercio y finanzas internacionales (Weiss, 2003; Bøås and McNeill, 2004). Otra limitante es la estrecha visión de la paz liberal internacional entendida como militarización de los conflictos e intervenciones humanitarias (Duffield, 2005). Adicionalmente y de tipo más estructural, es la ideología de la comunidad internacional epistémica que legitima, racionaliza y tecnifica las acciones de este orden de cooperación universal. Una red intelectual formada en el mismo conjunto de centros académicos que definen el pensamiento técnico de la cooperación internacional y cuya ideología reproduce estas visiones desde lo técnico más que subordinar este a la dimensión estratégica del cambio (Vivares y Zapata 2011).

Como corolario, se puede señalar que los cambios experimentados en el sistema internacional de inicios del nuevo milenio vienen de la mano del resurgimiento de Estados emergentes pertenecientes al Sur Global, que traen de vuelta el potencial del diálogo político desde perspectivas pluralistas. Ello explica en parte las diferentes iniciativas adoptadas por los gobiernos de países periféricos que pusieron en el centro del desarrollo el interés nacional y la autonomía en sus procesos de inserción internacional.

\section{La reemergencia de la Cooperación Sur-Sur en el siglo XXI}

Los procesos de reconfiguración del sistema internacional ahondados a finales del siglo XX han puesto en el centro de la transformación sistémica a los países emergentes pertenecientes al Sur Global y han evidenciado la paulatina crisis hegemónica de EEUU -visualizada en la pérdida de peso económico y autoridad política de EEUU (McCoy, 2017; Rica \& Lockhart, 2013). En este proceso, la República Popular China se establece como y la nueva potencia reguladora de 
la economía global (Spence, 2017), lo que ha posibilitado que antiguos Estados periféricos incrementen su influencia internacional y trasladen los focos de generación de instituciones, bienes globales y normas internacionales hacia el Asia Pacífico y, eventualmente hacia el resto de países periféricos (Serbín 2016).

De manera general, los países que lideran la actual narrativa de la CSS son las denominadas potencias medias emergentes cuyo nuevo posicionamiento internacional les ha permitido situar nuevos elementos de debate en la agenda internacional. Siguiendo a la categorización que realiza Nolte 2006 sobre las potencias medias emergentes, éstas se caracterizan por:

- formar parte de una región bien demarcada tanto geográfica como económicamente y según la autopercepción política (base regional);

- influir en la delimitación geopolítica y construcción político-ideológica de la región;

- tener la pretensión de un liderazgo en la región (voluntad y rol percepción);

- ostentar los recursos materiales (militares, económicos, demográficos), institucionales (políticos) e ideológicos para una proyección de poder en la región (recursos);

- estar interconectados con la región económica, política y culturalmente, lo que significa que sus aportes al GDP regional por sí mismo no es un indicador suficiente (inserción);

- ejercer efectivamente gran influencia en asuntos regionales (actividades y resultados);

- ejercer esa influencia en parte mediante estructuras de gobernanza regional;

- definir la agenda de seguridad regional (existencia de un complejo de seguridad regional);

- sus liderazgos regionales son reconocidos o al menos respetados por otros países en la región y fuera de ella, especialmente por las otras potencias regionales (aceptación);

- se insertan en foros interregionales y globales, en los cuales opera en función de la defensa de sus propios intereses, por lo menos en forma incipiente, y donde actúa como representantes de intereses regionales. 
China e India son las potencias emergentes pertenecientes al Sur Global que más destacan y que han considerado a la CSS como un eje transversal de su política exterior. En el ámbito económico, China se ha convertido en la economía más potente del mundo y marcó su formidable irrupción en el comercio mundial a partir de la primera década del siglo XXI liderando iniciativas regionales como el Área de libre comercio de Asia Pacífico (FTAAP por sus siglas en ingles), la asociación regional económica comprensiva (RCEP), la política de 'cooperación comprensiva' de China hacia América Latina; la 'ruta de la seda' ('Onebelt, Oneroad') impulsada en el ámbito euroasiático (Serbín 2016).

El ascenso de China al centro de la economía mundial, la rápida expansión de sus relaciones políticas internacionales y los intereses estratégicos que persigue en su vinculación con países periféricos, han sido objeto de intensos debates referentes a la caracterización del gigante asiático como una "potencia mundial", "potencia regional", "potencia emergente", "país en desarrollo", "país del tercer mundo". Si bien en la época contemporánea detenta la segunda economía mundial, hasta hace un siglo China fue un país semicolonial y semifeudal oprimido por las potencias imperialistas y sin intereses que proteger alrededor del mundo (Laufer 2013: 7).

Oficialmente, los dirigentes del país asiático señalan que China es un país de "en vías de desarrollo" involucrado en la "cooperación Sur-Sur" y que busca establecer relaciones de beneficio mutuo o "ganar-ganar". Históricamente, Beijin ha impulsado la CSS con miras a la consecución de una política exterior autónoma y de no alineamiento; mientras que India lo ha hecho con el objetivo de lograr una política económica que desestructure su situación colonial (Domínguez 2018: 50). De hecho, el espíritu de la Declaración de Bandung incluye los cinco principios que estos dos países ya habían declarado conjuntamente en 1954: coexistencia pacífica, respeto mutuo de la soberanía y la integridad territorial, no injerencia en los asuntos internos, no agresión, igualdad y privilegios recíprocos (Domínguez 2018: 50). 
Lo que resulta novedoso en la época contemporánea, es que China se encuentra en el epicentro de un proceso de transición hegemónica que se está desplazando de EEUU hacia el gigante asiático. Desde finales del siglo $X X$, se evidencia la paulatina erosión de la posición hegemónica de EEUU que abre la posibilidad de nuevas dinámicas que pueden contribuir a remodelar los mapas regionales y globales y otorgar mayor protagonismo a los países periféricos.

Una de las consecuencias de estos procesos de reajuste tiene que ver con la nueva geopolítica mundial que sitúa a China como el principal proveedor de CSS. Este país se ha convertido en el actor más visible de la CSS y la ha utilizado como una herramienta de poder blando en su estrategia de "ascenso pacífico" en la jerarquía global. La creciente expansión de su actividad diplomática ha hecho que su presencia sea cada vez mayor en foros, organismos internacionales y en instancias bilaterales de cooperación con una cantidad cada vez mayor de países y regiones (Slipak 2014a). Esto ha recuperado y revitalizado la tradición de autonomía, convirtiéndose en la superpotencia capaz de generar modelos de desarrollo en el siglo XXI (Domínguez 2019: 26).

El incremento de poder económico y financiero junto con su capacidad de influencia en la política global hacen que el país oriental sea la mayor locomotora de CSS para el desarrollo. Las reservas de divisas en su cuenta corriente ascienden a 3,4 billones de dólares a noviembre de 2015, a gran distancia de Brasil (357.000 millones de dólares), India (352.000 millones de dólares) y Venezuela (por debajo de 15.000 millones de dólares ${ }^{11}$ (Domínguez 2016: 14). En cuanto a montos como proveedor de cooperación oficial para el desarrollo de China, de acuerdo a estimados que siguen la métrica de la AOD neta del CAD, la ayuda externa neta de China ha aumentado paulatinamente pasando del decimosexto puesto en 2001 al sexto lugar en el 2013 cuando alcanzó \$ 7.1 mil millones, ubicándose detrás de EEUU, Reino Unido, Alemania, Japón y Francia. En cuanto a ayuda bilateral, desde el año 2012 se ubica en el lugar número 6, junto a Japón y Francia (Kitano y Harada 2014). De estos montos, la ayuda china

\footnotetext{
${ }^{11}$ No hay que olvidar que sus reservas de petróleo probadas son de cerca de 300.000 millones de barriles y son las mayores del mundo y, por tanto, su potencial de cooperación energética sigue siendo enorme (Domínguez 2015).
} 
entre los años 2010-2012 se distribuyó en un 51,8\% para África, 30,5\% para Asia y $8,4 \%$ para América Latina, con un $61,1 \%$ del total destinado a los LDC y otros países de renta baja (State Council 2014).

Otra de las consecuencias de las trasformaciones en las relaciones de poder en el nivel sistémico son las repercusiones en las bases que sostienen un cierto régimen internacional y sus instituciones, de tal manera que cuando el poder concentrado en una sola potencia hegemónica y sus instituciones se dispersa, se da paso al desarrollo de nuevos polos de poder y al desarrollo de nuevas institucionalidades (Nye 2011). Este proceso de cambio estructural pone en cuestionamiento los términos de relacionamiento entre los Estados, así como las competencias y límites de las actuales instituciones de gobernanza de la cooperación internacional (Moe Fejerskov, 2016).

En este sentido, la activa presencia de potencias emergentes en la arena mundial ha abierto espacio para el establecimiento de nuevas estrategias político institucionales con miras a afianzar su resurgimiento y visión de desarrollo. En el pilar institucional, se han conformado nuevas alianzas entre países del Sur como los BRICS, que contienen un Fondo de Contingencia de Reservas para la provisión de crédito a largo plazo sin condicionalidades económicas o reformas institucionales (como sucedió con el Consenso y Post-Consenso de Washington). De igual manera se ha establecido el Banco de Inversión e Infraestructura de Asia (AlIB); mientras que, en el brazo político, el año 2006 se constituye el Foro de Cooperación al Desarrollo de Naciones Unidas (UNDCF por sus siglas en inglés) y la Unidad de Cooperación Económica e Integración entre Países en Desarrollo de la UNCTAD en el 2009 (Gosovic 2016), y desde el frente bilateral, la State International Development Cooperation Agency en 2018 (Domínguez Martín, 2018).

Estas nuevas institucionalidades están haciendo contrapeso a la actual gobernanza de la cooperación compuesta por el sistema del CAD y su eje financiero representado por el Banco Mundial (BM). De igual manera, estas instituciones surgidas dentro de los espacios del Sur Global podrían constituir la base de un nuevo régimen internacional de CSS, que cuanto menos, pone 
presión a EEUU para negociar cambios en la arquitectura financiera internacional y sus modalidades crediticias, acordes con los intereses de China, de los BRICS y de los países en desarrollo (Trindade d'Ávila Magalhães, 2018). Otro de los pilares de este nuevo régimen es la financiación al desarrollo que comprende la cooperación para la transformación estructural basada en la inversión en infraestructuras (área de mayor enfoque de China) y los cinco ámbitos de acción: comercio e inversión, tecnología, construcción de capacidades, financiación concesional (líneas de crédito) y subvenciones (que son la base de la cooperación de India) (Chaturvedi, 2016; Chakrabarti, 2018; RIS, 2016).

Sobre esta base, resulta necesario recalcar que en la época contemporánea China juega un rol determinante en la reconfiguración de la economía política mundial porque pone en tela de juicio el rol de la hegemonía estadounidense, por lo menos en el ámbito económico. El gigante asiático se convierte en la base para el establecimiento de nuevas dinámicas geopolíticas y su liderazgo buscará dar forma a un entorno internacional más favorable a sus intereses, buscando atraer a su órbita a países aliados a través de incentivos económicos. Particularmente en América Latina, China ha asumido cada vez más un papel protagónico en la región en una época que coincide con la pérdida de prominencia de las relaciones con los socios del Norte, con lo cual, "la irrupción de China en Latinoamérica es inversamente proporcional al declive de Estados Unidos" (Jalife-Rahme 2012:12).

\section{Recapitulación}

Este capítulo se propuso comprender los principales enfoques académicos que giran alrededor del entendimiento de la cooperación Sur-Sur y para ello se hizo un repaso histórico-critico de los antecedentes, conceptos y principales premisas sobre las cuales se analiza su resurgimiento como mecanismo de la política exterior de los países periféricos. En este sentido, la presente tesis opta por un abordaje desde la perspectiva de la Economía Política Internacional, tomando distancia de los análisis más generalizados en el estudio del desarrollo, que la enmarcan dentro de la arquitectura de la AOD. 
Para ello, el argumento que se sostiene es que la cooperación y el desarrollo deben ser entendidos en el marco de las estructuras que componen el orden internacional actual, que se caracteriza por la asimetría de poder entre los actores que confluyen en el mismo. En este sentido, se retoma la perspectiva histórica que aborda la CSS como mecanismo de diálogo político de los países del Sur para consolidar alianzas para el cambio de las relaciones económicas internacionales. En la década de los sesenta este diálogo político se plasmó en mecanismos como el MNOAL y es esta narrativa reivindicativa la que retoman los países sudamericanos con gobiernos de corte progresista, en el ejercicio de su política exterior en los albores del nuevo milenio.

El análisis desde la perspectiva de la EPI crítica contribuye a explicar los cambios en las estructuras internacionales de poder que inciden en la reemergencia y fortalecimiento de la CSS. Siguiendo las categorías analíticas propuestas por autores clásicos como Robert Cox o Steven Lukes se buscó comprender cómo los factores relativos a las estructuras de poder económicas y políticas influencian las dinámicas de inserción internacional de los Estados débiles o periféricos en el sistema internacional. De igual manera, desde este enfoque se puede comprender la forma en que los países vulnerables perciben a la CSS como un mecanismo que puede ser apuntalado en sus políticas exteriores, como una práctica que les permite ampliar sus márgenes de autonomía y reducir relaciones de dependencia de potencias centrales.

A lo largo del capítulo, se hizo especial énfasis en el posicionamiento de China en el eje central de las transformaciones sistémicas del orden internacional contemporáneo porque su protagonismo ha hecho palpable el proceso de transición hegemónica, que paulatinamente desplaza a los EEUU de su lugar como única potencial mundial. Adicionalmente, se consideró relevante comprender el desembarco del gigante asiático en la región latinoamericana debido a que llegó a dinamizar las relaciones de América Latina con el Asia Pacífico abriendo nuevas oportunidades y alternativas de inserción internacional de la periferia. Su presencia cada vez más asertiva en la región y aupada por un discurso de cooperación Sur-Sur dio lugar a nuevas dinámicas de 
relacionamiento con los países latinoamericanos, y se mostró como un socio que podría apuntalar los modelos autónomos de desarrollo de los países periféricos en el sistema internacional. 


\section{CAPÍTULO II: DINÁMICAS DE LA COOPERACIÓN SUR-SUR EN AMÉRICA LATINA EN LOS ALBORES DEL SIGLO XXI}

\section{Discusión}

El renovado auge que adquirió la cooperación Sur-Sur en América Latina en los albores del siglo XXI trajo consigo nuevas prácticas que redimensionaron la idea de desarrollo e impulsaron procesos multidimensionales de coordinación y concertación. Las iniciativas registradas son variadas e incluyen espacios de integración regional, mecanismos de diálogo político, institucionalidades y políticas públicas que buscaron erigirse como estrategias complementarias 0 alternativas, según las visiones, para hacer frente a un sistema internacional asimétrico y corregir sus persistentes desigualdades.

El argumento central que se sostiene en este capítulo es que el fortalecimiento de la CSS en la región vino de la mano de tres dinámicas interrelacionadas, referentes al constante cuestionamiento a la globalización y la dominación político-económica del hegemón hemisférico (EEUU); a la búsqueda para redefinir modelos de inserción basados en la reafirmación del interés nacional y la vigencia de la idea de autonomía como elementos clave de desarrollo.

Sobre esta base, el objetivo de este apartado es ubicar el auge de la cooperación Sur-Sur en el contexto latinoamericano a inicios del nuevo milenio desde la perspectiva de la economía política internacional y las trasformaciones de las relaciones de poder. Para ello, primero se analiza la revitalización de la cooperación económica tomando como hilo conductor el desembarco de China en la región. Segundo, se estudia la cooperación técnica que se instaura en el marco de la cooperación al desarrollo como política pública de cooperación. Finalmente, la cooperación Sur-Sur en los procesos de integración regional de tipo autonómico, ALBA, UNASUR, CELAC, en la región.

\section{Influencia china en el resurgimiento de la CSS en América Latina}


El auge de la cooperación Sur-Sur en América Latina en los albores del siglo XXI se encuentra estrechamente ligado al paulatino desplazamiento del poder en el sistema internacional y sus cambios de carácter económico y político. Sobre la base de la tesis Coxiana de que toda teoría tiende a promover un orden existente o a entender el cambio, conflicto y desarrollo del mismo (Cox, 1981), este capítulo argumenta que el análisis de la CSS en la región debe contemplar su resurgimiento y misión estratégica dentro del actual orden internacional en transformación.

La investigación conjuga los postulados y premisas teóricas de la EPI y del pensamiento latinoamericano para dar luz sobre las dinámicas de CSS que se dieron en la región de América Latina una vez iniciado el nuevo milenio desde una visión innovadora. La primera fuente teórica sienta los fundamentos para entender las transformaciones en el sistema internacional, los cambios en las relaciones de poder y sus repercusiones en el ascenso del Sur Global; mientras que la segunda, da cuenta de los planes, agendas y políticas reivindicativas que adoptaron los países latinoamericanos en el ejercicio de su política exterior.

Este marco analítico permite indagar hacia dónde va el orden mundial y cuál es el nexo entre cooperación, conflicto y desarrollo. Con lo cual, retratar la CSS frente a los cambios globales permite dar cuenta de las alternativas y nuevos enfoques que surgieron en América Latina para pensar el desarrollo, redefinir el interés nacional y proponer nuevos diseños institucionales con miras a la refundación de las instituciones a nivel nacional y regional yendo más allá del centrismo liberal occidental.

Existe consenso en el ámbito académico en que uno de los factores trascendentales del cambio del orden internacional es la reubicación de los países emergentes en el centro del poder económico y político internacional. El ascenso de la República Popular China en los ámbitos económico, financiero, militar y político se ha convertido en uno de los acontecimientos más relevantes de finales del siglo XX. Especialmente debido a que, ya en el nuevo milenio, el país asiático se consolida como la segunda economía del planeta detrás de EEUU, el primer prestamista de la Reserva Federal estadounidense, el principal 
productor mundial de manufacturas, el quinto emisor global de inversión extranjera directa (IED), el primer consumidor global de energía y el segundo de petróleo (Slipak 2014b).

Desde su conformación como República en 1949, la política internacional de China ha dado prioridad a los "cinco principios de coexistencia pacífica" que incluyen el respeto mutuo por la integridad territorial, la no interferencia en asuntos internos de otras naciones y el trato igualitario entre los países cuyas relaciones deben ser de beneficio mutuo. A finales del siglo XX opta por una estrategia de apertura al mundo y retoma la narrativa ligada a reafirmar el "espíritu de Bandung" fundamentando su cooperación en la promoción de relaciones "solidarias", de tipo "ganar-ganar" y enfoca sus relaciones exteriores con miras a favorecer un desarrollo pacífico. Sobre esta base incursiona en América Latina, Eurasia y África convirtiéndose en un importante inversionista y agente dinamizador del comercio, que busca fortalecer la cooperación en los ámbitos político, económico-comercial y científico-tecnológico con los países.

En América Latina, el eje estructurante del auge de la CSS se encuentra estrechamente vinculado a la presencia cada vez más asertiva de China en el continente. El gigante asiático desembarca en la región con la propuesta de desarrollar vínculos de carácter cooperativo con los socios del Sur, fundamentando su relacionamiento en base al diálogo político y la creación de alianzas para acuerdos comerciales. En el ámbito político se muestra como un socio respetuoso de la soberanía nacional y la autonomía de los pueblos y en el ámbito económico como agente dinamizador del comercio. Este nuevo tipo de relacionamiento permitiría a los pares latinoamericanos superar las relaciones asimétricas y de dependencia que se han mantenido con las tradicionales potencias hegemónicas, dentro de un nuevo contexto multipolar.

La incursión de China en la región latinoamericana abre un nuevo espacio de cooperación que permite paulatinamente pensar en el establecimiento de un esquema de relacionamiento alternativo a la tradicional cooperación Norte-Sur. A partir de la primera década del siglo XXI su creciente presencia adquiere características de una cooperación económica Sur-Sur sustentadas en 
directrices teórico-prácticas que buscan un cambio en las estructuras económicas del desarrollo (Minutti y Lo Brutto 2018). De acuerdo a Domínguez, el comercio y la financiación reembolsable constituye la base sobre la que se apoya el pilar de diálogo político característico de la CSS (Domínguez 2016: 3) que, desde sus inicios, intentó fraguar alianzas para el cambio de las relaciones económicas internacionales, mediante "una solidaridad de oposición, de resistencia y de bloqueo" (Milani y Carvalho 2014).

El fortalecimiento de las relaciones con el gigante asiático influyó para que se de paso al planteamiento de nuevas narrativas que alteran las tradicionales divisiones Norte-Sur y por ende la visión de la cooperación internacional para el desarrollo (Domínguez 2015). Varios países de la región latinoamericana, especialmente aquellos cuyos gobiernos pertenecieron a la denominada "marea rosa", retoman la narrativa reivindicativa de la CSS y buscaron fortalecerla como objetivo primario de su relacionamiento, tanto con China como con el resto de países de la región. En este sentido, el fortalecimiento de las relaciones sinolatinoamericanas representa un quiebre paradigmático para la región en cuanto refleja el resurgimiento de un relacionamiento distinto a las dinámicas neoliberales de los años noventa.

La influencia de China se incrementa sobre la base de encuentros políticos y económicos que se pragmatizan en la firma de acuerdos de entendimiento y convenios de alto nivel -que anteponen los principios de solidaridad, complementariedad, equidad, no condicionalidad y respeto de la soberanía como bandera de relacionamiento (Lo Brutto y Minutti 2018). En América Latina, China ha promovido el diálogo y cooperación a través del foro de la CELAC, con quien mantiene una asociación estratégica. Esta plataforma sirve como mecanismo eficaz para desarrollar una cooperación integral, de tal manera que las relaciones entre ambas partes constituyan un modelo de vínculos internacionales.

El foro China-Celac se constituyó tras la I Conferencia Ministerial llevada a cabo en el año 2015 y se tornó en el marco institucional del sistema de asistencia, cooperación, comercio e inversiones entre la RPC y los países de América Latina (Foro China-Celac 2015). En este año se adoptó el Plan de Cooperación 2015- 
2019 donde se fijó la meta para alcanzar un intercambio comercial de 500.000 millones de dólares en 2025 (CEPAL 2018). Desde entonces, el acercamiento regional con China ha sido catalogado como uno de los logros más relevantes de esta organización. Posteriormente, en el año 2018, se llevó a cabo el II Foro Celac-China en Santiago de Chile, en el que las partes suscribieron un plan de acción para profundizar en su cooperación, solidaridad y complementariedad.

El foro representa un punto de anclaje en su estrategia global centrada en hacer girar las regiones clave del mundo en torno a China, aprovechando su impulso económico y financiero. De hecho, en la relación con América Latina, el país asiático se posiciona en los primeros lugares como principal proveedor de bienes, inversiones directas, préstamos y asistencia técnica de los países latinoamericanos, en la primera década del siglo XXI (Dollar 2018).

Si se analiza el aspecto económico-comercial, China se ha convertido en el principal receptor de las exportaciones provenientes de Latinoamérica; entre los años 2000 y 2012 se consolidó como la segunda fuente de importaciones de América Latina (después de los EEUU) y el tercer destino más importante de las exportaciones de la región después de los EEUU y la UE (Gallagher 2016). De acuerdo con cifras oficiales, los montos de comercio entre China y la región latinoamericana dan cuenta de que, entre el año 2000 y el 2015, los flujos de comercio han crecido 20 veces en comparación al año 2000, pasando de 12 mil millones de dólares a 263.600 mil millones de dólares (Cuéllar \& Bauer, 2019).

Las relaciones comerciales se han fortalecido con casi todos los países de la región. En el año 2014 Brasil, México, Argentina, Colombia, Perú y Ecuador exportaron un total de 83.300 millones de dólares a China e importaron aproximadamente 152.000 millones de dólares en productos y servicios del país asiático (Gallagher 2016). Brasil se ha convertido en el principal socio comercial de la RPCh, su comercio bilateral total (exportaciones e importaciones) fue de aproximadamente 78.000 millones de dólares en 2014, y China fue el destino del dieciocho por ciento de las exportaciones totales de Brasil en 2014, aunque estas exportaciones sólo representaron el 1,7 por ciento del producto interno bruto (PIB) de Brasil (Gallagher 2016). 
De estos flujos, el rubro que ha tenido mayor dinamismo es el de las materias primas o commodities. Se destaca el hecho de que los mayores lazos comerciales de China se mantienen con aquellos países que exportan materias primas, como es el caso de Chile, Ecuador, Perú, Brasil y Argentina. Por ejemplo, China importó cerca del $78 \%$ de soya de Brasil y el $41 \%$ de cobre de Chile hasta el año 2018 (Myers \& Gallagher, 2020) y, de manera general, el 60\% de las exportaciones totales de América Latina a China son de bienes primarios. Las exportaciones de estos países, que tradicionalmente se han destinado a EEUU, del año 2000 al 2015 muestran una tendencia a dispersarse en favor de la región Asia Pacífico, lo que ha implicado una mayor diversificación de socios comerciales. El gráfico 1 muestra de manera clara el flujo de exportaciones de bienes primarios de la región Sudamericana al resto del mundo.

Gráfico 1. Exportaciones de commodities desde Sudamérica al mundo

Año 2000

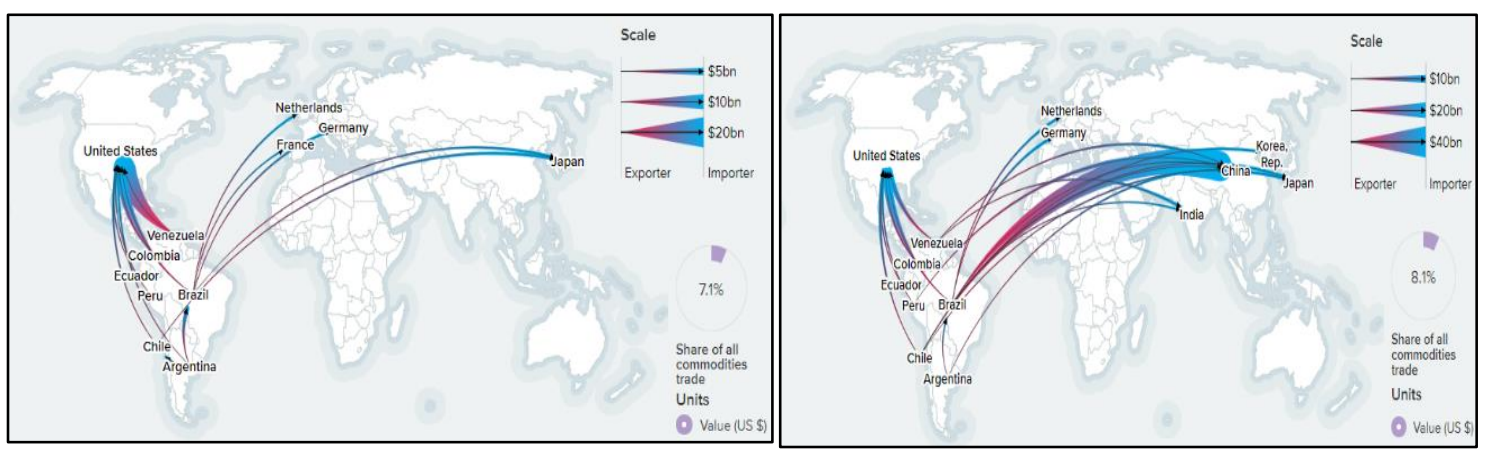

Elaboración propia

Año 2015
Fuente: A partir de datos de Resourcetrade.earth

El Diálogo Interamericano (The Dialogue: leadership of the Americas) lanzó una Base de Datos Financiera China-América Latina, que constituye una fuente de información en línea y actualizada sobre las finanzas chinas en América Latina y el Caribe elaborada en colaboración con la Iniciativa de Gobernanza Económica Mundial de la Universidad de Boston. De acuerdo a los datos allí recabados, la región latinoamericana se ha consolidado como el segundo destino más grande de las inversiones chinas, seguida solamente de la región 
de Asia. La financiación en la región alcanzó un máximo de 37.000 millones de dólares en 2010, más que la financiación del Banco Mundial, el Banco Interamericano de Desarrollo y el Banco de Exportación e Importación de los Estados Unidos combinados ese año (Gallagher y Myers 2020).

Desde el año 2005, el Banco de Desarrollo de China y el Banco de Exportación e Importación de China han concedido más de 137.000 millones de dólares en compromisos de préstamo a países de América Latina y el Caribe y a empresas estatales (Gallagher y Myers 2020). De acuerdo a información oficial, el número de empresas y corporaciones de capital chino o mixto en el año 2003 ascendían a 379, que contabilizaban un total de 683 millones de dólares, mientras que para el año 2010 China se convierte en la tercera fuente de Inversión Extrajera Directa (IED) en Latinoamérica representando un total del $9 \%$ de las inversiones captadas (CEPAL, 2010) y para el año 2014 representa un total de 98.900 millones de dólares en inversiones (Gallagher y Myers 2020). La mayor concentración de inversiones se encuentra principalmente en países como Brasil, Cuba, México, Perú y Venezuela y los sectores normalmente son la minería, petróleo, gas, productos agrícolas. Al respecto, entre 2010 y 2013 el 90\% de su IED estuvo relacionada con recursos naturales (Bruckmann, 2012; Nieto-Pereira, 2015)

Cabe destacar también las inversiones que se han impulsado con la "Iniciativa de la Franja y la Ruta" especialmente en el área de infraestructura y tecnología. Dicha iniciativa se ha convertido en las plataformas más prometedoras de la cooperación internacional que busca forjar un nuevo camino a la "globalización inclusiva que produce beneficios compartidos" (Xinhuanet 2019). El gigante asiático busca mirar a la región latinoamericana más que como un socio comercial, como parte de una nueva gobernanza económica mundial, que se adapta a los "intereses del Sur", a través de inversiones como la construcción de puertos y carreteras, o la implementación de conectividad 5G. Desde el año 2013 al 2019, a esta iniciativa se han sumado más de 18 países latinoamericanos, siendo Panamá el primero en incorporarse, y posteriormente países como Uruguay, Ecuador, Venezuela, Chile, Uruguay, Bolivia, Costa Rica, Cuba y Perú (Diálogo Chino 2019). 
Para la segunda década del siglo XXI, el gigante asiático se consolidó como el principal proveedor de CSS gracias a su súper-ciclo de crecimiento económico experimentado en los primeros años del nuevo milenio y que ha utilizado como una herramienta clave de su ascenso pacífico (Domínguez 2015). De hecho, para China la CSS puede ser considerada como el mecanismo que permitiría contribuir a la transformación del orden internacional promoviendo la independencia económica, social y política de todos los países involucrados (Harris \& Arias, 2016). Particularmente en América Latina, de acuerdo a los informes de la CEPAL de 2015 el incremento de relaciones comerciales e inversiones entre China y América Latina ha beneficiado a la región de diversas maneras:

\begin{abstract}
La gran demanda china de materias primas ha contribuido a que los precios de estos commodities se eleven, mejorando los términos de intercambio de los exportadores netos de productos básicos. El aumento de las exportaciones a China ha amortiguado el impacto de la caída de la demanda de productos por parte de mercados tradicionales como los Estados Unidos y la Unión Europea, especialmente después de la crisis financiera mundial de 2008. Las crecientes importaciones de productos manufacturados de China han contribuido a contener las presiones inflacionistas y a ampliar el acceso a bienes de consumo de los segmentos más desfavorecidos de la población. Además, las importaciones de bienes intermedios y de capital de China han ampliado la gama de proveedores a disposición de las empresas de la región, haciéndolas así más competitivas (CEPAL 2015).
\end{abstract}

Sin embargo, varios estudios señalan que dada la evolución de las relaciones comerciales entre China y los países latinoamericanos éstas no parecerían ilustrar la hipótesis de la promoción de relaciones de tipo Sur-Sur simétricas y más bien se avocan a ahondar los tradicionales problemas de dependencia de la región (Sevares, 2007; Slipak, 2014b, 2014a; Svampa, 2019; Svampa y Slipak 2015). Esto debido a que si bien la gran demanda china en el comercio mundial ha traído oportunidades dada la mejora de los términos de intercambio y el aumento de los ingresos de exportación que genera, los desafíos latentes siguen siendo las estructuras productivas y exportadoras de los países latinoamericanos. Cuanto menos, China ha estimulado la especialización en bienes primarios en detrimento de la industria. 
En este sentido, la intensificación del rol económico de China en la región mediante extracción de recursos naturales, bienes primarios y la construcción de mega-infraestructuras ha puesto de manifiesto nuevas relaciones de dependencia que se crean en relación con este país. La capacidad productiva del sector exportador latinoamericano es limitada, poco diversificada, y se concentra en productos primarios y procesados básicos. Mientras las materias primas representan en promedio cerca del $60 \%$ de las exportaciones totales de Latinoamérica hacia el país asiático (concentradas en el cobre y sus derivados, mineral de hierro, madera, frutas), nueve de cada diez de los productos que la región importa de China son productos manufacturados, con un fuerte énfasis en las áreas tecnológica y automotriz (Lo Brutto et al. 2015: 10).

Sin embargo, también hay que tomar en cuenta que, de acuerdo al último informe presentado por la CEPAL en el año 2018, la Inversión Extranjera Directa china hacia la región aumentó, superando los 25.000 millones de dólares en el año 2017, y comenzó a diversificarse hacia nuevos sectores como alimentos, telecomunicaciones y energías renovables (CEPAL 2018). Además, través de la Franja de la Franja y la Ruta para ALC, se prevé que el gigante asiático dinamizará el comercio impulsando unos 500.000 millones de dólares y unos 250.000 millones de dólares en inversión hasta el 2025, para ello existe el fondo de 35.000 millones de dólares para inversiones en infraestructura en América Latina (Gallagher 2016).

En palabras de Bárcena (2018), el fortalecimiento de las relaciones entre China y América Latina, permitió a todos los países de la región diversificar los flujos de comercio e inversión extranjera directa y abre la puerta para que la región aproveche las capacidades técnicas y financieras de China para reducir el déficit de infraestructura de la región. Es decir, "nos ofrece la oportunidad única de acortar la gran distancia territorial que nos separa mediante una mejor conectividad aérea, marítima y especialmente digital, para estrechar nuestros vínculos comerciales, de inversión, de turismo y de cultura" (CEPAL 2018).

Por otra parte, la fluidez de las relaciones sino-latinoamericanas tiene su paralelo también en el ámbito político. Desde la década de los cincuenta China desplegó 
su incursión diplomática basada en los principios de "coexistencia pacífica" promoviendo relaciones simétricas, soberanas y de mutuo beneficio. Durante las décadas de 1960-1970 el país asiático incrementó los contactos políticos con los Estados de la región que gradualmente le fueron otorgando el estatus de reconocimiento a la República Popular en detrimento de Taiwán. Este proceso se intensificó a partir de 1971 con el reconocimiento de un escaño en el seno de las Naciones Unidas (NNUU) a la China Popular, que desplazó así a la isla disidente (Slipak 2014).

Como resultado de su intensa actividad diplomática, el número de países que reconocen a Taiwán ha ido disminuyendo. En América Latina se encuentran 9 de los 16 países en el mundo que todavía reconocen a la isla, siendo Panamá, República Dominicana y el Salvador los últimos que han dado la espalda a Taiwán en el año 2017 y 2018 respectivamente (Global Affaires 2018). Mas allá del reconocimiento a la isla, el despliegue diplomático de China para ganar influencia en el ámbito de su política externa pone en evidencia que el alineamiento político de los países sigue siendo un tema de relevancia, especialmente cuando se trata de conseguir aliados que apoyen sus posturas en el seno de las NNUU y de definir socios de cooperación.

Una de las áreas donde se puede analizar la influencia política que ejerce tanto China como EEUU en la región es a través de las votaciones en el seno de la AGNU. El gigante asiático busca fortalecer alianzas con los Estados que comparten intereses comunes en temas sensibles como los derechos humanos, donde el posicionamiento del gobierno chino es el de adaptar su entendimiento en relación a la cultura nacional y al nivel de desarrollo del país (Xinhua, 2005). Por su parte, EEUU contabiliza las prácticas de alineamiento de los votos de los países y realiza seguimiento a través de reportes del Departamento de Estado, lo que determina en que flancos políticos ejercer presión internacional. En este contexto, recobra importancia el rol de los aliados políticos y su alineamiento para con uno de estos dos Estados.

Ante este panorama, América Latina se ha convertido en un continente en disputa en el marco de la creciente relevancia económico y política de China y la 
tradicional influencia estadounidense. Por lo que los países de la región han tenido que buscar un delicado equilibrio en las relaciones que sostienen con los dos actores optando por estrategias de alineamiento, de ruptura o de balance, de tal manera que su relacionamiento no les impida llevar adelante sus objetivos de interés nacional. Por ello, una vez terminados los quince primeros años del siglo XXI, que representaron el auge de la CSS, resulta pertinente mirar en retrospectiva los factores estructurales y de política doméstica que incidieron en las dinámicas de relacionamiento exterior de los gobiernos latinoamericanos para con EEUU y China.

Como corolario, resulta importante destacar que el despertar de la cooperación Sur-Sur en América Latina se da en el marco de reajuste de la geopolítica mundial y pone de relieve las históricas tenciones con la tradicional hegemonía estadounidense. La presencia cada vez más asertiva de China en la región, reaviva la cooperación económica y financiera como pilar fundamental para cambiar las dinámicas de relacionamiento de los países periféricos con los Estados centrales. El gigante asiático se muestra, por ende, como eje catalizador que podría coadyuvar en la búsqueda de relaciones más autónomas en términos políticos y menos dependientes en términos económicos en referencia a potencias centrales.

\section{Cooperación Sur-Sur: dimensión económica vs cooperación técnica}

Las investigaciones sobre la CSS en América Latina se han centrado de manera casi exclusiva en la cooperación técnica, dejando de lado la cooperación económica que representa el pilar fundamental de la CSS. De manera acotada se pueden distinguir dos líneas diferenciadas en el análisis de la CSS sobre las cuales han girado los estudios académicos: por una parte, los análisis que retoman un enfoque histórico-crítico y por otra, aquellos que enfatizan en la gestión de proyectos. De acuerdo a Domínguez, estas dos perspectivas pueden denominarse como entendimiento autónomo y entendimiento subalterno de la CSS respectivamente (Domínguez 2020) 
El entendimiento subalterno de la CSS asocia la cooperación únicamente al aspecto técnico y la considera como sinónimo de las acciones enmarcadas en el Plan de Acción de Buenos Aires (PABA). Este es un enfoque tecnicista de gestión de proyectos que enfatiza en que la CSS es una modalidad más del entramado de la arquitectura de la cooperación para el desarrollo y, por lo tanto, los estudios se centran en la métrica y gramática de los proyectos, acciones y programas de asistencia técnica entre países. Esta tendencia ha sido especialmente establecida, a nivel multilateral, por las agencias de cooperación como la Secretaría General Iberoamericana (SEGIB) y el CAD de la OCDE; mientras que a nivel doméstico ha sido adoptado por las agencias, secretarias y unidades de cooperación internacional de los países latinoamericanos (ver SEGIB 2011, 2014, 2017).

Estos análisis reducen el todo de la CSS únicamente a los intercambios de tipo técnico entre países del Sur (ver por ejemplo los informes de la SEGIB). Como señala Domínguez, el discurso sobre la CSS como relación horizontal, basada en el altruismo y la reciprocidad que arranca con el Plan de Acción de Buenos Aires en 1978, es coherente con el mandato de las agencias de cooperación internacional latinoamericanas, siguiendo la estela de la Agencia Brasileña de Cooperación en el marco de las reuniones de CTPD del Sistema Económico Latinoamericano y del Caribe (SELA) desde 1987 (Domínguez 2019). Por lo que se puede señalar que:

Buenos Aires envolvió el todo (la CSS como aspiración a un Nuevo Orden Económico Internacional), con sus valores de solidaridad, horizontalidad, respeto de la soberanía, no condicionalidad y beneficio mutuo, vinculados fundamentalmente a una parte (la CTPD) y, por ello, es en buena medida responsable de la retórica autolegitimadora de la CSS que desde América Latina se ha transmitido a los donantes del Comité de Ayuda al Desarrollo (CAD) (Domínguez 2016: 3)

Este enfoque multilateralista ha llevado a consolidar una visión de la CSS que tecnifica y cuantifica el desarrollo, alejándose de su iteración inicial esencialmente política y crítica a los modelos tradicionales de desarrollo que poco benefician al Sur y de las asimetrías del sistema internacional. De hecho, 
la CTPD entre países en desarrollo, llevada a cabo en Buenos Aires en 1978 fue "una posición de retroceso, no de avance" (Ernst, 1979). Esto debido a que:

\begin{abstract}
el espíritu de Buenos Aires se basó en una retórica transformista (apelando a los principios de Bandung para no aplicarlos) e interdependentista (pero de interdependencia entre desiguales), que rápidamente convergió con la noción de desarrollo individual como reducción de la pobreza y ampliación de las capacidades (desarrollo humano) de la teoría neoinstitucionalista de la eficiencia de los mercados (Domínguez, 2019).
\end{abstract}

La CSS va más allá de la bien valorada cooperación técnica y tiene como eje fundamental repensar de manera crítica el desarrollo e incentivar la autodeterminación de los países. Con lo cual, el riesgo de profundizar en una visión eminentemente técnica es que se deja oculto el potencial de la CSS como una forma de emancipación y liberación de los países periféricos del sistema internacional vigente.

Contrario a la perspectiva tecnicista y retomando un enfoque histórico-critico, se puede señalar que la CSS encuentra sus fundamentos en el ámbito económico y financiero, siendo el dialogo político el mecanismo para elevar propuestas reivindicativas respecto de la inserción de los países del Sur al sistema internacional. La CSS implica dos aspectos distintos:

por una parte, el de cómo pueden actuar los países en desarrollo de consuno para consolidar sus relaciones y su capacidad de negociación con el resto del mundo, y, por otra, el de cómo pueden estos mismos países fortalecer sus lazos mutuos para estimular su desarrollo económico (cfr. Tomassini, 1976: 28).

La CSS, entendida en el contexto donde evolucionaron estas ideas, abarca dos acepciones: la política más relacionada con las Conferencias del MNOAL y otra de tipo más económico vinculada a temáticas referentes al comercio y financiación del desarrollo, que incluía ayuda, inversión extranjera y transferencia de tecnología (Domínguez 2019). Sobre esta base, la idea central de los países en desarrollo era reforzar su poder de negociación frente a los países del Norte teniendo como mecanismo la "autosuficiencia colectiva", es 
decir, la capacidad de unidad hacia a dentro para resolver los desafíos comunes colectivamente (O’Neill, 1980).

La CSS de carácter autónomo se construyó desde sus orígenes en clave de movimiento reivindicativo basado en el modelo del Estado desarrollista y vinculado a los principios de la Conferencia Afro-Asiática de Bandung de 1955, que impulsaba el desarrollo como cambio estructural y convergencia (Bracho 2018; Domínguez 2019). Para lograr estos objetivos se propuso una cooperación de tipo económica, con base en el aspecto financiero, comercial y tecnológico entre los países periféricos y con la finalidad de avanzar a la construcción de un nuevo orden económico internacional (Domínguez 2020).

Algunas iniciativas autónomas que se plantearon desde la periferia fueron impulsadas por países como China, Venezuela, Cuba, Brasil en el seno del G77 en la UNCTAD y en el MNOAL como acción colectiva para un NOEI. Se destacaron acciones en las que "los países en desarrollo más avanzados deberían organizar sus propios programas de asistencia externa en beneficio de los países más pobres y menos desarrollados" (Tomassini 1979: 309). Por ejemplo, la cooperación financiera de la OPEP, o las facilidades petroleras de Venezuela y México con los países de Centroamérica y Panamá que se canalizaron en los Acuerdos de Puerto Ordaz, constituyeron el Primer Programa de Cooperación Financiera con América Central y el Caribe (Domínguez 2020).

Retomando esta perspectiva, el componente técnico de la CSS es solamente una parte de la cooperación económica y se "estructura como transferencia de recursos humanos y conocimientos incorporados en el capital humano que contienen dichos recursos, a partir de una lógica consciente de elevar las capacidades de absorción de la cooperación financiera" (Domínguez y Caria 2016: 5). La idea que subyace a este postulado es considerar el coste real y de oportunidad (que no se monetariza) en los que se incurre cuando se realiza la cooperación financiera no reembolsable (Domínguez \& Tezanos, 2012; Jolly et al., 2004). 
De esto se colige que, el aspecto técnico de la CSS implica en esencia una capacidad de absorción de las transferencias financieras con miras a reformar las relaciones Norte-Sur y transformar las relaciones asimétricas en las que se insertan los países periféricos (Domínguez 2016). Es decir, lo técnico y lo económico se encuentran estrechamente vinculados entre sí para la puesta en marcha de planes de desarrollo, pero lo técnico constituye un componente más de la cooperación principal que es el aspecto económico y financiero (Domínguez 2016).

Estas dos perspectivas de entendimiento: la autónoma y la subordinada, se han ido disputando su lugar en los análisis de la CSS en la región latinoamericana. A finales de la década de los ochenta, en un contexto internacional marcado por la globalización neoliberal y el avance de la interdependencia económica se atrajo a la CSS al ámbito multilateral con el ofrecimiento de buscar "la gestión equitativa de la interdependencia global" y los beneficios que ello pueda aportar para los países del Sur (Domínguez 2019). De esta manera, se fueron sentando las bases de la arquitectura del desarrollo y los posteriores indicadores de las categorías de desarrollo basadas en el PIB per cápita del BM (países de renta baja, renta media y renta alta) (Domínguez 2020).

Sobre esta base, la cooperación española ha adoptado la doctrina subordinada para entender a la CSS y, esto incluye la comprensión de estudios enfocados en el rol de los nuevos donantes del Sur o la cooperación triangular. Desde el año 2008, esta es la perspectiva que ha adoptado la SEGIB en el ámbito de América Latina, coincidiendo con la OCDE que, en esta misma región, busca impulsar la cooperación triangular como "puente entre las formas de cooperación Sur-Sur emergentes y las más tradicionales" (ECLAC y OCDE 2018). Esto hace que las acciones que se llevan a cabo bajo su bandera expandan el modelo de acumulación neoliberal inequitativo que caracteriza al sistema económico actual.

En palabras de Morvaridi:

la emergencia de nuevos donantes amplia el potencial de integrar nuevas áreas del Sur en el modelo de acumulación capitalista; su emergencia ha producido nuevas e innovadoras maneras de comercialización de corte neoliberal que buscan integrar las áreas productoras de commodities del 
Sur en la economía global (traducción propia) (Morvaridi y Hughes 2018: 2).

Por su parte, los países que son los mayores exponentes de la CSS no se han integrado a las métricas del CAD de la OCDE. Tal es el caso de países como China, India, Brasil, Venezuela y Cuba, que constituyen los motores principales de la CSS (Domínguez 2020: 57). Varios think tanks han propuesto la necesidad de crear estructuras de cooperación al desarrollo más globales e inclusivas, en donde la participación de China e India sea el eje central de una "asociación global de la cooperación para el desarrollo más legítima" (Li et al. 2018: 148).

Al respecto, varios autores señalan que China está construyendo un régimen de CSS competitivo con el CAD, a partir del denominado Cinturón de la Ruta Económica de la Seda y la Ruta Marítima de la Seda del siglo XXI, también conocido como The Belt and Road Initiative. Este proyecto representa casi siete veces el monto actualizado del Plan Marshal y está abierto a todos los países de América Latina (Domínguez 2017). Este proyecto se reivindica como un espacio autónomo focalizado en la economía e inversión como medidas necesarias para una transformación estructural del desarrollo (Domínguez 2020).

Esta CSS autónoma, que se revitaliza en América Latina en los albores del siglo $\mathrm{XXI}$, se retoma gracias al liderazgo de China que apuesta por la CSS como mecanismo de cambio estructural y convergencia para el desarrollo. El desembarco del gigante asiático en la región coincide con una época de reajuste de la política interna de los países latinoamericanos caracterizada por la asunción del poder de gobiernos de izquierda o de corte progresista. Estos liderazgos, especialmente el de los presidentes de Brasil y Venezuela, propiciaron el "retorno de la política" (Dabène 2012) y trajeron de vuelta las "agendas de desarrollo" de los Estados, la prevalencia del interés nacional y la noción de autonomía tanto para manejar sus asuntos internos como para ampliar sus márgenes de acción exterior. Con ello, se retomó la CSS como una herramienta funcional a las estrategias de política exterior impulsando propuestas y prácticas alternativas que buscaron idealmente reivindicar las relaciones asimétricas características de la cooperación Norte-Sur. 
Resulta relevante recalcar que, durante esta época, Brasil y Venezuela se fortalecieron como modelos de CSS y se posicionaron como agentes dinamizadores de las relaciones económicas no solo en Sudamérica y el Caribe, sino que incluyeron inversiones en el continente africano. Su modelo de cooperación se centró en el fortalecimiento de alianzas estratégicas a través de acuerdos económicos y de inversión, que también incluyeron como parte la transferencia de conocimiento y habilidades a sus pares. La mayor parte de la ayuda brasileña se destinó a África, especialmente a los países de lengua portuguesa, y a América Latina y su cooperación Sur-Sur se convirtió en un modelo denominado "embrión de un modelo global" (Cabral \& Weinstock, 2010).

Por su parte, Venezuela se destacó por las acciones canalizadas, tanto en número como en volumen, el país realizó unos desembolsos netos de ayuda de 1.166 millones de dólares ( $\mathrm{mmd}$ ), equivalentes al 0,71\% de su PIB, en 2006, y de 2.330 en 2008, según cifras de las NNUU (Rodríguez, 2013). En el Caribe, Venezuela impulsó el programa Petrocaribe, que más allá de constituirse como un acuerdo interestatal de intercambio de servicios y productos energéticos a precios concesionales, se constituye como una herramienta de cooperación económico-financiera alternativa al paradigma neoliberal dominante (Zapata, 2017).

Como potencia emergente extra hemisférica en la región latinoamericana, China se posiciona como líder en el intercambio de conocimientos, experiencias y capacidades tecnológicas a través de proyectos, programas y acciones de cooperación desplegados por diversos actores estatales y no estatales. El gigante asiático rige su cooperación en base al principio de beneficio mutuo y ganancia compartida; $y$ trabaja normalmente en áreas relacionadas al suministro de energías y recursos (Lo Brutto y González 2015). Esta cooperación está vinculada a procesos de ampliación de la inversión externa e internacionalización de empresas chinas, con lo cual, su cooperación está normalmente ligada (se exige que el contratista sea chino y que el cincuenta por ciento de los bienes y servicios para su ejecución sean chinos). Dentro de esta modalidad de 
cooperación también se incluye el otorgamiento de créditos a cambio de pagos anticipados de materias primas como petróleo.

De acuerdo a la base de datos "The Dialogue, China-América Latina", entre el año 2005 y el año 2013 China otorgó 102,000 millones de dólares en préstamos a América Latina (Gallagher y Myers 2020), posicionándose por encima de los préstamos otorgados por el FMl y el BM en el mismo periodo. Estos préstamos normalmente están dirigidos a proyectos mineros, agrícolas y energéticos, lo que a largo plazo fomenta la reproducción de patrones de producción primarios en detrimento de poblaciones más vulnerables (Noyola, 2015:2). Esto demuestra que el gigante asiático se ha insertado en la economía global de manera decidida y se ha convertido en un actor cada vez más dominante en las naciones de la región latinoamericana.

Como corolario, en América Latina la CSS se fortaleció como un eje transversal en la construcción de la política exterior fundamentado sobre la base económica, financiera y de inversiones de países protagonistas como Venezuela, Brasil y China. Específicamente, el desembarco del gigante asiático en la región ha revitalizado la CSS y ha abierto una gran oportunidad para retomar el ADN financiero, característico de la CSS autónoma, que ha permitido a los países contar con "mayor libertad de maniobra internacional" (Ferrer 1978). Por lo tanto, resulta inútil insistir en un entendimiento reduccionista y subalterno de la CSS (como gestión técnica de proyectos) ante la inminencia de cambios estratégicos y proyectos de cooperación internacional de amplio calado -como el que ha puesto en marcha china con la iniciativa de Cinturón de la Ruta Económica de la Seda y la Ruta Marítima de la Seda del siglo XXI.

\section{Cooperación Sur-Sur: dimensión regional}

Vincular la esfera de la CSS con los procesos de regionalismo surgidos en la región latinoamericana durante el nuevo milenio no resulta una tarea sencilla; pero es sin duda la dimensión de la política exterior que más impulsaron los gobiernos, especialmente los denominados "marea rosa" en su proceso de inserción en el sistema internacional. Las iniciativas surgidas gracias al 
fortalecimiento de las relaciones con sus pares del Sur cambiaron el panorama geopolítico de la región inaugurando una nueva oleada de alternativas unionistas que persiguieron fines autonómicos.

Desde el inicio de su vida independiente hasta la actualidad América Latina ha sido testigo de la evolución de varios procesos de integración regional por lo que su estudio se ha convertido en un tema de alto interés tanto en términos de su historia temprana como de los diferentes enfoques teóricos usados para su análisis. Normalmente, se ha considerado a dichos procesos como mecanismos alternativos para promover desarrollo y enfrentar los retos y las tendencias del entorno político-económico prevaleciente, por lo que los factores que impulsan la construcción regional tienen una vertiente política y económica. Esto ha dado lugar a proyectos de carácter heterogéneo y multidimensional que han definido los espacios regionales en términos de fuerzas "centrípedas", fortaleciendo propuestas que contemplan medidas de protección y comercio intrarregional, y fuerzas "centrífugas", cuya mirada se enfoca hacia afuera en el comercio exterior.

Durante la primera década del siglo XXI, las dinámicas de cooperación regional que se consolidaron se caracterizaron por fortalecer el diálogo político bajo principios de complementariedad, equidad, respeto a la soberanía y el retorno del Estado como eje fundamental para vigorizar la integración. Es decir, se retoma el pilar de la cooperación Sur-Sur con la finalidad de lograr una mejor inserción de los países periféricos en el sistema internacional asimétrico. Una muestra de ello es la creación de bloques como la Unión de Naciones Suramericanas (UNASUR) (UNASUR 2008), la Alianza Bolivariana para los Pueblos de Nuestra América (ALBA 2004), la Comunidad de Estados Latinoamericanos y Caribeños (CELAC 2010) que representaron propuestas de concertación propias que reavivaron el énfasis de lo político sobre lo comercial como herramienta de desarrollo e inserción internacional.

Dichos esquemas de integración representan una experiencia innovadora en términos de posicionamiento regional porque retoman una perspectiva geopolítica sobre el lugar de la región en el mundo. Estos mecanismos proponen 
un replanteamiento de las relaciones exteriores de los Estados latinoamericanos y un fortalecimiento de la política unionista como mecanismo de ampliar sus márgenes de autonomía en un contexto multipolar. Su fortalecimiento marcó una ruptura en relación a las estrategias de regionalismo abierto vigentes en América Latina hasta finales de la década de los noventa y que estuvieron marcadas por políticas neoliberales de corte economicista basado la apertura de mercados nacionales al mundo y la liberalización comercial como motor de crecimiento.

La superación del regionalismo abierto se dio en el marco del paulatino proceso transición hegemónica donde se intensifica la disputa por el poder a escala global. El desembarco de China en América Latina ofrece nuevas alternativas a los entonces gobiernos progresistas de la región en detrimento de la política intervencionista de EEUU. A escala regional los gobiernos de la "marea rosa" se reposicionan con una tendencia antineoliberal, reorientan de forma estratégica las relaciones exteriores de sus países, fortalecen su acercamiento con potencias emergentes como China o Rusia, reformulan las instituciones de integración existentes y crean nuevas alternativas basadas en el fortalecimiento de las relaciones de cooperación Sur-Sur.

El entendimiento de estos nuevos procesos vino de la mano de consideraciones teóricas que retomaron el pensamiento latinoamericano en materia de regionalismo y pusieron en vigencia las ideas autonómicas. Históricamente, los argumentos a favor de la integración regional se encuentran presentes en el pensamiento de líderes políticos y pensadores desde el periodo de independencia en el siglo XIX; quienes veían a la integración como un mecanismo para consolidar la independencia y lograr mayores márgenes de autonomía de los Estados frente a potencias regionales (Briceño 2014: 2). La dimensión política y de seguridad fueron la base de la inclinación regionalista latinoamericana desde sus inicios, de hecho, la integración económica no surgió de manera inmediata en los Estados recientemente independizados puesto que varios de ellos optaron por el desarrollo basado en la exportación de recursos primarios y solo gradualmente, a inicios del siglo XX, se pensó en la creación de uniones aduaneras intrarregionales como mecanismo de inserción internacional (Briceño 2013). 
En los albores del siglo XXI, el pensamiento latinoamericano recobró vigencia de la mano de la consolidación de nuevos esquemas de integración regional. Principalmente, se retomaron dos teorías importantes que ayudan a entender la relación entre economía, política y sociedad en la región: el estructuralismo ligado a la teoría de la dependencia cuyo fundamento económico es la base del análisis de la integración regional y el autonomismo ligado al pensamiento político en materia de política exterior ${ }^{12}$.

La teoría de la dependencia, liderada por Prebisch ofrece un primer acercamiento teórico al tema de la inserción internacional y regionalismo tomando como punto de partida la historia de las ideas económicas aplicadas a las condiciones históricas propias de la periferia latinoamericana. La escuela Cepalina señala que uno de los mejores medios para reducir la dependencia tradicional en el comercio de bienes primarios se logra a través de la promoción de la integración regional y la cooperación económica. Las primeras referencias teóricas en relación al regionalismo pasan de la idea de unionismo a la idea de la constitución de grandes proyectos de escala asociados al desarrollo económico nacional y apoyados en las políticas de industrialización y sustitución de importaciones marcadas por las tensiones centro-periferia (Prebisch 1963).

En este sentido, la región fue entendida como una unidad económica de la periferia subdesarrollada y el regionalismo se abordó en tanto instrumento para mejorar el rendimiento económico y la inserción internacional mediante el desarrollo económico. Por lo tanto, el regionalismo impulsado por la escuela cepalina en los años sesenta era una integración comercialista basada en el mercado y liderada por los Estados, dejando de lado otros temas, actores y la idea de la autonomía como punto de convergencia de los países latinoamericanos que comparten valores e identidad comunes (Puig 1986). La década de los años sesenta y setenta vieron las primeras manifestaciones de integración desde este enfoque comercial con el impulso de la Asociación

12 Partes de este acápite fueron publicadas en el artículo "El regionalismo latinoamericano en la primera década del siglo XXI: repensando la idea de autonomía" (Zapata 2017) 
Latinoamericana de Libre Comercio (ALALC), Mercado Común Centroamericano (MCCA).

Sobre la base del pensamiento estructuralista, Puig y Jaguaribe coinciden en la premisa de que los Estados latinoamericanos se encuentran en una situación de dependencia a potencias externas debido a las relaciones asimétricas existentes entre los países del centro y de la periferia y por ello proponen como indispensable optar por acciones que mejoren la capacidad de toma de decisiones en el sistema internacional usando el regionalismo como mecanismo de inserción internacional (Briceño 2014, Simonoff 2015). Desde esta perspectiva, el regionalismo es visto como una plataforma para la autonomía en política exterior y como una forma de resistencia a la intervención extranjera en los asuntos regionales.

El desarrollo del pensamiento autonomista imprime un vuelco importante en el entendimiento del regionalismo en América Latina porque se pasa del análisis de la dependencia económica y de las estrategias de desarrollo meramente comerciales a una visión política y social del regionalismo como mecanismo para resistir a la intervención de grandes poderes. En efecto, desde la mirada puiguiana, 'la integración es un fenómeno social en el que dos o más grupos humanos adoptan una regulación permanente de ciertos asuntos que hasta entonces eran de su dominio exclusivo' (Puig 1986: 41). Puig plantea una visión que va más allá del Estado centrismo pues no limita el regionalismo al rol del Estado nación, las elites que lo dirigen o a las elites funcionales del proyecto autonómico, sino que también debe ser producto de las sociedades e implica a cualquier otra agrupación micro (como sociedades y empresas) y macro (comunidad internacional). En definitiva, el objetivo es concretar conductas cuyo propósito busque que los grupos sociales en cuestión renuncien en determinadas materias a la actuación individual, para hacerlo en forma conjunta y con sentido de pertenencia (Puig 1986).

A pesar de que el instrumento que empuja el proceso de integración sea el Estado, Puig concibe al regionalismo como un 'fenómeno social' y como una condición que debe ser reforzada por quien lo impulsa. El regionalismo puede 
ser conducido sea de forma comercialista o un regionalismo de la solidaridad, valores compartidos y alianzas que se podrían concretar para la defensa conjunta de los Estados. La primera opción refuerza el régimen internacional vigente y tiende a profundizar las asimetrías entre los socios porque adopta una visión únicamente económica e interdependiente. El regionalismo con miras autonómicas da énfasis a lo político y cultural, se fundamenta en la unión de Estados decididos a alcanzar objetivos sectoriales determinados y es un instrumento para lograr la autonomía sobre la base de reconocer un mismo estatus o valores. Es decir, la asociación de los países es fundamental para que puedan ampliar sus escasos márgenes de maniobra a largo plazo (Simonoff 2015: 134).

A la luz del pensamiento autonómico latinoamericano se puede entender el surgimiento de los proyectos como el ALBA, UNASUR y CELAC que pusieron en el centro del debate el rol de lo político y de las estructuras históricas como determinantes del desarrollo. Estos mecanismos trastocan los equilibrios preexistentes en la región e imprimen un posicionamiento estratégico de la región en un mundo más multipolar. La ALBA marcó la pauta del discurso antiimperialista y de rechazo al neoliberalismo propuesto por EEUU a través del ALCA; la UNASUR se posicionó como interlocutor válido en temas de resolución de conflictos, políticas de defensa y en apalancamiento de cooperación Sur-Sur para mejorar la infraestructura física y de observación electoral (A. Sanahuja \& Comini, 2018), y la CELAC logra abarcar a los 33 miembros latinoamericanos situándose como contraparte de la estrategia de cooperación integral entre China y América Latina.

\subsection{La Alternativa Bolivariana para los Pueblos de Nuestra América -Tratado de Comercio de los Pueblos (ALBA-TCP)}

La ALBA-TCP fue un proyecto regional concebido por Fidel Castro y Hugo Chávez en el año 2004 y se la pensó como parte de una alianza política estratégica entre Venezuela y Cuba para hacer frente a la propuesta estadounidense de crear un Área de Libre Comercio de las Américas (ALCA). La ALBA se posiciono desde sus inicios como una plataforma de integración 
alternativa que amalgama una postura antiimperialista-anticapitalista, critica las asimetrías estructurales del sistema internacional y bajo estos postulados logró condensar de manera pragmática las nuevas realidades de la cooperación SurSur (Aponte, 2014; Aponte y Amézquita, 2015).

Las condiciones para su surgimiento fueron muy favorecedoras. El ascenso de los BRICS, en especial el acercamiento de China a Latinoamérica presagiaba un orden internacional favorable para los países periféricos del Sur Global, como Venezuela. El florecimiento de grandes liderazgos en América Latina y el ascenso de gobiernos de tinte "progresista" daban por clausurada la era del neoliberalismo en la región. El fallido golpe de Estado del 2002 contra Chávez y su fortalecimiento en el poder coincidieron con el alza del precio del petróleo. En este contexto, y estrechamente vinculada a los preceptos de política exterior que reestructura Chávez en el ejercicio de su gobierno, el ALBA ha dejado huellas en tres aspectos: el ideal bolivariano de unión y regionalismo, la promoción del multilateralismo y la lucha contra el neoliberalismo y el impulso de la Cooperación Sur-Sur en el área social, financiera y energética (Zapata 2017).

Como mecanismo de integración regional, la ALBA da un nuevo aliento al sueño unionista bolivariano que tuvo eco no solo en los 11 países que lo integran, sino también impulsó una narrativa regional aglutinadora que inauguró el "nuevo regionalismo latinoamericano" y Venezuela estuvo dispuesto a pagar los costos de ese liderazgo. Bajo el mandato de Chávez se impulsaron iniciativas como la UNASUR, CELAC, Mercosur social con gobiernos de diferentes signos ideológicos que logran hacer factible el sueño unionista de la "Patria Grande", sin la presencia de potencias hemisféricas -EEUU y sus instituciones, léase OEA, FMI, BM- haciendo sombra en su conformación. El rechazo al ALCA en la cumbre presidencial en Mar del Plata del 2005 sepulta la etapa del "regionalismo abierto" y la región opta por un modelo de integración que busca mayor relacionamiento con socios del Sur Global enfatizando en la cooperación política, complementaria y solidaria (Serbin et al., 2012).

EI ALBA sostiene un posicionamiento antiimperialista y anticapitalista relacionado con una visión estratégica y de largo aliento para reubicar a 
Venezuela, junto a América Latina, en un polo privilegiado de poder en la transición geopolítica y geoeconómica del orden internacional aún en curso. Chávez había advertido la decadencia del mundo unipolar y la conformación de un nuevo mundo multipolar, en el que era necesario para la región reubicarse con inteligencia estratégica y soberana. La idea de Venezuela de hacer contrapeso a la política imperial y hegemónica de EEUU, de proponer un nuevo balance de poder y reestructurar las lógicas económicas de desarrollo rechazando el neoliberalismo, claramente implica un desafío al status quo internacional (Zapata 2017).

En este sentido, la ALBA se convirtió en un instrumento de soft balancing frente a EEUU, es decir, un mecanismo no militar que pretende debilitar, retardar, frustrar las políticas del hegemón hemisférico hacia la región, levantando barreras que desafíen sus intereses. Sin embargo, su efectividad se puso a prueba cuando Latinoamérica sucumbe progresivamente ante las tentadoras propuestas norteamericanas de recuperar espacios estratégicos perdidos a través de la iniciativa de "Seguridad Energética del Caribe" para la CARICOM en clara contraposición al acuerdo de Petrocaribe; y retoma influencia con la lenta pero progresiva normalización de las relaciones con Cuba (Toro 2011). A esto se suma las fuerzas económicas centrífugas con la Alianza del Pacífico y el Acuerdo Transpacífico de Asociación Económica (TPP) y un clima regional adverso en el que Maduro ha ido perdiendo el apoyo de los gobiernos de la región, especialmente de Brasil y de Argentina.

Ligada con las prácticas de CSS, el ALBA ha desarrollado una intensa actividad retomando los principios de Bandung y desplegando a nivel internacional -tanto en América Latina, el Caribe y África- programas de cooperación social, energética y financiera. Resaltan las operaciones sociales como "Misión Milagro", "Yo sí puedo", "Adopta una escuela en África” -los de mayor visibilidad e impacto- que proveyeron atención médica, cirugías oftalmológicas gratuitas, alfabetización, entre otras. Sin embargo, en este tipo de cooperación resulta muy complicado tener una idea clara del volumen real, trayectoria seguida y destino de los flujos invertidos, pero no sorprende la presencia de rasgos típicos de la ayuda tradicional, tales como fenómenos de dependencia, fomento de redes 
clientelares y bolsas de corrupción ligadas a la falta de auditorías en estas transferencias -al igual que sucede en la cooperación tradicional Norte-Sur (Benzi 2017).

Adicionalmente, la ALBA no estuvo exenta de las prácticas de la "diplomacia petrolera" y la "petro-política" que ha marcado las relaciones exteriores venezolanas, por lo que la organización se alimentó con recursos provenientes del petróleo cuyos precios oscilaron entre 100 y 130 dólares el barril en la primera década del siglo XXI. Tanto la aplicación de la fuerza hegemónica para controlar dicho recurso energético, como el uso de la riqueza petrolera para influir en otros países, fueron usadas a cabalidad para desarrollar los programas de cooperación energética como Petrocaribe, Petroamérica y Petrosur mecanismos de redistribución de la renta petrolera a bajos costos. Sin duda, el Caribe fue el mayor beneficiario de la generosidad de alrededor de 100.000 cargamentos al día de petróleo venezolano barato, que al parecer no han sido suficientes para ganarse la simpatía del líder conservador Granger de Guyana cuando en el 2015 dio la espalda a Caracas (con el apoyo del Caribe) en el impase bilateral por la exploración de petróleo en El Esquibo (Zapata 2017).

Otra de las áreas de impacto del ALBA fue el impulso a la "Nueva Arquitectura Financiera Regional" con propuestas como el Banco del ALBA y el SUCRE. La filosofía central era menos dependencia de fuentes externas de financiamiento -realizando transacciones comerciales sin el uso del dólar como moneda de cambio y ahorrando divisas- y más autonomía -consolidando el autoabastecimiento energético a través del uso concertado de petróleo a nivel regional (Benzi 2017). Estos mecanismos y la diplomacia venezolana en general, se vieron debilitados ante la pérdida de poder de la chequera petrolera ante la pérdida de valor de los precios de los commodities, que durante los últimos años de la segunda década del milenio fluctuaron entre 30 y 50 euros el barril.

Como corolario, hablar de la ALBA implica profundizar en el ocaso de un proyecto contra-hegemónico que no logro más que esbozar propuestas alternativas para resistir al globalismo capitalista y que se encuentra condicionada por los vaivenes políticos y económicos que enfrenta el país. Si se 
analiza en retrospectiva, su gran deuda es no haber logrado -lo que habría sido su mayor legado y propuesta inédita- la consolidación de una integración "desde abajo" a través de la "diplomacia de los pueblos". Esto es evidente cuando se mira la trayectoria del Consejo de Movimientos Sociales del ALBA y sus capítulos nacionales, que no han conseguido definir horizontes y contenidos de una integración desde las bases que articule a los pueblos organizados y los jefes de Estado y que resulta vital en la construcción de los nuevos esquemas de integración (Benzi, 2016).

En un contexto mundial en el que los países buscan redefinir sus posiciones en el tablero geoestratégico que se cuece en la actualidad, el ALBA no logró consolidar a largo plazo su regionalismo de resistencia e ir más allá de la narrativa de la cooperación Sur-Sur y la retórica altermundista. Su debilitamiento paulatino fue producto de la caída del precio del petróleo a partir de la segunda década del siglo $\mathrm{XXI}$, se intensificó tras la muerte de Hugo Chávez y de Fidel Castro y posteriormente tras la salida de varios miembros como Ecuador o Bolivia, que fueron aliados importantes políticos.

\subsection{Unión de Naciones Suramericanas -UNASUR}

El renovado auge de la cooperación entre los países del Sur tuvo uno de sus hitos en la creación de la UNASUR en el año 2008 en un contexto internacional caracterizado por la el cuestionamiento a la hegemonía estadounidense y el fortalecimiento de potencias emergentes, como Brasil en el caso sudamericano. Este mecanismo de integración fue el resultado de la diplomacia brasileña que buscó consolidar a "Sudamérica" como una comunidad políticamente activa y cohesionada que le permita al gigante portugués posicionarse estratégicamente en el escenario global. De manera pragmática, la "sudamericanización" de los asuntos políticos relevantes es un mecanismo de inserción internacional de Brasil con unos riesgos relativamente bajos, unos costes compartidos y una maximización de los réditos obtenidos (Gardini, 2010)

Su creación marca un hecho importante para la región porque la UNASUR constituye el primer bloque conformado por todos los países de América del Sur 
con gobiernos de diferente signo ideológico y que persiguen diversos modelos de desarrollo. A pesar de las diferencias en poco tiempo logró consolidar una institucionalidad reconocida incluso en el seno de la AGNU, como miembro observador. Su enfoque fue buscar la cohesión regional en temas referentes a la solución de conflictos, la defensa del orden democrático, infraestructura física, defensa, educación, desarrollo social, cultura, salud, observación electoral, entre otros, incorporados en doce consejos ministeriales (Vázquez 2019)

Como proyecto de integración regional se desenmarca de la tendencia económica que propone la integración a base del aumento de los niveles de comercio entre los países y más bien se enfoca en la constitución de un bloque político y estratégico de contrapeso a la política exterior de EEUU en términos de seguridad hemisférica (Insignares Cera, 2013). Su constitución y desarrollo retoman los siempre presentes ideales de autonomía y unionismo latinoamericanos, apegados al activismo en organizaciones regionales y defensa en apego al derecho internacional, redefiniendo estas categorías en clave sudamericana.

En este sentido, la UNASUR puede ser considerada como una muestra de pragmatismo del diálogo político que se basó en la CSS para formular planteamientos reivindicativos en materia de seguridad y defensa. Por ejemplo, el bloque se mostró muy efectivo en la intermediación frente a intentos separatistas en Bolivia, la condena del golpe de Estado que derroco al presidente hondureño Manuel Zelaya en el 2009, el rechazo a la presencia militar inglesa en las Islas Malvinas, la mediación entre Ecuador y Colombia tras el bombardeo de una base de las FARC en 2008, la amenaza del Reino Unido de violar la embajada de Ecuador en Londres, el bloqueo económico de la isla de Cuba (Vázquez 2019: 250). Esto consolidó al bloque como un espacio autónomo de procesamiento de conflictos en la región.

Si bien la cooperación alcanzada por los miembros de la UNASUR se vio reflejada en la creación de doce consejos ministeriales enfocados al tratamiento de diversas temáticas relevantes para la región, el área más destacada fue la promovida por el Consejo de Defensa Sudamericano (CDS). Este consejo se 
creó con objetivos específicos: a) consolidar una zona de paz suramericana, b) construir una visión común en materia de defensa, c) articular posiciones regionales en foros multilaterales sobre defensa, d) cooperar regionalmente en materia de defensa, e) apoyar acciones de desminado, prevención, mitigación y asistencia a víctimas de desastres naturales (ALBA-TCP, 2009).

Los proyectos de cooperación desarrollados en el marco del Consejo de Defensa son varios, pero los que más se destacan es la elaboración de estudios metodológicos para conocer el inventario militar de los países miembros, implementación de acciones que hagan frente a amenazas cibernéticas e informáticas en el área de defensa, la creación del Centro de Estudios Estratégicos de Defensa (CEED) en el 2011, la Escuela Sudamericana de defensa en Quito en 2015 (en contraposición a lo que fue la Escuela de las Américas) (Vázquez 2019: 251). Adicionalmente, el Consejo Suramericano de Infraestructura y Planeamiento (COSIPLAN) se mostró muy activo. Su proyecto más importante fue la Iniciativa para la Integración de la Infraestructura Regional Sudamericana (IIRSA), que buscó vincular el espacio sudamericano en el área de transporte, telecomunicaciones y energía. Esto incluye la creación de centros logísticos, redes eléctricas, pasos fronterizos, corredores para acelerar el flujo de mercancías, bienes y personas, entre otros (Vázquez 2019: 252).

Sin embargo, las iniciativas no estuvieron carentes de tensiones, especialmente en referencia a los modelos de desarrollo sustentados en la explotación de recursos naturales, la sobreexplotación de recursos energéticos, minerales y el agua, que fueron la base del modelo seguido por los gobiernos de progresistas de la primera década del siglo XXI (Acosta, 2012; Estay, 2018; Gudynas, 2013; Svampa, 2012). Por lo tanto, el dilema sigue siendo los límites de la explotación, tanto de los extractivismo conservador como el de Perú o Colombia, como del neoextractivismo progresista impulsado por Ecuador o Bolivia, que buscaron una reapropiación social de la naturaleza implementando simultáneamente mecanismos de consulta con los grupos indígenas y campesinos respecto a la gestión de los recursos naturales ubicados en sus tierras (Domínguez \& Caria, 2016) 
Adicionalmente, tras el cambio de signo político en varios de los países sudamericanos la UNASUR entra en estancamiento, crisis y posterior declive. De acuerdo a Juan Gabriel Tokatlian, desde el año 2014 empiezan a manifestarse varios elementos que llevaron a la irrelevancia y el posterior declive de la UNASUR, a saber:

a) el gradual desinterés de Brasil -durante el segundo mandato de Dilma Rousseff primero y aún con la breve presidencia de Michel Temer después- de invertir recursos diplomáticos en América del Sur; b) la desafortunada elección del ex presidente Ernesto Samper al frente de la Secretaría General de la Unión de Naciones Suramericanas; c) la acefalía en la conducción de Unasur desde principios de 2017 en medio de distintas estrategias simultáneas de diferentes países destinadas más a la obstrucción de candidaturas que al logro de un candidato de consenso; d) el fracaso de las gestiones de buenos oficios auspiciadas por Unasur con la participación de los ex mandatarios José Luis Rodríguez Zapatero, Leonel Fernández y Martín Torrijos, ante la profundización de la crisis en Venezuela en el marco de irresponsabilidades compartidas por parte del gobierno y de la oposición; e) el establecimiento del llamado Grupo de Lima en agosto de 2017 con el fin de debilitar, cercar y aislar al gobierno de Nicolás Maduro en Venezuela; f) la mediocre presidencia pro témpore de la Argentina entre abril de 2017-abril 2018 que nunca citó una cumbre de mandatarios, de cancilleres o de ministros de Defensa; g) la suspensión de la participación de la Argentina, Brasil, Chile, Colombia, Perú y Paraguay en el bloque sudamericano justo cuando la presidencia pro témpore pasaba a Bolivia; y h) la salida definitiva de Colombia (agosto 2018) y Ecuador (marzo 2019) del mecanismo de concertación.

La creación de la UNASUR y las iniciativas iniciadas durante la primera década del siglo XXI demostraron la generación de un pensamiento propio sudamericano que buscó amalgamar visiones comunes para consolidar políticas regionales desde una visión estratégica de desarrollo. Sin embargo, parecería que los esfuerzos institucionales no lograron apostar por iniciativas a largo plazo que no dependan de factores coyunturales o ideológicos, como por ejemplo: el recambio político de los gobiernos sudamericanos, la creciente estratificación de la región con iniciativas como las del Grupo Prosur o la Alianza del Pacífico, el agotamiento del boom de los commodities, y la restructuración de las relaciones hemisféricas cuando EEUU vuelve a poner en vigencia la Doctrina Monroe como respuesta a la creciente presencia de China.

\subsection{Comunidad de Estados Latinoamericanos y Caribeños -CELAC}


La CELAC se constituye como un mecanismo de diálogo y concertación política que reúne a los 33 países de América Latina y el Caribe y que avanza sobre la convergencia de acciones e intereses comunes, planteando la posibilidad de vinculación política en gobiernos de distintos signos ideológicos (Bonilla y Álvarez 2013). Nace en el año 2010 en un contexto de reformulación de la política hemisférica latinoamericana, que, a lo largo de la primera década del siglo XXI, ha ido transfiriendo las funciones del Grupo de Río y de la Cumbre de América Latina y del Caribe (CALC) a la CELAC.

La CELAC se configura se posiciona como el espacio común de concertación y cooperación tanto de los países latinoamericanos como de los grupos subregionales activos en la región (Sanahuja 2013). Su fortaleza radica en su alcance como "espacio regional propio que une a todos los Estados", como se señala en sus estatutos constitutivos, con la posibilidad de formular estrategias conjuntas, llegar a acuerdos comunes y discutir los temas relevantes de la comunidad sin la injerencia de EEUU. En este sentido, logró consolidar la identidad latinoamericana, aupada desde las luchas por la independencia, e hizo pragmático el sentido de la solidaridad Sur-Sur con miras a reducir las inequidades de la región y la búsqueda de solucionar conflictos desde la propia realidad (Bonilla y Álvarez 2013). Se enfatizó en la reivindicación de la soberanía de los pueblos, el rechazo a la colonización económica, política y cultural y la resolución dialogada de controversias (Tolcachier, 2020).

Su relevancia radica en que logra pragmatizar los ideales autonómicos latinoamericanos estableciendo un nuevo paradigma de relacionamiento para con actores internacionales. Se reactivó una narrativa unionista para el conjunto de la región y la posibilidad de actuación conjunta en el ámbito externo, es decir, la CELAC buscó consolidarse como un marco común donde los grupos subregionales existentes, como la CEPAL o el SELA, puedan coexistir actuando en un espacio común de cooperación, en función a las temáticas técnicas o funcionales definidas por los países (Sanahuja 2014). En este sentido, una de sus ventajas es que logra integrar en un espacio común tanto a mecanismos subregionales como a países que orbitan directamente bajo la sombra de EEUU, como el caso de México o los países caribeños como Cuba. Con ello, se logra 
reafirmar la identidad latinoamericana y se proporciona una alternativa, al menos en el aspecto simbólico, a su fuerte vinculación alrededor de los EEUU (J. A. Sanahuja, 2014).

A inicios del nuevo milenio y en el marco de los procesos de reordenamiento de las jerarquías a nivel mundial, los gobiernos de los países en América Latina y el Caribe cuestionaron la hegemonía estadounidense, los planes del “panamericanismo abierto", la aplicación de políticas derivadas del consenso de Washington y sus instituciones satélites como la OEA. Especialmente los países sudamericanos se proclamaron en contra de las políticas destinadas a promover el control político y militar de los EEUU sobre la región. En este aspecto, la CELAC constituyó un hito histórico en el desarrollo institucional y fortalecimiento de la identidad de la región porque materializa el anhelo latinoamericano por aunar esfuerzos integracionistas sin presencia formal de la potencia hegemónica de EEUU en la región.

Las dos visiones que históricamente han surgido para pensar el espacio latinoamericano han sido, a groso modo, el monroísmo norteamericano y el bolivarianismo latinoamericano, que representan dos visiones antagónicas sobre cómo entender la región. Estas dos posturas siempre se han mantenido vigentes, pero en la primera década del siglo XXI se evidencia de manera clara una posible contraposición pragmática entre la CELAC y la OEA. Al respecto, el pensamiento de Juan Gabrial Tokatlian en 1984 sigue vigente para dar cuenta de las históricas disputas en la región:

La actual crisis de la OEA es la manifestación concreta de las contradicciones y el deterioro creciente de las relaciones entre América Latina y el Caribe y los Estados Unidos. No asistimos a la mera inoperancia administrativa de la OEA, sino que aquella es el producto de divergencias económicas, políticas y estratégico-militares profundas en el seno del sistema interamericano. En términos muy sintéticos, y luego de más de un siglo de historia, se corrobora la incompatibilidad entre el monroismo norteamericano y el bolivarismo latinoamericano; dos proyectos alternativos que significan la antítesis entre un modelo hegemónico-imperial y una propuesta unitaria de federalismo anfictiónico entre pares latinoamericanos y del Caribe insular (Tokatlian, 1984). 
Si bien la CELAC no se plantea como un mecanismo alternativo a la OEA, si se configura como un mecanismo donde tratar temas pertinentes para la región como la provisión de bienes públicos regionales, la estabilidad política y desarrollo, o incluso temas que se tratan en el seno de la OEA, como la promoción de la democracia, la lucha contra el tráfico de drogas o los derechos humanos. Por lo que la CELAC implicó fortalecer el espacio político con la posibilidad de formular estrategias conjuntas, llegar a acuerdos comunes y discutir los temas relevantes sin la presencia de EEUU y Canadá. Uno de los países más críticos ha sido Ecuador, por ejemplo, en relación al Sistema Interamericano de derechos humanos porque está alineado a los intereses de los grupos dominantes norteamericanos. La posición que se mantuvo durante el mandato de Correa es que "no tiene sentido discutir sobre estos temas ante una institución (la OEA) que no ha firmado la Convención Interamericana de derechos humanos" (Díaz Segovia 2014).

Una de sus fortalezas, que también se constituyó en debilidad es que la CELAC logró reunir a toda la región latinoamericana en un solo bloque, lo que ha sido calificado como un "milagro político". Pero a la vez, enfrenta el dilema de lograr que la unidad de los miembros prevalezca sobre los intereses particulares y las contradicciones ideológicas de los modelos que conviven en el continente (Yepe, 2013). En este sentido, sus debilidades descansan en la posibilidad de fractura al presentarse como una alternativa ideológica más que de complementariedad de los modelos existentes en la región (Vivares et al. 2014). Con lo cual, corre el riesgo de repetir las frustraciones de procesos anteriores no consolidados y de caer en exceso de reuniones, declaraciones, planes de acción y burocratización sin resultados prácticos para el desarrollo de los pueblos (Yepe, 2013).

En cuanto a su dimensión interna, la institucionalización también es otro punto a considerar porque al ser un mecanismo de concertación y cooperación su alcance es eminentemente político y no llega a tener ni un tratado constitutivo, ni se consolida como una organización internacional. Esto da cuenta de la histórica posición de los países latinoamericanos donde prima la idea de defender la soberanía nacional de cada Estado, y ha dado lugar a un mayor "intergubernamentalismo" o "diplomacia de cumbres" (Sanahuja 2013: 29). 
En cuanto al ámbito externo, la CELAC se ha posicionado como el interlocutor regional de las relaciones con varios socios estratégicos y ha fortalecido su rol de ente representativo y locutor valido ante actores diversos y significativos en el actual contexto internacional como China, India, Rusia y la UE (Yepe, 2013). En el año 2015 se posicionó como interlocutor legítimo del continente americano para con China, cuando se celebró la Primera Reunión Ministerial del Foro de la CELAC-China en Beijing. En dicho encuentro, ambas partes adoptaron el Plan de Cooperación China-Estados Latinoamericanos y Caribeños (2015-2019) en el cual el país asiático se comprometía a canalizar USD 250000 millones en cooperación a la región durante los próximos diez años a través de créditos de gobierno a gobierno y de inversiones directas (Foro China-CELAC 2015).

Uno de los retos más grandes que persisten para la CELAC es impulsar una visión estratégica de la cooperación internacional anclada a entender los procesos de reordenamiento de las estructuras internacionales y los cambios a nivel interno de los países latinoamericanos. Una vez culminada la segunda década del siglo $X X I$, se hizo palpable la recomposición de fuerzas conservadoras en el continente, con lo cual los múltiples procesos de integración y concertación atravesaron transformaciones que impactan la dinámica regional. Particularmente la CELAC se encuentra paralizada desde el año 2017 por los posicionamientos ideológicos antagónicos debido a la crisis en Venezuela y Nicaragua. Por una parte, está el posicionamiento del Grupo de Lima, formado por trece países de la región más Canadá, y por otra el grupo bolivariano de los países que aún integran la ALBA y respaldan a estos gobiernos.

\section{Recapitulación}

El objetivo del presente capítulo fue ubicar el resurgimiento de la CSS, las iniciativas, mecanismos y acciones que de ella se desprendieron en el contexto latinoamericano de los albores del siglo XXI. Para ello, se enmarcó el análisis tomando como perspectiva, por una parte, la economía política internacional y los cambios en las relaciones de poder; y por otra, se resaltó la vigencia del pensamiento latinoamericano para comprender las nuevas dinámicas de CSS 
que se promovieron. El argumento general que se sostiene a lo largo de este acápite es que el renovado auge de la CSS trajo consigo nuevas prácticas que redimensionaron la idea de desarrollo y pusieron en el centro del debate el interés nacional, la autonomía y el cuestionamiento a la globalización neoliberal plasmada en las relaciones Norte-Sur.

Sobre la base del análisis de los cambios en el orden mundial existe consenso en que uno de los factores trascendentales de este fenómeno es la reubicación de los países emergentes en el centro del poder económico y político internacional. Por ello, se tomó como hilo conductor del resurgimiento de las iniciativas de CSS la presencia de la cooperación China en América Latina y la consecuente rivalidad que genera con EEUU. Se dio especial relevancia a delinear las iniciativas de CSS en tres dimensiones: cooperación económicofinanciera, cooperación técnica y procesos de integración regional.

El incremento de la cooperación económico-financiera reembolsable de China es uno de los aspectos fundamentales para el resurgimiento de la CSS en la región latinoamericana. El gigante asiático desembarca en el continente con una narrativa que retoma los principios de solidaridad, complementariedad, equidad, no condicionalidad y respeto a la soberanía en el manejo de sus relaciones exteriores. Bajo estos principios, su presencia se vuelve cada vez más asertiva a través de préstamos, financiamiento, intercambios comerciales e inversiones; de tal manera que se convierte en el principal socio comercial de países como Brasil y el primer inversionista en Ecuador, Bolivia y Venezuela.

La presencia China en la región consiguió desplazar, en el ámbito comercial, a socios tradicionales como EEUU o la UE, por lo que el análisis de los vínculos económicos y políticos con esta potencia resultan imprescindibles para la discusión tanto de la reemergencia de la CSS como para entender el auge de modelos alternativos de desarrollo basados en la autonomía política y la independencia económica que surgen en la región. En este sentido, resulta relevante un estudio de caso más profundo de las relaciones comerciales que permita verificar las dinámicas que se instauran al enfocar el comercio mayoritariamente en el intercambio de materias primas. 
En este capítulo también se analizó el ascenso al poder de gobiernos de corte progresista en la región durante la primera década del siglo XXI, y el giro que adoptan en cuanto a reivindicar ciertas políticas públicas, como aquella de la cooperación al desarrollo. Se delinearon los cambios de perspectiva que se dieron en la región buscando instaurar nuevos esquemas de relacionamiento alternativos al tradicional esquema de cooperación Norte-Sur. En este sentido, se estudió el fortalecimiento de institucionalidades e iniciativas surgidas para fortalecer los marcos de CSS técnica. Sin embargo, se hizo énfasis en retomar un enfoque histórico que vaya más allá de la bien valorada cooperación técnica, que normalmente se analiza desde la perspectiva de la OCDE y de la contabilización de proyectos.

Finalmente, se retomó el eje de la CSS vinculado a los procesos de integración regional de corte autonomista que surgen en la región latinoamericana, haciendo énfasis en los proyectos de concertación y diálogo político como el ALBA, UNASUR y CELAC. Estos mecanismos tienen una naturaleza distinta a los enfoques eminentemente económicos surgidos hasta la década de los noventa y redefinen la importancia de la región en un contexto internacional cada vez más multipolar. La relevancia de estos mecanismos de integración radica en que lograron plasmar de manera pragmática los ideales autonómicos latinoamericanos y establecieron un nuevo paradigma de relacionamiento para con las potencias hegemónicas. De igual manera, redefinieron el rol de la cooperación entre los países del Sur, que a pesar de las diferencias ideológicas o de los distintos modelos de desarrollo que persiguen, abrieron la posibilidad de pensar en mínimos comunes para comprender y afrontar los desafíos de desarrollo en la periferia en un mundo cambiante. 


\section{CAPÍTULO III. COOPERACIÓN SUR-SUR Y POLÍTICA EXTERIOR EN LA PERIFERIA: FUNDAMENTOS TEÓRICOS Y METODOLOGÍA.}

\section{Discusión}

La revisión de los cuerpos teóricos y de las comunidades epistémicas predominantes en el estudio de la Cooperación Sur-Sur y su relación con el ejercicio de la política exterior de los países periféricos constituye un eje central para entender las principales visiones que dominan su panorama actual. Para el abordaje de estas dinámicas en la región latinoamericana, la presente investigación dialoga con la propuesta de varios autores quienes han llamado en los últimos años a 'romper las cárceles conceptuales' establecidas en el ámbito académico e incluir reflexiones teóricas que incorporen el pensamiento producido en la región desde enfoques propios (De Lombaerde 2016: 1; Tickner 2002; Vivares y Cvetich 2014).

Dentro de este contexto, la investigación busca retomar el aporte teórico surgido en América Latina en materia de Relaciones Internacionales y estudios del Desarrollo porque ha demostrado su capacidad para producir ideas originales y aportar a la teorización y entendimiento de las realidades de Estados no centrales. A partir de la segunda mitad del siglo XX, son especialmente relevantes las contribuciones que aporta el Realismo Periférico, que es una teoría que se deriva de una cosmovisión sistémico-estructural e introduce una manera alternativa de ver el mundo -desde aquellos Estados que no imponen las "reglas de juego", que son sujetos de las mismas o sufren costos altos cuando confrontan dichas reglas (Escudé 2012).

Considerando este punto de partida, el objetivo de este capítulo es sentar las bases teórico-metodológicas para analizar cómo se retoma la cooperación Sur-Sur en el ejercicio de la política exterior de los países periféricos como mecanismo que podría apuntalar la consecución de mayores márgenes de autonomía y reducción de dependencia de potencias centrales. De manera consecuente con la teoría, se opta por método estructural sistémico para el análisis de estrategias política exterior porque toma como eje central tanto 
factores estructurales, como de agencia que inciden en los procesos de inserción internacional. Esto permite informar sobre el peso, por un lado, de los factores como la distribución del poder, la interdependencia económica; y por otra, las fuerzas a nivel doméstico como la ideología y el perfil del gobierno en la política exterior.

El capítulo se organiza de la siguiente manera. Para comenzar, se discute La política exterior en el pensamiento latinoamericano, específicamente el Realismo Periférico y los abordajes sobre autonomía. Posteriormente, se delimitan los principales postulados teóricos e hipótesis que se adoptan en la tesis. Finalmente, se vinculan los postulados teóricos con la estrategia metodológica siguiendo el método estructural sistémico. Esto permite sentar las bases para desarrollar las dos fases del análisis de la investigación: primero el modelo explicativo de la política exterior en América Latina; y, segundo, el estudio de caso de Ecuador.

\section{La política exterior en el pensamiento latinoamericano: Realismo Periférico y autonomía}

El acervo teórico latinoamericano sobre política exterior y relaciones internacionales señala que las políticas exteriores de los países periféricos suelen estar condicionadas, por un lado, por factores estructurales relacionados con el poder y su distribución en el contexto internacional y por otro, debido a cuestiones domésticas concernientes al rol de las élites, las instituciones y los factores sociales. El área de intersección de estas variables sistémicas y domésticas constituye la política exterior, que es una política que se desarrolla tanto desde dentro del Estado, como desde las constricciones de la política internacional (Malamud y Neto 2015: 2).

Uno de los aportes teóricos, que emergen de forma externa a los centros epistémicos de poder mundial con la finalidad de explicar el esquema de vinculación de los Estados periféricos para con las grandes potencias, es el pensamiento latinoamericano en Relaciones Internacionales; que acuña teorías como el realismo periférico, la autonomía y la dependencia. Estas visiones 
analizan los procesos de inserción internacional y estrategias de política exterior de los Estados periféricos para ampliar sus márgenes de autonomía en el ejercicio de su política exterior en favor de la consolidación de Estados nacionales y el desarrollo; considerando sus vínculos con las grandes potencias para mejorar su inserción internacional (Escudé, 1983, Rivarola y Briceño-Ruiz, 2013; Tickner, 2013 y 2015; 2015; Briceño-Ruiz y Simonoff, 2017).

De acuerdo a estos postulados teóricos, el posicionamiento de un país en el concierto mundial está definido por relaciones centro-periferia lo que da cuenta de un orden internacional asimétrico y jerárquico. De acuerdo a Russell y Calle 2009, el concepto político de la periferia está vinculado con la idea de un espacio con distintos grados de subordinación a un centro dominante con el que mantiene relaciones de colaboración y de oposición. Es decir, la característica primordial que define a toda periferia es la asimetría de poder con el núcleo central (Russell y Calle 2009: 7-8). Por su parte, la acepción geográfica de la periferia indica un espacio que limita con un núcleo, pero su entendimiento es complejo de pragmatizar dado que su alcance geográfico es una construcción política del centro sujeta a cambios continuos. Su perímetro siempre acompaña las fluctuaciones de los intereses de seguridad del núcleo que derivan de la interacción de factores sistémicos, metropolitanos y periféricos (Russell y Calle 2009, 7-8).

A partir de la vinculación e interacción entre los actores de centro y de la periferia en el escenario internacional se derivan relaciones de dependencia para con una potencia central y la prioridad de los Estados periféricos de ampliar sus márgenes de autonomía en la conducción de su política exterior con miras a optimizar su inserción internacional. La autonomía es un concepto político que hace referencia al margen de maniobra de un país periférico en el orden internacional; mientras que la dependencia es un concepto que hace alusión al ámbito económico y se manifiesta a través del "comportamiento internacional de Estados económicamente débiles cuyas economías dependen en gran medida de uno o dos socios comerciales" (Hey 1993: 241). 
Desde este enfoque, se introduce una visión alternativa en las relaciones internacionales desde aquellos Estados que no forman parte de los hacedores de las "reglas del juego" sino más bien, de aquellos Estados que las asumen y que enfrentan costos cuando se confrontan a las reglas establecidas. De ello deriva la centralidad del concepto de autonomía, que implica la "libertad de acción de un Estado frente a los condicionamientos externos" (Tokatlián y Carvajal, 1995, p. 8). En este sentido, el ejercicio de la política exterior de los países periféricos suele estar enmarcada en la identificación de estrategias que permitan ejecutar el interés nacional definido en términos de desarrollo y el cálculo de la utilización de la autonomía, o márgenes de maniobra, en cuanto ello puede derivar en acciones de confrontación con las potencias centrales.

La identificación de estas estrategias no es sencilla por lo que resulta necesario revisar los factores estructurales que influencian el ejercicio de la política exterior. Siguiendo a Escudé (1983):

\begin{abstract}
“(...) desde los países dependientes (...) la política hacia las grandes potencias siempre es relevante, por las reacciones positivas o negativas, directas o indirectas, que puede suscitar". Así, los países periféricos en tiempos de "transiciones hegemónicas" tienden a implementar políticas exteriores de tipo pendular entre las dos potencias (Escudé, 1983: 183).
\end{abstract}

El desarrollo de estrategias de política exterior en los países periféricos, de acuerdo con Escudé, se basa en implementar acciones tendientes a eliminar las confrontaciones políticas con las grandes potencias, reduciendo el ámbito de sus discrepancias a aquellos asuntos materiales vinculados directamente a su bienestar y base de poder. Además, sus decisiones no sólo se calibran en términos de costo y beneficios sino también en función de los costos potenciales y se redefine el concepto de autonomía, en términos de capacidad y de costo relativo de confrontación (Escudé, 1983). La lógica que subyace es que, ante cambios en las estructuras sistémicas o procesos de transición hegemónica, los países periféricos tienden a buscar estrategias de relacionamiento para mejorar sus vínculos con el poder en ascenso sin que eso implique desafiar a la potencia dominante. 
Desde este enfoque, las opciones de política exterior para la periferia dependen de factores que conforman lo que autores como Puig (1980) y Jaguaribe (1979) denominan la "permisibilidad internacional" y la "viabilidad nacional". La permisibilidad internacional está relacionada con los factores estructurales que analizan la medida en que, dada la situación geopolítica de un Estado y de sus relaciones internacionales, éste dispone de condiciones para neutralizar el riesgo proveniente de terceros países, dotados de suficiente capacidad para ejercer sobre él formas eficaces de coacción (Jaguaribe, 1979: 22). Esta definición incluye no solamente capacidades económicas y militares sino también la adopción de estrategias para el establecimiento de alianzas, potencial de recursos humanos y el grado de cohesión socio cultural de un país, que es lo que constituye la viabilidad nacional (Jaguaribe, 1979).

De este interrelacionamiento se derivan premisas fundamentales sobre las cuales pende la política exterior de los países periféricos. Por una parte, se destaca su subordinación a estructuras internacionales donde los Estados son en principio tomadores de reglas y por ende su política exterior es defensiva y altamente condicionada a su posición en la estructura internacional. El principio que ordena el sistema internacional es la anarquía combinada con la jerarquía que imprimen los actores centrales. Los Estados periféricos ejercen su política exterior principalmente de manera defensivo-posicionalista, ya que deben cuidar su posición en la estructura o lidiar con los costos de enfrentarse a los poderes centrales. Su capacidad de agencia se ejerce en base al poder que detenta y esto constituye la base de su capacidad de autonomía en las relaciones internacionales. Como corolario, se reconoce la distribución de poder como un condicionante que permite entender por qué existen "Estados que mandan, Estados que obedecen y Estados rebeldes que sin tener el poder necesario desobedecen las reglas" (Escudé 1999: 14).

En este contexto, se desarrollan diferentes estrategias autonomistas como uno de los propósitos que persigue la política exterior de todos los Estados contemporáneos (Holsti 1992: 83 en Russel y Tokatlian 2002: 1). La autonomía como concepto central en la política exterior de los países periféricos está estrechamente relacionada a la capacidad que puede ejercer un Estado-nación 
de 'contar con un autodesarrollo, una autoconciencia de que se actúa con referencia a metas y propósitos propios; y una libertad de acción frente a los condicionamientos externos' (Tokatlián y Carvajal 1995: 8).

Dada la naturaleza polisémica del concepto de autonomía, a continuación, se presentan los principales entendimientos teóricos que han surgido en el pensamiento latinoamericano en las últimas décadas.

\section{Abordajes teóricos sobre la autonomía}

La idea de la autonomía está presente en el pensamiento y acción latinoamericana en tanto se encuentra estrechamente vinculada con el ámbito de su proyección e inserción internacional. Se pueden recalcar al menos tres acepciones del concepto de autonomía en el pensamiento latinoamericano: autonomía como principio, como interés nacional y como condición.

Por una parte, la autonomía como principio está ligada a la concepción wesftfaliana de territorialidad y soberanía en el que se busca garantizar la competencia exclusiva de los asuntos internos de cada Estado. La autonomía como condición es una propiedad que el Estado puede o no tener a lo largo de un continuo en cuyos extremos se dan dos situaciones ideales: total dependencia o completa autonomía (Russel y Tokatlian 2001: 2). En este sentido, es una cuestión grado que depende de la capacidad del Estado de desarrollar habilidades duras y blandas, y de las condiciones externas que enfrenta (Russell y Tokatlian 2002: 2).

Por otra parte, la autonomía como interés nacional representa una guía normativa para la acción y se convierte en un poder causal que predispone al Estado a actuar de cierta manera por lo que el grado de jerarquía que se otorgue a uno o a otro de estos principios dependerá del contexto en el que se desarrolle la política exterior del Estado. Esta visión es cercana al pensamiento constructivista que señala que el interés nacional sería el resultado de "ideas compartidas, identidad nacional y prácticas normativas" (Wendt 2005 en Guzzini y Leander); esto, lejos de ser un concepto estático se forma dentro de un 
contexto cultural y en un momento histórico determinado que cambia con el tiempo y presenta una "combinación particular de patrones de pensamiento, condiciones materiales e instituciones humanas, que tiene cierta coherencia entre sus elementos" (Cox 1986).

Los cimientos de la fecunda producción intelectual sobre el pensamiento autonómico en América Latina se enmarcan en el contexto de la Guerra Fría que buscaron poner en debate el rol de 'unidades dependientes' que otorgaban las teorías centrales de relaciones internacionales a los países periféricos. Los preceptos autonomistas apuntan a la ampliación de los márgenes de acción o maniobra de los países periféricos en relación con las imposiciones de los países centrales considerando que tanto la búsqueda del desarrollo económico como la implementación de planes y políticas públicas a nivel nacional no podían ser escindidos del entendimiento de las estructuras internacionales. Es decir,

\begin{abstract}
los modelos de inserción internacional y de desarrollo económico se entrelazan y retroalimentan toda vez que la autonomía contribuye para que los países latinoamericanos puedan proyectar y ejecutar proyectos nacionales de desarrollo desafiantes de la división internacional del trabajo que impide su industrialización, favoreciéndose, de esta manera, una participación activa y no subordinada en el sistema interestatal capitalista y en la globalización (Ferrer 2006: 13).
\end{abstract}

La Cepal instala los debates sobre dependencia en la década de los cincuenta, mientras que el pensamiento autonómico toma auge a partir de los setenta y ochenta con los intensos aportes por parte de intelectuales y formuladores de política exterior, principalmente de Juan Carlos Puig en Argentina y Helio Jaguaribe en Brasil (Colacrai 2009: 35; 1992). Desde entonces, los principales abordajes teóricos se dan desde una perspectiva política y desde el área socioeconómica con los aportes de la lectura escudeana o neoconservadora, la autonomía neoliberal o relacionista y la escuela socio histórica. El método, la visión del mundo y los aspectos fundacionales de carácter epistemológico y ontológico con que abordan la temática de estudio, la autonomía, difieren en cada uno de ellos, como se muestra en los acápites siguientes. 


\subsection{La autonomía en el pensamiento de Juan Carlos Puig}

El pensamiento autonomista encuentra uno de los más grandes aportes en el aporte puiguiano que se desarrolla a partir de los años setenta en un contexto social, económico y político marcado por la polarización internacional de la Guerra Fría. Su pensamiento parte de las premisas del realismo clásico como la división de funciones en el sistema internacional y la idea de anarquía -entendida como ausencia de una autoridad superior a los Estados nación- para señalar que los Estados cuentan con cierto grado de flexibilidad y margen de maniobra para defender su interés nacional; esto le permite sustentar la existencia de la autonomía en la política exterior (Puig en Simonoff 2015: 125).

Puig precisa que el funcionamiento del régimen internacional 'como en cualquier grupo humano -macro o micro- posee una división de funciones y criterios supremos de reparto -impuestos, aceptados o sugeridos espontáneamente- que rigen las conductas de quienes integran el grupo, en este caso la comunidad internacional' (Puig 1984). Sobre esta base, caracteriza a los actores internacionales en tres grupos: 'los repartidores supremos, que son los gobernantes de las superpotencias mundiales y quienes toman decisiones y supervisan su cumplimiento; los repartidores inferiores, que son los mandatarios de los demás Estados, que ejecutan esas decisiones; y, finalmente, el resto de los habitantes del mundo que son los recipientarios, los que obedecen' (Puig 1984). Los criterios de esta división vienen dados por: a) posesión de un

potencial de destrucción masiva, b) impermeabilidad interbloque, c) autonomización intrabloques, d) permeabilidad extrabloques; e) prohibición del uso de la fuerza para pequeños y medianos Estados (Puig 1984).

Estos planteamientos y premisas forman parte de lo que se describe como 'realismo de la periferia' y constituyeron una teoría normativa orientada a la acción política exterior donde los Estados están en capacidad de aumentar de forma significativa la autonomía entendida como condición (Russel y Tokatlian 2003). Si bien el pensamiento puiguiano se desarrolla bajo la influencia de la teoría del realismo en $\mathrm{RI}$, su unidad de análisis va más allá del Estado-nación e incluye el estudio de los grupos de presión y élites gobernantes y el rol que le 
asignan al proyecto del Estado. Desde este enfoque, la política exterior puede ser estudiada en relación al potencial margen de autonomía que se puede obtener aprovechando las condiciones para un comportamiento autonómico y la capacidad de adecuación del Estado en el contexto nacional e internacional.

Puig tipifica algunos grados de comportamiento en política externa que van del menor al máximo nivel de autonomía:

a) dependencia paracolonial, que se caracteriza por no tener un proyecto de Estado propio y por lo tanto la élite gobernante es apéndice de otro país y su plan nacional está plegado a la Gran Potencia,

b) dependencia nacional, que va ligado a poseer un proyecto de Estado dependiente pero ser consciente de tal dependencia y querer obtener el mejor provecho de la situación,

c) autonomía heterodoxa, se acepta la conducción estratégica de la potencia dominante pero 'no acepta que se impongan dogmáticamente, en nombre del 'bloque', apreciaciones políticas y estratégicas que sólo consultan el interés propio de la potencia hegemónica; interés que, en la inmensa mayoría de los casos, refleja en realidad las aspiraciones de determinados grupos de presión o factores de poder internos',

d) autonomía secesionista, que implica una ruptura estratégica y desligarse de la potencia dominante y de los lineamientos del bloque; por lo tanto, es el grado más alto de autonomía y por consiguiente el más costoso (Puig 1984).

Sobre esta base, se define a la autonomía como 'la máxima capacidad de decisión propia que se puede tener, teniendo en cuenta los condicionamientos objetivos del mundo real' (Puig 1984). Esta idea está estrechamente relacionada con el desarrollo del interés nacional objetivado por un uso racional. Es decir,

el logro de una mayor autonomía supone un juego estratégico previo de suma cero, en el cual alguien gana lo que otro pierde (...), la maniobra estratégica que éste (el antiguo cliente) debe poner en movimiento solo será exitosa en la medida en que el diagnostico político referido al adversario (la potencia dominante) sea correcto y, como consecuencia, 
movilice recursos de poder que sean suficientes para dominar la voluntad del oponente (Puig en Simonoff 2015: 125).

El juego de suma cero es el rasgo que han tomado algunos académicos para leer a la autonomía puiguiana en clave de 'autonomía por oposición', 'autonomía por contraste', o 'autonomía antagónica' y señalar su desactualización. Sin embargo, Puig percibe a la autonomía en términos dialecticos, en la relación con el bloque (en referencia a los bloques de la Guerra Fría) como suma cero, y se considera el autonomismo heterodoxo como el más viable para los países latinoamericanos.

La vocación autonómica de tipo heterodoxo supone que 'existe una aceptación del liderato de la o las potencias dominantes y que, en cuestiones realmente cruciales, los periféricos optaran por responder a las aspiraciones del centro' (Puig 1984). Por lo tanto, si bien se acepta la conducción estratégica del bloque, existen tres aspectos que la alejan de percepciones antagónicas: a) el modelo de desarrollo interno puede no coincidir con las expectativas de la metrópoli; b) las relaciones internacionales del país periférico no son globalmente estratégicas, y c) se separa el interés nacional de la potencia dominante y el interés estratégico del bloque (Puig en Simonoff 2015: 126).

La vigencia del pensamiento autonomista radica en la capacidad de los Estados periféricos para buscar estrategias adecuadas para implementar la autonomía heterodoxa, para lo cual, las decisiones deben estar guiadas sobre la base de 'conocer con razonable exactitud el punto crucial en que los intereses cotidianos de la potencia se convierten en vitales' (Puig en Simonoff 2015: 127). Se rechaza la idea de que toda acción implica confrontación porque en ciertos casos, las políticas impuestas por el dominante no necesariamente tienen que ser perjudiciales para el subordinado (Puig en Simonoff 2015: 127).

\subsection{La autonomía neoconservadora: el aporte de Escudé}

El pasaje de los años setenta a los noventa estuvo marcado por el fin de la Guerra Fría y Carlos Escudé desarrolla su pensamiento autonomista bajo el impulso de la oleada neoliberal y neoconservadora. Mientras desde las teorías 
realistas anglosajonas se explicaba la totalidad del sistema internacional como una anarquía, Escudé, siguiendo a Puig y Jaguaribe, defendía la idea de un sistema internacional jerárquico y asimétrico tomando como referencia la ubicación de los países latinoamericanos en la periferia geográfica de la potencia hegemónica del siglo XX.

Escudé acuña el concepto de 'Realismo de la periferia', 'realismo de los débiles', o 'realismo periférico' que sustenta la aceptación del orden político (de características unipolares), económico y financiero internacional (marcado por la globalización) y sobre esta base propone una relectura de la idea de autonomía señalando que:

La autonomía no es libertad de acción. La libertad de acción de casi todo Estado mediano es enorme y llega al límite de la autodestrucción, y no sirve por tanto como definición de autonomía. Esta se mide en términos de los costos relativos de hacer uso de esa libertad de acción....asimismo es preciso saber distinguir entre la autonomía en sí misma y el uso que a esta se le da. A su vez, este uso puede conceptualizarse como inversión de autonomía, cuando apunta a la demostración exhibicionista de que uno no está bajo el tutelaje de nadie (Escudé en Russel y Tokatlian 2010: 123).

Desde este punto de vista, la política exterior de los países débiles debe desplegarse no sólo a partir de 'un riguroso cálculo de costos y beneficios materiales, sino también en función de los riesgos de costos eventuales' (Escudé 1992). Desde este enfoque, todo país posee una suerte de autonomía básica, mayor o menor según el poder acumulado, que no debe derrocharse buscando gratificaciones elitistas ni malgastarse en gestos y actitudes simbólicas, contestatarias y desafiantes. En cambio, la autonomía debe mantenerse y acrecentarse a través de decisiones y políticas que contribuyan a elevar el conjunto de atributos de poder de un país y mejorar el bienestar material de la población. Esto implica una sostener una actitud prudente, una visión estratégica y un cálculo utilitarista para determinar tanto el alcance y el sentido como el contenido y la práctica de la autonomía (Escudé 1992).

La autonomía, desde el realismo periférico señala que a los Estados débiles les correspondería racionalizar pragmáticamente su falta de autonomía y capitalizar 
al máximo sus escasas y bastante ocasionales posibilidades de inserción menos subordinada y dependiente en la política mundial (Santana y Bustamante 2013). Esto debido a que en el panorama internacional existe una pugna permanente entre poderosos con autonomía, por lo que la heteronomía ${ }^{13}$ definiría la conducta de los actores menores del sistema. Replantea la idea de autonomía por aislamiento y confrontación y señala que la autonomía está vinculada a costos, riesgos y beneficios y redefine a la autonomía en dos formas de uso: a) orientado hacia la exhibición de la autonomía 'consumo de autonomía' y b) orientado a la generación de desarrollo o poder 'inversión de autonomía' (Escudé 1988).

Escudé señala que la estrategia de política exterior de los países periféricos debe estar enmarcada y ejecutada de tal manera que el interés nacional, definido en 'términos de desarrollo', se logre evitando cualquier tipo de confrontación con las grandes potencias y midiendo los costos relacionados con el uso de esa libertad, puesto que 'ninguna confrontación se justifica a no ser que genere un beneficio material claro y tangible para el Estado Periférico en cuestión' (Escudé 1988: 297). Una política exterior inspirada en estos parámetros debe reducir los enfrentamientos externos a los asuntos materiales vinculados en forma directa con el bienestar y la base de poder del país (Escudé, 1991).

Los dos autores, Drekonja y Escudé, se valen de las premisas de la escuela realista de las $\mathrm{RI}$; sin embargo, en su pensamiento autonómico prevalece el uso de la filosofía utilitarista que hace hincapié en un riguroso cálculo de costos y beneficios en la toma de decisiones de política exterior. Predominantemente hace uso de la noción de utilidad como criterio de validación de lo que realmente genera dividendos en las relaciones internacionales; hace énfasis en el costobeneficio para comprender tanto la motivación como la acción humana; usa la reivindicación de una ética de los principios; rechaza el pensamiento especulativo e idealista; y la comprensión de la política como instancia dirigida a la gratificación económica egoísta.

\footnotetext{
${ }^{13}$ La estrategia de 'intercambio heterónomo sugiere que en una relación desigual las contrapartes más débiles y periféricas son demasiado pobres para priorizar la autonomía política y deben optar por las ganancias previsibles de un intercambio material; es decir, realizar un trade off entre el bienestar y la autonomía (Klink 1990)
} 
Por estos motivos, se ha categorizado su pensamiento como 'utilitarismo de la periferia'. Los dos autores comparten que la idea de que la autonomía se la debe incrementar de manera gradual y esperando la coyuntura más propicia para ampliar la capacidad de acción propia (Russel y Tokatlian 2003). Esta estrategia está muy asociada a la idea de bandwagoning ${ }^{14}$ en el pensamiento tradicional de las relaciones internacionales.

\subsection{Autonomía relacional y la escuela socio histórica}

El pensamiento autonomista en América Latina ha ido evolucionando y modificándose en contenidos desde su surgimiento en el siglo XIX hasta el siglo $\mathrm{XXI}$. El enfoque de la escuela socio-histórica se caracteriza por amalgamar sus análisis no solo en términos políticos, sino considerando también la 'influencia decisiva' de los modelos de acumulación 'en la evolución del Estado, los regímenes políticos y en la formación de la política exterior' (Simonoff \& Briceño 2015: 129). Los principales pensadores de esta corriente de pensamiento son Mario Rapoport, Raúl Bernaza, Amado Cervo y Helio Jaguaribe quienes proponen una 'mirada propia' de la realidad latinoamericana fuera de la influencia anglosajona, partiendo de un abordaje multidimensional y considerando al objeto de estudio en el marco de una 'historia social' (Simonoff 2015: 140).

Esta línea teórica propone un enfoque multidisciplinario, dentro de una corriente de pensamiento de carácter reflectivista, en el que adquiere un peso relevante la visión del mundo o el 'contexto para la acción' en el que se desarrollan los conceptos. Siguiendo a Cox (2013), el 'marco para la acción' comprende:

Una combinación particular de patrones de pensamiento, condiciones materiales e instituciones humanas, que tiene cierta coherencia entre sus elementos y constituyen el contexto de los hábitos, presiones, expectativas y restricciones dentro de las cuales la acción tiene lugar. Este contexto evoluciona y tiene la forma de estructura histórica dentro de la cual se deben analizar los fenómenos sociales (Cox, 2013: 141).

\footnotetext{
${ }^{14}$ Bandwagoning es una estrategia empleada por los Estados débiles cuando se alinean a los
} Estados fuertes para obtener beneficios que de lo contrario le serian difíciles de conseguir. 
Desde esta perspectiva, la autonomía no es estática, es siempre relativa y la posibilidad de su ejercicio resulta de un proceso dialectico que afecta al sujeto y al objeto de referencia en momentos históricos dados y que puede expandirse 0 reducirse de acuerdo con condiciones estructurales o coyunturales' (Tokatlián y Carvajal 1995: 20). El peso de las circunstancias y el tiempo han hecho que el 'marco para la acción' para el entendimiento de la autonomía se modifique. Sobre la base de la teoría crítica, la sociología histórica y un enfoque ecléctico en las Relaciones Internacionales, los autores proponen repensar el tema de la autonomía combinando variables estructurales y funcionales y adoptando un enfoque holístico basado en el realismo estructural, neomarxismo y el constructivismo.

Esta corriente retoma del constructivismo de Wendt la idea de que la autonomía 'se refiere a la capacidad del complejo Estado-sociedad para ejercer el control sobre la distribución de sus recursos y la elección de su gobierno' (Wendt 1999: 235). Mientras que desde el realismo estructural de Waltz y del pensamiento neomarxista se da énfasis en que la entidad constitutiva de los órdenes mundiales es el complejo Estado-sociedad civil y no únicamente el Estadonación y se rechaza la percepción del Estado como una 'fuerza autónoma que expresa algún tipo de interés general' (Cox 1993, 1986). Como resultado, se elude la identificación excluyente del Estado y se incorpora un elemento de voluntarismo, a la vez que reconoce las limitaciones y condiciones del enfoque de la interdependencia y los condicionamientos del sistema global (Tokatlian y Carvajal 1995: 21).

El nuevo contexto mundial caracterizado por la globalización, fin de la Guerra Fría, la integración y la democratización hacen indispensable repensar la idea de autonomía como condición y como interés nacional. Es decir, como la capacidad de los Estados de tomar decisiones sin seguir los deseos, preferencias u órdenes de otros (Russell y Tokatlian 2003: 175). Sobre esta base, se proyecta el planteamiento de trascender de la idea de autonomía, otrora considerada por oposición y confrontación, hacia una autonomía relacional con capacidad de adaptarse a los cambios de los nuevos tiempos (Russell y Tokatlian 2003). 
La propuesta de actualización de la idea de la 'autonomía relacional' plantea en términos generales que ésta debe entenderse como la 'capacidad y disposición de un país para tomar decisiones con otros por voluntad propia y para hacer frente en forma conjunta a situaciones y procesos ocurridos dentro y fuera de sus fronteras' (Russell y Tokatlian 18: 2003). Esta visión se aleja de la idea anacrónica de ampliar el margen de autonomía con políticas nacionales o subregionales de aislamiento, autosuficiencia u oposición, más bien, la autonomía como condición y como interés nacional, hacen referencia a:

La capacidad y disposición de un país para actuar independientemente y en cooperación con otros, en forma competente, comprometida y responsable. La autonomía relacional como interés nacional objetivo -esto es la preservación y ampliación de grados de libertad- se funda en un nuevo patrón de actividad, una nueva estructura institucional y un nuevo sistema de ideas e identidades. Prácticas, instituciones, ideas e identidades se definen y desarrollan dentro de un marco de relaciones en que 'el otro', en vez de opuesto, comienza a ser parte integral de lo que uno es (Russel y Tokatlian 2003: 179).

La autonomía relacional como práctica se visualiza, citando a Tokatlian y Russel 2003 en:

- Creciente interacción, negociación y una participación activa en la elaboración de normas y reglas internacionales tendientes a facilitar la gobernabilidad global. Se define como el poder para controlar procesos y acontecimientos externos en contraste al poder de un país de aislarse.

- Las organizaciones y regímenes constituyen el soporte indispensable para afrontar problemas comunes y alcanzar propósitos complementarios para el ejercicio de la autonomía en un marco de creciente interdependencia

- Exige del agente autónomo un nuevo modo de ver el mundo y de estar en él, que da prioridad a la competencia, el compromiso, la responsabilidad y la confianza.

- Requiere de un cambio progresivo en la posición del sujeto de la autonomía, que conduzca a la constitución de lo que Wendt ha denominado 'identidades colectivas', en las que el Yo y el Otro forman una sola 'región cognoscitiva'. Esta idea, que ha sido expresada en la literatura de diversas formas ('we-feeeling', 'solidaridad», 'sujeto plural', 
'actuar en equipo', etc.), se basa en un proceso histórico y cultural que ha contribuido a la formación de una conciencia de sociedad, así como también de valores y objetivos comunes.

Los enfoques tradicionales, especialmente de la visión del utilitarismo y realismo de la periferia consideran que la autonomía se ejerce solamente desde la política exterior de los Estados, o que el nuevo 'contexto para la acción' reduce la autonomía del Estado u obliga a cederla en nombre de otros principios como los derechos humanos o la democracia. Sin embargo, la autonomía relacional toma en cuenta rol cada vez más preponderante que los actores no estatales desempeñan un en los asuntos internacionales contemporáneos, se concibe como una condición co-constitutiva de los demás intereses nacionales objetivos, y lejos de suponer una visión idealista de la política mundial, reconoce las relaciones de dominación y subordinación y las prácticas de la política de poder convirtiéndose en una herramienta para disminuir las asimetrías de poder y contrarrestar esas prácticas mediante una participación competente, activa, comprometida y responsable en los asuntos mundiales (Russell y Tokatlian 180: 2003).

De la definición propuesta por los autores subyacen tres premisas primordiales (Tokatlian y Carvajal 1995: 21):

a) La autonomía no se ejerce globalmente por un Estado monolítico, sino sectorialmente tanto en términos de actores, cuestiones y momentos.

b) Se da énfasis en el contenido y no en la forma en cuanto a la praxis autonómica, lo fundamental es concretar la acumulación de recursos de poder y asegurar el aumento de la capacidad negociadora de un determinado agente.

c) No se debe confundir la retórica y el protagonismo discursivo en política exterior con la ampliación substantiva de la autonomía ni con el logro de presuntos espacios y márgenes de inserción que eventualmente deberían ser cubiertos con actos y no con palabras. 
Como se puede observar, repensar la idea de la autonomía ayuda, en mayor o menor medida, a sentar los fundamentos materiales de los que se podría hacer uso para alcanzar un cierto poder relativo que aumente las posibilidades autonómicas de los Estados. Desde esta perspectiva, se abre camino para entender la autonomía en un sentido más amplio con un enfoque ecléctico en el que se combinan variables tanto estructurales como de agencia; además se incluye el análisis de agentes no gubernamentales con voluntad y capacidad autonómica y manifiestan cierto voluntarismo reconociendo los límites y condicionamientos del sistema global (Tokatlian y Carvajal 1995: 22).

\subsection{Autonomía y política exterior}

La política exterior de los países latinoamericanos ha tenido como rasgo fundamental la búsqueda de autonomía. De acuerdo a Russel y Tokatlian (2013), entre los factores que influencian esta constante búsqueda se encuentran: la condición subordinada de estos países al sistema internacional y al orden económico mundial, así como su pertenencia al área de influencia de los EEUU (Russel y Tokatlian 2013).

Para el caso latinoamericano, resulta importante entender el rol detentado por la potencia hegemónica en el hemisferio, es decir, los EEUU porque de ello se derivan opciones de relacionamiento basadas en el acoplamiento, acompañamiento o aislamiento en materia de política exterior. Es decir, los países pueden optar por acciones tendientes al acoplamiento de la relación entre el país periférico con la potencia central para obtener protección por parte del hegemón respecto de un tercer país que represente una amenaza. Segundo, puede existir acompañamiento con el hegemón en cuanto a preconcepciones ideológicas o preferencias por tipos o patrones de desarrollo; o, tercero, puede ser que la clase gobernante de un país subordinado aproveche los recursos de poder de la potencia dominante para mantenerse como gobierno, relegando a un segundo plano el objetivo de autonomía (Becerra 2013: 11). 
Estas características se encuentran en mayor o menor grado en las relaciones que mantienen los países latinoamericanos con EEUU; con lo cual, la autonomía ha sido entendida como compitiendo con otros objetivos de política exterior. De acuerdo a Becerra (2013), quien realiza una tipología de las diferentes estrategias de los países latinoamericanos basado en la propuesta teórica de Russel y Tokatlian, se pueden percibir tres tipos de estrategias:

\begin{abstract}
Las estrategias de "acoplamiento", "acompañamiento" y "aislamiento" asignan una mayor importancia relativa a los beneficios económicos de la relación con Estados Unidos subordinando el objetivo de preservación de autonomía; la estrategia de "oposición selectiva" busca preservar espacios de autonomía, con el objetivo de reducir la dependencia (bajo esta estrategia existe colaboración selectiva con Estados Unidos, ya que es entendido como un poder dual, es decir, fuente de amenaza y de oportunidades); finalmente, la estrategia de "desafío" subordina a los objetivos de autonomía todo objetivo de mayor bienestar económico producto de una mejor relación con Estados Unidos (Becerra, 2013)
\end{abstract}

De acuerdo a Becerra, los aportes teóricos de diversos autores como Abernethy (1986), Womack (2006 y 2007), Johnson (1986), Russell y Tokatlian (2002), y Russell y Calle (2009), incorporan al debate de la autonomía algunas ideas clave y especificidades para entender las relaciones en la periferia, tales como:

- La importancia de la "perspectiva" en la configuración de las percepciones $y$, por ende, en el comportamiento de los agentes;

- el papel que cumplen tanto las condiciones materiales como las ideas en la determinación de las relaciones dominante-subordinado;

- la cartera de objetivos de política exterior que tienen los países periféricos (autonomía, bienestar económico y seguridad) y la disposición a subordinar uno de ellos a los otros,

- la necesidad de cooperación mediante la conformación de grupos de interés, foros, y hasta instituciones regionales, al nivel de las periferias, para avanzar objetivos de política exterior cuando sus intereses no están plenamente alineados con los del país dominante o hegemón;

- la posibilidad de que, en ciertas circunstancias, se generen incentivos para que el subordinado coopere con el dominante, a fin de alcanzar objetivos tanto de política exterior como de política doméstica, y 
- el carácter político y geográfico de las dinámicas centro-periferia, en donde tanto el comportamiento del centro como el de la periferia se encuentran mutuamente influenciados.

Estos postulados se encuentran estrechamente relacionados con los fundamentos teóricos de la teoría de la asimetría y la noción que se otorga a las "percepciones" de los agentes involucrados en dichas relaciones. En una relación asimétrica, el actor que ejerce mayor poder tenderá a actuar con falta de atención respecto de las entidades periféricas, mientras que el lado de menor poder tenderá a errores de exceso de atención (Becerra 2013: 9).

\section{Delimitación de principales postulados teóricos e hipótesis}

El acervo teórico que se deriva del Realismo Periférico, así como las estrategias de autonomía propias de las políticas exteriores emprendidas por los países latinoamericanos se revitalizaron en los albores del siglo XXI. Varios autores sostienen que el propósito autonómico continúa siendo consustancial, no solo a la identidad regional de los Estados, sino también como un elemento en la praxis de las políticas exteriores en su ámbito de proyección e inserción internacional (Briceño \& Simonoff, 2015). El análisis alrededor del interés autonómico en la periferia sigue siendo un tema complejo, pero uno de los mecanismos que aportan a su comprensión en la época contemporánea es su análisis en relación a un contexto político-económico históricamente situado.

Partiendo del método de contextualización histórica, se busca detallar las principales premisas que derivan de esta teoría y su vínculo con la idea de autonomía, con la finalidad de relacionar los conceptos que surgieron en contextos históricos diferentes y plasmarlos en función de las coyunturas internacionales contemporáneas. Este ejercicio permite caracterizar el marco en el que se desarrollan las políticas exteriores de los países latinoamericanos en los albores del siglo XXI, así como los cambios en los factores estructurales y domésticos que inciden en sus estrategias de inserción internacional. De igual manera, permite derivar las hipótesis generales que guían la investigación y que se desarrollan a lo largo de la tesis. 
Como se señaló anteriormente, uno de los postulados principales que se considera en el realismo periférico es la configuración de capacidades y relaciones de poder de los actores del sistema internacional. De esta relación se deriva la adopción de estrategias de política exterior de corte confrontativo o adaptativo. De acuerdo a Escudé, los Estados periféricos en su ejercicio de autonomía deben considerar no solo la capacidad relativa de confrontación, sino también el coste y riesgos de ejercer dicha capacidad dado que, para un Estado periférico, el coste relativo de una confrontación varía en función de su poder relativo y de la relevancia de cada confrontación (Escudé 2012: 105)

Sobre la base de la observación del rol de los Estados de centro en el sistema internacional y el margen de acción que les queda a los Estados periféricos en el marco de procesos de inserción internacional, se deriva la primera premisa relativa a la estructura del sistema internacional que es la distribución del poder mundial. Esto concierne a la naturaleza del sistema internacional en un determinado período que puede tomar tres modalidades: unipolaridad, bipolaridad y multipolaridad.

Los postulados subyacentes al realismo periférico fueron desarrollados en el contexto histórico determinado por la Guerra Fría, que consolidó una estructura bipolar de relacionamiento internacional, donde los países debían optar por alinearse a una de las dos potencias antagónicas: EEUU o la URSS. En un contexto marcado por la bipolaridad es plausible argumentar que la potencia en ascenso demande mayor alineamiento político por parte de los países periféricos para marcar su área de influencia, tal como se dio en el caso de los EEUU al implementar la Doctrina Monroe, cuando explícitamente pidió la exclusión de poderes extracontinentales en el hemisferio occidental (Neto y Malamud, 2015).

Por su parte, tras el colapso de la URSS y el reordenamiento del poder en una sola potencia hegemónica, la estructura internacional se redefine hacia el unipolarismo encabezado por EEUU. Por ello, en la época que va hasta finales del siglo XX, es posible señalar que las condiciones de alineamiento político para los países periféricos se relajan provocando como consecuencia mayor 
dispersión en el grado de alineamiento político hacia el poder hegemónico. Mientras que, a partir del siglo XXI la estructura internacional se vuelve multipolar, con lo cual, la distribución del poder mundial se traslada a varios polos consecuencia del ascenso de potencias emergentes.

Sobre la base de la relevancia teórica de este factor estructural se deriva la primera hipótesis:

H1. La estructura de distribución del poder mundial (unipolarismo, bipolarismo, multipolarismo) influencia el grado de alineamiento político de los países periféricos para con las potencias dominantes.

Otro de los postulados que se deriva de la teoría es el posicionamiento relativo de un Estado en la distribución del poder mundial. Se parte de la premisa de que el sistema internacional no es estático, ni estable, ni permanente, lo que da lugar al surgimiento de periodos inéditos o "cambios sistémicos" en el orden internacional. En este contexto se plantea la problemática de la reconfiguración del poder mundial y de los procesos de transición hegemónica. Para dar cuenta de estos procesos, dicha noción se observa de forma transhistórica, donde el foco se centra en el análisis de los cambios de la dominación o supremacía que un Estado ejerce sobre los otros.

El poder relativo de las potencias mundiales es más significativo que el poder individual de cada país periférico en el panorama internacional, con lo cual, el incremento relativo del poder de una potencia emergente permitiría a los países periféricos flexibilizar las relaciones de dominio con la potencia tradicional. Históricamente, se puede hablar de tres períodos de transición hegemónica. El primero sucedió entre 1810 y 1850 aproximadamente cuando el dominio español y portugués cayeron dando paso a la consolidación de la hegemonía británica. La segunda, sucede el dominio británico al estadounidense, en el periodo entre el comienzo de la Primera Guerra Mundial (1914) y el fin de la Segunda (1945). Actualmente, Wallerstein señala que China se está convirtiendo en la nueva potencia hegemónica global, pero asegura que está condenada a entenderse con la potencia en decadencia (EEUU), del mismo modo que Gran Bretaña y EEUU se entendieron después de 1945 (Wallerstein, 2017). 
La coyuntura de los albores del siglo XXI da cuenta de que la potencia emergente China y la potencia tradicional EEUU se encuentran en una relación de poder asimétrico decreciente, en términos económicos la asimetría se ha reducido sistemáticamente a favor del gigante asiático, mientras que en el plano militar y de defensa EEUU ocupa una posición ubérrima sin rival alguno en el horizonte (Bolinaga, pág. 22). El aumento relativo de poder por parte de China condicionaría la orientación de los países periféricos hacia la potencia emergente. De ello se deriva la segunda hipótesis relacionada con el poder relativo de los Estados en el escenario internacional.

H2. El declive relativo del poder de la potencia hegemónica disminuye la cohesión política de un país periférico para con dicha potencia, mientras que el apoyo se traslada a la potencia emergente.

El tercer factor que incide en las estrategias de relacionamiento de un Estado periférico para con una u otra potencia de centro es el grado de interdependencia económica. La lógica que subyace a esta proposición es que el aumento de relaciones comerciales con un Estado generaría mayores posibilidades de ganar adeptos políticos en la arena internacional. Esta premisa ha sido analizada ampliamente por Hirschman (1945) cuyo trabajo estudia las consecuencias del comercio para la política exterior; el autor demostró que el incremento del comercio y la dependencia comercial entre los Estados produce convergencia en la política exterior.

La literatura académica señala que cuanto más comercio existe entre los Estados, más costosas resultan las interrupciones a dicha relación comercial, por lo tanto, ambas partes tienen incentivos para converger en asuntos de política exterior, porque temen que las disputas de política externa puedan interferir con los beneficios del comercio (Hirschman, 1945). Esto conlleva mayores responsabilidades y riesgos al considerar las acciones de política exterior, con lo cual se deriva la siguiente hipótesis. 
H3. Mayor interdependencia comercial (aumento relativo del comercio bilateral) con una potencia mayor alineamiento político.

La cuarta premisa, hace referencia a los factores de agencia que son fundamentales para definir el relacionamiento de un Estado periférico con las potencias centrales. Esto se vincula con la idea de viabilidad nacional que informa sobre las condiciones que permiten, mas no garantizan, que un Estado pueda llevar a cabo un proyecto autonómico. De acuerdo con Puig (1980) y Jaguaribe (1979), dependerá de factores como el compromiso de las elites para llevar a cabo un proyecto autonómico, el grado de cohesión sociocultural, la existencia de un modelo de desarrollo interno, la relación existente entre los recursos humanos, naturales y tecnológicos de que dispone una nación, la capacidad del país para la integración regional. Siguiendo a Puig (1980), el rol de las élites nacionales es fundamental, debido a que la formación del "interés nacional" está construido por los grupos que logran integrar los círculos de toma de decisiones nacionales. En este sentido, las visiones del mundo o ideas sobre las Relaciones Internacionales armadas por las "élites nacionales" tienen una influencia determinante sobre la estrategia particular de la inserción internacional (Puig, 1980).

Particularmente en el contexto latinoamericano, el rol que cumplen las elites políticas resulta crucial en la adopción de las estrategias nacionales de Estado y en el proceso que adopta el país en su vinculación con socios internacionales. Existe consenso en la literatura académica que, en el caso particular de América Latina, las fuerzas de signo político de izquierda han sido las que más intensamente han buscado desafiar el statu quo y han buscado cambiarlo a través de la política exterior. De hecho, históricamente, las fuerzas de izquierda han sido tradicionalmente asociadas con el sentimiento de antiamericanismo. Lo que resulta relevante es que, en el área de la política exterior, se puede observar mejor el cambio en el accionar internacional mediante gestos simbólicos o declaraciones oficiales del ejecutivo o de las cancillerías (Neto y Malamud, 2015). Sobre esta base, se considera relevante plantear una hipótesis relacionada con la tendencia de la fuerza política dominante en los Estados latinoamericanos y su posicionamiento hacia las potencias mundiales. 
H4. El signo político de un Estado incide en la definición de tendencias de inserción internacional y estrategias de política exterior.

La quinta proposición hace referencia al rol del régimen político y su incidencia en las estrategias de inserción internacional de los países periféricos. Esta premisa deriva del análisis de los factores de agencia. La idea que subyace a esta selección es que mientras más cercanos estén dos países en el tipo de instituciones políticas hay más probabilidades de que tengan acciones similares en política exterior (Voeten, 2000). Con ello, se argumenta que la consolidación de un cambio de régimen o el establecimiento de mecanismos democráticos está íntimamente asociado a la idea institucional del Estado dominante en la relación de política exterior, es decir:

H5. Un régimen político democrático tendería a optar por estrategias de inserción internacional en línea con países que mantengan el mismo régimen político.

Sobre la base de estos postulados teóricos que se derivan del pensamiento latinoamericano en relaciones internacionales, específicamente el realismo periférico y la autonomía, se busca mostrar especificidades en las estrategias de inserción internacional de los países de la región en los albores del siglo XXI. Cada una de las proposiciones surgen de una base teórica sólida y enmarcan las acciones de política externa en el contexto internacional contemporáneo, donde los factores de estructura y de agencia se interrelacionan dando paso a posibles explicaciones sobre las opciones de política exterior de los Estados periféricos en la región.

\section{El método estructural sistémico: variables estructurales y de agencia}

Siguiendo la lógica de los postulados teóricos detallados anteriormente, en esta investigación se opta por el método estructural sistémico para el análisis de estrategias política exterior y su vinculación con el fortalecimiento de la CSS. Este enfoque metodológico parte de la premisa de que la realidad bajo objeto de estudio forma parte integral de un sistema más amplio cuyos componentes están 
articulados entre sí, no como una cadena de causas y efectos sucesivos, sino como una "causalidad circular", es decir que son fenómenos mutuamente relacionados e insertos en una totalidad que es la estructura del orden internacional (Palazuelos, 2015).

Al optar por este marco metodológico se busca hacer legible el resurgimiento de la CSS como mecanismo de la política exterior de los países periféricos como una de las unidades interactuantes del sistema internacional. Esto permite contextualizar los procesos "emancipadores" en el marco de las relaciones de poder asimétricas, que es la condición estructural donde los diferentes actores se interrelacionan. Es decir, considerando este marco dialéctico de elementos sistémicos y domésticos, la política exterior de los países periféricos suele tener márgenes de actuación estrechos, lo que permite explicar, en gran medida, sus distintas manifestaciones de autonomía-dependencia. Como señala Dallanegra, es en la estructura donde se debe "leer" cuáles son las características del funcionamiento del sistema, así como cuáles son los "parámetros de cambio" líneas de control intrahegemónicas- dentro de los cuales la política exterior es razonable, obteniendo más beneficios que costos (Dallanegra, 2008).

La operacionalización de este método se realiza a través de la identificación de variables dependientes e independientes y de indicadores que permiten de manera empírica dar cuenta del fenómeno estudiado. Para ello se consideran dos fases de análisis. En una primera instancia, la investigación propone la creación de un modelo de carácter explicativo, para lo cual se busca contrastar las hipótesis derivadas de la teoría que se encuentran detalladas en la sección precedente. La idea central es acercarse a los factores estructurales y domésticos que influencian la política exterior de los países latinoamericanos buscando caracterizar los alineamientos políticos para con la potencia hegemónica EEUU y para con China como líder de la CSS. En un segundo momento, la tesis se adentra en el estudio de caso a profundidad para lograr capturar las dinámicas de autonomía-dependencia en la política exterior de un país periférico, como es el caso del Ecuador en su relación con las dos potencias. 
Las variables tanto estructurales como domésticas y los indicadores para el entendimiento de la política exterior, que se consideran en las dos fases de la implementación de la metodología, se derivan de los fundamentos teóricos del realismo periférico, pero se buscó actualizarlos para su análisis en la época contemporánea del XXI. En cuanto a las variables de orden estructural se considera: a) la distribución del poder entre los Estados que puede ser cuantificada con indicadores relativos al poder económico y militar en la jerarquía internacional; b) el grado de interdependencia asimétrica con la potencia central que se muestra a través de indicadores como las exportaciones y diversificación de relaciones en función de la potencia central; y, c) la prioridad estratégica que le asigna la potencia central que se puede verificar a través del desarrollo de relaciones bilaterales. Por su parte, las variables domésticas están relacionadas al rol de las instituciones, las elites, y los actores sociales, que se puede observar a través de indicadores relativos a la opción política de las elites o la conformación del régimen de los Estados.

\subsection{Fase I. Modelo explicativo: variables e indicadores}

La primera fase de la investigación es de carácter explicativo porque busca conocer el peso de los factores estructurales y domésticos en las opciones de política externa de los países latinoamericanos en el marco de las actuales transformaciones del sistema internacional. Para efectuar este análisis se parte del establecimiento de variables dependientes e independientes que se usan en la construcción del modelo propuesto.

El objetivo principal que se busca en esta primera etapa es caracterizar la política exterior de los países periféricos. Para hacer operativo este ejercicio se considera relevante usar como proxi de las votaciones de los Estados en el seno de las AGNU. Varios autores revalidan el uso de este aproximamiento porque sirve como un indicador de la orientación general de la política exterior de los Estados en el sistema internacional. La literatura señala que las votaciones ayudan a identificar posiciones de los países en temas de política internacional en temas multilaterales o para analizar alineamientos regionales; además varios autores revalidan su uso, por ejemplo, Amorim es uno de los pioneros en el uso 
de la metodología cuantitativa para el análisis de la política exterior de Brasil (Lijphart, 1963; Selcher, 1978; Marín-Bosch, 1998, Amorim 2011).

De esto se derivan dos variables dependientes: el alineamiento de votos de los países latinoamericanos con EEUU y el alineamiento de votos con China. Para la operacionalización de las variables se toman en cuenta las resoluciones adoptadas en la AGNU, un total de 1906 votos, de $18^{15}$ durante el periodo 1970 a 2015. Este lapso temporal de análisis se seleccionó considerando el período cuando China continental ${ }^{16}$ recupera su poder de voto en lugar de Taiwán en el seno de las NNUU. Además, son los años para los cuales se logró consolidar bases de datos actualizadas y completas.

Dicho período histórico se lo analiza en tres etapas marcadas por los diferentes momentos de polaridad internacional, es decir: periodo de Guerra Fría (19761991), el de unipolaridad (1992-2002) y el de multipolaridad (2003-2015) porque permiten tener un acercamiento más aproximado a los cambios en las estructuras de poder a nivel internacional. En cuanto al procesamiento de los datos, se recurre a herramientas de análisis estadístico considerando relaciones bivariadas, regresiones lineales múltiples, y análisis factorial.

En lo que respecta a las variables independientes y de control, éstas también se derivan de los postulados teóricos relacionados al realismo periférico anteriormente mencionados. En este sentido, se consideran variables concernientes a la ideología del gobierno, la dependencia económica, la distribución del poder y el perfil democrático del gobierno, así como sus efectos en la política exterior. A continuación, se detalla la selección de cada una de las variables independientes y de control seleccionadas que permiten tener un acercamiento empírico al estudio de las estrategias adoptadas en política exterior por los dieciocho países analizados.

\footnotetext{
15 Se consideran los siguientes países: Brasil, México, Venezuela, Ecuador, Bolivia, Perú y Colombia, Argentina, Chile, Costa Rica, República Dominicana, Uruguay, Paraguay, El Salvador, Guatemala, Honduras, Panamá y Nicaragua.

${ }^{16}$ A través de la aprobación de la resolución 1668 en el seno de NNUU, en octubre de 1971, se reconoció a la República Popular de China (RPC) como "el único representante legítimo de China ante las Naciones Unidas" y expulsó "a los representantes de Chiang Kai-shek del puesto que ocupan ilegalmente en las Naciones Unidas".
} 
La primera variable independiente es la distribución del poder mundial, que hace referencia a la estructura histórica que enmarca la relación internacional entre los Estados. La posición del país en la jerarquía internacional del poder hace referencia al poder relativo o la proporción de poder mundial que detenta cada Estado en un periodo de tiempo determinado. En este aspecto se busca estudiar la intensidad con la que las potencias buscan alinear a los países periféricos al ámbito de sus intereses. Para operacionalizar esta variable se usa el índice CINC del proyecto Correlates of War (Singer, Bremer y Stuckey, 1972; Greig y Enterline, 2017) que mide de 0 a 1 el nivel de poder de un Estado a partir de seis componentes: producción de hierro y acero, gasto militar, personal militar, consumo de energía primaria, población total, y población urbana.

$$
\mathbf{C I N C}_{\mathbf{P W i n d e x}}=\frac{\text { milper }+ \text { milex }+i r s t+p e c+t p o p+u p o p}{1}
$$

La segunda variable es el rol de la ideología como eje fundamental para comprender las luchas políticas en la región. Para la primera fase del análisis se considera la relevancia de esta variable ya que las votaciones en la AGNU tienen una dimensión normativa, lo que permitiría informar sobre las posturas relativas y posicionamiento ideológico ante diversos temas como los derechos humanos o la intervención por motivos humanitarios. Para construir esta base de datos se utilizan los datos de ideología y partidos políticos de Murillo, Oliveros y Vaishnav (2010), quienes miden en una escala de 1 a 5 , los posicionamientos ideológicos de los gobiernos a partir de las políticas implementadas y promovidas en los programas electorales, siendo 1 izquierda, 2 centro izquierda, 3 centro, 4 centro derecha y 5 derecha.

La tercera variable independiente es el tipo de régimen político que permite cuantificar el desarrollo democrático de un país año tras año. El indicador que se utiliza es el Polity IV, índice que va de -10 a 10, donde -10 es el menor grado de democracia o de mayor autoritarismo y 10 el grado más alto de democracia, caracterizando la naturaleza y el Estado actual de gobierno de un país (Marshall y Jaggers, 2008; Marshall, Monty y Gurr, 2015). La cuarta variable es de tipo 
económico y busca entender el rol de la interdependencia comercial entre los países y su posible influencia para generar adeptos políticos.

Para hacer más robusto el análisis, se optó por incluir dos variables de control. Por un lado, con relación a la variable del poder, se incluye el poder relativo de cada uno de los Estados sobre el grado de convergencia en la AGNU. La idea es verificar en qué medida el declive relativo de EEUU incide en el análisis de los 18 Estados de la región y se usa la misma base de datos de CINC. Otra de las variables de control relacionada a la asimetría del poder es la AOD, considerando que esto puede servir de instrumento para acercar posiciones en las votaciones de la AGNU.

Se toma como indicador las trasferencias de AOD como porcentaje del Producto Bruto Nacional realizadas por las potencias extranjeras hacia el país latinoamericano con el cual se analiza la convergencia. La información sobre flujos de AOD fue extraída de la base de datos del Development Assistance Committee de la Organización para la Cooperación y Desarrollo Económicos (OCDE), mientras que los datos de China se extrajeron de AidData. Finalmente, se agrega el PIB per cápita obtenido con datos del BM, que permitirá controlar los efectos de los flujos económicos entre los países. La inclusión de estas variables de control tiene la finalidad de reducir el efecto sobre la variable dependiente y definir el verdadero impacto de las variables independientes.

El modelo propuesto permite capturar de manera empírica el alineamiento de las políticas exteriores de los países latinoamericanos durante los cuarenta y cinco años analizados, haciendo énfasis en el análisis a partir del año dos mil cuando la presencia de China se hace más relevante en la región, al tiempo que los EEUU se enfocan en su política internacional en otras regiones del mundo. El alineamiento político de los países para con uno $u$ otro actor es un indicador de la búsqueda de autonomía a través de la diversificación de relaciones no solo económicas sino a nivel político que los países latinoamericanos, especialmente los de corte progresista, buscaron en su relacionamiento con el gigante asiático. 


\subsection{Fase II: Estudio de caso. La CSS en la política exterior del Ecuador}

El modelo cuantitativo de análisis de la política exterior de los países latinoamericanos nos permite tener una idea generalizada del peso de los factores estructurales y domésticos que inciden en el ejercicio de su política externa, a la vez que da cuenta de las tendencias de los países a alinearse con sus socios internacionales. Sin embargo, este modelo resulta insuficiente para detallar las dinámicas locales de autonomía y dependencia que las relaciones Sur-Sur pueden estar generando en el interrelacionamiento de los países periféricos de la región latinoamericana con los nuevos socios del Sur. Para complementar el análisis, esta investigación se plantea el desarrollo de un estudio de caso a profundidad.

Resulta importante resaltar que el caso de Ecuador es un ejemplo paradigmático y poco estudiado en la literatura académica, que permite ejemplificar la búsqueda de autonomía y el interés nacional a través del fortalecimiento de las relaciones de cooperación Sur-Sur. Como se señaló anteriormente, se elige este caso de estudio porque la política exterior del país andino ha estado históricamente marcada por su condición de Estado periférico y por su posicionamiento subordinado en la relación que mantiene con los EEUU. Sin embargo, a partir de la llegada a la presidencia del economista Rafael Correa en el año 2006 la perspectiva de posicionamiento del Ecuador en el mundo cambia. La literatura especializada coincide en que el país se propuso escalar la estratificación sistémica desafiando al statu quo buscando un lugar propio en el mundo a través de la diversificación de relaciones políticas y económicas con el Sur Global.

Se define la temporalidad del estudio de caso durante el periodo 2000 al 2015 porque este lapso permite caracterizar tanto el giro en la política exterior del país con el ascenso de Rafael Correa a la presidencia de la república en el año 2006, como entender dichos clivajes a la luz de lo que sucedía en el Ecuador en años anteriores. Con la llegada de Correa al poder, la política internacional del país andino puso como eje central de su administración el interés nacional enfatizando en el establecimiento de políticas que "multipliquen los nexos SurSur y cimienten la diversificación de sus relaciones exteriores" (Senplades 2013- 
2017). La finalidad fue llevar a cabo un modelo de desarrollo basado, en lo económico, en la menor dependencia de los bienes primarios que exporta al mundo, concentrados en unos pocos socios tradicionales como EEUU y la UE. Mientras que en el ámbito político buscó tomar distanciamiento de los países del Norte y fortalecer relaciones con socios del Sur Global, convirtiendo a China en socio estratégico y financista de su desarrollo.

Para el abordaje de esta fase de estudio de caso se recurre a una serie de herramientas de análisis de carácter cualitativo y cuantitativo que permiten el procesamiento de la información. Resultan particularmente útiles los datos recabados a través de conversaciones con investigadores especializados en la temática en Ecuador y la participación en diferentes congresos internacionales donde se discutió los principales postulados de esta tesis. De igual manera, se recopiló información a través de la realización de entrevistas semiestructuradas focalizadas a funcionarios públicos de alto nivel, quienes ejercieron sus funciones durante el período de Correa. Esto se realizó durante los meses de enero y febrero de 2018 en la ciudad de Quito. Además, para la consolidación de las bases de datos, se hizo uso de fuentes oficiales de información tanto gubernamentales como de organismos internacionales e instituciones académicas.

Siguiendo la lógica que se deriva de los postulados teóricos del Realismo Periférico y con el afán de caracterizar las dinámicas de CSS en el ejercicio de la política exterior del Ecuador el estudio de caso adopta un planteamiento holístico de carácter interpretativo, que se diseña a través de la selección de elementos teóricos y conceptuales como mecanismos orientativos. Esto permite capturar, a través del uso de datos empíricos, las dinámicas de autonomía y dependencia del país en su relacionamiento externo tanto con EEUU (la potencia hegemónica tradicional) como con China (la potencia emergente del Sur Global). Para ello, se procede de la siguiente manera.

Primero, se realiza una contextualización de la política exterior del Ecuador en el marco de la teoría propuesta, para lo que se retoma las variables estructurales y domésticas que definen la política externa del país andino. Esto ubica el análisis 
en un marco histórico determinado y permite situar el panorama general de la política exterior ecuatoriana en el mundo. Posteriormente, se detallan los factores de ruptura que se pragmatizan en ejercicio de la política internacional una vez inaugurado el gobierno de la Revolución ciudadana enfatizando en la relevancia que adquiere el fortalecimiento de las relaciones de cooperación SurSur para el país.

Una vez situada la política exterior del Ecuador en el marco histórico específico se procede al análisis de la política externa en relación a la potencia hegemónica de EEUU y a la potencia emergente de China. Estas dos variables son centrales para dar luz sobre los conceptos de autonomía y dependencia que se derivan del Realismo Periférico. La literatura especializada señala que no resulta fácil capturar las dinámicas de autonomía y dependencia en el ejercicio de la política internacional de los países; sin embargo, el uso de ciertos indicadores puede ayudar caracterizar este relacionamiento.

En el caso de la dependencia, se usará este concepto para dar cuenta de la dimensión económica buscando comprender la subordinación de los Estados a modelos primario exportadores de inserción internacional, que se puede visualizar en el grado de diversificación de socios comerciales y de composición de la canasta exportadora. Para ello resulta relevante comprender las estructuras económicas del país y comparar los cambios en su composición a la luz de la narrativa desarrollista que imprime la llegada de un gobierno de corte progresista al poder. En este sentido, el estudio de caso se enfoca en comprender los derroteros económicos que se plantea el país, a través de indicadores como la evolución de las exportaciones e importaciones de bienes y servicios; la diversificación de socios comerciales, la balanza comercial de bienes y servicios. El trasfondo radica en contrastar si la apuesta por fortalecer la cooperación con socios del Sur Global ayuda a superar la base primario exportadora del Ecuador o si a su vez reproduce los mismos patrones de relacionamiento que la cooperación con socios tradicionales. Es decir ¿el fortalecimiento de las relaciones de tipo Sur-Sur que impulsó el Ecuador contribuyeron a reducir su dependencia económica? 
Los dos principales indicadores que se examinan de manera detallada para caracterizar las dinámicas de dependencia del Ecuador son: el IVCR y el índice Balassa. Estos indicadores permiten entender el tipo de relaciones que se promueve en los intercambios comerciales, es decir, su especialización primario exportadora o su grado de reprimarización y la dirección de los flujos de comercio, es decir si el comercio va en una sola dirección o no (Álvarez y Durán Lima 2008: 25).

El índice IVCR se usa para entender las ventajas o desventajas comparativas de los intercambios comerciales de un país con sus socios comerciales. Para ello, se mide el total de las importaciones y exportaciones del Ecuador a los mercados de EEUU y de China, para delinear de manera general la tendencia importadora o exportadora del Ecuador en relación a los dos mercados. Con el índice IVCR, un resultado igual a -1 revela especialización total en cuanto a las importaciones; mientras que si el índice es igual a 1 la especialización exportadora es total y si el valor es cercano a 0 entonces hay un comercio bidireccional.

Por su parte, el Índice Balassa mide el grado de importancia de un producto dentro de las exportaciones de un mercado a otro mercado, versus la importancia de las exportaciones del mismo producto en las exportaciones del mismo producto hacia el mundo. A este índice se lo conoce también como IVCR de las exportaciones y se expresa de la siguiente manera (Álvarez y Durán Lima 2008: 25), donde:

$$
I B_{i j}^{k}=\frac{X_{i j}^{k} / X T_{i j}}{X_{i w}^{k} / X T_{i w}} \quad \begin{aligned}
& X_{i j}^{k}=\text { Exportaciones del país } j . \\
& X T_{i j}=\text { Exportaciones totales del país } i \text { al país } j \\
& X_{i w}^{k}=\text { Exportaciones del producto } k \text { realizadas por el país } i \text { hacia } i \text { hacia }
\end{aligned}
$$

el mundo $(w)$

$X T_{i w}=$ Exportaciones totales del país $i$ al mundo $(w)$

Para el análisis específico de los mercados de China y de EEUU, se utiliza el índice Balassa con algunas variaciones, siendo la fórmula la siguiente: 
$I B=\left[\frac{X_{i-\text { China a }}^{k} / X T_{\text {iw }}}{M T_{\text {China }-i t} / M T_{\text {China - -w }}}\right]$

$I B=\left[\frac{X_{i-E E . U U}^{k} / X T_{i w}}{M T_{E E . U U .-i} / M T_{\text {EE.UU.-w }}}\right]$

Donde:

$X_{i \text {-China }}^{k}=$ Exportaciones del país $i$ hacia China/ EEUU del producto $k$;

$X T_{\text {iv }}=$ Exportaciones totales del país $i$ al mundo $(w)$;

$M T_{\text {China }-1}=$ Importaciones totales de China/ EEUU desde el país $i$;

$M T_{\text {China }--w}=$ Importaciones totales de China/ EEUU desde el mundo $(w)$.

Estos dos índices se analizan de manera detallada en el capítulo $\mathrm{V}$ de la investigación, donde se provee las tablas y modelos utilizados para caracterizar la categoría de dependencia del Ecuador en relación con la potencia hegemónica de EEUU y la potencia emergente de China.

Por otra parte, en cuanto a la autonomía, este es un concepto de carácter político que hace alusión a los márgenes de acción que un país puede tener para llevar a cabo su visión de desarrollo y se puede identificar de manera relacional comparando las acciones del país periférico para con las dos potencias analizadas. Para su comprensión, la literatura especializada señala que se debe enmarcar a todas las acciones en el marco amplio en el que se desarrollan dichas acciones autonómicas. Es decir, el contenido de la política es menos importante que el contexto en el que se desarrolla y el estímulo al que responde, por lo que, el criterio sobre el procedimiento adquiere relevancia -si la política se desarrolla fuera del contexto de dependencia basta para ser clasificada como una política autónoma (Hey, 1993).

Entre los indicadores puede considerarse los tratados de cooperación con países vecinos, visitas diplomáticas a líderes políticos afines, políticas que avocan a principios universales como los derechos humanos o la protección del medio ambiente, alineamientos políticos con una u otra potencia, entre otros. Siguiendo como proxi de la política exterior el análisis de las votaciones en el seno de la 
AGNU, esta parte del estudio de caso se enfoca en comprender el grado de alineamiento político que implica el fortalecimiento de las relaciones con el Sur Global, específicamente con China y EEUU. La idea central es analizar el alineamiento de votos del país andino y señalar si la influencia de China en la región muestra alcances político-estratégicos.

Este ejercicio permite tener una idea más amplia de la forma en que votaba el Ecuador antes de que China fuese uno de sus principales socios comerciales a inicios de la década del 2000, y cómo lo hace en los años recientes cuando la cooperación económica podría estar derivando en influencia en el ámbito político. En este sentido, si bien el estudio de la categoría de la dependencia da luz sobre el incremento de intercambios económicos bilaterales y el tipo de relaciones que se promueve, la categoría de la autonomía nos ayuda a comprender si este incremento comercial se correlaciona con una mayor incidencia política, medida a través de la coincidencia de votos en NNUU.

Para ello, se observa el posicionamiento del Ecuador en relación a la postura política de China como de los EEUU, recurriendo al análisis votaciones en la AGNU, durante siete períodos que corresponden desde la sesión 55 a la 69, que se llevan a cabo entre los años 2000 a 2014 (año hasta el cual se puede encontrar datos actualizados y completos). Las temáticas que se consideran en el estudio son las siguientes: conflicto palestino (ME), armas y material nuclear $(\mathrm{NU})$, colonialismo (CO), derechos humanos (HR), desarrollo económico (CE), control de armas y desarme (DI).

En el aspecto metodológico, se elaboró una base de datos -tipo panel- que contempla en total 489 resoluciones, que dan lugar a 2916 votaciones. Esta base se desagrega considerando únicamente las resoluciones y votos clasificados como "importantes" (según las publicaciones del Departamento de Estado) para EEUU siendo un total de 214 resoluciones y 642 votos. En cuanto a la contabilización de los votos se opta por la propuesta de Lijphart (1963), retomada por Voeten (2015), quien calcula porcentaje de votos idénticos emitidos por los países a analizar: se codifica como 1 si es coincidente y 0 si el voto es en cualquier otro sentido (vota si y si, vota no y no, se abstienen). Esto permite 
caracterizar áreas sensibles en cuestiones internacionales y los giros que se dan en el ejercicio de la política internacional.

Finalmente, el estudio de caso a profundidad se revela como elemento útil para caracterizar la política exterior de un país periférico como el Ecuador durante el período 2000-2015 y permite comprender las dinámicas de autonomía y dependencia que se reproducen en línea con el fortalecimiento de las relaciones con socios del Sur global. Esto permite dar luz al entendimiento de las dinámicas de CSS que se establecieron en la región sudamericana en los albores del siglo XXI.

\section{Recapitulación}

El presente capítulo tuvo la finalidad de sentar las bases teóricas y metodológicas que permiten comprender el resurgimiento de la CSS como mecanismo de la política exterior y las relaciones que reproduce en los países latinoamericanos en los albores del siglo XXI. Para ello, la investigación considera relevante retomar el pensamiento latinoamericano en materia de relaciones internacionales elaborado en la región como marco teórico para abordar el objeto de estudio. En este sentido, se recurre a las contribuciones del Realismo Periférico y del pensamiento autonómico para entender la política exterior en la periferia.

El argumento que se sostiene a lo largo de la tesis es que los países periféricos retoman la narrativa reivindicativa de la CSS y la plasman en el ejercicio de la política exterior como mecanismo que apuntala la consecución de mayores márgenes de autonomía y de reducción de dependencia de las potencias centrales. Para captar estas dinámicas, el capítulo se enfoca primero en entender los principales postulados teóricos y las variables tanto dependientes como dependientes que se derivan de la teoría adoptada; pero se va más allá, al buscar enmarcar su análisis en el contexto contemporáneo en el que se desarrollan las acciones de política exterior analizada, es decir para el periodo 2000-2015. 
Posteriormente, sobre la base de una propuesta teórica sólida se definen tanto los factores estructurales como de agencia que permiten caracterizar el ejercicio de política internacional en los países latinoamericanos y específicamente el caso de Ecuador. De este ejercicio se derivan cinco hipótesis principales que guían la investigación y se definen los indicadores empíricos para su análisis. Consecuentemente con el modelo propuesto, se considera relevante adoptar el método estructural sistémico para desarrollar la investigación.

Metodológicamente el análisis se divide en dos fases. Una primera etapa se enfoca en un análisis de tipo explicativo, que permite entender la reconfiguración de poder a nivel internacional y caracterizar de manera general el alineamiento político de dieciocho países de la región latinoamericana en referencia con la potencia hegemónica EEUU y con la potencia emergente China. Para ello se recurre como proxi de la política exterior a las votaciones en el seno de la AGNU y a una serie de indicadores de tipo estructural y domestico que inciden en la política exterior.

En una segunda fase, se realiza un estudio de caso único y a profundidad tomando en cuenta el caso paradigmático de Ecuador. Esto permite enfocarse en un análisis detallado de las categorías de autonomía y dependencia en un periodo específico. Para ello, primero se recurre al estudio de los factores estructurales y domésticos que sirven para ubicar la política exterior del país en el marco más amplio del sistema internacional. Posteriormente, se detallan los factores de dependencia considerando el Índice VCR y el índice Balassa y se analiza la categoría de autonomía usando de manera empírica las votaciones del país en las NNUU en 6 diferentes áreas.

Esta combinación permite contar con una base teórico y empírica sólida que ayuda a comprender, por una parte, la apuesta de los países periféricos por fortalecer sus relaciones de cooperación Sur-Sur y los factores que inciden en el ejercicio de su política exterior; y por otra, da pie al análisis específico de las dinámicas de autonomía y dependencia que se pueden observar en el caso de la política exterior del Ecuador. 
En el Anexo 1, se presenta una síntesis del modelo analítico que se construye para el desarrollo de la investigación. Se detallan las principales hipótesis derivadas del Realismo Periférico, las fases de investigación y las variables dependientes, independientes y de control; al igual que las fuentes empíricas que se operacionalizan para el entendimiento de la política exterior de los países latinoamericanos y del caso de estudio de Ecuador. 


\section{CAPÍTULO IV: LA POLÍTICA EXTERIOR EN AMÉRICA LATINA ANTE LA POTENCIA HEGEMÓNICA DE ESTADOS UNIDOS Y LA POTENCIA EMERGENTE DE CHINA.}

\section{Discusión}

La estructura del sistema internacional actual se encuentra en procesos de profunda transformación que traen como consecuencia la reconfiguración de la pirámide del poder mundial. Uno de los cambios más trascendentes radica en el mayor protagonismo de los países emergentes y del Sur Global, que ubican a la región de Asia Pacífico y en particular a China en el centro de atención de la política y la economía mundial. Su ascenso mueve los cimientos del tradicional eje del Atlántico Norte compuesto por EEUU, Europa y Japón, sobre el que se fundamenta el sistema internacional actual, y articula tendencias en cuanto a la promoción del multilateralismo e institucionalismo, demanda mayor poder de decisión sobre los asuntos mundiales y persigue una redefinición de los organismos internacionales.

El resurgimiento del gigante asiático implica el mayor desafío al orden mundial existente desde finales de la Guerra Fría (Li, 2010) porque ha puesto en disputa el liderazgo hegemónico detentado por EEUU. De acuerdo a Li, el ascenso de China es cada vez más comparable al antiguo papel de los EEUU como un "país indispensable" en el mundo ( $\mathrm{Li}, 2010)$. Su ascenso se fundamenta en un crecimiento económico sostenido que le ha llevado a ganar mayor participación en el mercado global, así como en el fortalecimiento de su poder militar y su rol de líder geoestratégico. Lo novedoso de este proceso de transición es que China se posiciona en el sistema internacional bajo los principios de un "ascenso pacífico" y promueve una retórica en la que se mira como un país en vías de desarrollo, que prioriza las relaciones Sur-Sur y busca asociaciones estratégicas con poderes emergentes como los BRICS, que han servido como paraguas de protección de sus políticas de expansión global (Bernal-Meza 2016: 64).

La reconfiguración de las relaciones entre el auge y caída de grandes poderes nunca es sencilla y condiciona la orientación de la política exterior de los Estados 
periféricos (Modelski 1983; Kennedy 1994). Las estrategias de estos países hacia las grandes potencias suelen estar condicionadas, por un lado, por factores estructurales relacionados con el poder y su distribución en el escenario internacional y por otro, debido a cuestiones domésticas concernientes al rol de las élites, las instituciones y factores sociales. Los países de América Latina no escapan a las dinámicas de latente reconfiguración el nuevo orden mundial y han debido reorientar sus estrategias de inserción internacional. Su condición estructural de subordinación tanto al sistema internacional como al orden económico mundial, sumado al hecho de pertenecer al área de influencia de los EEUU, han determinado los fines y estrategias en la formulación de la política exterior latinoamericana (Rusell y Tokatlian, 2013).

A partir de la primera década del siglo XXI, los países latinoamericanos experimentaron un cambio de ciclo marcado por el recambio de elites políticas que buscaron dar un "enfoque asertivo a la política exterior latinoamericana" (Gardini y Lambert, 2011) y apostaron por el fortalecimiento de las relaciones con socios del Sur, el regionalismo y el apoyo al multilateralismo para su inserción internacional (Dabène, 2012). A la par de un crecimiento económico boyante, con China como principal socio comercial, los países de la región, principalmente los sudamericanos auparon el retorno de proyectos desarrollistas y revitalizaron su tradición autonómica -que con variedad de grado e intensidad ha dado lugar a políticas exteriores contra-hegemónicas (Sanahuja, 2016; Domínguez, 2018).

Este contexto definió los nuevos alineamientos geopolíticos que concurrieron como péndulos entre el poder dominante y las fuerzas anti sistémicas, donde los países periféricos tuvieron que redefinir sus estrategias de vinculación, haciendo el mejor uso de sus recursos para mejorar sus relaciones con el poder en ascenso sin desafiar a la potencia dominante, por medio de alternativas de alineamiento o de autonomía. El esquema latinoamericano de los albores de este siglo, basado en el retorno de la política, el Estado y el desarrollo (Serbín, 2017:83), dio pie al incremento de cuestionamientos a la hegemonía estadounidense en el hemisferio, y buscó excluirla diversificando sus relaciones externas en la multipolaridad. Esto ha dado paso a la generalizada percepción 
de que las crecientes interacciones entre China y América Latina, específicamente con Sudamérica, dinamizadas por la economía y la promoción de relaciones horizontales o Sur-Sur, habrían implicado a la vez, un mayor grado de cohesión política de la región a favor del gigante asiático y en detrimento de EEUU.

En este marco, cabe preguntarse, ¿qué factores influencian la política exterior de los países latinoamericanos en la época contemporánea? A lo largo de este capítulo, se busca explicar y caracterizar el alineamiento político de dieciocho países latinoamericanos hacia las grandes potencias desde la perspectiva de una relación triangular: América Latina, EEUU, y China. De esta manera, se busca verificar empíricamente la hipótesis de que los países latinoamericanos tendieron a alinearse políticamente con el país asiático alejándose de EEUU. Si bien existen diversos estudios de índole económico-comercial sobre el relacionamiento de la región con China, las estrategias de cohesión política han sido menos exploradas por la literatura especializada.

Para efectuar este análisis se desarrollan las categorías analíticas, las hipótesis y el modelo propuesto en el capítulo metodológico, que se deriva del Realismo Periférico, para el análisis de la política exterior de los países latinoamericanos. Para ello, se toma como eje central los factores estructurales y de agencia relacionados al ejercicio de la política exterior de los países periféricos. Lo anterior permite informar sobre el peso de los factores como la ideología, la interdependencia económica, la distribución del poder y el perfil del gobierno en la política exterior. Una manera de operacionalizar la variable dependiente es a través del posicionamiento de los Estados en las votaciones de la AGNU, que es "el gran foro para el debate general sobre los principales problemas de la humanidad" (de Seixas Corrêa, 2013) y se toma como base las votaciones de los países latinoamericanos desde $1970{ }^{17}$ a 2015, otorgando especial atención al análisis de patrones de alineamiento con China a partir del año 2000.

17 China forma parte de las NNUU desde el 26/10/1971 con la Resolución 2758 (XXVI) "Restauración de los derechos legítimos de la República Popular de China en las Naciones Unidas" 
El capítulo que se muestra a continuación se organiza de la siguiente manera. Después de esta introducción, se detallan los principales fundamentos teóricos e hipótesis propuestas en la investigación, contextualizándolas al ámbito latinoamericano. El siguiente apartado es de carácter explicativo y muestra los factores que influencian la política exterior latinoamericana. Posteriormente, se testean las hipótesis y se corren los principales modelos de regresión. Finalmente, se ofrecen los principales hallazgos y conclusiones de carácter descriptivo y explicativo ${ }^{18}$.

\section{2. ¿Qué factores influencian la política exterior en América Latina? Principales hipótesis}

El surgimiento de Estados emergentes y nuevas potencias mundiales, que se hace más patente a partir de la primera década del siglo XXI, trajo aparejado un cambio en la concepción de la política internacional y del rol de los Estados periféricos en el sistema internacional. Existe consenso en que las transformaciones de las relaciones de poder sobre las cuales se asienta el orden mundial actual están dando paso a un escenario más multipolar, donde la hegemonía detentada por EEUU se ve cuestionada por la asertiva presencia de China.

De acuerdo a los postulados teóricos del realismo periférico, las opciones de inserción internacional de los Estados débiles se encuentran marcadas en virtud de las dinámicas que desarrolla con los Estados de centro. Esto define estrategias de política exterior que fluctúan entre la búsqueda de mayores márgenes de autonomía y de relaciones de dependencia para con las potencias centrales, en virtud de su posicionamiento en una estructura determinada. Por lo que resulta relevante entender el momento histórico en el que se define una política exterior y las estrategias autonomizantes por las que optan los Estados. De acuerdo a Cox, "el marco de acción cambia con el tiempo y tiene la forma de

\footnotetext{
${ }^{18}$ Algunas partes de este capítulo forman parte del artículo en proceso de revisión: Zapata, S. y Martínez, A. (2020). La política exterior latinoamericana ante la potencia hegemónica de Estados Unidos y la potencia emergente de China.
} 
una estructura histórica, una combinación particular de patrones de pensamiento, condiciones materiales e instituciones humanas, que tiene cierta coherencia entre sus elementos" (Cox 1981).

La literatura académica señala que las estructuras internacionales han adquirido particularidades específicas durante los últimos cincuenta años, por lo que no es lo mismo optar por estrategias de inserción internacional durante la época de la Guerra Fría que en una época de unipolarismo o multipolarismo. En el caso particular de los Estados latinoamericanos, la estructura internacional hace referencia no solamente a la capacidad de neutralizar el riesgo proveniente de terceros países, dotados de suficiente capacidad para ejercer sobre él formas eficaces de coacción, sino también, a la adopción de estrategias para el establecimiento de alianzas, potencial de recursos humanos y el grado de cohesión socio cultural de un país (Jaguaribe 1979: 22).

En el contexto de la Guerra Fría, la política exterior de los países en la región estuvo marcada por el relacionamiento de los Estados periféricos a una estructura internacional dicotómica, donde se debía tomar un posicionamiento claro de alineamiento ante una de las dos potencias mundiales antagónicas EEUU o la URSS. Lo que mejor caracteriza a esta época en América Latina es la reivindicación de la doctrina Monroe por parte de Truman, cuando afirmó que "hay un plan Marshall para el hemisferio occidental durante el siglo y medio [Es] conocido como la Doctrina Monroe" (Reid, 2009). Sobre esta base, EEUU marcó su hegemonía en la región latinoamericana que representa además su esfera de influencia directa.

En este sentido, en un panorama marcado por la bipolaridad es plausible argumentar que la potencia en ascenso demande mayor alineamiento político para marcar su área de influencia, tal como se dio en el caso de los EEUU al implementar la Doctrina Monroe, cuando explícitamente pidió la exclusión de poderes extracontinentales en el hemisferio occidental (Neto y Malamud, 2015). Esto perfiló la poca tolerancia a cualquier modelo de desarrollo alternativo al que promulgaba la democracia liberal de estilo estadounidense (Agüero Javier, 2016). 
Tras el colapso de la URSS y el reordenamiento del poder en una sola potencia hegemónica, la estructura internacional se redefine hacia el unipolarismo encabezado por EEUU. En esta época que va hasta finales del siglo XX, es posible señalar que las condiciones de alineamiento político para los países periféricos se relajan provocando como consecuencia mayor dispersión en el grado de alineamiento político hacia el poder hegemónico. Así, iniciada la década de los noventa, la región privilegia la cooperación sistemática entre los Estados Latinoamericanos a través de procesos de regionalismo abierto y se busca apoyar la creación de "polos de poder alternativos" para enfrentar el orden unipolar estadounidense (Briceño, 2011).

Por su parte, el nuevo milenio inaugura una estructura multipolar cada vez más latente caracterizada por la distribución del poder en varios polos, como consecuencia directa del ascenso de potencias emergentes al centro del poder internacional. El ascenso de China al rango de potencia mundial es el rasgo más sobresaliente de la época contemporánea porque marca una tendencia en la adopción de políticas exteriores que enfatizan en la promoción de la cooperación Sur-Sur para así distanciarse de los tradicionales Estados hegemónicos. Una de las características de este multipolarismo es la creación de "polos de poder alternativos" a la hegemonía norteamericana y el "giro hacia el Sur". En la región latinoamericana esto se visualiza a través de la búsqueda de una política exterior más autónoma e independiente, capaz de impulsar modelos de desarrollo alejados del modelo neoliberal propuesto por EEUU.

Sobre la base de estos postulados teóricos contextualizados para el estudio de la política exterior latinoamericana, la primera hipótesis que se busca probar es la siguiente:

H1. La estructura de distribución del poder mundial, definida en periodos de unipolarismo, bipolarismo, multipolarismo, influencia en el grado de alineamiento político de los países periféricos para con las potencias dominantes. 
Otro factor relevante en línea con las premisas teóricas sobre las que se basa esta investigación y que incide en los procesos de inserción internacional de los países periféricos es el posicionamiento o poder relativo de un Estado en el escenario internacional. De este postulado se deriva que el aumento relativo de poder por parte de China en la región latinoamericana a partir de la primera década del siglo XXI, condicionaría la orientación política de los países periféricos hacia la potencia emergente. esto principalmente, porque China desembarca en la región latinoamericana con un discurso político basado en la no injerencia en asuntos internos y con fuertes inversiones económicas. Esto da la posibilidad a los países de la región de contar con alternativas a la hegemonía tradicionalmente ejercida por Norteamérica.

Adicionalmente, la literatura señala que el poder relativo de la potencia hemisférica tradicional ejercida por EEUU se encontró mermada debido a que sus prioridades de política exterior de inicios del nuevo milenio se enfocaron en otras regiones fuera de América Latina. A raíz de los atentados del 11 de septiembre de 2001 EEUU inaugura una nueva etapa de relacionamiento con el mundo y da un giro en su política exterior que trae repercusiones directas para la región latinoamericana -su zona de influencia natural. De acuerdo a varios analistas, EEUU "abandonó la región" para dar prioridad a otras zonas geográficas como Medio Oriente, Europa o Rusia donde se encontraban asuntos críticos de su política exterior como por ejemplo la guerra iniciada en Irak y Afganistán.

De esto se colige que la prioridad estratégica que EEUU da a una subregión, a ciertas alianzas o a diversos procesos de integración no son homogéneos en cada momento histórico. De hecho, la proyección de la potencia norteamericana también se adecua al contexto de transformación internacional y a las tendencias globales en cada periodo histórico, lo que deja espacio para que los países periféricos opten por políticas tendientes a la diversificación de sus relaciones comerciales y mayores vínculos políticos con diversos actores; en palabras de Borón, "deja espacio para las luchas contra-hegemónicas de los pueblos y de los gobiernos que se oponen a la dominación" (Borón, 2014). 
En el caso de los países latinoamericanos, sus políticas exteriores y de inserción internacional a partir del nuevo milenio estuvieron marcadas, por una parte, por el declive relativo de la potencia hegemónica de EEUU, coincidente con su menor presencia en la región, y por la creciente presencia de China. Sin embargo, es importante recalcar que EEUU sigue siendo la principal potencia mundial, el centro económico financiero, político e ideológico y cultural a escala global. Sobre esta base del declive de poder relativo de la potencia hegemónica se plantea la siguiente hipótesis:

H2. El declive relativo del poder de la potencia hegemónica disminuye el alineamiento de los votos latinoamericanos con EEUU, mientras que el aumento relativo del poder de la potencia ascendente aumenta el alineamiento de votos latinoamericanos para con China.

La tercera variable derivada de la teoría hace alusión a la interdependencia económica. La literatura académica señala que cuanto más comercio existe entre los Estados, más costosas resultan las interrupciones a dicha relación comercial, por lo tanto, ambas partes tienen incentivos para converger en asuntos de política exterior, porque temen que las disputas de política externa puedan interferir con los beneficios del comercio (Hirschman, 1945). Los estudios sobre relaciones comerciales entre China y América Latina coinciden en que el gigante asiático se ha convertido en uno de los principales destinos para las exportaciones y que dicho patrón está fundamentado en el comercio de materias primas y recursos naturales.

De acuerdo a cifras oficiales, China se ha convertido en el socio comercial más importante para Brasil, Chile, Perú y Uruguay y a nivel regional ha desplazado a EEUU y a la UE. Adicionalmente, es el país que más inversiones tiene en Sudamérica, en el año 2002 las inversiones ascendían a 17 mil millones de dólares, mientras que en el 2018 la cifra alcanza alrededor de los 306 mil millones de dólares (Gallagher y Myers 2020). Desde 2005, China ha otorgado más de 100.000 millones de dólares en compromisos de préstamos a través de sus bancos (particularmente el Banco de Desarrollo de China y el Banco de Exportación e Importación de China) que se convirtieron en una de las mayores fuentes de financiamiento para países como Argentina, Brasil, Ecuador y 
Venezuela (Gallagher et al., 2012). Esto concuerda con las cifras que señalan que para 2013 China tenía ya la segunda mayor reserva (después de EEUU) de inversión extranjera directa en el mundo, con aproximadamente 1,8 billones de dólares (Gallagher et al 2012: 35).

En procesos de transición hegemónica las economías ascendentes intensifican la competencia por el control de los recursos naturales y esto se materializa en el fortalecimiento de nuevas alianzas comerciales (Krasner 1976; Gilpin 1981). Para el caso particular de la región latinoamericana, el desembarco chino a través de grandes inversiones y su demanda de importaciones de materas primas dio paso al denominado "Boom de las commodities", que marcó un ciclo prolongado de precios altos de las materias primas. Esto permitió a los países de la región no solo aumentar sus ingresos fiscales sino también, diversificar sus socios comerciales y obtener mayor independencia de la potencia norteamericana.

Sobre esta base, "la motivación para la inversión directa (préstamos y comercio) (...) es principalmente la adquisición de mercados y el control de la gestión (...) para crear relaciones económicas y políticas permanentes y significativas." (Gilpin, 1976: 184). En el caso particular de China, su estrategia de internacionalización económica se ha visto seguida de estrategias en el ámbito político, a través del reconocimiento a varios países de la región como "Socios Estratégicos", con quienes ha firmado acuerdos de cooperación en áreas como ciencia, inversiones y finanzas, en las que se prevé la participación de empresas estatales chinas (Domínguez 2006).

El incremento de la interdependencia económica entre China y los países de América Latina podría ser leído a través de la lente de la "diplomacia económica", que hace referencia al "uso de medios económicos al servicio de los fines de la política económica y de la política exterior" (Baldwin, 1985; Drezner, 1999). La idea que subyace es que "los amigos que comparten al menos algunos de sus valores y principios de política internacional ayudarían a China a promover su visión del orden mundial" (Strüver, 2014). Como señalan Layne, Roett y Paz, romper con la dependencia de la región hacia Washington podría ser una forma 
de forjar alianzas que podrían resultar útiles en el ámbito multilateral (Layne, 2008; Paz, 2012; Roett \& Paz, 2008).

En base a este fundamento teórico, la hipótesis que se deriva es la siguiente:

H3. Mayor interdependencia comercial (aumento relativo del comercio bilateral) con una potencia mayor alineamiento político.

Por su parte, la literatura especializada también hace referencia a los factores de agencia que inciden en las estrategias de inserción internacional de los países periféricos. En este sentido, esto está estrechamente relacionado con el rol de las elites y su voluntad para llevar a cabo un proyecto autonómico y la existencia de un modelo de desarrollo interno consensuado. Existe consenso en que los países latinoamericanos de inicios del siglo XXI, liderados por gobiernos de izquierda y de corte progresista, optaron por el retorno del Estado, la diversificación de sus relaciones exteriores y recurrieron, en mayor o menor grado, al fortalecimiento de relaciones con China como socio económico y político alternativo a los EEUU.

En el contexto específico de los países latinoamericanos, el papel de las élites resulta crucial en la adopción de la estrategia internacional del Estado y, en particular, en el proceso de vinculación con sus socios internacionales. La literatura señala ampliamente que las fuerzas de izquierda han sido las que más intensamente desafían el statu quo y buscan cambiarlo a través de la política exterior; además, la izquierda política en la región ha sido tradicionalmente asociada con el sentimiento de antiamericanismo. De hecho, es en esta área de la política, donde se puede observar mejor el cambio en el accionar internacional mediante gestos simbólicos o declaraciones oficiales del ejecutivo o de las cancillerías (Neto y Malamud 2015).

Este postulado teórico resalta la importancia de los factores domésticos y ejemplifica las afinidades ideológicas que se tejieron entre la denominada "marea rosa" y China en la primera década del siglo XXI. Un elemento en común del "giro a la izquierda" fue la clara ruptura con los postulados del Consenso de 
Washington de comienzos de la década de los noventa, el rechazo a proyectos de integración como el ALCA y la visión reivindicativa de las relaciones para con la potencia del Norte. Sobre esta base, se establece la hipótesis relacionada al rol de la tendencia de la fuerza política dominante en los Estados latinoamericanos y cómo esta incide su posicionamiento hacia las potencias mundiales.

H4. Cuanto más a la izquierda se encuentre un país, menos convergencia de votos con EEUU y más con China.

Finalmente, el quinto postulado que identifica la literatura sobre la inserción de los Estados en el sistema internacional hace referencia al régimen político. Esta variable se deriva del análisis de los factores de agencia y señala que los regímenes políticos democráticos tenderían a extender vínculos con Estados que persigan sus mismos intereses. Eso debido a que en una democracia las decisiones se fundamentan en los principios basados en el Estado de Derecho, el voto universal, respeto a las libertades públicas, la soberanía popular, la división de poderes, la alternancia del poder, la autonomía del poder judicial, respeto a los derechos humanos entre otros.

La idea que subyace a esta selección es que mientras más cercanos estén dos países en el tipo de instituciones políticas hay más probabilidades de que tengan acciones similares en política exterior (Voeten, 2000). En este sentido resulta más fácil coordinar acciones de cooperación cuando se tiene ideales en común y cuando se comparte una visión similar de mundo. El desembarque de China en la región latinoamericana se ha dado a través de un posicionamiento político que impulsa el principio de independencia y la autodeterminación. Si bien el gigante asiático no puede ser calificado como una democracia, el país ha aupado la narrativa de colaboración entre socios del Sur. En este sentido, busca ganar aliados políticos que defienden una perspectiva similar de inserción mundial que, sin oponerse de manera frontal a las naciones desarrolladas y democráticas, se basa en la idea de no injerencia en asuntos internos (de Oliveira, 2006).

H5. Mayor democracia, mayor tendencia alinearse con EEUU. 
Esta combinación de circunstancias externas e internas permite mostrar especificidades en la dinámica concerniente a la política exterior latinoamericana. A partir de la primera década del siglo XXI, los países de la región buscaron fortalecer las relaciones Sur-Sur impulsando la generación de iniciativas, a nivel estatal y regional, con la intención de consolidar modelos propios de desarrollo que amplíen sus márgenes de autonomía. Por lo tanto, la alineación política con una u otra potencia estaría determinada bajo la lógica de cuál de éstas le permite ampliar sus márgenes de acción exterior y consecuentemente perseguir su interés nacional.

Por una parte, alinearse con EEUU podría resultar benéfico a corto plazo, pero a costa de adoptar políticas contrarias a su proyecto nacional de desarrollo. Por otra parte, a largo plazo es más deseable consolidar mayores márgenes de autonomía alineándose con una potencia que promulga su cooperación sin ejercer intromisiones con sus intereses nacionales. Por ello, la introducción de una serie de temas relativos al interés específico de las potencias dominantes permitiría capturar de mejor manera la alineación política de los países latinoamericanos hacia las potencias.

\section{Alineamiento en política exterior: variables e indicadores.}

Este estudio busca dar luz sobre los patrones de alineamiento de la política exterior latinoamericana hacia la potencia hegemónica EEUU y la potencia emergente China. La investigación toma como variable dependiente el alineamiento de la política exterior hacia estas potencias. Lo anterior, a partir de las resoluciones adoptadas en la AGNU de 18 países latinoamericanos desde 1970 a 2015. La observación de este período se hace en tres etapas marcadas por diferentes relaciones de poder a nivel internacional: se observa el momento de bipolaridad durante la Guerra Fría (1976-1991), el de unipolaridad (19922002) y el de multipolaridad (2003-2015).

Este acápite, al ser de carácter explicativo sobre los factores que influencian la política exterior latinoamericana, hace uso del método cuantitativo con análisis estadísticos (relaciones bivariadas, regresiones lineales múltiples, análisis 
factorial). Para ello, el diseño metodológico contempla la observación de dimensiones (variables independientes) fundamentalmente asociadas a los factores estructurales y domésticos del ejercicio de la política exterior en los países latinoamericanos. En este sentido, se analizan los factores como la ideología del gobierno, la dependencia económica, la distribución del poder y el perfil democrático del gobierno, así como sus efectos en la política exterior.

La operacionalización de la variable dependiente, usando como proxi los votos en la AGNU, no es un tema consensuado en la literatura especializada. Las críticas señalan que las resoluciones adoptadas en la AGNU no son legalmente vinculantes y carecen de fuerza legal por lo que la falta de rendición de cuentas hace que los votos se conviertan en una cuestión simbólica (Kennedy, 2006). Sin embargo, esta investigación toma la decisión metodológica impulsada por los autores que revalidan su uso porque son indicadores que ayudan a identificar las posiciones de los países en la arena de la política internacional, en temas multilaterales o en alineamientos regionales (Lijphart, 1963; Selcher, 1978; Marín-Bosch, 1998); y por tanto, indican la orientación general de la política exterior (Tomlin, 1985; Thacker 1999; Voeten, 2000). En el ámbito latinoamericano, Amorim (2011) es uno de los pioneros en el uso de métodos cuantitativos para entender la política exterior de Brasil usando la mencionada metodología; Neto y Malamud (2015) estudian las votaciones para definir factores que determinan a política exterior de Argentina, Brasil y México; Schenoni (2012) también revalida su uso.

Sobre la base de los estudios que anteceden, se argumenta que los votos en la AGNU reflejan preferencias de política internacional que conllevan consecuencias políticas, por lo que conceptualmente sirve como un proxy a las dinámicas de alineamiento en política exterior, lo cual define la variable dependiente de esta investigación. Así, para el cálculo del alineamiento, se extraen los registros de votos de la base de datos Data and Analyses of Voting in the UN General Assembly (Voeten, 2015). A partir de esta fuente se analiza el alineamiento político con EEUU y China por parte de los 18 países latinoamericanos, durante 45 años y se considera una $\mathrm{N}$ de 1906 resoluciones. Para cada resolución se registró el voto por país latinoamericano (Argentina, 
Brasil, Bolivia, Chile, Colombia, Costa Rica, Ecuador, El Salvador, Guatemala, Honduras, México, Nicaragua, Panamá, Paraguay, Perú, República Dominicana, Uruguay y Venezuela), el voto de EEUU y el voto de China, así como su nivel de coincidencia (963 el primero y 943 el segundo).

Siguiendo la metodología propuesta en esta investigación, se observan dos variables dependientes: el alineamiento con los votos de EEUU y el alineamiento con China. En lo que se refiere al cómputo de votos se optó por la propuesta de convergencia de Voeten (2015) basada en el índice de Lijphart (1963), quien calcula porcentaje de votos idénticos emitido por los países a analizar: se codifica como 1 si es coincidente y 0 si el voto es en cualquier otro sentido. El índice, al ser agregado y tener una codificación binaria, toma en cuenta las seis áreas en las que los países votan. La lógica de selección de este método tiene que ver con las características del voto de América Latina en las NNUU que contabiliza pocas abstenciones y donde se puede observar el grado de similitud de sus votos con EEUU y China

De acuerdo a la propuesta teórica detallada en el capítulo III, a continuación, se muestra el modelo propuesto llevado a un análisis empírico donde se muestran las variables dependientes, independientes y de control que se derivan del Realismo Periférico.

En la tabla Nro. 1 se puede observar el detalle de las variables dependiente, independiente y de control. La primera variable es la distribución del poder mundial, que hace referencia a la estructura histórica que enmarca la relación internacional entre los Estados, se utiliza como indicador el índice CINC. La segunda variable rol de la ideología como eje fundamental para comprender las luchas políticas en la región medido a través del posicionamiento ideológico (medido en una escala de 1 a 5, siendo 1 izquierda, 2 centro izquierda, 3 centro, 4 centro derecha y 5 derecha). La tercera variable hace referencia al tipo de régimen político medido a través del indicador Polity IV, que es un índice que va de -10 a 10 , donde -10 es el menor grado de democracia o de mayor autoritarismo y 10 el grado más alto de democracia. La cuarta variable es de tipo 
económico y hace referencia al rol de la interdependencia comercial entre los países latinoamericanos y las potencias analizadas.

Tabla 1: Descriptivos

\begin{tabular}{|c|c|c|c|c|c|c|c|}
\hline Dimensión & & Variable & $\mathrm{N}$ & Mín. & Máx. & $M$ & Sd \\
\hline \multirow{9}{*}{ Independientes } & \multirow{2}{*}{ Control } & Año & 963 & 1970 & 2015 & 1992 & 13.283 \\
\hline & & País & 21 & & & & \\
\hline & \multirow{4}{*}{$\begin{array}{l}\text { Política } \\
\text { interna }\end{array}$} & Ideología gobierno & 670 & 1 & 7 & 3.501 & 1.2247 \\
\hline & & Año de democracia & 578 & 1949 & 1997 & 1978 & 12.608 \\
\hline & & Edad de democracia & 578 & 0 & 66 & 20.35 & 14.39 \\
\hline & & $\begin{array}{l}\text { Cualidad democrática } \\
\text { (Polity IV) }\end{array}$ & 963 & -9 & 10 & 3.48 & 6.651 \\
\hline & \multirow{3}{*}{ Económica } & PIB Per Cápita & 916 & 986.57 & 56443.9 & 8006.3 & 7421.4 \\
\hline & & $\begin{array}{l}\text { Dependencia económica } \\
\text { con EEUU / China }\end{array}$ & 818 & -594 & 862 & 68.42 & 120.6 \\
\hline & & Índice de poder (CINC) & 902 & 0.0002 & 0.2181 & 0.0167 & 0.042 \\
\hline \multirow[b]{2}{*}{ Dependientes } & Alineamiento & V_AgreeUS & 963 & 0.028 & 1 & 0.2526 & 0.2034 \\
\hline & $\begin{array}{l}\text { / } \\
\text { convergencia }\end{array}$ & V_AgreeChina & 943 & 0.066 & 1 & 0.7669 & 0.1826 \\
\hline
\end{tabular}

Fuente: elaboración propia.

\section{La política exterior en América Latina: factores sistémicos y factores agenciales.}

El modelo temporal de este estudio contempla tres períodos históricos: bipolaridad (1976-1991), unipolaridad (1992-2002) y multipolaridad (2003-2015). De acuerdo con los periodos de polaridad, la estructura de distribución del poder mundial (bipolaridad, unipolaridad, multipolaridad) influencia en el grado de cohesión política de los países periféricos hacia las potencias dominantes.

En primera instancia, el período de bipolaridad (1976-1991) se caracteriza por la polarización de las relaciones internacionales en dos bloques antagónicos. Por una parte, el conflicto Norte-Sur moldeó el establecimiento de la agenda internacional del "Movimiento de los No Alineados" y el "Grupo de los 77" con China como socio del Sur Global (lida, 1988) y por otra, la región latinoamericana 
se constituyó como el área de influencia directa de la hegemonía estadounidense en el hemisferio. Como refieren Neto y Malamud (2015), en esta época cabría esperar mayor alineamiento de votos de los paises latinoamericanos con EEUU, especialmente por la presión ejercida durante la Guerra Fría para enfrentar al comunismo.

Tras la implosión de la URSS se impone el predominio del unilateralismo (19922002) ejercido por la potencia norteamericana, pero a la par, marca el ascenso económico de países emergentes como China en el ámbito de influencia internacional. Estos procesos de reordenamiento del poder mundial inauguraron una etapa de multipolaridad (2003-2015) que se caracterizaría por una mayor dispersión del alineamiento de votos latinoamericanos para con los EEUU. Para América Latina, este período está marcado no solo por el desembarco económico del gigante asiático en la región, sino también, por su creciente influencia política en las relaciones con los potenciales socios estratégicos (Gráfico 2).

Gráfico 2. Alineamiento de América Latina con EEUU y China (1970-2015).

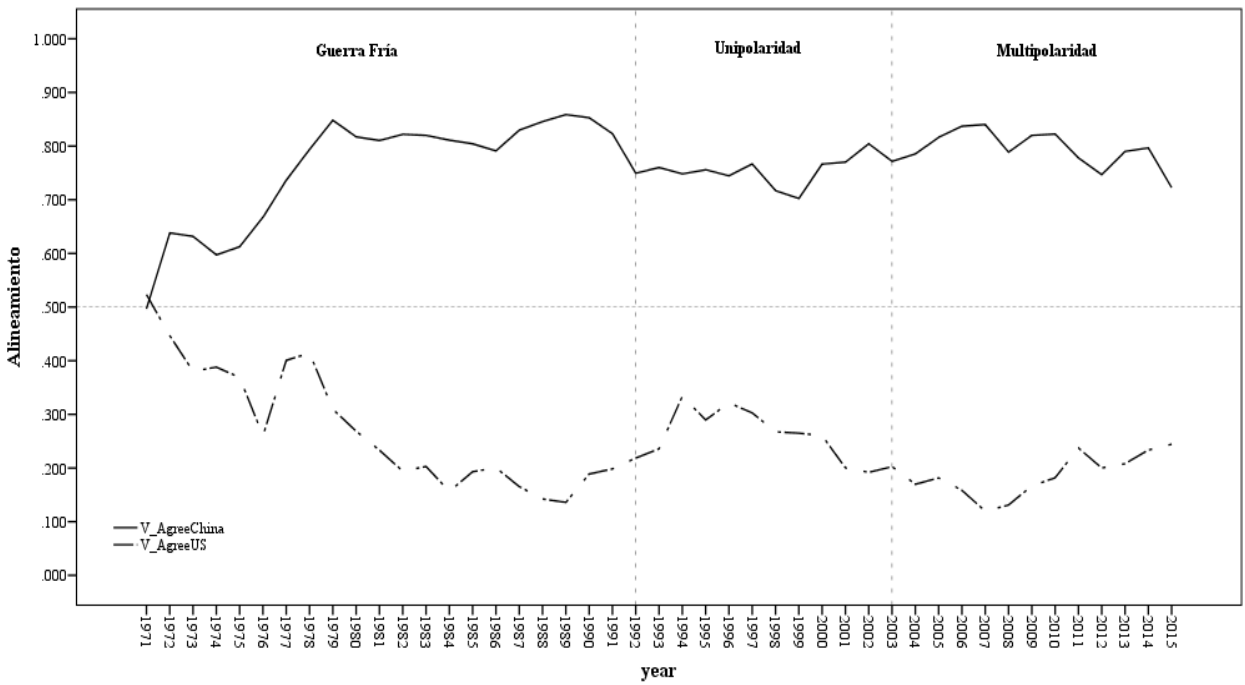

Fuente: Data and Analyses of Voting in the UN General Assembly Elaboración propia 
En los periodos de bipolaridad y unipolaridad, los intereses de América Latina convergen con EEUU, aunque de manera dispersa y van disminuyendo paulatinamente, como se muestra en los gráficos 3 a-b. A pesar de la importancia norteamericana, la región latinoamericana encuentra de forma bastante estable, mayor convergencia con China. Esto se explica en parte porque el gigante asiático tuvo una actitud más favorable para con los países del "Tercer Mundo" que para con las naciones desarrolladas de occidente. Esta tendencia se profundiza y se hace más evidente en el período de multipolaridad, donde la convergencia de los votos hacia el actor emergente encuentra una normalización. Se puede señalar que el declive relativo del poder de EEUU disminuye la convergencia de votos de los países latinoamericanos, mientras que el poder relativo de China aumenta la convergencia del voto de estos países durante el periodo analizado.

Una posible explicación es el declive relativo del poder de la hegemonía estadounidense que, siguiendo los postulados derivados de la teoría del sistema mundo, comienza a palparse desde la década de los setenta y se acentúa a inicios del siglo XXI; lo cual da paso a la dispersión del alineamiento político de los países periféricos en favor de la potencia ascendente, en este caso China (Gráfico 3 a-b). Estos tres periodos, no solo evidencian la polarización del alineamiento en torno a estas dos potencias, sino también su flujo y reordenamiento. En donde China progresivamente ha logrado un mayor alineamiento con los países latinoamericanos en detrimento de la potencia norteamericana. Esto, además, permite comprobar que el gigante asiático ha sido exitoso demostrando su compromiso pro Tercer Mundo y su posición para liderar los ideales del Sur Global. 
Gráfico 3 a-b. Alineamiento de América Latina con EEUU y con China. Periodo de polaridad global
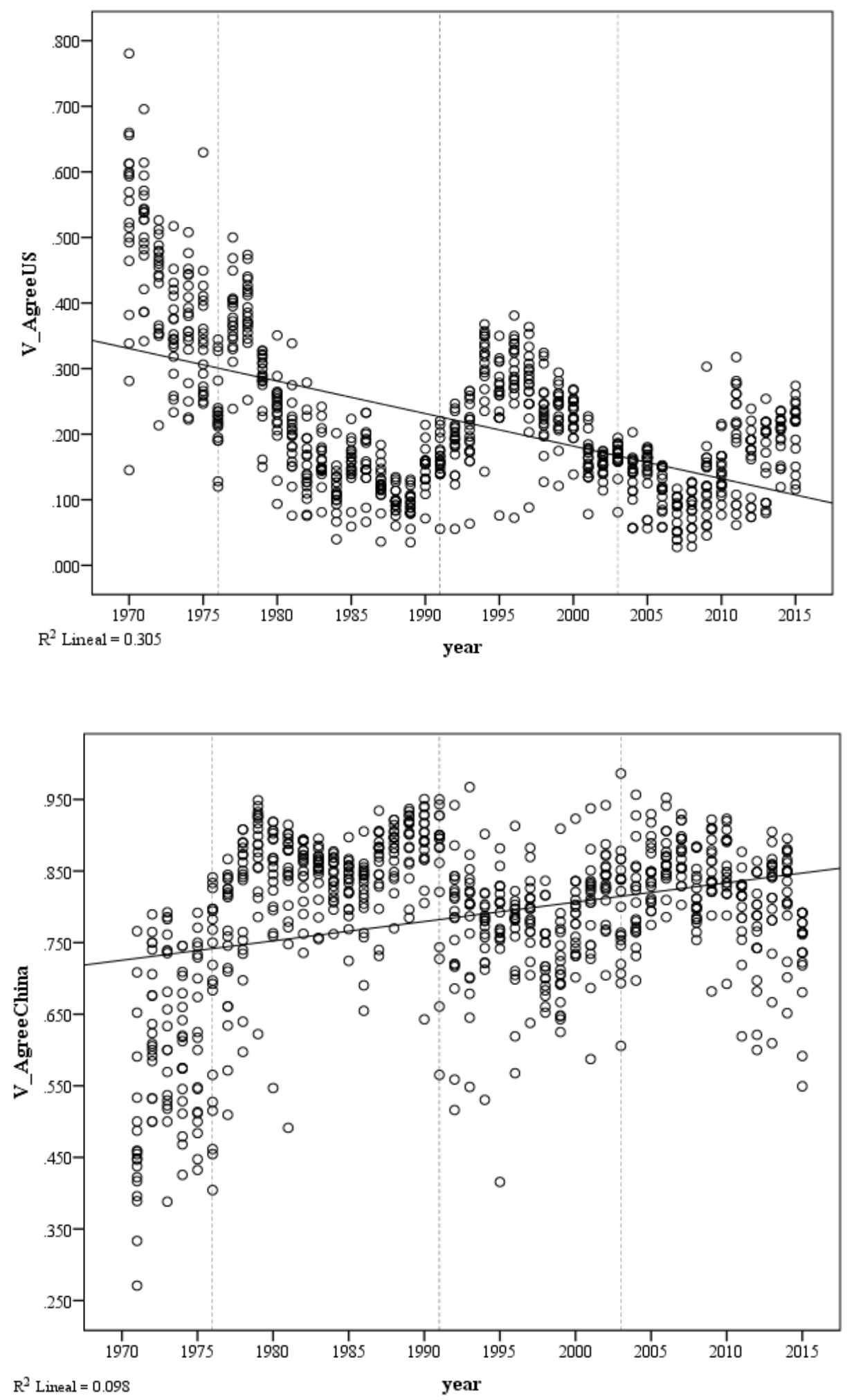

Fuente: Data and Analyses of Voting in the UN General Assembly Elaboración propia 
Los factores estructurales expuestos a partir del alineamiento de los votos latinoamericanos para con las potencias analizadas durante los períodos de reconfiguración del poder mundial, específicamente del poder hegemónico de EEUU, son limitadas para mostrar patrones de alineamiento político de manera determinante. Por ello, a continuación, se analizan las dinámicas internas de los países porque arrojan mayor evidencia para establecer patrones de comportamiento en las dinámicas internacionales.

La primera variable que se analiza es el posicionamiento ideológico de los gobiernos, aunado a los ciclos políticos de los países latinoamericanos. Los gráficos 4 a-b, evidencian la relación entre el alineamiento con las dos potencias (EEUU y China) y el posicionamiento ideológico de los gobiernos latinoamericanos. En un primer momento, se puede observar que el alineamiento con EEUU aumenta cuando los gobiernos latinoamericanos se posicionan más a la derecha de la escala ideológica. En un sentido contrario, cuanto más a la izquierda se encuentran los gobiernos, mayor convergencia de votos con China, es decir, los países de tinte progresista convergen más con la potencia emergente. Se observa que lo anterior no está solamente relacionado con el perfil ideológico de los gobiernos latinoamericanos, sino también con los propios ciclos políticos de la región.

En cierto sentido, una mayor convergencia de los países latinoamericanos se dio con EEUU cuando sus gobiernos consolidaron el Consenso de Washington, teniendo como referencia gobiernos con proyectos neoliberales asociados a posicionamientos ideológicos de derecha, principalmente a finales de la década de 1980 y durante toda la década de 1990. Por otro lado, la convergencia con China comenzó a ascender con mayor velocidad precisamente a principios del siglo XXI, que es cuando comenzaron a surgir gobiernos progresistas en América Latina, a la par del llamado Consenso de las Commodities (Sánchez y García, 2019; Martínez-Hernández y Bohigues, 2019). Estos dos presupuestos ideológicos, coinciden con los periodos de polaridad expuestos anteriormente. 
Gráfico 4 a-b. Alineamiento de América Latina con EEUU y con China. Ideología del gobierno.
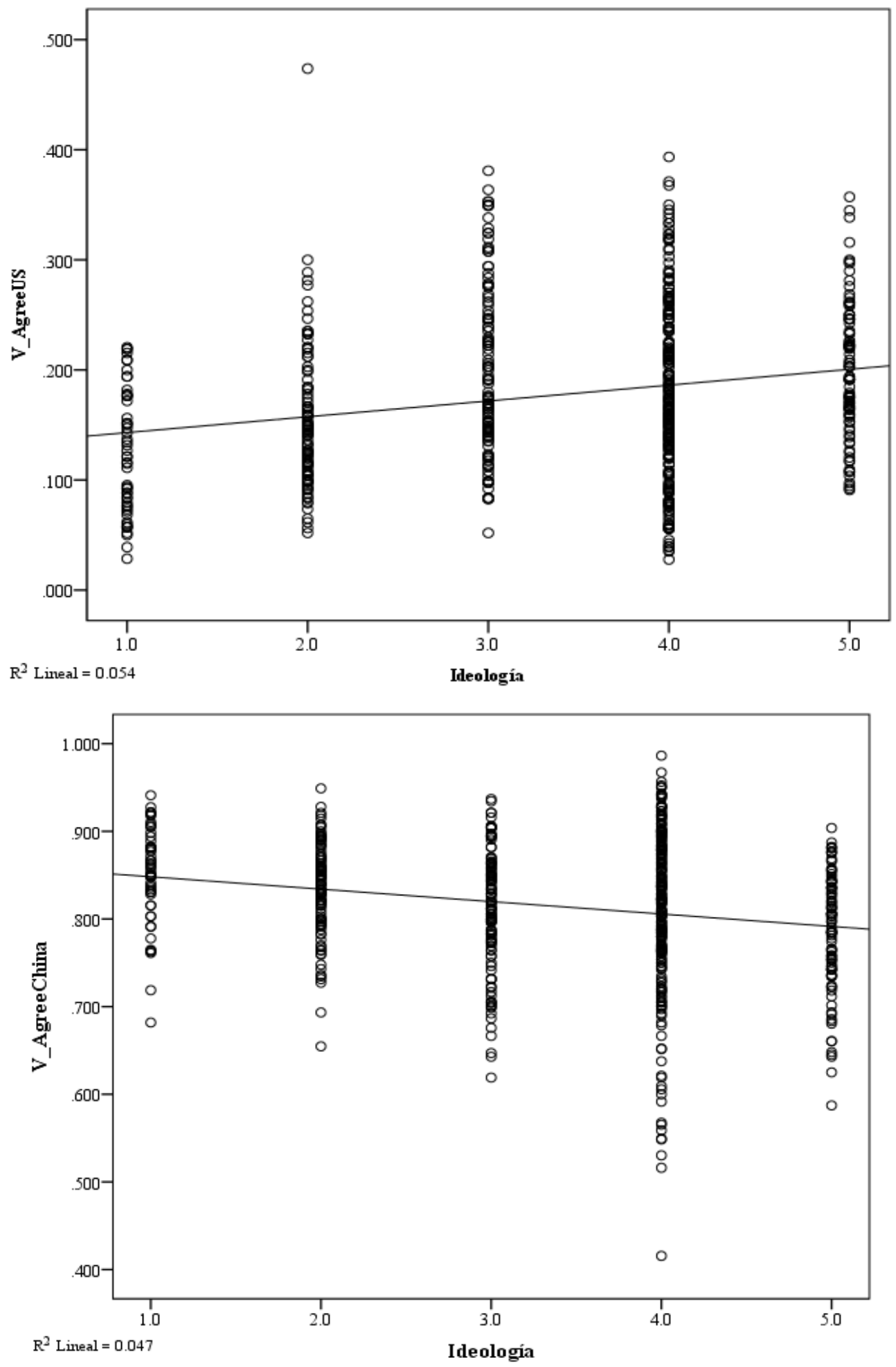

Fuente: Data and Analyses of Voting in the UN General Assembly Elaboración propia 
Gráfico 5 a-b. Alineamiento de América Latina con EEUU y con China. Cualidad democrática del gobierno
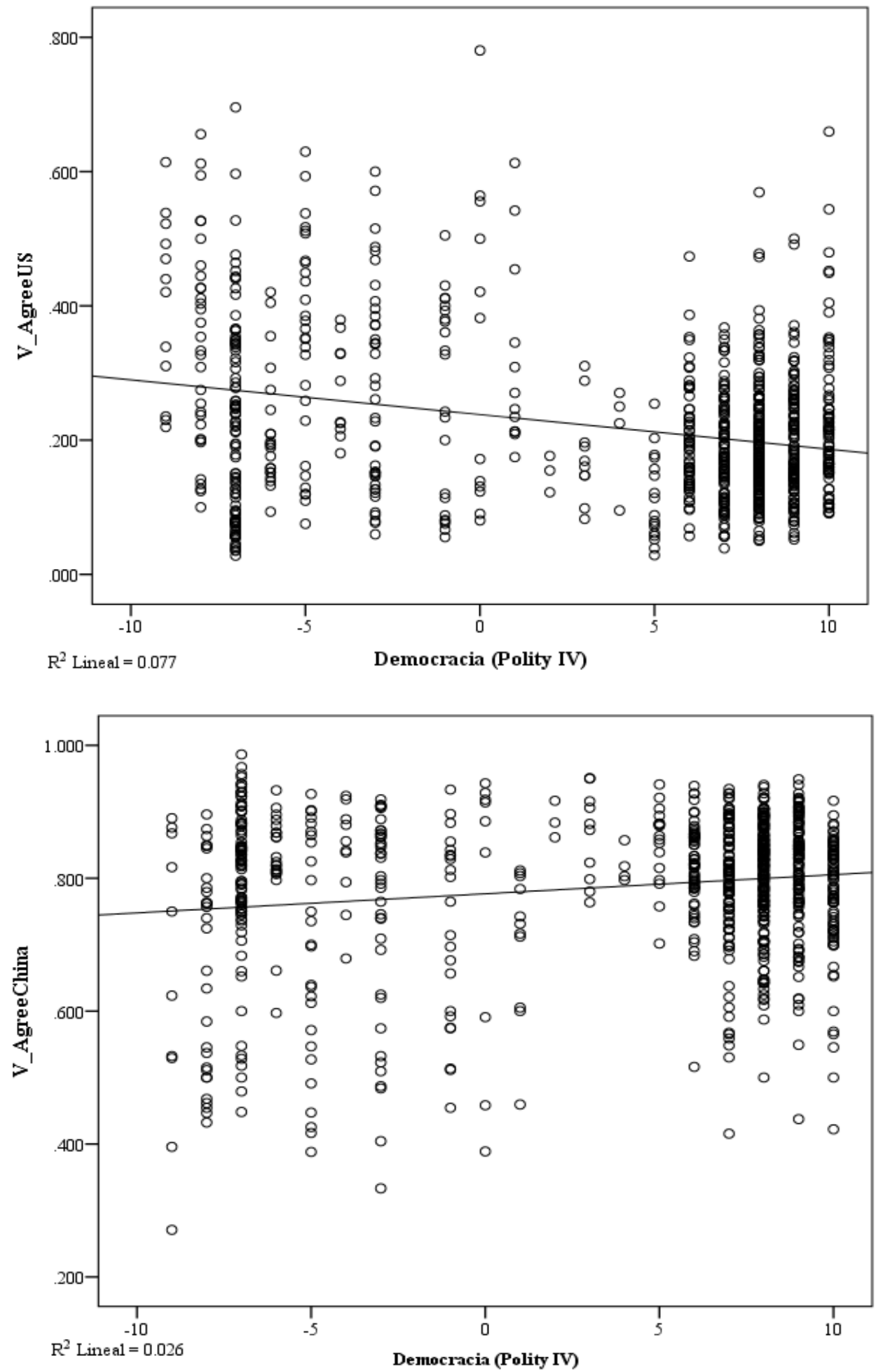

Fuente: elaboración propia con datos de Data and Analyses of Voting in the UN General Assembly" (Voeten, 2015) y Polity IV (Marshall y Jaggers, 2008; Marshall, Monty y Gurr, 2015) 
Gráfico 6 a-b. Alineamiento con EEUU y con China. Capacidad económica de América Latina
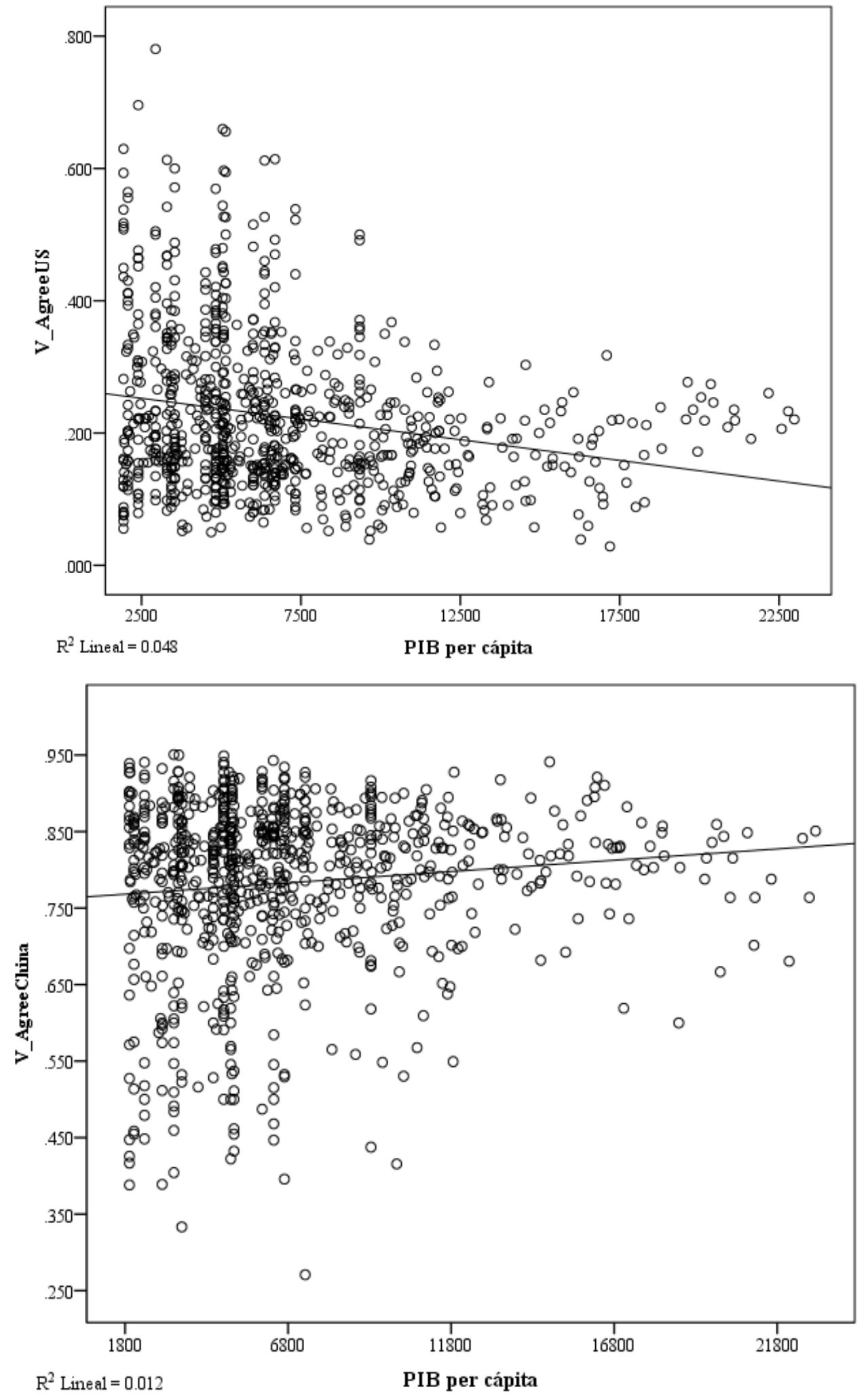

Fuente: Data and Analyses of Voting in the UN General Assembly

Elaboración propia 
Gráfico 7 a-b. Alineamiento de América Latina con EEUU y con China. Concentración de poder
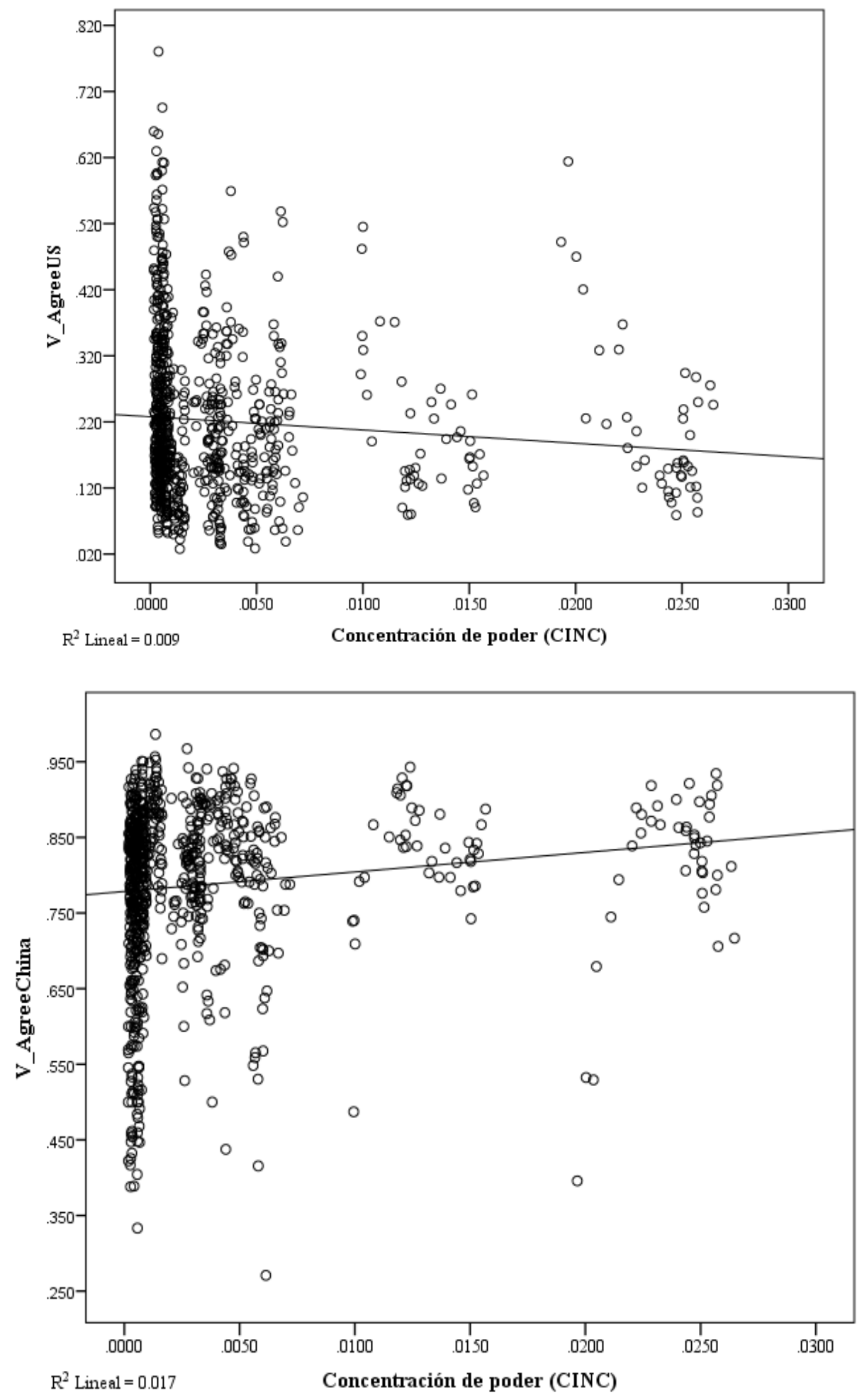

Fuente: Data and Analyses of Voting in the UN General Assembly Elaboración propia 
La segunda variable que ayuda a entender los procesos internos y su relación con el alineamiento de los países latinoamericanos con EEUU y China son las instituciones políticas. La política interior de los países latinoamericanos comenzó su ciclo democratizador en el último tercio del siglo $\mathrm{XX}$, desarrollándose por más de tres décadas hasta principios del siglo XXI. En este sentido los estudios demuestran que cuanto más cercanos están dos países en el tipo de instituciones políticas hay más probabilidades de tener acciones similares en política exterior. Bajo esta óptica, los gráficos 5 a-b, manifiestan una cierta contradicción a lo antes expuesto; la evidencia demuestra que, a mayor democracia menor tendencia a alinearse con EEUU.

La existencia de instituciones políticas similares y los niveles de alineamiento no presentan un efecto estadístico muy fuerte, por ello la tendencia refleja que pese a que China mantiene un perfil poco democrático y EEUU es la cuna democrática del continente americano, la similitud de instituciones no es necesariamente un condicionante para la convergencia entre los países periféricos y las potencias. Lo anterior puede contener una explicación de los casos y la temporalidad. Como se mencionó anteriormente, los procesos democratizadores en América Latina sucedieron justo al finalizar la Guerra Fría, que es cuando EEUU mantuvo mayores niveles de convergencia con los países latinoamericanos, y es en efecto un proceso regional. En contraposición, la convergencia con China inicia su periodo más álgido precisamente cuando los países latinoamericanos inician su proceso de consolidación democrática.

Por otro lado, la tercera y cuarta variable de carácter doméstico tienen que ver con las características económicas. La literatura menciona la centralidad de la interdependencia y se asumen los supuestos de que el aumento de relaciones comerciales con un Estado generaría mayores posibilidades de ganar adeptos políticos en la arena internacional (Hirschman, 1945; Arreola, 2017). En cierto sentido, la disponibilidad de recursos de una potencia hacia un país periférico promueve incentivos para la convergencia en política exterior con un interés de fondo comercial. En América Latina, como se muestra en los gráficos 6 a-b, se manifiesta no sólo la relación positiva entre capacidad económica y 
convergencia, sino también, dos elementos en las dinámicas de poder de los países periféricos.

En un primer momento, se evidencia que los países latinoamericanos con menor PIB per cápita tienden a converger con EEUU y los países con mayor PIB per cápita tienden a alinearse con China. En segundo lugar, la interdependencia económica asume que los países que han obtenido más apoyos económicos de parte de las potencias tienden a converger en temas de política exterior con quien les proporcionó dicha ayuda, lo que consolida el supuesto de que, a mayor ayuda económica, mayor alineamiento político (Tabla 2). Resulta relevante señalar que, en el ámbito económico, China es el primer socio comercial de los países con mayor potencial de crecimiento económico en América Latina como Argentina, Brasil, Bolivia, Chile, Perú y Uruguay, y el segundo de México. El comercio bilateral entre China y Latinoamérica se ha multiplicado por 26 del año 2000 al 2016 y se han invertido más de 110 mmdd en la región desde 2003, la mayoría en los últimos siete años. El 65\% de las inversiones chinas desde 2001 se destinó a materias primas, sector donde se creó la mitad del empleo por inversión china (Arreola, 2017). Por ello, se puede establecer que las dinámicas comerciales suponen un punto de inflexión en las relaciones internacionales porque se genera un fuerte vínculo entre la interdependencia económica y los patrones de polaridad internacional.

De acuerdo con los postulados del realismo periférico (Puig, 1980; Corrales y Feinberg, 1999; Escudé, 2012), la asimetría estructural en la distribución del poder en la esfera internacional impone limitaciones a los Estados débiles para ejercer libremente sus posicionamientos de política externa frente a otras potencias mundiales. En los gráficos $7 a-b$, se muestra que los países con menores niveles de concentración de poder tienden a alinearse con la potencia hegemónica EEUU, pero con una creciente tendencia a la convergencia con la potencia emergente China. De hecho, se confirma que el aumento de poder relativo de China en el ámbito internacional ha permitido a los países periféricos disminuir el dominio político de la potencia americana en la región. 


\section{Modelos explicativos}

Para conocer el peso de cada una de estas variables sobre la convergencia medida a partir de las votaciones en la AGNU (variable dependiente), se utilizan datos de panel, que combinan una dimensión temporal con otra transversal, permitiendo analizar un mismo fenómeno por periodos. La utilidad de este método es que permite estudiar a la vez variaciones de tiempo y variaciones entre casos otorgando mayores grados de libertad para explorar relaciones entre variables. A su vez, esto permite controlar las variables a partir de su cambio a lo largo del tiempo y dar cuenta de la heterogeneidad individual que pueda existir en cada uno de los países. Dada las características de la muestra es necesario recurrir a modelos estadísticos que den cuenta de la variación de la variable dependiente a partir de la variación en las variables independientes. Para ello, como se indicó en el apartado metodológico se utilizaron dos modelos de regresión lineal múltiple, los cuales obedecen a cada variable dependiente utilizada: el alineamiento con EEUU y China. De la misma forma, cada modelo analiza la influencia de las variables independientes antes mencionadas: democracia, posicionamiento ideológico, poder relativo/concentración de poder, capacidad económica, dependencia económica, años de polarización y edad de la democracia.

La tabla 1 y el gráfico 8 , sintetizan los modelos de regresión y sus resultados. La evidencia manifestada en los modelos analíticos indica los dos patrones de comportamiento en las dinámicas de política exterior latinoamericana, antes observada por las variables domésticas a nivel individual. 
Tabla 1. Modelos de análisis. Factores de alineamiento de los países latinoamericanos hacia EEUU y China (Regresión lineal múltiple).

\begin{tabular}{|c|c|c|c|c|}
\hline & \multicolumn{2}{|c|}{ MODELO 1: EEUU } & \multicolumn{2}{|c|}{ MODELO 2: CHINA } \\
\hline & B & SD & B & SD \\
\hline (Constante) & $3.2076^{\star \star \star}$ & $(0.863)$ & $6.910^{\star \star}$ & $(3.393)$ \\
\hline İdeología del gobierno & $0.0187^{* \star *}$ & $(0.003)$ & $-.019^{\star * *}$ & $(0.003)$ \\
\hline Edad de democracia & -0.0001 & $(0.000)$ & .000 & $(0.000)$ \\
\hline $\begin{array}{l}\text { Cualidad democrática } \\
\text { (Polity IV) }\end{array}$ & $0.00241^{*}$ & $(0.001)$ & -.001 & $(0.002)$ \\
\hline $\begin{array}{l}\text { CINC: Índice de Poder } \\
\text { PIB per cápita } \\
\text { Dependencia económica } \\
\text { Año }\end{array}$ & $\begin{array}{l}-1.6671^{\star *} \\
0.0000 \\
-0.0001^{\star \star *} \\
-0.0016^{\star \star *}\end{array}$ & $\begin{array}{l}(0.542) \\
(0.000) \\
(0.000) \\
(0.000)\end{array}$ & $\begin{array}{l}.222 \\
-7.428 \mathrm{E}-07 \\
6.535 \mathrm{E}-13 \\
-.003^{\star *}\end{array}$ & $\begin{array}{l}(0.727) \\
(0.000) \\
(0.000) \\
(0.002)\end{array}$ \\
\hline $\mathrm{R}$ & $.442^{\star \star \star}$ & & $.650^{\star \star \star}$ & \\
\hline $\mathrm{R}_{2}$ & $0.195^{* *}$ & & $0.4227^{\star \star \star}$ & \\
\hline $\mathrm{R}_{2}$ ajustado & $0.184^{\star *}$ & & $0.365^{\star \star \star}$ & \\
\hline $\mathrm{N}$ & 499 & & 478 & \\
\hline
\end{tabular}

Fuente: elaboración propia

***La correlación es significativa en el nivel 0.01 * La correlación es significativa en el nivel 0.05. (B: Beta) (SD: Desviación estándar)

Gráfico 8. Efectos internos y sistémicos en el alineamiento de América Latina hacia China y EEUU

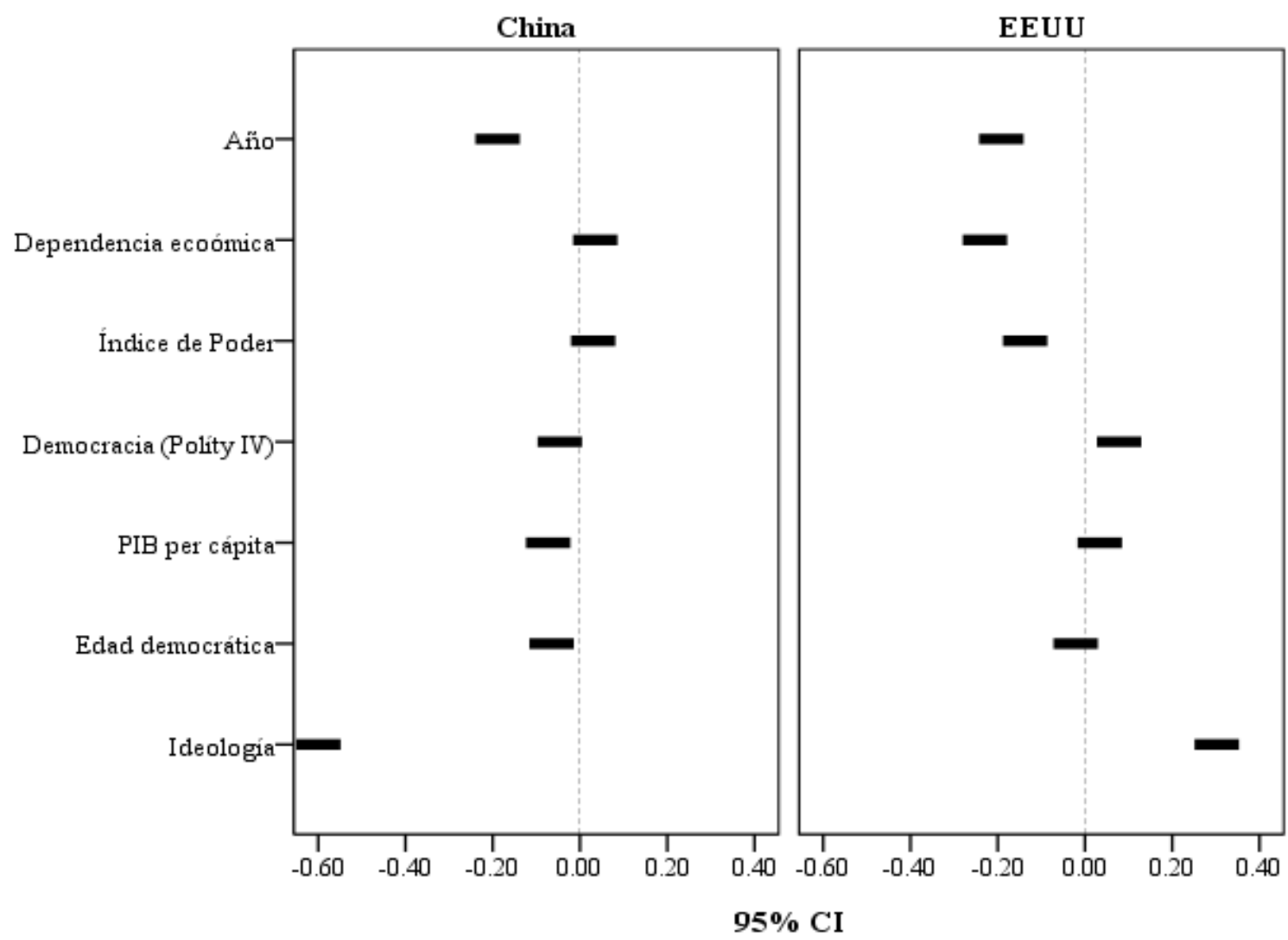

Fuente: elaboración propia. *Beta estandarizada. 
En el modelo 1, que utiliza como variable dependiente el alineamiento con EEUU evidencia que los países con perfiles ideológicos de gobiernos tendientes a la derecha de la escala $\left(0.0187^{\star * \star}\right)$, con rasgos poco democráticos $\left(0.00241^{\star}\right)$, con un poder relativo inferior $\left(-1.6671^{\star *}\right)$, con menor capacidad económica, y una mayor dependencia económica $\left(-0.0001^{\star \star *}\right)$ tienden a alienarse con EEUU $\left(3.2076^{\star \star *}\right)$, lo anterior, manteniendo las demás variables constantes, fue más evidente durante los periodos de bipolaridad $\left(-0.0016^{\star \star \star}\right)$. Este modelo, pese a manifestar la baja influencia de dos variables como lo son los años de democracia y la propia capacidad económica, explica el 19.5\% de la varianza del alineamiento de los países latinoamericanos con EEUU, $\left(R_{2}: 0.195^{* *}\right)($ Tabla 1 y gráfico 8).

El modelo 2 cuya variable dependiente es el alineamiento de los países latinoamericanos con China, manifiesta que los países con perfiles ideológicos de gobiernos tendientes a la izquierda de la escala $\left(-.019^{* * *}\right)$, con rasgos democráticos (-.001), con un poder relativo mayor (.222), con menor capacidad económica (-7.428E-07), y con mayores apoyos o deuda económica con la potencia $(6.535 \mathrm{E}-13)$ tienden a alienarse con China $\left(6.910^{\star *}\right)$, lo anterior, manteniendo las demás variables constantes, fue más evidente durante los periodos de multipolaridad $\left(-.003^{\star \star}\right)$. Este modelo a pesar de manifestar la baja influencia estadística de las variables democracia, edad de la democracia, poder relativo, capacidad económica e independencia económica, explica un $42 \%\left(R_{2}\right.$ : $0.4227^{\star \star \star}$ ) de la varianza del alineamiento de los países latinoamericanos con China, lo cual es alto para un modelo estadístico (Tabla 1 y gráfico 8).

La importancia de estos dos modelos se ubica en el peso de las variables que más efectos manifiestan en la varianza de la convergencia de los países latinoamericanos hacia las dos potencias. En términos estrictos, la ideología como variable independiente tiene un fuerte vínculo con el comportamiento de los países latinoamericanos y su política exterior. Los perfiles ideológicos de los gobiernos, aunado a los periodos de polaridad explican gran parte del fenómeno analizado. El alineamiento de América Latina con EEUU y China, mantienen un fuerte vínculo ideológico (Tabla 1 y gráfico 8). Pese a la importancia de los factores económicos como la capacidad y dependencia económica, el poder 
relativo, la similitud de las instituciones políticas medida por el nivel de democracia (Polity IV) que manifiestan mayores efectos en la convergencia hacia EEUU por parte de los países latinoamericanos, manifiestan menor incidencia en el alineamiento hacia China. Este fenómeno, pese a que corrobora algunas relaciones de las variables a nivel individual analizadas en el apartado anterior, tiene que ver precisamente con la heterogeneidad de las dinámicas internas en los países latinoamericanos.

Para aclarar estos dos patrones manifestados anteriormente, el gráfico 9, realiza un análisis factorial $\mathrm{Hj}$ Biplot, con un modelo de clusters jerárquicos (MartínezHernández y Bohigues, 2019), el cual ubica gráficamente a los casos y su relación estadística entre las variables dependientes e independientes. Este método se utiliza con el objetivo único de observar primero, los patrones de comportamiento de los países y las variables al mismo tiempo, y segundo, evidenciar los grupos de países que tienen mayor concordancia respecto al alineamiento con las potencias analizadas.

Gráfico 9. Alineamiento de los países latinoamericanos hacia EEUU y China. Análisis factorial Hj Biplot: Clusters jerárquicos.

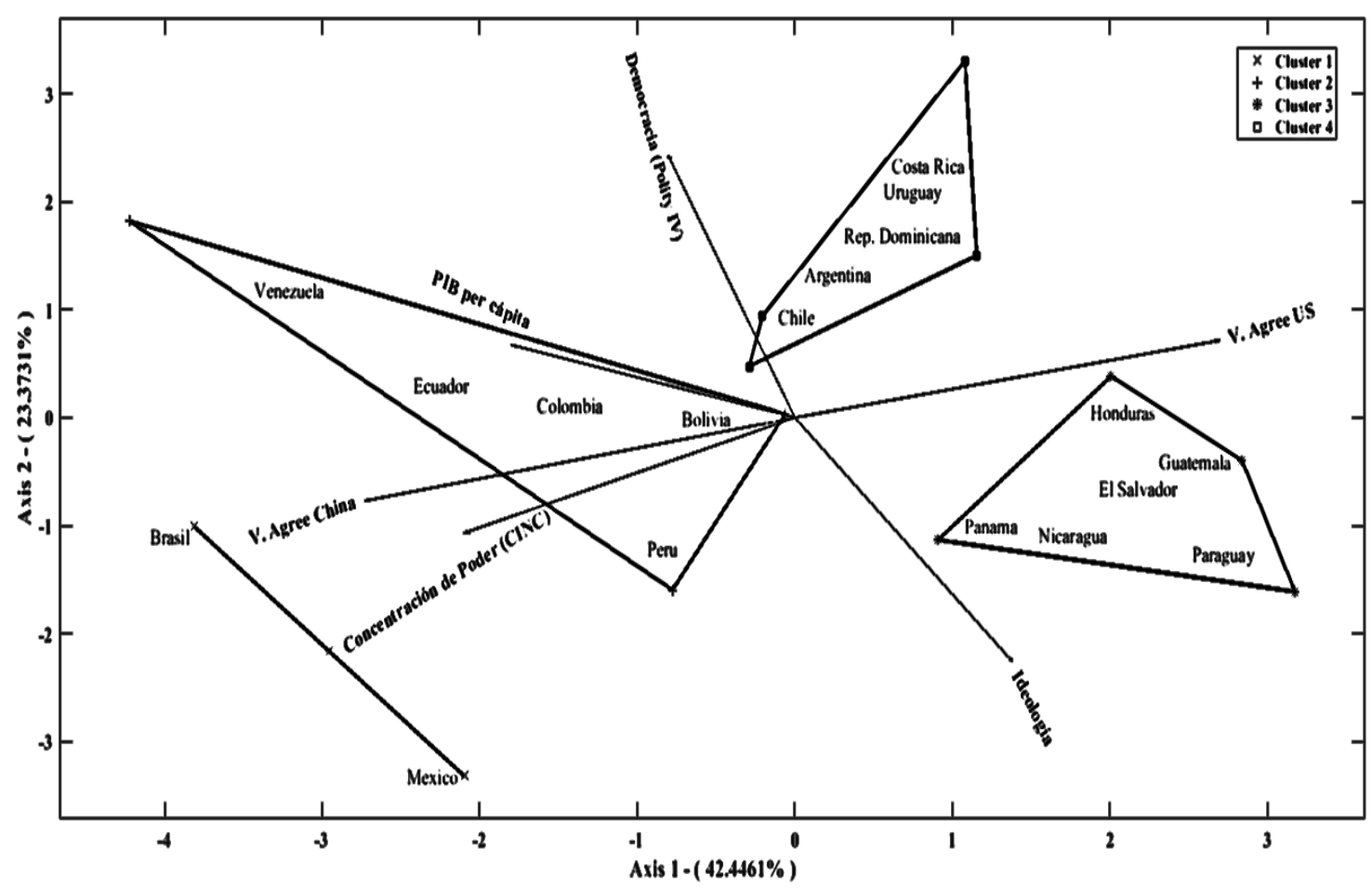

Fuente: Data and Analyses of Voting in the UN General Assembly Elaboración propia 
Como se puede apreciar en el gráfico 9, el análisis contempla las dos variables dependientes analizadas en los modelos explicativos: alineamiento con EEUU y con China. Además de las variables independientes: poder relativo, ubicación ideológica, capacidad económica (PIB per cápita) y democracia (Polity IV). En este sentido, el análisis factorial permite establecer que existen al menos cuatro grupos de países que se diferencian por su convergencia con EEUU y China.

En primer lugar, existe un grupo de países que se caracterizan por tener una alta capacidad económica, con niveles de democracia medios y con un alto poder relativo que tienden a alienarse más con China, en este grupo se encuentran las dos economías más fuertes de América Latina: Brasil y México, que al momento del análisis mantenían posicionamientos ideológicos de izquierda el primero y de centro derecha el segundo. El segundo grupo de países manifiesta medios y bajos niveles de capacidad económica, niveles bajos de democracia, niveles bajos de poder relativo y ubicaciones ideológicas de izquierda, los cuales tienden a alienarse más con China, en este grupo se encuentran Venezuela, Ecuador, Bolivia, Perú y Colombia. El tercer grupo de países manifiesta mayor nivel de convergencia con EEUU, y se caracterizan por tener niveles medios y altos de democracia, niveles medios de capacidad económica y poder relativo, aunque divergen en su posicionamiento ideológico, en este grupo de países se encuentran Argentina, Chile, Costa Rica, República Dominicana y Uruguay. Finalmente, el cuarto grupo de países se encuentran Paraguay, El Salvador, Guatemala, Honduras, Panamá y Nicaragua. Estos países manifiestan posicionamientos ideológicos tendientes a la derecha de la escala, con un bajo poder relativo, con bajos niveles de democracia, y con una baja capacidad económica, evidencian mayores niveles de alineamiento con EEUU.

Esta clasificación, a pesar de ser restrictiva y simplificadora (como es su intención), señala las tendencias regionales hacia dos patrones de comportamiento en las dinámicas internacionales con las dos potencias globales. Como se apreció, la fuerte influencia de EEUU principalmente en América Central, y de China en América del Sur, someten a juicio no sólo la polarización ideológica de la región, sino que también deja ver las dinámicas interregionales de América Latina en el marco internacional. Esto concuerda con 
la literatura especializada que señala que, principalmente los casos de Brasil, Venezuela, Ecuador, Bolivia son países donde se experimenta una política exterior más asertiva y de matriz contrahegemónica que pugnan por un mundo multipolar y apoyan proyectos progresistas de integración regional para aumentar la autonomía (Sanahuja, 2016). Además, implementaron políticas de rechazo a los regímenes tradicionales que mantienen el estatus quo y optaron por proyectos unionistas emancipatorios, políticas de diversificación comercial con socios del Sur Global (Russell y Tokatlian, 2006: 266). La política exterior de este grupo de países buscó el fortalecimiento político, la potencialización del desarrollo social y temas de seguridad-defensa, distanciándose de objetivos tradicionales basados en el comercio e inversiones y otorgando prioridad al papel del Estado, la coordinación política y los acuerdos intergubernamentales en una agenda multidimensional.

\section{Recapitulación}

La investigación realizó un esfuerzo explicativo acerca de la relevancia de factores estructurales y domésticos que influyen en el alineamiento de la política exterior de los Estados latinoamericanos en su relación con la potencia hegemónica de EEUU y la potencia emergente de China. Sobre el fundamento teórico del Realismo Periférico, se postuló el argumento de que la política exterior de los países periféricos se define en base a cálculos de costos, beneficios y riesgos que se conjugan para perseguir su interés nacional y ganar mayores márgenes de autonomía en su acción exterior alineándose con las potencias internacionales. Por ello, se introdujo variables relacionadas a la distribución del poder mundial, el peso de un Estado en el contexto internacional, la interdependencia económica, factores ideológicos y de democracia; y se captura la influencia de cada uno de estos elementos en la alineación política desde 1970 hasta el año 2015.

Los resultados obtenidos comprueban, con variedad de grado, las hipótesis formuladas. Se apunta a la consolidación de China como el actor preponderante en las dinámicas internacionales con América Latina en el marco de un declive significativo de EEUU en el entorno regional. El alineamiento de los votos en el 
seno de la AGNU podría ser una señal de que desde la década de los setenta y con mayor intensidad en la etapa del multipolarismo, el aumento de poder relativo de China en el ámbito internacional, más allá de su incidencia económica, podría estar ganando aliados políticos en los países periféricos. Para los países latinoamericanos el desembarco de china en la región les ha posibilitado contar con otras alternativas y, por ende, tener la posibilidad de ampliar su margen de elección de socios estratégicos en el ejercicio de su política exterior. Esto coincide con el giro ideológico hacia la izquierda que experimentaron varios países latinoamericanos, que se caracterizó por el intento de fortalecer las relaciones Sur-Sur impulsando la generación de iniciativas que fortalezcan modelos propios de desarrollo.

Los ciclos políticos en América Latina, aunado a los procesos ideológicos y proyectos programáticos de los gobiernos latinoamericanos, se posicionan como los elementos nodales para el entendimiento de la acción exterior de los países periféricos y su rol frente a las potencias mundiales, en este caso EEUU y China. Las dinámicas internas se configuran como elementos centrales que inciden en los procesos internacionales, especialmente una vez inaugurado el nuevo milenio; por ello, un análisis de los giros ideológicos y la involución de la democracia en la región resultan fundamentales. Otro de los factores que tiene alta incidencia en el modelo aplicado es la interdependencia económica y el vínculo que genera hacia el gigante asiático, que en los últimos años se ha consolidado como el primer socio comercial de algunos de los principales países sudamericanos. 


\section{CAPÍTULO V. LA COOPERACIÓN SUR-SUR EN LA POLÍTICA EXTERIOR ECUATORIANA: 2000-2015}

\section{Discusión}

El comienzo del siglo XXI inauguró un nuevo ciclo en el quehacer político latinoamericano que vino ligado al fortalecimiento de las relaciones Sur-Sur, aupadas por el dinámico y rápido crecimiento de los intercambios políticos y comerciales entre países en desarrollo. La creciente presencia de la República Popular China coadyuvó a crear nuevas formas de relacionamiento entre los países latinoamericanos y sus socios comerciales tradicionales y revitalizó, con variedad de grado e intensidad, la proyección de políticas exteriores asertivas, en unos casos, y contrahegemónicas, en otros.

En el caso particular del Ecuador, su política exterior se define por variables relativas a su condición de Estado periférico en el ámbito internacional y, por lo tanto, a través de indicadores que aluden a su condición de Estado pequeño y débil $^{19}$. En este sentido, un rasgo estructural del ejercicio de su política externa es su subordinación al sistema internacional y la práctica de lógicas de autonomía o de aquiescencia (Russel y Tokatlian 2013: 161). En este caso, la posición del país en el orden mundial ha Estado históricamente marcada por una relación ambivalente con los EEUU, lo que ha definido conductas que fluctúan entre lógicas de disenso y evasión hasta lógicas de complacencia para con la potencia central; lo que ha condicionado el ejercicio de una política exterior que priorice un modelo de inserción basado en su interés nacional.

La llegada a la presidencia del economista Rafael Correa en el año 2006 alteró la perspectiva sobre el rol del Ecuador en el mundo y buscó posicionar al país como un Estado con un lugar propio en el panorama internacional, rompiendo con el statu quo preestablecido y transformando la política externa sobre la base

\footnotetext{
19 En las Relaciones Internacionales, el concepto de debilidad puede construirse desde la tradición teórica que prioriza la jerarquía y que señala que las capacidades de los Estados definen su importancia en el sistema internacional; o desde la lógica de la interdependencia, un Estado puede ser vulnerable o sensible según su relación con otros Estados o entidades (Bonilla 2006).
} 
de dos principios "la soberanía nacional y la dignidad del pueblo" (Patiño, 2007). Su ascenso marcó un giro en el ejercicio de la política internacional porque puso como eje central de su praxis el interés nacional y la autonomía, enfatizando en la construcción de políticas que "multipliquen los nexos Sur-Sur y cimienten la diversificación de sus relaciones exteriores” (Senplades 2013-2017).

Partiendo de estas premisas, el objetivo de este capítulo es analizar la política exterior ecuatoriana en lo referente a sus estrategias y prácticas de Cooperación Sur-Sur a la luz de las teorías provenientes del Realismo Periférico durante el período 2000-2015. Para ello se busca llevar el debate teórico a un análisis empírico identificando, por una parte, la retórica desarrollista impulsada por el gobierno de Rafael Correa; y por otra, las prácticas que den cuenta de una política exterior autónoma con los poderes centrales. Para ello, el análisis se enfoca en la cooperación económica reembolsable, que el gobierno ecuatoriano se avocó a fortalecer, a través de estrategias como la diversificación de socios comerciales enfatizando en las relaciones con China. Este análisis permitirá verificar la hipótesis de que la creciente presencia del país asiático en el país ha abierto oportunidades y creado ventajas para quienes persiguen formas autónomas de inserción internacional y buscan reducir la dependencia de economías primarias enfocadas.

Teniendo en cuenta la complejidad del análisis de la autonomía al concretarlo en las políticas exteriores, se hace necesario su estudio en relación a un contexto político-económico geográfica e históricamente situado. Por ello, este capítulo refleja aplicación de un estudio de caso que permite comprender cómo se configuraron los diferentes escenarios y lecturas sobre la autonomía y dependencia en el contexto ecuatoriano. En cuanto a la información recabada, se hace uso extensivo de fuentes primarias abiertas y disponibles, de tipo estadístico, localizadas en bases de datos de instituciones públicas, especialmente el BCE y el Ministerio de Finanzas, así como en bases de datos de organismos internacionales como el FMI, el BM, la Comisión Económica para 
América Latina y Caribe (CEPAL), sistema WITS ${ }^{20}$, bases de datos de las NNUU, entre otros.

El capítulo se divide en tres partes. Primero, se expone la literatura principal sobre la política exterior ecuatoriana, a la luz de la teoría de realismo periférico y el pensamiento autonomista latinoamericano. Segundo, se realiza una contextualización histórica del ascenso de Rafael Correa a la presidencia del Ecuador buscando definir los clivajes y las particularidades en el ejercicio de la política exterior. Tercero, se analiza las estrategias comerciales en materia de política económica, a través de indicadores empíricos, que buscan identificar cambios en la en la matriz productiva o diversificación de socios comerciales del Ecuador. Finalmente, se ofrecen conclusiones.

\section{Ecuador en el mundo: panorama general de su política exterior}

La política exterior del Ecuador se encuentra directamente relacionada con su posicionamiento en el asimétrico orden internacional que lo ubica como un país periférico, vulnerable y dependiente. Por ello, las estrategias de relacionamiento externo del país son aquellas asociadas a las de un país pequeño y débil tanto a nivel estructural como a nivel doméstico. Esta particular vinculación del Ecuador con el mundo ha determinado que el país busque posibles mecanismos para reducir su grado de vulnerabilidad y dependencia externas y ha perseguido como objetivo ampliar su margen de autonomía en su accionar internacional.

Siguiendo el método estructural sistémico para el análisis de la política exterior resulta pertinente identificar los factores estructurales y domésticos que influencian el ejercicio de la política internacional del país sudamericano para de esta manera entender cuáles son los márgenes de acción que le han permitido maximizar su capacidad de desarrollo endógeno y fortalecer sus capacidades nacionales.

\footnotetext{
20 El programa informático "Solución Comercial Integrada Mundial" (WITS, por sus siglas en inglés) fue creado por el Banco Mundial en colaboración con la Conferencia de las Naciones Unidas sobre Comercio y Desarrollo (UNCTAD) para poner a disposición de los usuarios información sobre comercio y aranceles, obtenida a partir de bases de datos de instituciones internacionales gubernamentales y entidades privadas.
} 
A continuación, se busca llevar a un análisis de caso empírico las principales variables de carácter estructural y doméstico relacionadas al ejercicio de la política exterior del país andino. En cuanto a los factores estructurales, la primera variable está vinculada con la distribución del poder y puede ser cuantificada con indicadores relativos al poder económico y militar, la segunda variable hace referencia al grado de interdependencia asimétrica con la potencia central que se muestra a través de indicadores como las exportaciones y diversificación de relaciones en función de la potencia central; y la tercera se relaciona con la prioridad estratégica que le asigna la potencia central al país periférico. En cuanto a las variables domésticas, éstas están vinculadas al rol de las instituciones, las elites, y los actores sociales y que se puede observar a través de indicadores relativos a los niveles de institucionalización, posicionamiento ideológico, calidad de la democracia, entre otros.

\section{Variables estructurales de la política exterior ecuatoriana}

A nivel estructural, las estrategias de inserción internacional del Ecuador se han visto marcadas por el rol desempeñado por la potencia central detentada por los EEUU y la prioridad estratégica que ésta imprime en la región latinoamericana. Después de la Guerra Fría, la influencia estadounidense en el sistema interamericano ha sido un factor esencial porque ha logrado rehegemonizar las relaciones en el hemisferio occidental y ha afianzado relaciones basadas en la debilidad económica y la dependencia de los países de la región (Bonilla 2008). Este patrón se ha consolidado, entre otros principios, a través de la implementación de la Doctrina Monroe en 1823 o las políticas de cooperación para el desarrollo. La primera ha servido como justificativo de EEUU para proteger el orden y la estabilidad en áreas sensibles de los intereses norteamericanos y asegurar el acceso sin obstáculos de sus productos a los mercados de la región, e iniciada la década de los ochenta la Doctrina Monroe sirve como paraguas para justificar políticas intervencionistas y agresivas en los países latinoamericanos (Sánchez Padilla 2016: 14). En el caso de la ayuda, una vez culminada la II Guerra Mundial, se empieza a utilizar la ayuda exterior, los créditos, la inversión extranjera como herramientas de poder blando para ejercer 
presión sobre los países periféricos de Suramérica y que de esta manera adopten políticas favorables a sus intereses (Sánchez Padilla 2016: 14).

Para EEUU, el Ecuador no representa una prioridad estratégica y más bien ocupa un rol periférico; pero para el país andino la relación es viceversa. Desde el retorno a la democracia del país en 1979 se dio paso a una sucesión de gobiernos que aplicaron, sin cuestionamientos, las políticas del Consenso de Washington. Esto ha incidido en que la relación del Ecuador para con la potencia del norte esté marcada por un constante y sostenido alineamiento hegemónico avalado por los diferentes gobiernos de turno, independientemente de sus preferencias ideológicas (Hey, 1999). Los estudios de política exterior de Hey, que toman como caso de estudio al Ecuador, documentan y explican la orientación de las estrategias políticas adoptadas desde la década de los ochenta que refuerzan la dependencia del Ecuador con los EEUU independientemente de la retórica que sostienen durante el ejercicio del poder o del signo político del gobierno de turno (Hey 1999). Por ello, si bien el país ha ocupado un rol bastante periférico para los EEUU, las élites económicas y políticas ecuatorianas e inclusive las fuerzas armadas han visto en esta relación bilateral tanto una relación de privilegio como un espacio para ganar legitimidad (Jaramillo 2008).

Una variable de orden sistémico que ayuda a caracterizar la capacidad de una nación para ejercer y resistir la influencia de fuerzas externas es el poder. La operacionalización de esta variable se la puede realizar a través del análisis del CINC, que es un indicador que ayuda a medir la variable poder a través del cálculo de las capacidades materiales que detenta un país. El índice combina seis componentes que representan la fuerza militar (gastos y personal), la demografía (población total y urbana), y lo económico (producción de hierro, acero, consumo de energía) (Singer et al. 1972). Es decir, este indicador refleja el promedio de la participación de un Estado en el total del sistema, ponderando el peso de cada componente por igual. EI CINC oscila entre 0 y 1 , donde "0.0" indica que el Estado tuvo un $0 \%$ de las capacidades totales del sistema ese año; mientras que "1.0" indica que el Estado tuvo 100\% de las capacidades dadas en un año determinado. 
En el caso del Ecuador, al ser un Estado débil, vulnerable y pequeño, no posee recursos económicos, militares o políticos que le permitan intervenir de manera proactiva fuera de sus fronteras. Esto deriva en que su política exterior tanto en materia de defensa como en materia comercial y financiera se ha limitado a ser reactiva, pasiva y sin capacidad de perfilar a su favor dinámicas que eventualmente le afecten. Como se puede observar en el gráfico Nro. 10 el índice mantiene un promedio de 0.0013 puntos desde el año 1970 hasta 2012, que es la última fecha de actualización de los datos proporcionados por el proyecto CINC.

Gráfico 10. Promedio CINC Sudamérica

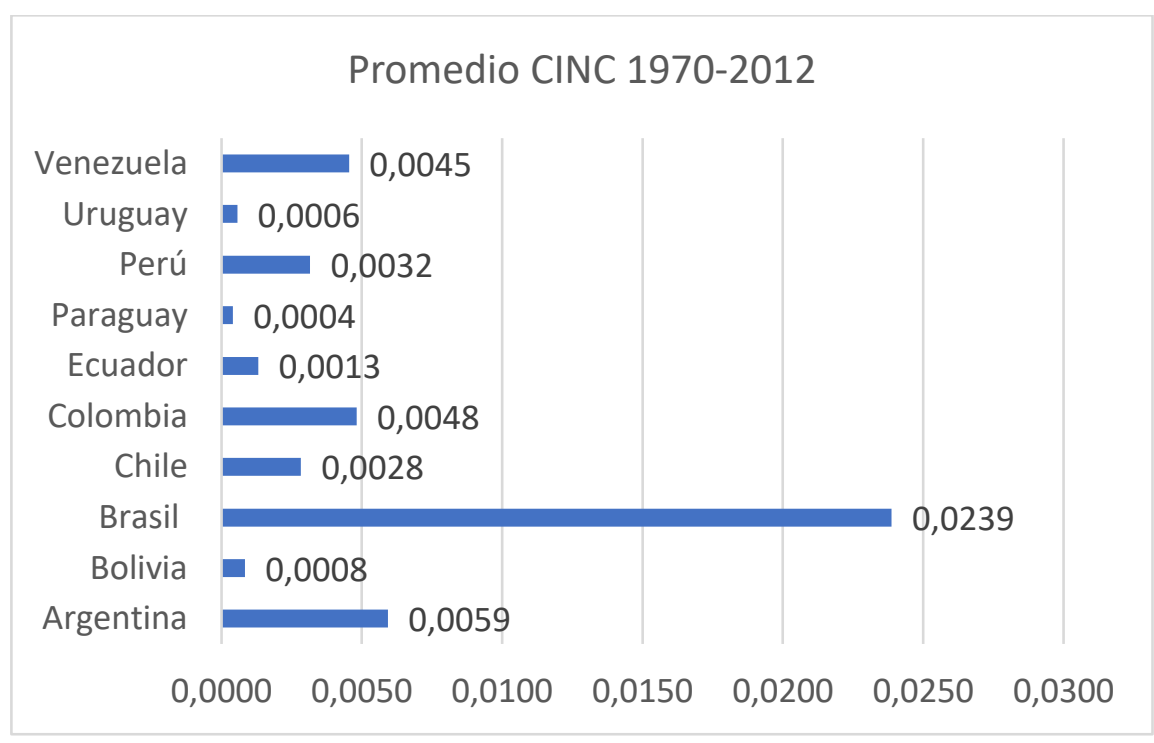

Fuente: Base de datos CINC

Elaboración propia

Si se compara este indicador con el conjunto de los países sudamericanos, las capacidades materiales del Ecuador se encuentran entre las más bajas junto con las de Uruguay, Paraguay y Bolivia. El gráfico de áreas apiladas Nro. 11 muestra el volumen de capacidades materiales que cada país sudamericano detenta durante los cuarenta y dos años analizados. Aquí se refleja que Brasil, Argentina, Colombia y Venezuela alcanzan mayores niveles de "poder duro" por lo que tienen mayores capacidades para ejercer influencia internacional. Destaca el rol 
de Brasil con 0.0239 puntos debido a su contingente poblacional y económico. En el gráfico Nro. 12 se puede visualizar la tendencia y la evolución de este indicador a lo largo del tiempo, para cada país sudamericano.

\section{Gráfico 11. CINC Sudamérica 1970-2012}

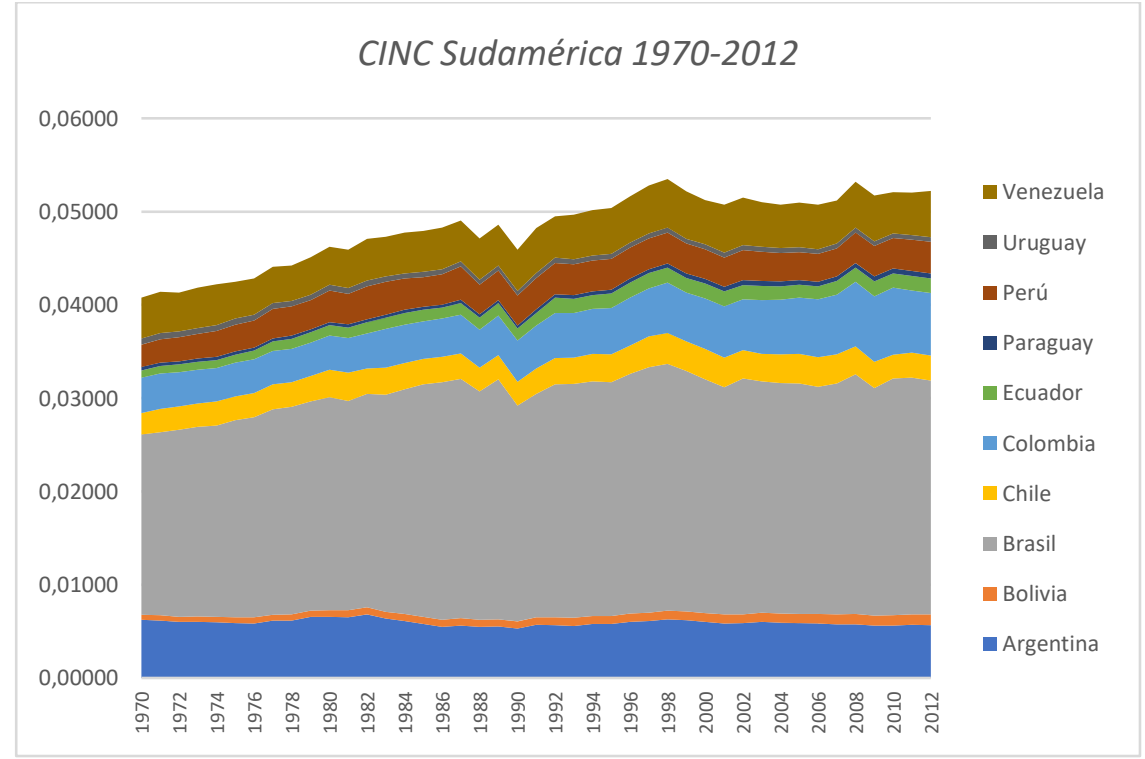

Fuente: CINC

Elaboración: propia

Gráfico 12. Evolución CINC Sudamérica 1970-2012

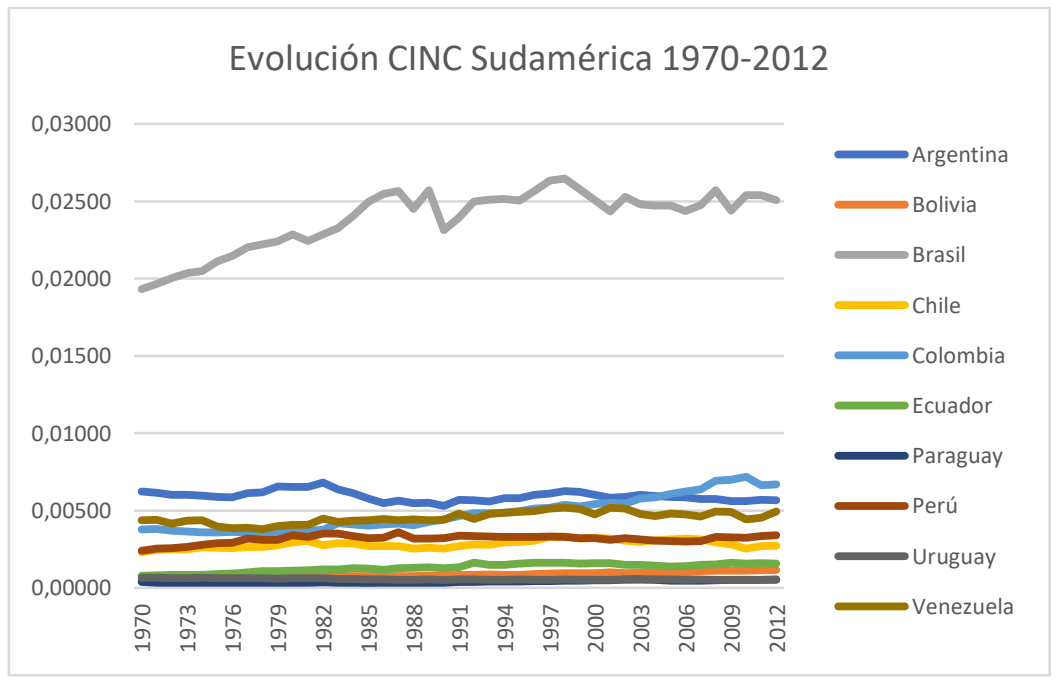

Fuente: CINC

Elaboración: propia 
Una tercera variable de carácter estructural es el grado de interdependencia asimétrica con la potencia central. La presencia de EEUU se ha convertido en el eje gravitacional de la política económica y comercial del Ecuador, lo que le ha generado una situación de subordinación y dependencia que deja poco margen de maniobra para oponerse a los intereses de la potencia. Un indicador relevante para medir el nivel de dependencia económica entre los países es el análisis de las exportaciones. Para el caso de Ecuador encontramos que los EEUU se han convertido en su mayor socio comercial; sin embargo, la relación es desigual porque los intercambios bilaterales se han basado principalmente en la exportación de productos primarios, agrícolas, ganaderos y no procesados -esto debido a la falta de un sector industrial pujante y la baja competitividad de la industria ecuatoriana (Lapeña y Czubala 2018: 2). De hecho, en la economía del Ecuador, más del $40 \%$ de sus exportaciones van hacia EEUU, lo que muestra una gran convergencia económica con las potencias, específicamente con Washington, lo que ha generado una "institución de dependencia" que, de acuerdo a Jaramillo (2011) tiende a seguir el siguiente camino:

\begin{abstract}
La búsqueda de oxígeno para la caja fiscal en las líneas de crédito del FMl y el Banco Mundial. Este oxígeno requería a su vez de la cooperación de Estados Unidos como mayor decidor en estas organizaciones. La búsqueda de cooperación estadounidense generaba a su vez procesos de alineamiento político/diplomático con la agenda estadounidense en materia de drogas, seguridad y ahora terrorismo y la versión liberal de democracia. Este alineamiento a su vez alimentaba nuevas formas de coordinación/dependencia con el gobierno estadounidense que a su vez inhibían iniciativas independientes sobre temas de política exterior ecuatoriana (Jaramillo 2011).
\end{abstract}

La lectura de estos factores hace ineludible que el Ecuador sea categorizado como un país periférico, débil y con presencia marginal en el panorama internacional. Una herramienta que permite visualizar de manera empírica y comparada el posicionamiento de un país en el ámbito mundial es el Índice Elcano de Presencia Globa ${ }^{11}$ que calcula anualmente la proyección de 110 países fuera de sus fronteras tomando en cuenta su presencia militar, económica y presencia blanda. Este índice combina factores económicos (energía, bienes

${ }^{21}$ El Índice Elcano de Presencia Global agrega y cuantifica, sobre la base de datos objetivos, la proyección exterior y el posicionamiento internacional de los de países en función de las tres dimensiones que conforman su presencia: económica, militar y blanda. 
primarios, manufacturas, servicios, inversiones), presencia militar (tropas, equipamiento militar), presencia blanda (migraciones, turismo, deportes, cultura, información, tecnología, ciencia, educación, cooperación al desarrollo).

La presencia global podría definirse como la medida y la forma en la que los países se muestran en la esfera internacional independientemente de que ejerzan influencia o poder, lo que permite analizar su evolución, ascenso o declive en las diferentes dimensiones que contempla (Índice Elcano). A continuación, la tabla Nro. 2 muestra una comparación de la presencia global del Ecuador durante el período 2005 y durante el año 2015.

Tabla 2. Índice Elcano de Presencia Global Ecuador

\begin{tabular}{|l|c|c|c|c|}
\hline \multicolumn{6}{|l|}{ Índice Elcano de Presencia Global Ecuador } \\
\cline { 2 - 5 } Variable & $\begin{array}{c}\text { Valor } \\
\text { índice }\end{array}$ & $\begin{array}{c}\text { Contribución } \\
\text { de presencia }\end{array}$ & $\begin{array}{c}\text { Valor } \\
\text { índice }\end{array}$ & $\begin{array}{l}\text { Contribución } \\
\text { de presencia }\end{array}$ \\
\hline $\begin{array}{l}\text { Presencia } \\
\text { Global }\end{array}$ & 7,2 & - & 10,9 & - \\
\hline $\begin{array}{l}\text { Presencia } \\
\text { económica }\end{array}$ & 8,4 & $46,7 \%$ & 13,2 & $48,6 \%$ \\
\hline $\begin{array}{l}\text { Presencia } \\
\text { militar }\end{array}$ & 10,5 & $29,0 \%$ & 8,3 & $15,2 \%$ \\
\hline $\begin{array}{l}\text { Presencia } \\
\text { blanda }\end{array}$ & 4,4 & $24,3 \%$ & 9,9 & $36,2 \%$ \\
\hline
\end{tabular}

Fuente: índice Elcano de presencia global

Elaboración: propia

Se puede corroborar que la evolución de la presencia global del Ecuador durante la década analizada muestra un cambio significativo caracterizado por una mayor presencia del país en la arena internacional. El índice en el año 2015 era de 7,2 puntos mientras que en una década aumenta 3,7 puntos llegando a alcanzar un puntaje de 10,9 en el año 2015. A inicios de la década el factor que más contribuyó fue la presencia militar que contribuía con un $29 \%$; mientras que para el año 2015 gana mayor representación el área económica que llega a contribuir con $48,6 \%$ del total de factores analizados. Esto tiene sentido porque los diez años estudiados coincide con la década en la cual el país experimento mayores ingresos económicos debido a los altos precios de los commodities que 
incidieron en el flujo de importación y exportación de mercancías. La presencia blanda es la que más incrementa pasando de un valor de 4,4 a un valor de 9,9. Esta área está relacionada con temáticas como la migración, turismo, deporte, cultura, cooperación al desarrollo, entre otros aspectos que dan cuenta de la presencia del Ecuador en el mundo.

\section{Variables domésticas de la política exterior ecuatoriana}

Entre los factores de la política exterior ecuatoriana se encuentran factores domésticos relacionados con las instituciones, las elites y actores sociales. El Ecuador se maneja bajo un régimen presidencialista que ha estado fundamentado en el patrimonialismo, clientelismo y el liderazgo caudillista de entidades colectivas; lo que ha dejado que la agenda de política externa sea vulnerable a influencias privadas en el orden doméstico (Bonilla 2006: 166). Esto combinado con instituciones frágiles y que compiten entre sí ha dado lugar a decisiones fragmentadas y contradictorias en política exterior (Bonilla 2006: 167).

La literatura académica sobre las relaciones sociedad-estado señalan que el Ecuador de finales del siglo XX enfrenta una profunda crisis de representación ${ }^{22}$ (Freidenberg, 2000; Burbano, 1998; Freidenberg y Alcántara, 2001), que se reestructura desde la influencia abusiva de los partidos políticos en las funciones del Estado, lo que limita e inmoviliza la base social del aparato político y restringe el ejercicio de una política exterior proactiva. Entre las características sobresalientes de esta etapa se evidencian las prácticas clientelares, corporativistas, personalismo y la poca credibilidad en el sistema de partidos (León, 1994; Bustamante, 2000).

Durante la década de los noventa el Ecuador experimenta un deterioro de las instituciones del régimen democrático y un desencanto por la partidocracia que se expresó en el levantamiento de amplios sectores populares. Esto condujo a

\footnotetext{
${ }^{22}$ Sobre la naturaleza de la representación ver: orientaciones ideológicas (Freidenberg, 2000), cultura política (Burbano, 1998) y organización interna (Freidenberg y Alcantara, 2001).
} 
que ningún presidente logre culminar su período presidencial y para el año 1995 se dio la primera interrupción de un mandato gubernamental, cuando el Congreso enjuició y destituyó al vicepresidente Alberto Dahik. Entre 1997 y 2005 se derrocaron a tres presidentes electos: Abdala Bucaram (1966-1997), Jamil Mahuad (1998-2000) y Lucio Gutiérrez (2003-2005), después de masivas protestas contra la corrupción y la implementación de una agenda neoliberal. De igual manera, se reorganizaron varias veces los organismos de control del Estado y la Corte Suprema de Justicia. El Congreso se disolvió en el año 2007 y quedó demostrada la disfuncionalidad de la democracia ecuatoriana, así como el carácter polarizado y excluyente del aparataje político.

La organización política en el Ecuador se encuentra tradicionalmente alineada con los intereses de las élites y de grupos de poder que dejan inermes al resto de sectores sociales y un ejemplo claro de ello fue el manejo de la crisis financiera de 1999-2000. En este ámbito, si se analiza los intereses que se jugaron y hacia dónde se inclinó la representación política en Ecuador, encontramos que el sector financiero benefició a la banca, el Estado pagó grandes sumas de dinero en el rescate financiero y cuando la banca quebró ésta fue adquirida por el Estado, saneada con recursos públicos y devuelta al sector privado (Bonilla 2008: 3). Según el BCE, las pérdidas económicas ascendieron a \$ 8.600 millones de dólares. Cerraron el 70\% de instituciones financieras del Ecuador, la moneda local el Sucre se depreció un 190\%, y la inflación fue del $96,1 \%$ para el año 2000. Ante la gravedad de la crisis financiera, y en un desesperado movimiento para detener la hiperinflación, el presidente Jamil Mahuad optó por dolarizar la economía en el 200123. Los ecuatorianos habían pasado en un $70 \%$ sus activos a la moneda norteamericana, frente a la crisis general y la inflación ${ }^{24}$. La dolarización consiguió detener la inflación, primero con una reducción a $12 \%$ (2002), y luego a $8 \%$ en 2003 , y a $2.75 \%$ en $2004^{25}$.

\footnotetext{
${ }^{23}$ El plan consistió en dolarizar la economía (todas las transacciones), después de una fuerte devaluación, con una cotización de 25.000 sucres por dólar (Guevara, 2017).

${ }^{24}$ Con ello, el país renunciaba a la política monetaria (soberanía monetaria), y dejaba el señoreaje a la Reserva Federal de EEUU, a cambio de la estabilidad monetaria.

${ }^{25}$ Esta desaceleración de la inflación implicó inflación en dólares, con el resultado de un acople lento y costoso a nivel económico y social de la economía ecuatoriana a la global.
} 
Como resultado de la implementación de políticas ortodoxas de corte neoliberal desde la década de 1990 y la crisis financiera, el Ecuador quedó marginado y subsumido en una grave crisis económica. Sus efectos fueron devastadores y dejaron un saldo negativo en todos los indicadores sociales: para el año 2000 la pobreza alcanzó casi al $65 \%$ de la población, la desigualdad tuvo sus puntos más altos, y el poder adquisitivo se derrumbó con la inflación ${ }^{26}$. La inestabilidad económica e institucional originó la mayor ola migratoria de la historia del Ecuador, se estima que entre 1998 y 2000 la población migrante fue de un millón de personas, es decir, el 20\% de la población económicamente activa (Guevara, 2017). Por otro lado, para los albores del siglo XXI, la contracara de la emigración tuvo como resultado que Ecuador fuera el país de Sudamérica con mayor ingreso por remesas desde el exterior.

Para el año 2002, se empieza a gestar de manera incuestionable un sentimiento de rechazo a las políticas neoliberales y a la injerencia estadounidense en los proyectos nacionales de desarrollo; esto se hace evidente en el aparecimiento de nuevas prácticas, discursos, luchas y nuevos actores sociales, que buscan cambiar las maneras de hacer política. En este año se evidencia un cambio en las preferencias electorales y democráticas del Ecuador, cuando Lucio Gutiérrez asciende a la presidencia de la república con el respaldo masivo de grupos de la sociedad civil organizada -especialmente del movimiento indígena y opciones políticas de izquierda- y con una propuesta de gobierno alternativa al modelo pro estadounidense, que propone opciones más autónomas de inserción internacional (Jaramillo 2008). Sin embargo, en los primeros meses de su gobierno da un giro inesperado que marca los ejes temáticos que guiarán la política doméstica y exterior de su gobierno.

La política exterior de Gutiérrez da un vuelco tras cumplir su primera visita oficial a Washington cuando decide declararse el "mejor aliado" de los EEUU y alinearse con las políticas de la potencia adoptando medidas complacientes a los intereses norteamericanos. En lo financiero, firma una nueva carta de

${ }^{26}$ El Índice de Gini para los años 1999 y 2000 fue de 0.59 y 0.57 respectivamente. La inflación fue de 52 y $92 \%$ respectivamente, bajando a $40 \%$ en el 2001, y a $12 \%$ en 2002 , gracias a la dolarización. 
intención con el FMI, en lo económico, empieza las negociaciones de un Tratado de Libre Comercio bilateral y en el ámbito de Cooperación Técnica, se alinea con las prioridades de seguridad marcadas por EEUU enfocadas en el Plan Colombia -cuya finalidad fue acabar con la guerrilla y el narcotráfico en la frontera compartida (Jaramillo 2008). La adopción de estas medidas minó durante aproximadamente dos años las demandas populares y fue gestando una rebelión de la clase media que no veía representados sus intereses como sociedad en su gobierno.

Para el año 2005, la presión popular de rechazo a sus medidas fue tan alta que Gutiérrez decidió volver a dar un giro de 180 grados a la política exterior retomando la esencia de sus promesas de campaña electoral. Inició un proceso de distanciamiento de EEUU suspendiendo las negociaciones del TLC, se alejó del BM y suspendió el alineamiento con Colombia en temas de seguridad en la frontera norte (Jaramillo 2008). En el ámbito de la toma de decisiones de la política exterior, que tradicionalmente se encontraban influenciadas por las elites económicas y políticas de las principales ciudades del Ecuador, dio paso a la construcción de un plan de política exterior pensado desde el Estado y concertado con diferentes actores del país. El Plan Nacional de Política Exterior 2006-2020 (PLANEX) fue liderado por la Cancillería Ecuatoriana y con la participación de la academia, la sociedad civil organizada, y diversos movimientos que expresaron su opinión y llegaron a consensos clave acerca del carácter y preferencias que debía priorizar la política exterior ecuatoriana (Jaramillo 2008: 3).

\section{Ruptura con el centro: el ascenso de Rafael Correa}

Gran parte del sentimiento antinorteamericano desatado en el discurso de política exterior de la década de 2000 no solo de Ecuador, sino de países tan variados como Venezuela, Argentina, Bolivia y Brasil ha sido una respuesta a la historia de la infracción directa e indirecta en la autonomía nacional por parte de los EEUU en la región (Burges y Chagas 2016). En el contexto de la creciente desconfianza en la institucionalidad democrática y la desgastada economía ecuatoriana, cobró mayor fuerza la figura de un líder carismático observado 
como concentrador en su personalidad de las capacidades gubernamentales y de representación del conjunto del Estado y que dio un giro a la política exterior ecuatoriana (Bonilla 2008: 4).

El economista Rafael Correa inauguró su campaña en 2006 sin un partido político, con la creación de un movimiento denominado "Patria Altiva i Soberana" (PAIS), que agrupó a militantes de izquierda, intelectuales, académicos, movimientos sociales y actores políticos. En la carrera a la presidencia en octubre, su movimiento se ubicó en el segundo lugar en las elecciones, con el $26.8 \%$. En la segunda vuelta en noviembre, derrotó en las urnas al hombre más rico del Ecuador, el multimillonario Álvaro Noboa, con el 56.7\% de los votos. Correa recogió el descontento popular capitalizando sentimientos antipartidistas y antineoliberales (síntomas de la crisis de la democracia representativa), marcando una ruptura con el pasado inmediato. Su discurso estuvo cargado de referencias a la nueva etapa que se abría para la izquierda y, con grandilocuencia, se embarcó en un proyecto político que giró en torno a ideales como "recuperar la patria" y "salir de la larga noche neoliberal". Convocó a todos los ecuatorianos de "manos limpias, mentes lúcidas y corazones ardientes" a sumarse a la "revolución ciudadana" porque "la patria ya es de todos" (Burbano 2015: 10). La propuesta que se convirtió en el pilar de campaña, y posterior hoja ruta para su primer año de gobierno, fue convocar a una Asamblea Constituyente.

El presidente se erigió como líder anti-establishment, y la elaboración de la Constitución, altamente respaldada por movimientos sociales, defensores de derechos humanos, académicos de izquierda, indigenistas, etc., se convirtió en la nueva utopía para refundar el Estado. El objetivo apuntaba a tener un Estado más inclusivo, construir una sociedad más igualitaria y renovar las instituciones políticas corruptas (Bernal 2014: 442-443). La Revolución Ciudadana inició un proceso de refundación institucional legitimado a través de las urnas con la aprobación del referéndum para la creación de una nueva Constitución de Montecristi (refrendada por el 63,9\%). De esta manera, se inauguró un nuevo período en las dinámicas políticas, económicas y sociales del Ecuador que se avocaron a la reestructuración del Estado y a la recuperación de sus 
capacidades de rectoría, coordinación y regulación. Esto vino de la mano de la consolidación de un nuevo aparataje institucional y procesos de planificación de políticas públicas cuya finalidad era la "gestión soberana" de recursos nacionales.

En el plano de la política exterior, la agenda se reorganizó ampliando los horizontes tradicionales marcados por las relaciones bilaterales con EEUU, Colombia y Perú que copaban la política internacional hasta finales del siglo XX. De acuerdo a Adrián Bonilla, hasta entrado el siglo XXI, la política ecuatoriana en el ámbito externo presentó una serie de episodios caracterizados por la necesidad del Estado de reaccionar ante agendas sobre las que el país no tiene control, siendo tres las temáticas dominantes: económica, seguridad territorial y agendas transnacionalizadas (Bonilla 2006: 165). En el ámbito económico, la temática gira alrededor de un tema estructural marcado por la Deuda Externa y las relaciones con la arquitectura institucional que regulaba la economía de distintos países. En cuanto a la seguridad nacional, las relaciones giran alrededor del conflicto limítrofe con el Perú que finalmente fue resuelto en 1998. Mientras que la dimensión transnacional está marcada por el conflicto colombiano, la migración, delitos transnacionales y nuevas agendas de seguridad (Bonilla 2006: 166).

Con el ascenso de Correa a la presidencia, las prioridades políticas internacionales se rearticulan en base a los postulados enunciados en su "Programa de Acción del Plan de Gobierno del Movimiento PAIS 2007-2011", con el que presentaron su candidatura a la presidencia de la república, y que posteriormente se plasman en el Plan Nacional de Desarrollo 2007-2010 y en los Planes Nacionales del Buen Vivir 2009-2013 y 2013-2017. Estos giran alrededor de siete ejes centrales: a) la defensa de la soberanía, b) el multilateralismo activo, c) la integración latinoamericana, especialmente sudamericana, d) la diversificación de mercados internacionales y cooperación Sur-Sur, e) la protección del medioambiente, f) la protección de los derechos de los migrantes ecuatorianos en el exterior, g) la libre movilidad de las personas y la ciudadanía universal (Zepeda y Egas 2011: 99). Esto representó una revisión de los postulados de inserción internacional del país en el mundo y su consecución se 
planteó a través del fortalecimiento de una diplomacia activa y dinámica que apoye el multilateralismo y busque consolidar el eje Sur-Sur de las relaciones internacionales, apuntando a la promoción de relaciones justas que hagan contrapeso a los poderes tradicionales.

Con la formulación y puesta en marcha de dichos instrumentos nacionales de planificación, el gobierno reasumió la dirección política del proceso de desarrollo nacional y de su inserción internacional a través de cinco "revoluciones": revolución constitucional y democrática, revolución ética, revolución económica, productiva y agraria, revolución social; y, revolución por la dignidad, soberanía e integración latinoamericana (Senplades 2010: 9). En líneas generales, el modelo de desarrollo planteado conjugó elementos centrales como la implementación de políticas económicas con fines redistributivos, el progreso material del país a través de obras públicas y la ampliación de la agenda social en áreas como educación, salud, seguridad social. Además, se propuso articular las necesidades de desarrollo nacional con la gestión internacional y la búsqueda de autonomía que permita al país posicionarse de manera privilegiada en el nuevo orden internacional.

La política externa inaugurada por Rafael Correa encontró sintonía en la región con la llegada a la presidencia de grandes liderazgos en América Latina y el ascenso de gobiernos de tinte "progresista" (Argentina, Bolivia, Venezuela, Nicaragua, Brasil, Uruguay y Paraguay) que marcaron la coyuntura perfecta para articular una política exterior asertiva y dar un renovado aliento al sueño unionista de conformar la "Patria Grande". La "diplomacia de cumbres" se convirtió en una herramienta efectiva para avanzar proyectos de planificación regional y el regionalismo latinoamericano convirtió en el pilar fundamental no solo para hacer frente a los países hegemónicos, sino también para mejorar la capacidad de renegociación de acuerdos dispares con los EEUU, consolidar un eje de cooperación que sea capaz de prescindir de las instituciones financieras internacionales en el futuro, y superar el escenario de marginalidad internacional característica de los países periféricos. 


\section{La política exterior en el marco de la Revolución Ciudadana}

Las relaciones internacionales durante el mandato de Rafael Correa adoptaron concepciones teóricas muy cercanas a las que aporta el Realismo Periférico sobre el desarrollo y el rol de la política exterior. Sobre la base del pensamiento autonomista, Aldo Ferrer concibe al desarrollo como un proceso que se da en un espacio nacional, abierto a su contexto externo, pero afirmado en la densidad nacional de los países; esto garantiza una relación simétrica no subordinada en el escenario internacional (Ferrer 2010). Durante la Revolución Ciudadana, el objetivo fundamental de la política externa fue potenciar el desarrollo endógeno del país, reequilibrando sus relaciones geopolíticas en un contexto internacional, que toma en cuenta diversos actores internacionales de manera estratégica. Esto implicó tomar distancia de las directrices convencionales, para insertar al país en redes políticas, económicas y sociales que brinden una mirada alternativa y complementaria del esquema de integración del país a nivel global (Senplades 2010).

Estas directrices dan una pauta acerca del debate que se suscita en el Ecuador entre dos modelos de inserción internacional: por una parte, los que priorizan el liberalismo económico y privilegian el alineamiento con la potencia dominante del momento; y por otra, un modelo desarrollista que se asocia con la búsqueda de la autonomía (Pignatta 2010). Durante la presidencia de Correa se recogió esta última tradición proponiendo la búsqueda de la autonomía, vinculada a un modelo de desarrollo nacional de perfil endógeno. De manera congruente, se impulsaron estrategias de inserción internacional que no buscaron la acumulación de poder a través del fortalecimiento de vínculos y alineamiento con actores poderosos, sino que se privilegió la idea de que un país se proyecta desde adentro hacia afuera.

Sobre la base de este entendimiento del desarrollo, el gobierno de Correa se avocó a fortalecer la cohesión social, la calidad del liderazgo, la estabilidad institucional y política, la existencia de un pensamiento propio sobre la interpretación de la realidad; que se traduce en políticas propicias al desarrollo económico -lo que Ferrer denomina como la “densidad nacional” (Ferrer 2010). 
Como eje central de su administración se enfatizó en políticas sociales y redistributivas enfocadas en la reducción de la pobreza, la creación de empleo, la reducción de la inequidad. En el ámbito económico, se mantuvo una política reivindicativa impulsando procesos de renegociación internacional basados en su interés nacional; asimismo, se mantuvo un pensamiento crítico sobre el sector financiero (BM, FMI) debido a las condiciones de política pública que imponen estas instituciones. En cuanto al modelo de desarrollo, se sostuvo una visión estatista y neo-desarrollista; además, se reivindicó la importancia de los socios del Sur, la integración regional y la apuesta por el multilateralismo.

En este sentido, la política internacional adquirió un matiz revisionista porque optó por contrapesar el dominio hegemónico de los países del Norte, especialmente de los EEUU y priorizar las relaciones con los socios del Sur Global. Así, las acciones tradicionales de política exterior mostraron ajustes y se rejerarquizaron en pro de favorecer la diversificación de socios comerciales y políticos. Esto se hace evidente cuando los vínculos a nivel estatal que se busca fortalecer miran al Asia Pacífico, especialmente a China, que se presenta como un como un socio estratégico perteneciente al grupo de los países "en vías de desarrollo" y juega un rol determinante en las políticas económico-comerciales del país. Mientras que, en el ámbito regional, Brasil y Venezuela adquieren un rol protagónico y se los considera eje central para construir la "patria grande" y sustentar la autonomía de la región.

\section{Cooperación Sur-Sur y estructuras económicas del Ecuador}

La CSS es uno de los pilares de la política externa que el gobierno ecuatoriano buscó impulsar a través de la cooperación económica. El carácter desarrollista que imprime la presidencia de Rafael Correa en el manejo de esta área temática se transversaliza en las estrategias nacionales de desarrollo que apuntan a una transformación de la estructura extractivista y primario exportadora -que tradicionalmente ha posicionado al Ecuador en la periferia de la división internacional del trabajo- hacia una reestructuración del sistema de acumulación, distribución y (re)distribución de la riqueza en el país mediante el fomento de una 
economía terciario exportadora (SENPLADES 2010). Esto implica, por un lado, el fortalecimiento de capacidades productivas y de diversificación de socios comerciales, y por otro, al manejo de la inversión extranjera y del endeudamiento público, como se señala en el PNBV 2009-2013:

En el sector externo de nuestra política [comercial], esto implica establecer en el corto, mediano y largo plazo, un esquema de alianzas y aliados estratégicos, alineados y armónicos a nuestros objetivos nacionales; de tal forma que podamos fortalecer ejes alternativos de relaciones internacionales enfocados hacia el «Sur», dejando atrás las clásicas cartas de intención y las agendas condicionadas de gobiernos anteriores (SENPLADES 2010).

Siguiendo los postulados de los instrumentos programáticos que guían el accionar del país, una de las estrategias fue buscar la disminución de la dependencia ${ }^{27}$ estructural y la vulnerabilidad externa a través de un cambio profundo en la "matriz productiva", que ha estado tradicionalmente enfocada a la explotación y disponibilidad de recursos de la exportación de petróleo. Esto se encuentra en línea con los objetivos de desarrollo señalados en el PNBV donde el Ecuador se plantea transitar de un de un "esquema primario exportador y extractivista a uno que privilegie la producción diversificada y eco-eficiente, así como los servicios basados en los conocimientos y la biodiversidad" (SENPLADES, 2010: 85). Es decir, se apostó por la transformación de la estructura primario-exportadora a través del "aumento de la productividad real y diversificación de las exportaciones y destinos mundiales" (SENPLADES 2010: $61)$.

Tradicionalmente, el Ecuador ha sido un país exportador de materias primas y hasta finales del siglo $\mathrm{XX}$, ha mostrado una tendencia estable, en niveles bajos, de sus exportaciones. A partir de los años setenta, el país experimenta una expansión moderada de las exportaciones que se sostiene hasta entrada la década de los noventa. Esta tendencia cambia a partir del nuevo milenio, cuando las exportaciones del Ecuador al mundo aumentan alcanzando niveles históricos

\footnotetext{
${ }^{27}$ Este postulado señala que el "posicionamiento de los Estados se ve limitado por su función dentro de la estructura económica internacional de producción y distribución", ya sea productor de bienes industrializados o bien de bienes primarios, acentuando esto las relaciones de dependencia de los países periféricos productores de materias primas con respecto a los países céntricos productores de bienes industrializados (Cardoso, 1967)
} 
y picos elevados como en el año 2008 con 21.100 millones de dólares o en el 2014 cuando alcanzó una cifra de 28.536 mil millones de USD (Gráfico 13).

Gráfico 13. Evolución de las exportaciones de Ecuador

\section{Evolución de las exportaciones de Ecuador. 1960-2017 (en millones de USD)}

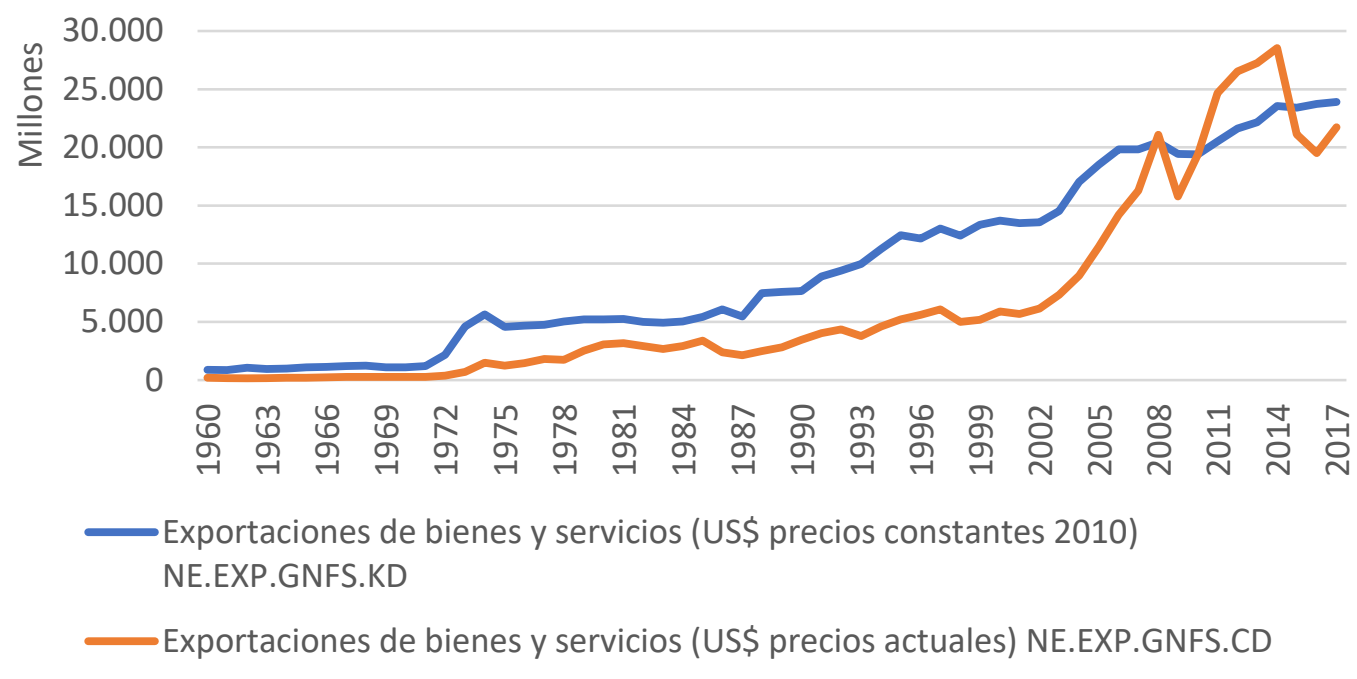

Fuente: BM

Elaboración propia

Para el caso ecuatoriano, el aumento de las exportaciones no da cuenta de mayores niveles de industrialización, por el contrario, muestra el carácter primario exportador del país. De acuerdo a la clasificación del BCE, los tres principales componentes de las exportaciones del país son los siguientes: a) exportaciones petroleras, b) las exportaciones no petroleras tradicionales; $y, c$ ) las exportaciones no tradicionales (Gráfico Nro. 14).

El petróleo crudo es el producto más representativo de la economía ecuatoriana $y$, desde la década de los sesenta, ha mantenido un peso relativo importante con porcentajes que bordean entre el $30 \%$ y el $50 \%$ del total de productos exportados. En el período de análisis, del 2006 al 2016, se puede observar que el porcentaje de exportaciones petroleras sobre el total no ha bajado del $50 \%$. Por su parte, las exportaciones no petroleras tradicionales incluyen cinco rubros: 
banano, café y elaborados, cacao y elaborados, camarón, atún y pescado. Históricamente, su importancia ha ido disminuyendo progresivamente a medida que ha aumentado la exportación de petróleo, hasta inicios del nuevo milenio representaban cerca del $40 \%$ y desde el año 2004 su peso en las exportaciones se mantiene alrededor del $20 \%$. Finalmente, las exportaciones no tradicionales, están representadas por un conjunto de productos primarios (flores, frutas, madera, productos mineros) e industrializados (jugos y conservas de fruta, harina y enlatados de pescado, químicos, vehículos). Desde la década del dos mil, el peso relativo de cada uno de estos dos grupos se ha mantenido relativamente estable, alrededor del $30 \%$.

Gráfico 14. Composición de exportaciones de Ecuador

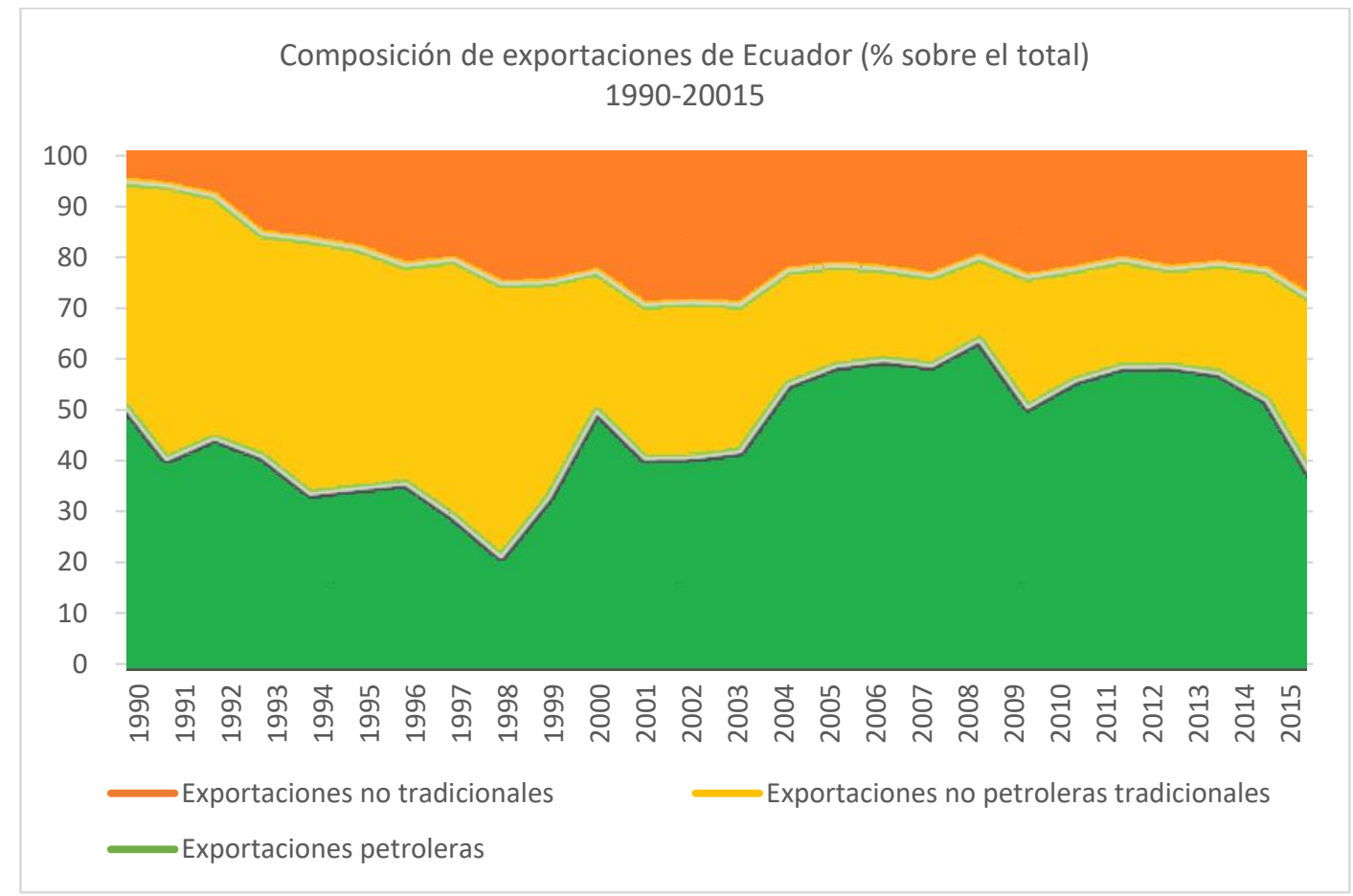

Fuente: BCE

Elaboración: propia

Para el análisis de la estructura de las exportaciones, el OEC de la Universidad de Harvard ofrece una visualización sobre el comercio internacional y su estructura en determinados años. Si se realiza una comparación para el caso ecuatoriano con cortes a inicios del nuevo milenio (figura 1), posteriormente 
cuando comienza el período de Rafael Correa en 2006 (figura 2) y cuando culmina su mandato en el año 2016 (figura 3), se puede observar que la canasta de exportaciones continúa estando altamente concentrada en productos primarios.

El petróleo es el principal producto de exportación, concentró un 36\% del total de exportaciones del país en el año 2000, seguido del plátano que alcanzó un $24 \%$ y rubros como las flores, crustáceos, pescado representaron, cada uno, menos del 7\% para el mismo año. Cuando Rafael Correa inicia su mandato, el porcentaje correspondiente a la exportación de petróleo alcanzó un 50\% y el plátano disminuyó a $16 \%$ y el resto de productos pasaron a representar cada uno menos del $4 \%$ de las exportaciones. Mientras que para el año 2016, el petróleo alcanzó un $31 \%$ de las exportaciones totales, los plátanos un $17 \%$ y se da un notable incremento en las exportaciones de crustáceos y moluscos que ocupan un $16 \%$ y el resto de productos ocupa individualmente cerca del $5 \%$.

Figura 1: Exportaciones del Ecuador año 2000

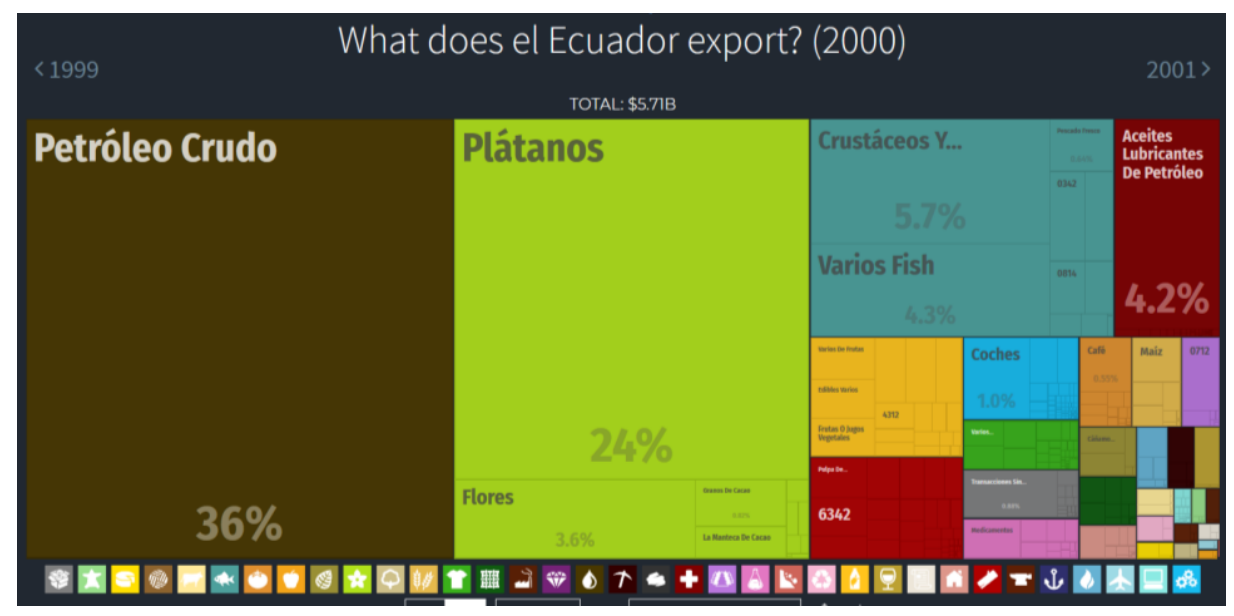


Figura 2. Exportaciones del Ecuador año 2006

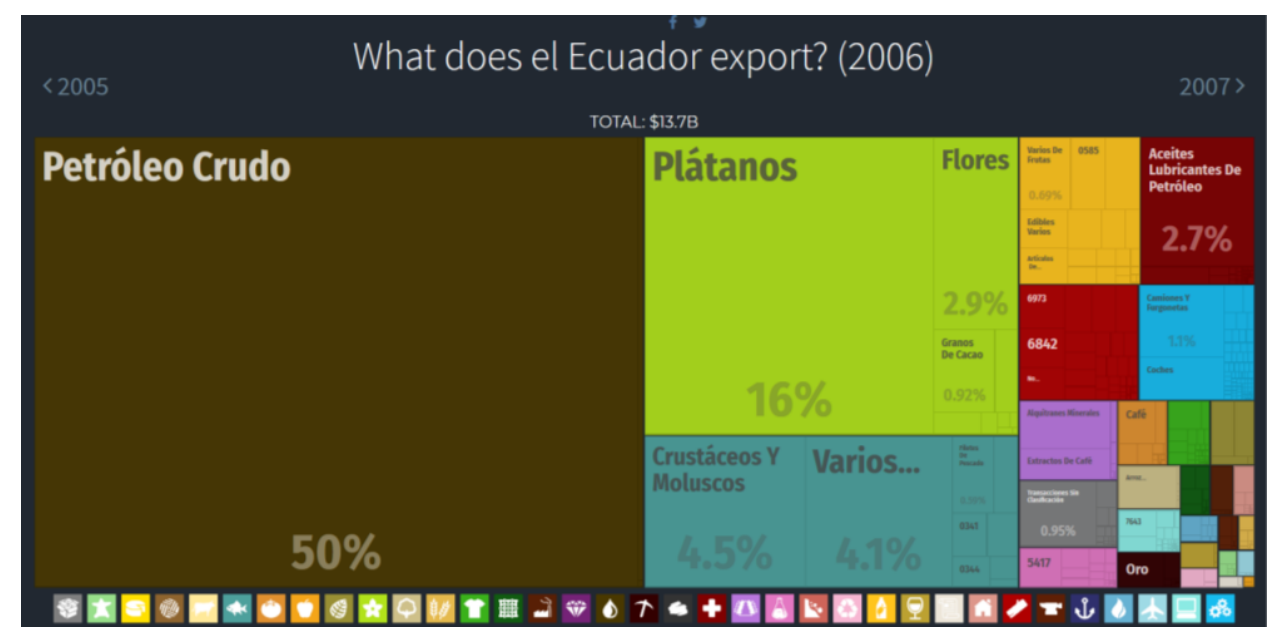

Figura 3. Exportaciones del Ecuador año 2016

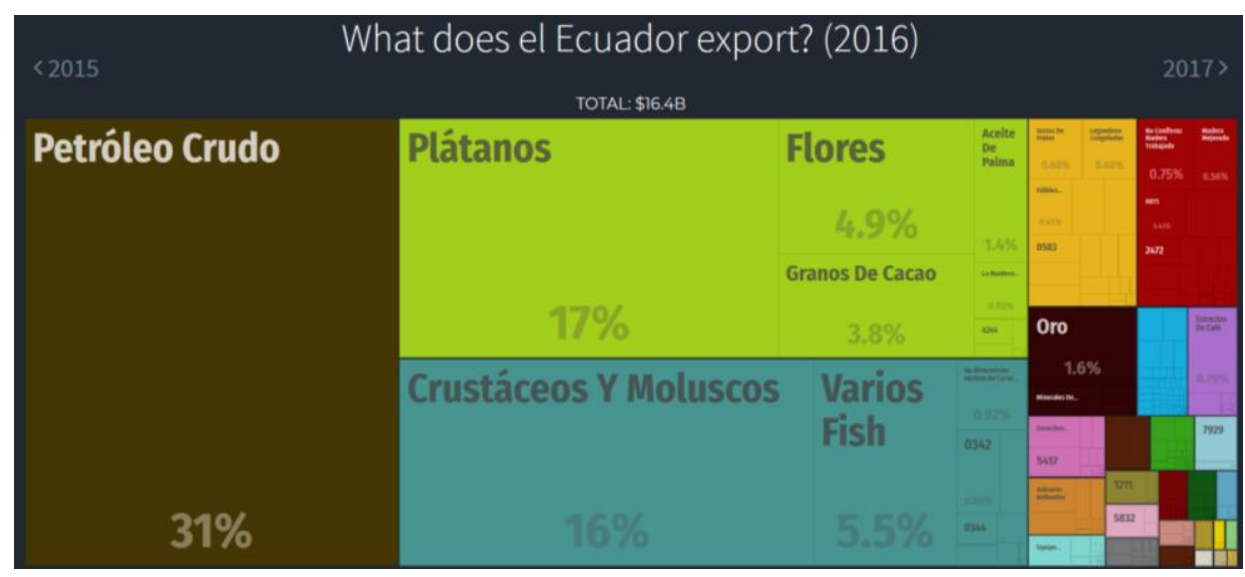

Elaboración: propia

Fuente: OEC

La poca especialización de los productos exportables acentúa la vulnerabilidad del país debido a que se encuentra inevitablemente vinculada con la volatilidad de los precios de los commodities. Por lo que, la fluctuación de los precios mundiales de los productos es uno de los principales factores de la inestabilidad del total de los ingresos de exportación en una economía dependiente de pocos productos primarios. Es decir, cuando los precios suben, se estimula la exportación de dichos bienes y aumentan los ingresos del país, lo que, a su vez, incita al consumo y aumento de importaciones. Sin embargo, cuando se enfrenta 
una desaceleración de precios, las importaciones que se estimulan por los ingresos obtenidos por las exportaciones provocarán una necesidad aun mayor de exportar bienes primarios para cubrir el déficit comercial (Martínez et al, 2014).

En el caso ecuatoriano, el aumento de los precios de las commodities que se exportan influyó positivamente en el crecimiento de la economía del país. Como se puede observar en el gráfico Nro. 15, las exportaciones en relación al PIB del Ecuador representan valores que van en aumento a partir del nuevo milenio. Así, si para 1960 este rubro representaba menos del 10\% del PIB, entre los años 2006 y 2016 representan de manera sostenida más del $28 \%$ del PIB del país, llegando en el año 2008 a representar cerca del 33\% de los ingresos de la economía ecuatoriana.

Gráfico 15.Exportaciones de bienes y servicios Ecuador

Exportaciones de bienes y servicios. 1960-2016

(\% del PIB)

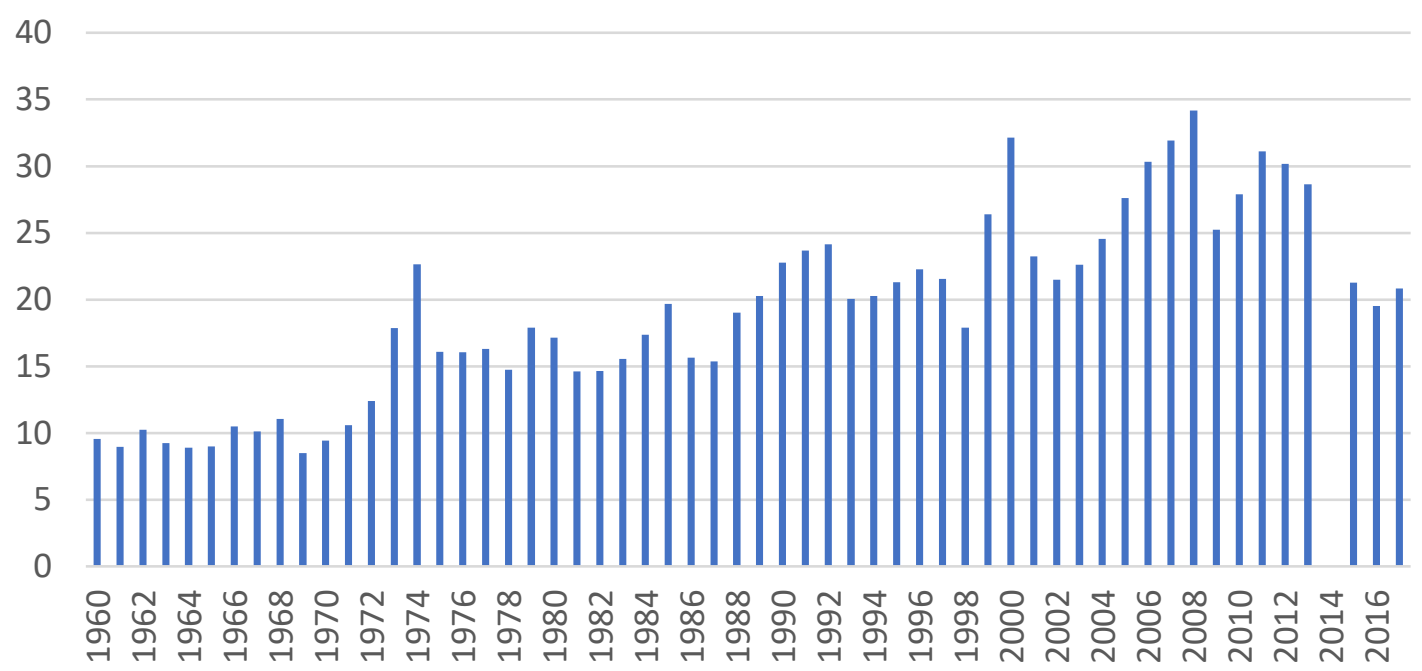

Elaboración: propia

Fuente: BM

La volatilidad de los precios de las materias primas es un elemento externo que incide en la política económica de un país periférico. De acuerdo con la CEPAL, 
uno de los factores fundamentales en el aumento de los precios de los productos básicos ha sido la gran demanda de commodities por parte de países emergentes, especialmente de China. Estas economías se encuentran en una etapa de desarrollo intensiva en cuanto a consumo de recursos primarios tales como metales, minerales, petróleo por lo que su demanda incidió sobre los precios en la década de los 2000 (Cepal 2012).

Esto ha dado lugar a que América Latina experimente el denominado ciclo de las commodities, que es un concepto que hace referencia a las fluctuaciones de los precios superiores a su tendencia que se extienden durante décadas y afectan a un amplio rango de productos básicos (CEPAL, 2012: 63). Erten y Ocampo 2012 señalan que, a partir de la primera década del siglo XXI, la economía internacional experimenta una nueva etapa económica caracterizada por el incremento de los precios reales de las materias primas. De hecho, desde 1865 al 2010 se han experimentado cuatro super ciclos económicos, siendo el último en la década del 2000. En esta década se duplica el precio de los metales y se eleva hasta un $75 \%$ los precios de productos agropecuarios y energéticos como el petróleo (Erten y Ocampo 2012).

Este boom de los precios influyó positivamente en el crecimiento del PIB de la economía ecuatoriana, y en general de las latinoamericanas; pero al aumentar el ingreso por persona se amplió el mercado doméstico y la demanda de bienes de consumo y de capital, lo que provocó un crecimiento más elevado de las importaciones (Martínez et al. 2014). En el caso específico del país andino, en el grafico Nro. 16, se puede observar que las importaciones aumentaron de manera constante, con una aceleración a partir de la primera década del año 2000). 
Gráfico 16. Importaciones de bienes y servicios Ecuador

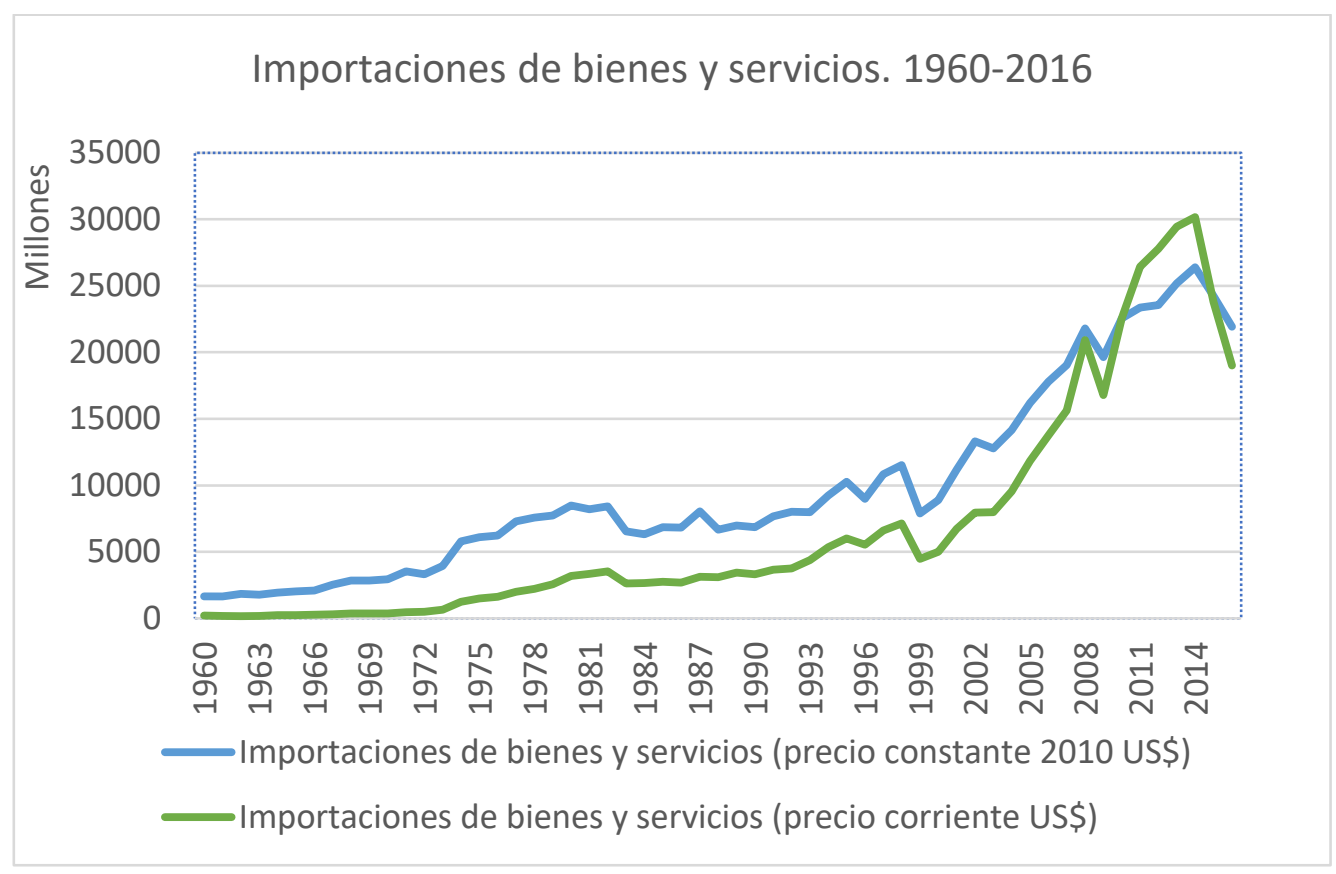

Elaboración propia

Fuente: BM

Otra de las características estructurales de los países periféricos es el poco nivel de industrialización de su economía. En el caso específico de las importaciones del Ecuador, el Banco Central del país clasifica a los componentes de las importaciones en: a) bienes de consumo, b) combustibles, c) materias primas; $y$, d) bienes de capital. Del total de importaciones del país, las materias primas han disminuido su peso de cerca del $45 \%$ en el año 2000 a un $35 \%$ en el 2016 , los bienes de capital mantienen un peso relativo de alrededor de un $25 \%$ mostrando una leve tendencia descendente desde inicios del nuevo milenio (Gráfico 17). Los bienes de consumo muestran una tendencia a la baja habiendo representado cerca de un $28 \%$ en el año 2002 y sosteniéndose durante la década analizada en alrededor del $20 \%$ del total de importaciones.

El componente que más ha experimentado un crecimiento es la categoría de combustibles y lubricantes que aumenta de manera notoria, de un $7 \%$ en el año 2000, a un 25\% de las importaciones totales en 2014 y termina representando alrededor de un $16 \%$ en el 2016. Su incremento está ligado a la importación de mayores volúmenes de combustibles que tienen alta volatilidad de precios y 
coincide con el alza generalizada de los precios de las materias primas durante el período estudiado.

Gráfico 17. Componente de importaciones ecuatorianas (en \% sobre el total)

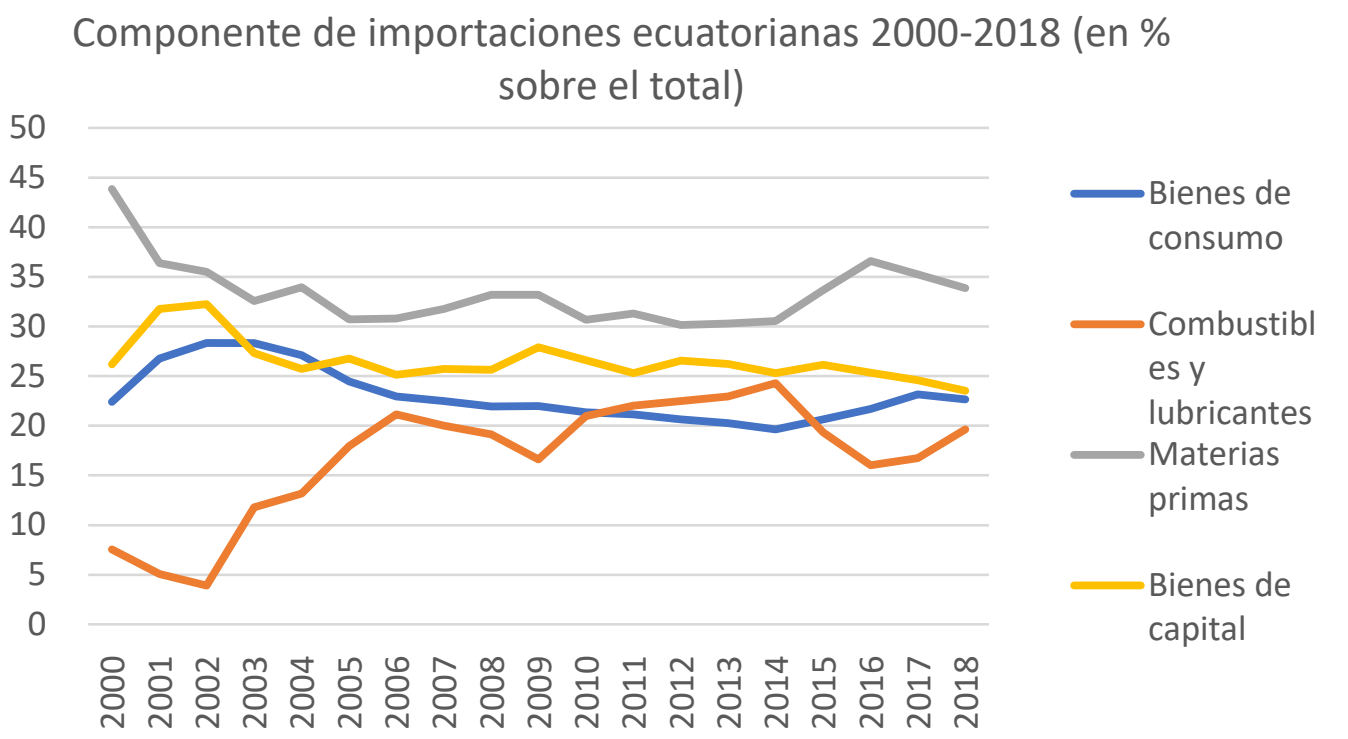

Elaboración propia

Fuente: BCE

Las reservas de petróleo existentes en Ecuador atraen la demanda de crudo por parte de economías industrializadas, especialmente las de mayor dinamismo y que consumen energía y materias primas, como es el caso de China y de otros países emergentes. Este aumento de la demanda, junto con el incremento de los precios de dicho commodity, dio paso a que el Ecuador aumente sus ingresos económicos y tenga mayores superavits monetarios. Sin embargo, el país también experimentó mayores déficits físicos debido a que el auge de los ingresos por las exportaciones estimuló un mayor aumento en las importaciones, lo que deja déficit tanto en la balanza comercial monetaria como en la balanza comercial física (Martínez et al. 2014).

Si se analiza la balanza comercial monetaria del país andino, ésta presenta un alto grado de oscilación, con una tendencia a experimentar déficit comercial monetario durante el período analizado. El máximo superávit se alcanza en 1999 
con $\$ 1,4$ mil millones, luego entra en déficit en 2001, y se recupera hasta alcanzar nuevamente un superávit pico en 2006 con $\$ 614$ millones. A partir del 2008, la balanza comercial monetaria ecuatoriana entra en un déficit histórico alcanzando en el año 2010 \$ -3 mil millones. Esta tendencia se sostiene con ciertas variaciones hasta el año 2015 que alcanza \$ -2 mil millones (gráfico 18).

Gráfico 18. Balanza comercial de bienes y servicios (US\$ a precios actuales)

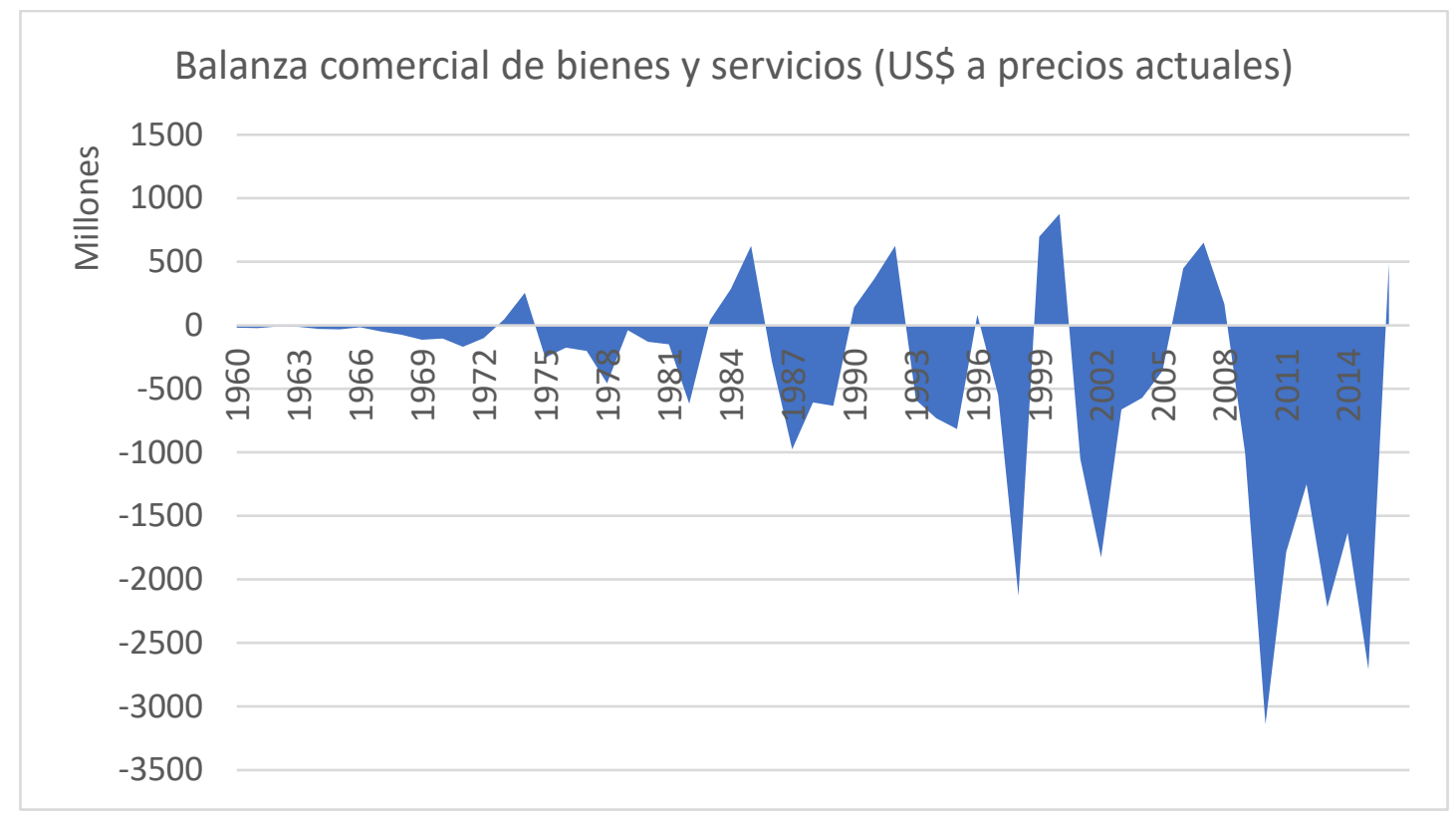

Elaboración propia

Fuente: BM

Esta tendencia de déficit comercial monetario trae consigo el incremento de déficit en cuenta corriente y mayores niveles de endeudamiento. Esto a su vez, provoca aumentos en la extracción de crudo y una mayor tendencia a la reprimarización de la economía, lo que ha dado lugar a una nueva situación, en la que se presentan al mismo tiempo déficits físicos y monetarios (Martínez et al, 2014). Otra de las características de la economía ecuatoriana es su marcada influencia y volatilidad a la demanda externa y su dependencia de exportaciones de bienes primarios. Esto hace que el rol de los precios internacionales estimulen las exportaciones -que históricamente han estado concentradas en bienes primarios, desde la época del cacao en el siglo XIX, del banano hasta la mitad 
del siglo $\mathrm{XX}$ y del petróleo desde los años sesenta hasta la actualidad (Domínguez y Caria 2016).

\section{El rol de China y de Estados Unidos en el panorama económico del Ecuador}

La cooperación económica constituye la base sobre la que se apoya el pilar del diálogo político característico de la CSS que desde sus inicios buscó consolidar alianzas para el cambio de las relaciones económicas internacionales y promover un Nuevo Orden Internacional (Domínguez 2016: 2). Esta área de la política externa y del financiamiento del desarrollo se caracteriza por el reducido margen de maniobra que el país periférico puede detentar para hacer prevalecer su interés nacional sobre el interés de las naciones centrales; a diferencia del campo de la diplomacia, donde los Estados encuentran mayor soltura para desenvolverse y planificar sus comportamientos de política internacional. El margen real de actuación en cuanto a temáticas comerciales y financieras es muy reducido e impide implementar una política económica autónoma, especialmente cuando los intereses de los países centrales se encuentran bajo amenaza (Hey y Klak 1999).

La actividad económica del Ecuador ha sido históricamente impulsada por las exportaciones de recursos primarios a economías desarrolladas, en este sentido, las relaciones que ha consolidado el país andino con EEUU tienen las características de una relación convencional entre centro y periferia. Por el contrario, el vertiginoso incremento de las relaciones con China muestra una característica singular porque este país es considerado una economía emergente y perteneciente al Sur Global y por lo tanto promovería términos de intercambio más horizontales.

Analizar la naturaleza de los flujos de comercio para con estas dos economías resulta relevante para entender las hipótesis implícitas en esta investigación, sobre si el fortalecimiento de las relaciones Sur-Sur con China así como el incremento de su comercio bilateral, han impulsado patrones diferenciados de aquellos que reproducen las relaciones centro periferia, o si más bien, se 
fortalece dicho modelo de relacionamiento debido a la demanda de recursos naturales típica de una potencia en ascenso. Desde este punto de partida, las variables comerciales son centrales para el análisis del dinamismo económico experimentado por la economía ecuatoriana para con China, principal motor de la CSS, y para con EEUU con el que ha mantenido un elevado grado de dependencia comercial y financiera.

Durante la época analizada, las relaciones comerciales que el Ecuador ha sostenido tanto con China como con EEUU se han mostrado muy dinámicas. Como se puede observar en el gráfico Nro. 19 el intercambio comercial con China ha crecido de manera exponencial en el Ecuador. La tendencia a importar desde el país asiático, medida como porcentaje sobre el total de importaciones, ha ido en aumento; así, en el año 2006 el porcentaje ascendía a 9,57\%, mientras que para el año 2016 estas representaron 19,09\% sobre el total de importaciones. Lo que refleja un incremento de alrededor de 10 puntos porcentuales. Por su parte, las importaciones que realiza el país andino desde EEUU representan un porcentaje de $19,46 \%$ en el año 2006 y terminan en un $23 \%$ en el año 2016. Es decir, un aumento de cuatro puntos porcentuales.

Gráfico 19. Importaciones del Ecuador (\% sobre el total de importaciones)

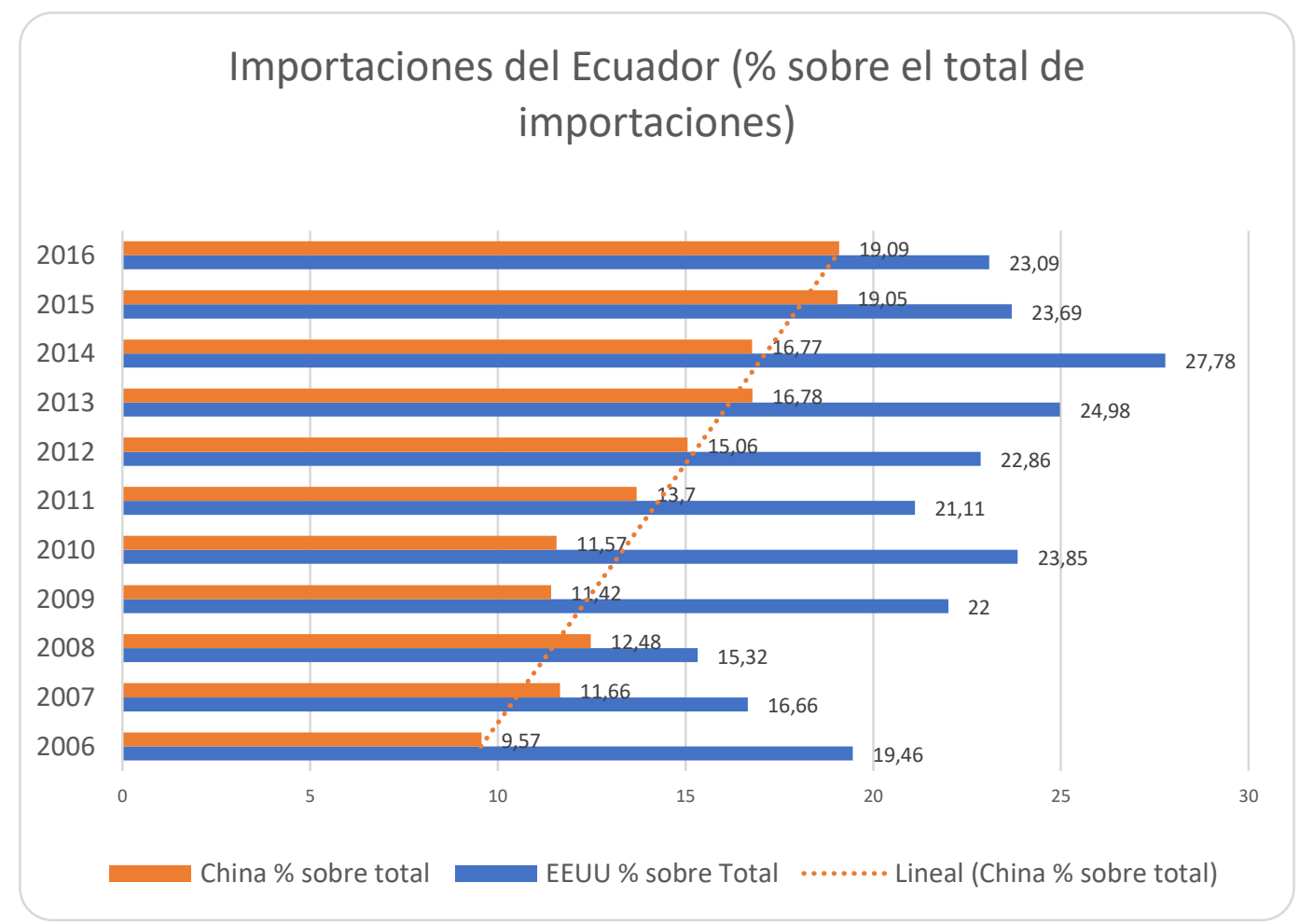


Fuente: ALADI

Elaboración: propia

En cuanto a las exportaciones del Ecuador medidas como porcentaje total de este rubro, podemos observar que EEUU detenta un lugar preminente en el comercio con el país andino. En el año 2006, cerca del 53\% de las exportaciones fueron dirigidas a este país, mientras que, en el 2016 el porcentaje alcanza un $32 \%$ (Gráfico 20). Si bien existe una tendencia a la baja de las exportaciones al socio del norte, los valores comercializados superan en gran medida a las exportaciones realizadas hacia China, representando durante todo el periodo analizado por lo menos un tercio del total de este rubro. Por su parte, las exportaciones del Ecuador al gigante asiático muestran una tendencia continua al alza, pero llegan a representar como máximo cerca del $4 \%$ del total de productos que exporta el Ecuador.

Gráfico 20. Exportaciones del Ecuador (Valores en miles de US\$)

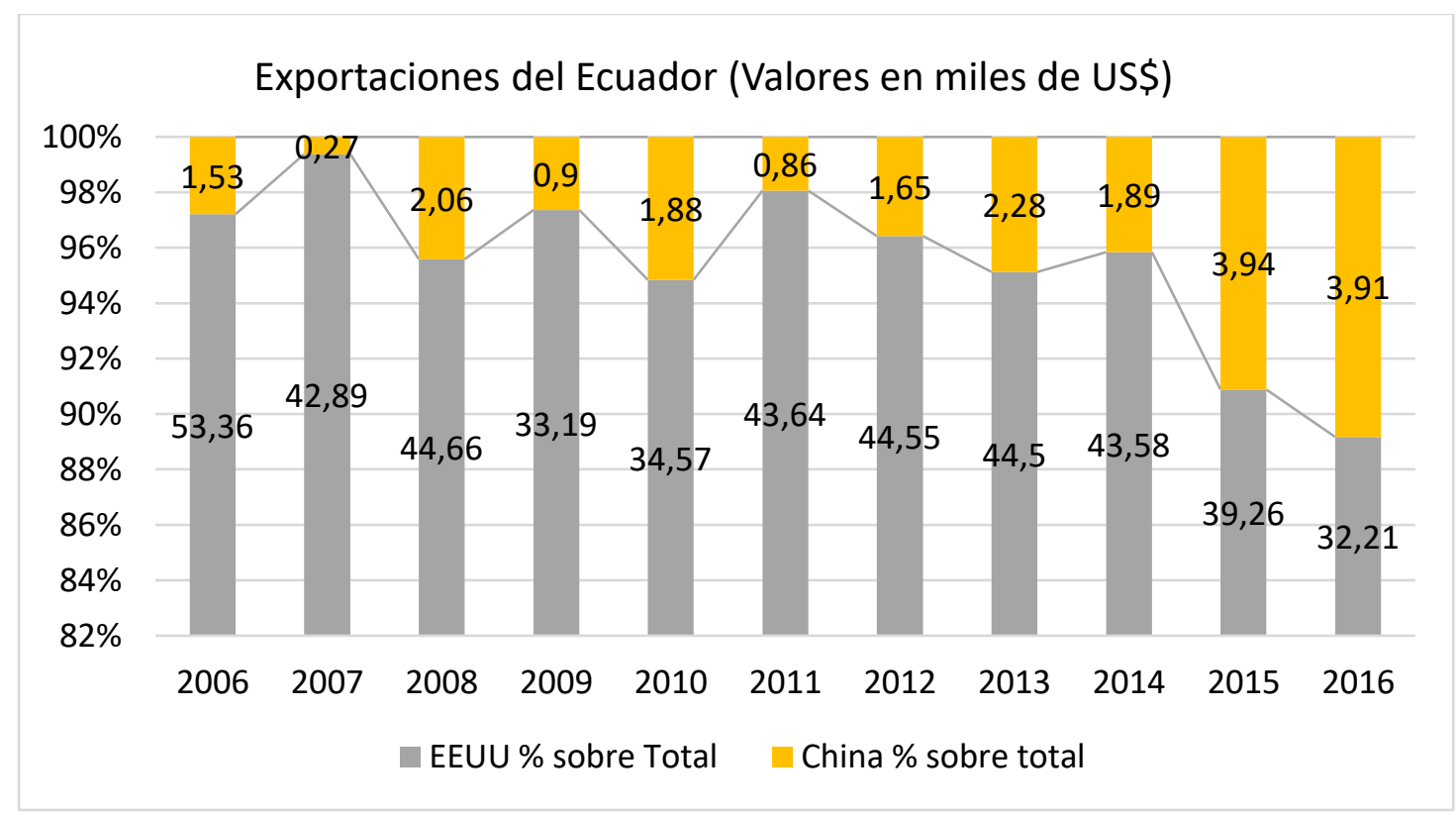

Fuente: ALADI

Elaboración: propia

El siguiente cuadro muestra un resumen del incremento y evolución de las relaciones comerciales del Ecuador tanto con China, como con EEUU donde se puede observar las cifras en dólares y el porcentaje que representa durante cada 
año. EEUU se mantiene como el socio más dinámico para el Ecuador, sin embargo, lo notable es el crecimiento del comercio con el gigante asiático de quien el Ecuador pasó a importar un $20 \%$ del total de su comercio en el año 2016.

Tabla 3. Importaciones y exportaciones de Ecuador. China-EEUU

\begin{tabular}{|c|c|c|c|c|c|c|c|c|}
\hline \multicolumn{5}{|c|}{ Exportacic } & \multicolumn{4}{|c|}{ Importaciones del Ecuador } \\
\hline Año & EEUU \$ & $\begin{array}{l}\text { EEUU } \\
\% / \text { total }\end{array}$ & $\begin{array}{l}\text { China } \\
\% / \text { total }\end{array}$ & China \$ & EEUU \$ & $\begin{array}{l}\text { EEUU } \\
\% / \text { Total }\end{array}$ & China \$ & $\begin{array}{l}\text { China } \\
\text { \%/total }\end{array}$ \\
\hline 2006 & 6.791 .447 & 53.36 & 1.53 & 194.728 & 2.347 .100 & 19.46 & 1.153 .592 & 9.57 \\
\hline 2007 & 6.142 .050 & 42.89 & 0.27 & 39.136 & 2.302 .117 & 16.66 & 1.610 .965 & 11.66 \\
\hline 2008 & 8.405 .186 & 44.66 & 2.06 & 387.465 & 2.848 .740 & 15.32 & 2.320 .381 & 12.48 \\
\hline 2009 & 4.600 .913 & 33.19 & 0.9 & 124.208 & 3.319 .729 & 22 & 1.722 .759 & 11.42 \\
\hline 2010 & 6.046 .029 & 34.57 & 1.88 & 328.738 & 4.910 .725 & 23.85 & 2.382 .411 & 11.57 \\
\hline 2011 & 9.742 .366 & 43.64 & 0.86 & 192.322 & 5.125 .855 & 21.11 & 3.326 .859 & 13.7 \\
\hline 2012 & 10.586 .300 & 44.55 & 1.65 & 391.697 & 5.784 .296 & 22.86 & 3.810 .392 & 15.06 \\
\hline 2013 & 11.013 .256 & 44.5 & 2.28 & 563.904 & 6.688 .611 & 24.98 & 4.493 .526 & 16.78 \\
\hline 2014 & 11.211 .730 & 43.58 & 1.89 & 485.076 & 7.643.341 & 27.78 & 4.614 .572 & 16.77 \\
\hline 2015 & 7.197.272 & 39.26 & 3.94 & 722.966 & 5.067 .526 & 23.69 & 4.073 .757 & 19.05 \\
\hline 2016 & 5.410 .920 & 32.21 & 3.91 & 656.382 & 3.737 .721 & 23.09 & 3.090 .211 & 19.09 \\
\hline
\end{tabular}

Fuente: ALADI

Elaboración: propia

Se tiende a pensar que el desembarco de China en la región sudamericana y particularmente en el Ecuador tendería a promover lógicas de intercambio más horizontales, por ser un país que pertenece al Sur Global y maneja una retórica de promoción de relaciones ganar-ganar. El análisis de estas dinámicas comerciales y de posibles nuevas dependencias económicas se pueden entender si se realiza un análisis detallado de los patrones de comercio del país andino. Más allá del aumento en el volumen comercial e intercambios entre las dos potencias más importantes del mundo China y EEUU, resulta útil analizar el tipo de intercambios que se realizan y verificar si éstos tienden a ahondar o no los patrones de reprimarización de la economía ecuatoriana.

Para ello, resulta útil recurrir a la comprensión de dos variables: la primera, es la reprimarización de la economía y la segunda variable es la autonomía política. 
Los indicadores que se usan para la primera variable son el índice IVCR y el índice Balassa; mientras que para dar cuenta de la autonomía política se toma como indicadores las votaciones en el seno de la AGNU.

\section{La reprimarización de la economía ecuatoriana: índice IVCR y Balassa}

Cuando se hace referencia al fenómeno de la reprimarización de la economía, se hace alusión al hecho de que el sector primario adquiere relevancia en detrimento del sector industrial, manufacturero o tecnológico, medido en relación al total del valor agregado de la economía (Nadal, 2009). Normalmente, el sector primario de la economía está compuesto por la producción de materias primas y productos básicos como las commodities y los bienes intermedios de poca elaboración. De acuerdo a la literatura especializada, los índices que resultan útiles para el análisis de la especialización primario exportadora son el IVCR y el índice Balassa (índice de ventajas comparativas). Estos indicadores nos ayudan a entender el tipo de relaciones que se promueve en los intercambios comerciales, es decir, su especialización primario exportadora o su grado de reprimarización y la dirección de los flujos de comercio, es decir si el comercio va en una sola dirección o no (Álvarez y Durán 2008: 25).

En este acápite, primero se realiza el análisis del índice IVCR que se usa para entender las ventajas o desventajas comparativas de los intercambios comerciales de un país con sus socios comerciales. Para ello, se mide el total de las importaciones y exportaciones del Ecuador a los mercados de EEUU y de China, para definir de manera general las tendencia importadora o exportadora del Ecuador en relación a los dos mercados. El índice considera que las exportaciones son una expresión de ventajas y las importaciones revelan desventajas. Para su aplicación se recoge el saldo comercial de todos los productos que el Ecuador exportó durante desde el 2005 al 2015, menos sus importaciones y se divide para el monto total del comercio, es decir sus exportaciones más sus importaciones. De esta manera, lo que se busca medir es la importancia del saldo comercial sobre la magnitud total del comercio. 
Con el índice IVCR, un resultado igual a -1 revela especialización total en cuanto a las importaciones; mientras que si el índice es igual a 1 la especialización exportadora es total y si el valor es cercano a 0 entonces hay un comercio bidireccional. Para facilitar la lectura de los índices se divide los resultados en tres categorías: entre -1 y $-0,33$ representa una baja competitividad; entre -0,33 y 0,33 representa una competitividad media y flujos bidireccionales de comercio; entre 0,33 y 1 representa la existencia de competitividad en el sector. En cuanto a la recolección de los datos de esta sección el estudio recurre a la base de datos de ITC (International Trade Center, agencia adjunta a NNUU y a WTO) y se utiliza la clasificación de dos dígitos porque otorga el detalle de todos los productos importados y exportados desde Ecuador a los mercados de China y de EEUU.

En el cuadro y el gráfico Nro. 21 se puede observar la relación entre Ecuador y los mercados de China y de EEUU durante el período 2005 a 2015. El resultado del IVCR señala que Ecuador es un importador neto en su relación comercial con China, pues sus índices son cercanos a -1. El menor índice se presenta en el año 2006 y 2008 con valores de -0,62, que, si bien muestran una pequeña tendencia a equiparar los flujos bidireccionales de comercio, no llegan al rango entre 0,33 y $-0,33$ que dan cuenta de mayores intercambios que van en una sola dirección (unilateral). Esto revela de manera contundente la especialización importadora del Ecuador para con el mercado asiático.

En cuanto a la relación con los EEUU, el Ecuador mantiene una relación de histórica dependencia comercial; sin embargo, los índices señalan que la relación comercial con este mercado está muy cercano a la especialización exportadora del Ecuador. La tendencia muestra valores positivos, que, si bien no llegan a superar los 0,46 puntos durante el período analizado, dan cuenta de que el Ecuador se ha especializado en las exportaciones al socio del norte. De manera general, se puede señalar que un índice de VCR mayor que cero indica la existencia de un comercio competitivo y con potencial. Por su parte, en la mayoría de los años estudiados la tendencia indica que existen flujos bidireccionales de comercio entre estas dos economías. 


\section{Gráfico 21. IVCR Ecuador con China y EEUU}

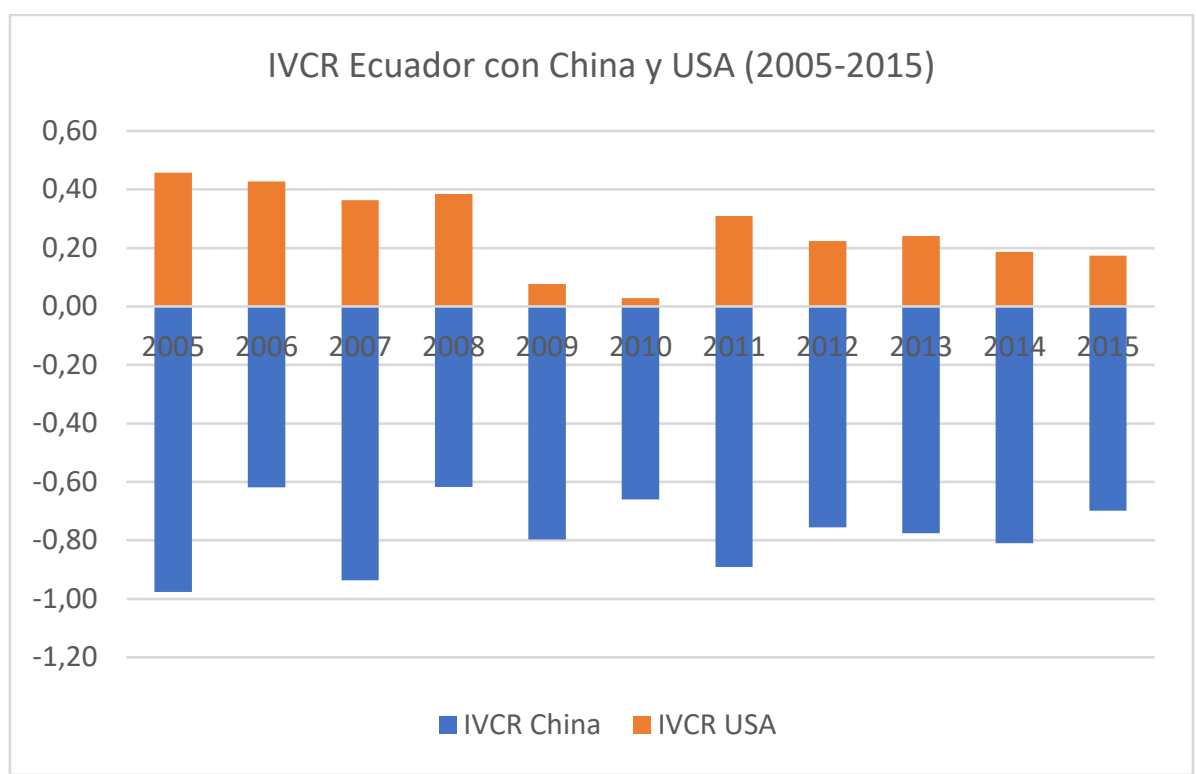

Fuente: International Trade Center (ITC)C Elaboración: propia

Tabla 4. IVCR Ecuador en relación con China y EEUU

\begin{tabular}{|c|c|c|c|c|c|c|}
\hline & 2005 & 2006 & 2007 & 2008 & 2009 & 2010 \\
\hline $\begin{array}{l}\text { Exportaciones } \\
\text { hacia China }\end{array}$ & 7.205 & 194.728 & 36.550 & 387.466 & 124.208 & 328.738 \\
\hline $\begin{array}{l}\text { Importaciones } \\
\text { desde China }\end{array}$ & 621.733 & 828.182 & 1.121 .735 & 1.636 .363 & 1.100 .283 & 1.606 .562 \\
\hline $\begin{array}{l}\text { Total comercio } \\
\text { con China }\end{array}$ & 628.938 & 1.022 .910 & 1.158 .285 & 2.023 .829 & 1.224 .491 & 1.935 .300 \\
\hline $\begin{array}{l}\text { Exportaciones } \\
\text { hacia EEUU }\end{array}$ & 4.941 .481 & 6.824 .753 & 5.977 .819 & 8.435 .396 & 4.625 .857 & 6.077 .496 \\
\hline $\begin{array}{l}\text { Importaciones } \\
\text { desde EEUU }\end{array}$ & 1.842 .725 & 2.738 .812 & 2.794 .782 & 3.748 .244 & 3.962 .365 & 5.736 .443 \\
\hline $\begin{array}{l}\text { Total comercio } \\
\text { con EEUU }\end{array}$ & 6.784 .206 & 9.563 .565 & 8.772 .601 & 12.183 .640 & 8.588 .222 & 11.813 .939 \\
\hline IVCR China & $-0,98$ & $-0,62$ & $-0,94$ & $-0,62$ & $-0,8$ & $-0,66$ \\
\hline \multirow[t]{2}{*}{ IVCR EEUU } & 0,46 & 0,43 & 0,36 & 0,38 & 0,08 & 0,03 \\
\hline & 2011 & 2012 & 2013 & 2014 & 2015 & \\
\hline $\begin{array}{l}\text { Exportaciones } \\
\text { hacia China }\end{array}$ & 191.850 & 391.462 & 568.770 & 485.076 & 722.966 & \\
\hline $\begin{array}{l}\text { Importaciones } \\
\text { desde China }\end{array}$ & 3.326.991 & 2.810 .684 & 4.508 .391 & 4.614 .573 & 4.073 .756 & \\
\hline $\begin{array}{l}\text { Total comercio } \\
\text { con China }\end{array}$ & 3.518 .841 & 3.202 .146 & 5.077 .161 & 5.099 .649 & 4.796 .722 & \\
\hline $\begin{array}{l}\text { Exportaciones } \\
\text { hacia EEUU }\end{array}$ & 9.725 .735 & 10.662 .567 & 11.130 .951 & 11.239 .608 & 7.226 .224 & \\
\hline $\begin{array}{l}\text { Importaciones } \\
\text { desde EEUU }\end{array}$ & 5.138 .353 & 6.773 .934 & 6.807 .961 & 7.692 .957 & 5.085 .696 & \\
\hline $\begin{array}{l}\text { Total comercio } \\
\text { con EEUU }\end{array}$ & 14.864 .088 & 17.436 .501 & 17.938 .912 & 18.932 .565 & 12.311 .920 & \\
\hline IVCR China & $-0,89$ & $-0,76$ & $-0,78$ & $-0,81$ & $-0,7$ & \\
\hline IVCR EEUU & 0,31 & 0,22 & 0,24 & 0,19 & 0,17 & \\
\hline
\end{tabular}

Fuente: ITC

Elaboración: propia 
Por su parte, el índice Balassa también forma parte de los índices de VCR y mide el grado de importancia de un producto dentro de las exportaciones de un mercado a otro mercado, versus la importancia de las exportaciones del mismo producto en las exportaciones del mismo producto hacia el mundo. Normalmente se lo conoce como IVCR de las exportaciones (Álvarez y Durán 2008: 25). Partiendo de la aplicación de dicho índice, usando las fórmulas detalladas en el capítulo III referente a los aspectos metodológicos del estudio de caso, a continuación, se especifica las escalas que se utiliza para dar lectura al indicador:

Entre $+0.33 y+1$ : Existe ventaja para el país, existe competitividad para el país. Entre -0.33 y -1: Existe desventaja para el país o baja competitividad Entre -0.33 y +0.33 : Existe tendencia hacia un comercio intraproducto, representa una competitividad media.

Para lograr la lectura del índice en dichas escalas se pueden normalizar los datos a un máximo de 1 y un mínimo de 1, de tal manera que los índices resultantes tomarán valores entre 1 y -1 y será más fácil su lectura. Cuando el índice indica un valor igual a -1 indica una completa especialización en cuanto a las importaciones, es decir indica presencia (ausencia) de VCR en dicho producto. Por su parte, si el índice es igual a 1, la especialización exportadora es total; si es igual a 0 entonces hay un comercio bidireccional de aquel producto o grupo de productos analizados (Sequeiros y Redondo: 2003). La normalización se consigue considerando la siguiente fórmula:

IVCR Norm $=\frac{I V C R-1}{I V C R+1}$

A continuación, se muestra el análisis para con China y con EEUU con la finalidad de realizar una comparación entre las relaciones que sostiene el Ecuador con estos dos países. La idea es poder comparar si la creciente presencia de China en la economía ecuatoriana ha modificado de alguna manera las relaciones de dependencia que tradicionalmente sostenía con EEUU o si se reproducen patrones similares de relacionamiento. En el caso ecuatoriano, se 
realizó el cálculo para el caso particular del comercio con el mercado de China (Anexo 4) y el de EEUU (Anexo 5), desglosando la lista de los principales productos. Para llegar a este resultado se hizo necesario realizar el cálculo del IVCR a nivel de cada uno de los productos que comercia el Ecuador con los países analizados.

Como se puede observar en el anexo 4, en la relación entre el Ecuador y China, desde el año 2005 al 2015, el país andino carece de competitividad y es casi un importador neto de manufacturas de baja, media y alta tecnología. Esto se puede comprobar analizando los índices, que en su mayoría muestran valores de -1 o muy cercanos a -1 . Resulta especialmente notorio que en el área donde existe un alto nivel de especialización importadora es en las manufacturas de alta tecnología, como maquinaria, equipo y piezas eléctricas, bebidas, licores y vinagre aparatos mecánicos, entre otros.

China prácticamente consume del Ecuador manufacturas basadas en recursos naturales. Los índices cercanos a 1 dan cuenta de la competitividad y proximidad a la especialización exportadora del Ecuador. A lo largo de los años analizados, la tendencia sugiere una concentración (marcada en color gris) en bienes primarios como aluminio, granos, árboles y plantas, cocoa, cobre, artículos de madera, frutas, combustibles minerales, aceites minerales y productos de su destilación; pescados y crustáceos, entre otros. Estos bienes representan la categoría donde el Ecuador presenta ventajas, porque los índices marcan un valor elevado incluso rebasan el 0,95 en el área de combustibles minerales, es decir petróleo. Se podría señalar que existe un nivel elevado de especialización del Ecuador a exportar a la República Popular China bienes primarios.

En el caso de la relación comercial con los EEUU de América (Anexo 5), la tendencia a la primarización de las exportaciones se mantiene, mostrando la dependencia comercial e histórica que el país andino ha mantenido con esta economía. Sin embargo, si bien los índices estudiados de los bienes primarios son elevados, muy cercanos a la especialización exportadora, éstos son menores que en la relación con China. Esto daría cuenta de que la relación entre el país andino y los EEUU presenta grados menores de primarización que la 
relación del Ecuador con el socio asiático. Los productos más demandados por la economía norteamericana son más variados, incluyendo madera, hortalizas, cacao, perlas y metales preciosos, metales, frutos comestibles, crustáceos y combustibles y aceites minerales.

Si se analiza de manera comparada, se puede observar que en los productos que el Ecuador es importador neto, la relación con China es la que muestra índices más cercanos a -1, es decir a la especialización importadora. Al respecto, un dato relevante que cabe señalar de la relación entre Ecuador y el gigante asiático es que China no es un destino muy importante de las exportaciones ecuatorianas, pero si es uno de los principales orígenes de sus importaciones. Por su parte, si bien la relación de especialización primario exportadora se muestra muy elevada con las dos economías, con EEUU tiende ligeramente a emitir mayores estímulos para la especialización primario-exportadora. Es decir, la oferta de productos es más diversificada, a pesar de que cuenta con un porcentaje alto de exportación de bienes de origen natural derivado de industrias extractivas.

\section{Autonomía política: voto de Ecuador en NNUU}

Uno de los giros importantes que experimenta la política exterior ecuatoriana durante la primera de cada del siglo XXI se manifiesta en el fortalecimiento no solo de relaciones económicas sino también de lazos políticos, diplomáticos y estratégicos con la RPC. La presencia cada vez más asertiva del gigante asiático en la región está relacionada con los cambios en las estructuras de poder en el sistema internacional que marcan declive relativo de la hegemonía estadounidense en el hemisferio y ubican a China en el nivel de potencia global. De igual manera, responde a la emergencia de proyectos políticos de corte progresista en la región que buscaron alcanzar mayores niveles de autonomía frente a las potencias occidentales tradicionales. En este sentido, las relaciones entre Ecuador y China se insertan en el marco general que caracterizó a las políticas exteriores de los gobiernos progresistas sudamericanos que basaron sus modelos de inserción internacional en el retorno de la política, el Estado y el cuestionamiento a modelos tradicionales de desarrollo; lo que dio pie al 
incremento de cuestionamientos a la hegemonía estadounidense en el hemisferio buscando excluirla, a través de la diversificación de sus relaciones externas en la multipolaridad (Serbín 2017).

Formalmente, las relaciones diplomáticas entre Ecuador y China se establecieron el 2 de enero de 1980 y se han desarrollado buscando fortalecer los principios de igualdad, beneficio mutuo, cooperación ganar-ganar y desarrollo conjunto (MRERPC 2016). A nivel institucional, el afianzamiento de las relaciones concreta el apoyo que el país andino había mostrado desde décadas anteriores, iniciadas en el contexto de la Guerra Fría, cuando, por ejemplo, en 1971 ya se había pronunciado a favor de conferir a la RPC la legítima representación del pueblo chino en el seno de la AGNU (Borja, 2015).

A partir de entonces se establece una dinámica de crecientes intercambios oficiales. En la década de los ochenta el presidente Oswaldo Hurtado visita la RPC en 1984, en la década de los noventa se realizan dos visitas oficiales Sixto Durán Ballén en 1994 y Jamil Mahuad en 1999. En la primera década del siglo XXI, se realizaron tres visitas oficiales: Gustavo Noboa Bejarano en el año 2002, Lucio Gutiérrez en el 2003 y Rafael Correa en el año 2007. En la década subsecuente, el presidente Correa visita China en el año 2015 y se establece una "Asociación estratégica" y en noviembre de 2016 Xi Jinping es el primer jefe de Estado que visita Ecuador. Este último encuentro dio como resultado el establecimiento de la "Asociación Estratégica Integral China-Ecuador", que implica la profundización de las relaciones bilaterales en las dimensiones políticas, económicas y de cooperación (Embajada China, 2016).

El fortalecimiento de las relaciones políticas entre Beijin y Quito respaldadas por los crecientes intercambios bilaterales y dinamizadas por la promoción de relaciones solidarias, habrían implicado a la vez, un mayor grado de cohesión política a favor del gigante asiático. Con la finalidad de observar el posicionamiento del Ecuador en relación a la postura política de China como de los EEUU se recurre al análisis las resoluciones y votaciones en seis temáticas en el seno de la AGNU. El objetivo central es analizar el alineamiento de votos del país andino y definir si la influencia de China en la región muestra alcances 
político-estratégicos. Esto permite tener una idea más amplia de la forma en que votaba el Ecuador antes de que China fuese uno de sus principales socios comerciales a inicios de la década del 2000, y cómo lo hace en los años recientes cuando la cooperación económica podría estar ejerciendo influencia en lo político.

En el aspecto metodológico se recurre al análisis de las votaciones en la AGNU durante siete períodos de votaciones correspondientes desde las sesiones 55 a la 69, que se llevan a cabo entre los años 2000 a 2014. Para ello, se elaboró una base de datos -tipo panel- que contempla en total 489 resoluciones, que dan lugar a 2916 votaciones. Esta base se desagrega considerando únicamente las resoluciones y votos clasificados como "importantes" para EEUU siendo un total de 214 resoluciones y 642 votos. Para ello se recurre a los informes que solicita el Departamento de Estado de EE.UU., que, según ley pública, requiere una lista de "votaciones sobre cuestiones que afectaron directamente a importantes intereses de los EEUU y sobre las que los EEUU ejercieron un amplio lobby" (Naciones Unidas 2016). Esta decisión metodológica responde a relevancia política y económica que representa EEUU para la región y fortalece los argumentos presentados en la investigación que apuntan a comprender la idea de autonomía política y la influencia que China ha ganado en los últimos años.

La tabla Nro. 5 sintetiza las seis grandes áreas que se consideran en el análisis siguiendo la clasificación de la AGNU relacionadas con: conflicto palestino (ME), armas y material nuclear (NU), colonialismo (CO), derechos humanos (HR), desarrollo económico (CE), control de armas y desarme (DI). Se refleja el total de los 642 votos tanto del Ecuador como de China y EEUU desagregando las 214 resoluciones mayormente impulsadas por la potencia norteamericana. Esto da cuenta de la cantidad de votos a favor, en contra, abstenciones y ausencias en las resoluciones y los votos considerados en el estudio; lo que permite observar tanto la orientación general de la política exterior del Ecuador, así como su alineamiento ante las dos potencias en una instancia global como la AGNU. 
Tabla 5. Votaciones Ecuador, China y EEUU por temas en la AGNU

\begin{tabular}{|c|c|c|c|c|c|c|c|c|c|c|c|c|}
\hline \multicolumn{13}{|c|}{ Votaciones del Ecuador, China y EEUU por temas en la AGNU. Período ordinario de } \\
\hline & \multicolumn{3}{|c|}{ Ecuador } & \multicolumn{4}{|c|}{ China } & \multicolumn{3}{|c|}{ EEUU } & \multirow{2}{*}{$\begin{array}{l}\text { Total } \\
\text { resoluc. }\end{array}$} & \multirow{2}{*}{$\begin{array}{l}\text { Total } \\
\text { votos }\end{array}$} \\
\hline Temática & Si & No & $\mathbf{A b}$ & Si & No & $\mathbf{A b}$ & Aus & Si & No & $\mathbf{A b}$ & & \\
\hline $\begin{array}{l}\text { Conflicto } \\
\text { palestino }\end{array}$ & 43 & & & 42 & & 1 & & 1 & 42 & & 43 & 129 \\
\hline $\begin{array}{ll}\text { Armas } & y \\
\text { material } & \\
\text { nuclear } & \end{array}$ & 13 & & 3 & 8 & & 8 & & 9 & 7 & & 16 & 48 \\
\hline $\begin{array}{lr}\text { Control } & \text { de } \\
\text { armas } & y \\
\text { desarme } & \\
\end{array}$ & 15 & & 4 & 8 & & 10 & 1 & 11 & 8 & & 19 & 57 \\
\hline Colonialismo & 14 & & & 13 & & 1 & & 1 & 13 & & 14 & 42 \\
\hline $\begin{array}{l}\text { Derechos } \\
\text { humanos }\end{array}$ & 70 & 8 & 16 & 55 & 31 & 8 & & 36 & 55 & 3 & 94 & 282 \\
\hline $\begin{array}{l}\text { Desarrollo } \\
\text { económico }\end{array}$ & 24 & & 4 & 27 & & 1 & & 5 & 23 & & 28 & 84 \\
\hline Total & 179 & 8 & 27 & 153 & 31 & 29 & 1 & 63 & 148 & 3 & 214 & 642 \\
\hline
\end{tabular}

Fuente: AGNU

Elaboración: propia

Los gráficos 22 y 23 muestran la composición de las principales temáticas en la agenda internacional de la AGNU. Del análisis y categorización se destaca que los derechos humanos dominan la agenda multilateral y constituyen el principal ámbito de discusión de los Estados con un total de 282 votos, que representa un porcentaje del $44 \%$ del total de resoluciones atendidas. Seguido del conflicto palestino que ocupa el segundo lugar en importancia con 129 votos que representa el $20 \%$; en tercer lugar, se observan los votos referentes a desarrollo económico con 84 votos que representan el 13\% del total, siguiente en relevancia se encuentra el tema de control de armas y desarme con un total de 57 votos que representa el $9 \%$. Finalmente, armas y material nuclear ocupa el quinto lugar con 48 votos, correspondiente a $7 \%$ del total y la temática de colonialismo con 42 votos que representa un $7 \%$ del total de votos examinados. 
Gráfico 22. Número de resoluciones AGNU por temática. Ecuador, China y EEUU.

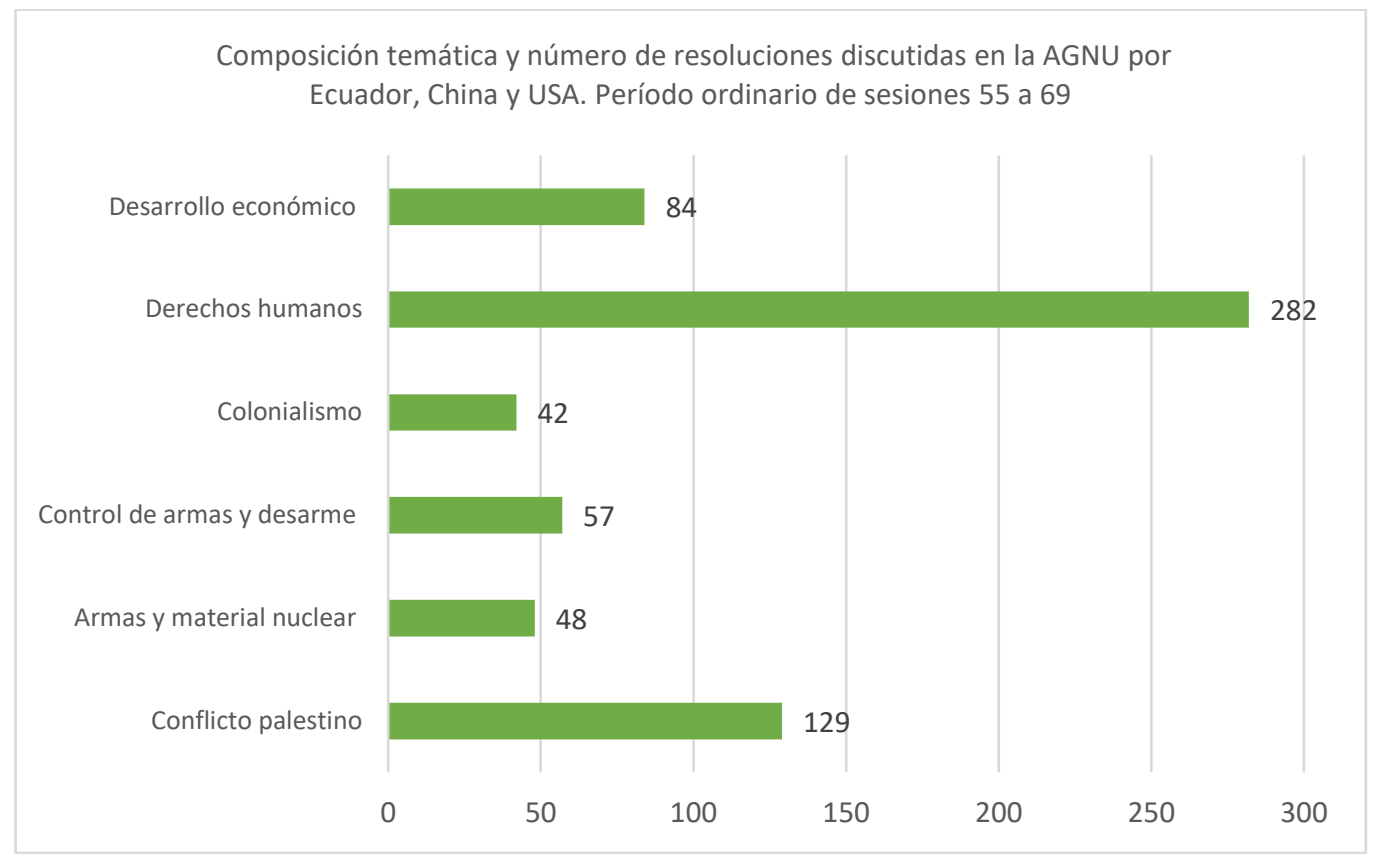

Fuente: AGNU

Elaboración: propia

Gráfico 23. Composición temática de resoluciones discutidas en la AGNU por Ecuador, China y EEUU

Composición temática de resoluciones discutidas en la AGNU por Ecuador, China y USA. Período ordinario de sesiones 55 a 69. (Porcentaje)

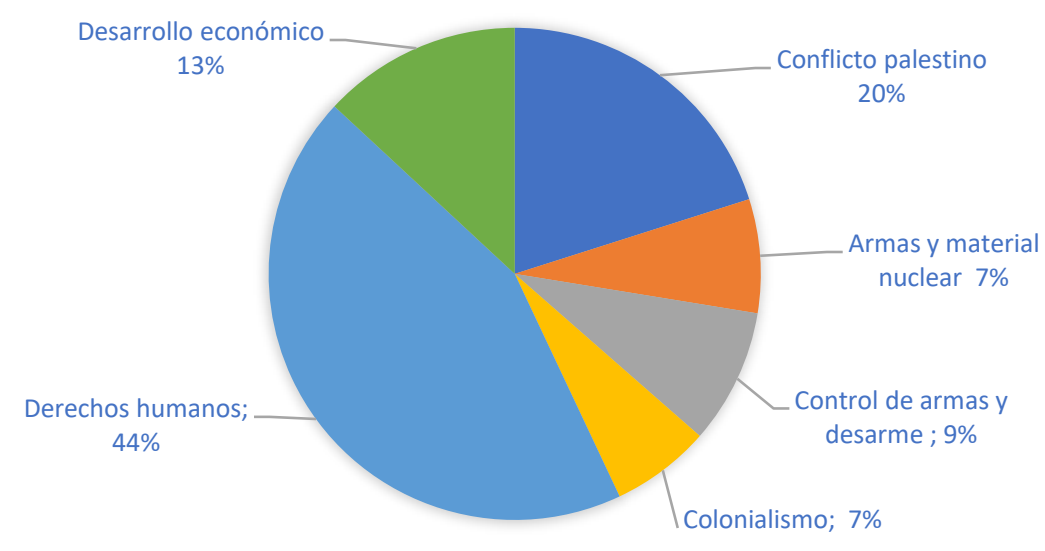

Fuente: AGNU

Elaboración: propia 
El desglose de las resoluciones discutidas en las principales temáticas de la agenda internacional, muestran una tendencia general sobre el comportamiento de las sesiones ordinarias a lo largo del tiempo en el seno de la AGNU. Sobre este marco, se busca comprender cuál ha sido el comportamiento general del Ecuador respecto de su posicionamiento en política exterior con China y EEUU.

El gráfico Nro. 24 muestra el total de votos sí, no, abstenciones y ausencias de los tres países analizados. Se destaca la alta coincidencia de los votos a favor entre Ecuador y China, en detrimento de EEUU; así como la alta divergencia de posicionamiento entre las dos potencias estudiadas. En el caso de Ecuador, los votos a favor alcanzan un $27,88 \%$ del total de votos durante el periodo analizado, un porcentaje muy cercano al de China que durante el mismo periodo vota un $23,83 \%$ de las veces de manera afirmativa. En cuanto a los votos en contra, si bien existe una convergencia menor entre China y Ecuador, la tendencia general de alineamiento se mantiene; mientras que la divergencia entre Ecuador y EEUU se acentúa cuando el país andino vota un $1,25 \%$ de veces no, el país norteamericano lo hace un $23,05 \%$ de veces. En el caso de las abstenciones Ecuador y China muestran una alta convergencia, 4,21\% y $4,52 \%$ respectivamente; lo que no sucede así con el caso del país andino y EEUU $4,21 \%$ y $0,47 \%$. 
Gráfico 24. Votaciones Ecuador, China, EEUU

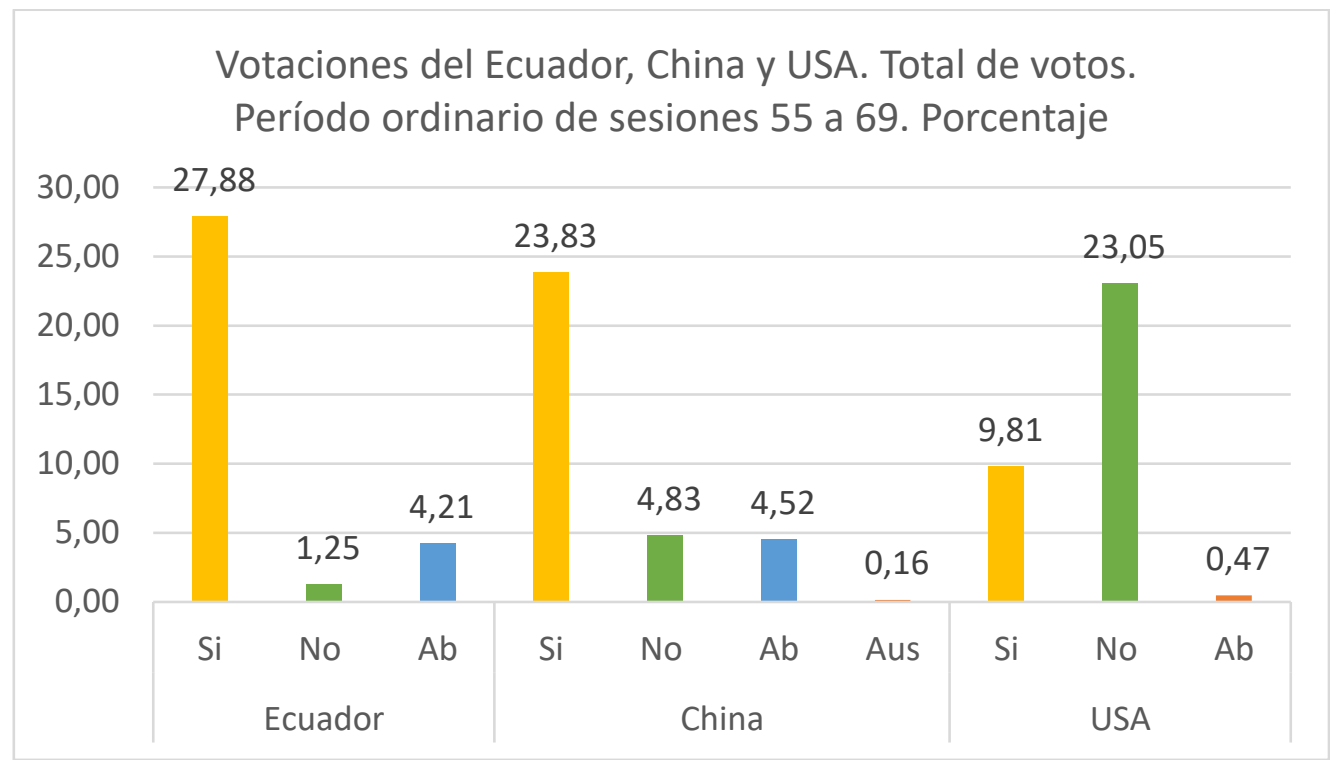

Fuente: AGNU

Elaboración: la autora

El gráfico Nro. 25 desagrega la tendencia de votos según su composición por temáticas y el número de resoluciones votadas por los tres países. En el gráfico se puede observar que en todas las áreas temáticas resaltan posicionamientos indiscutiblemente antagónicos entre EEUU y China; por ejemplo, en el área de $\mathrm{DDHH}$ los dos países votan de manera opuesta durante 55 oportunidades; de igual manera en la temática relacionada al Conflicto Palestino votan antagónicamente en 42 ocasiones. Esto da cuenta de que los subtemas que se abordan en estas dos áreas son muy sensibles en términos políticos e implican un mayor esfuerzo en cuanto a lobby político de EEUU para conseguir aliados internacionales.

Para el Ecuador adoptar una postura en áreas temáticas sensibles implica declarar una preferencia política abierta para con una u otra potencia. De manera general, se puede señalar que existe la tendencia a que el Ecuador y China voten de manera similar en todas las áreas. Por ejemplo, los dos países tienden a votar favorablemente y sin alterar su postura en los temas relacionados al conflicto palestino, que durante el periodo analizado muestran una coincidencia muy alta en votos afirmativos; cuando Ecuador vota 43 veces si, China vota 42 veces de 
igual manera. Lo mismo sucede en la temática de colonialismo, cuando Ecuador vota 14 veces de manera afirmativa y China lo hace 13 veces. Una tendencia similar se expresa en los votos relacionados con el desarrollo económico. Por su parte, las temáticas referentes a armas y material nuclear o control de armas y desarme, se reflejan comportamientos diferenciados por lo que la inclinación política del Ecuador con una u otra potencia es menos marcada.

Gráfico 25. Composición por temáticas y número de resoluciones

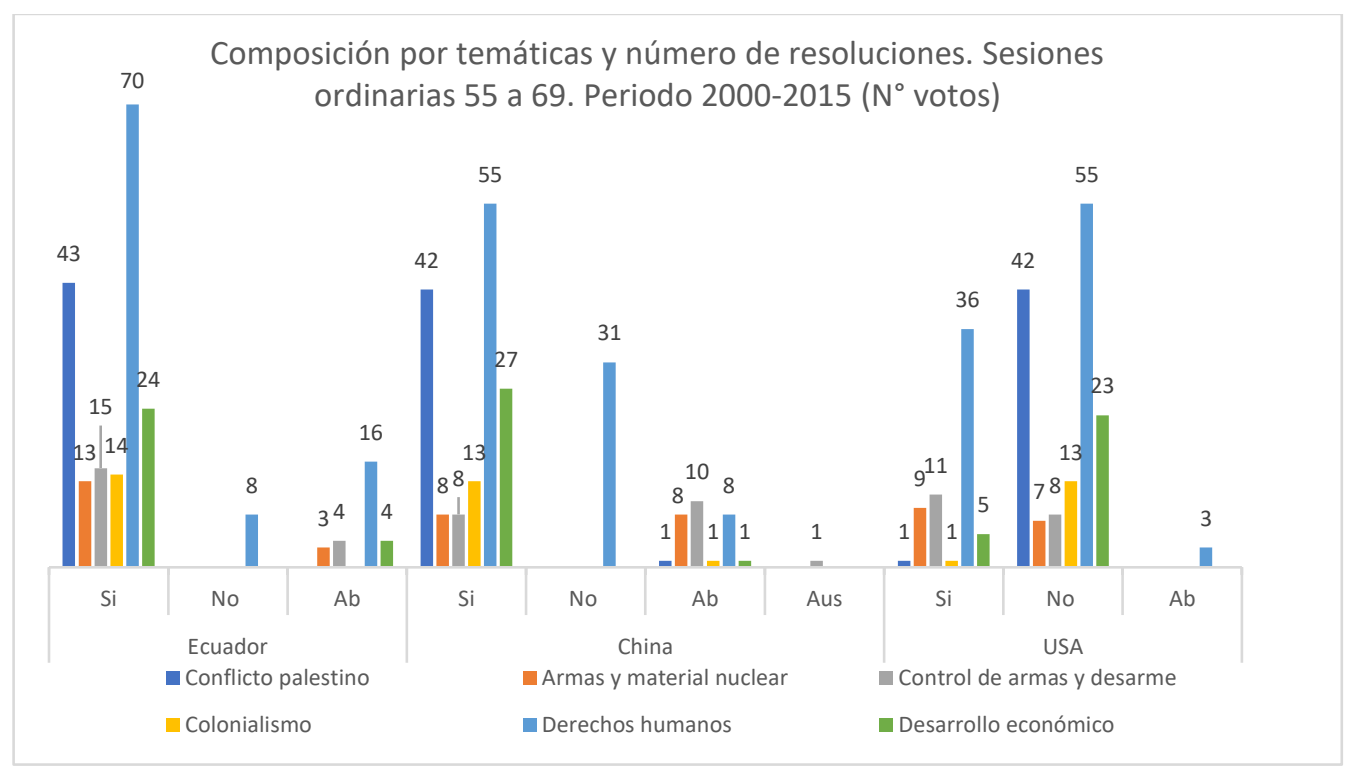

Siguiendo la estructura del análisis que se desprende del gráfico Nro. 25 resulta conveniente hacer un acercamiento analítico a las subtemáticas más importantes que se votan dentro de cada una de las seis áreas definidas en la AGNU, porque esto permite visualizar el posicionamiento del Ecuador frente a las dos potencias analizadas. De ello se desprende lo siguiente:

En el área de Derechos Humanos, las votaciones se realizan sobre temas relacionados con derecho indígena, derechos de grupos prioritarios, globalización, libre determinación, racismo, derechos humanos y terrorismo, reagrupación familiar, religión e intolerancia, entre otros. De estas subtemáticas, son considerados temas más sensibles aquellos que abordan aspectos específicos sobre la situación de derechos humanos en determinadas zonas geográficas. Ecuador y China coinciden en sus votos afirmativos en 52 
resoluciones que tratan la problemática en Medio Oriente y países africanos, por ejemplo, en la cuestión Palestina sobre el "comité para el ejercicio de los derechos inalienables del pueblo palestino" o en la "división de los derechos de los palestinos de la secretaría". De igual manera, coinciden en las resoluciones sobre Israel referentes a la investigación de las prácticas israelíes que afecten a los derechos humanos del pueblo palestino y otros habitantes árabes de los territorios ocupados. Sin embargo, es importante resaltar que ninguna de estas resoluciones hace alusión a la imposición de sanciones a los regímenes políticos por posibles vulneraciones a los derechos humanos, sino más bien, se refieren a la situación general de los derechos en dichos países.

En la temática específica a votos relacionados con el conflicto palestino, Ecuador y China coinciden en 43 resoluciones de manera afirmativa, especialmente en aquellas subtemáticas relacionadas con la proliferación nuclear en el medio oriente, donde se exhorta a Israel a que forme parte en el Tratado sobre la no proliferación de las armas nucleares, se adhiera a él sin más demora y no desarrolle, produzca, ensaye ni adquiera de otro modo armas nucleares, y renuncie a su posesión. Igualmente, acuerdan en la subtemática que se refiere a la Asistencia a los refugiados palestinos y apoyo al Organismo de Obras Públicas y Socorro de las Naciones Unidas para los Refugiados de Palestina.

En cuanto a los votos relacionados con armas y material nuclear, se puede observar que esta área es la única donde tanto China como EEUU y Ecuador coinciden en cuatro resoluciones relacionadas con "un mundo libre de armas nucleares" referente a la necesidad de una nueva agenda para un mundo libre de armas nucleares, y "ensayos de armas nucleares" referentes al tratado sobre prohibición completa de ensayos nucleares. Sin embargo, cuando este tema concierne directamente a las prácticas y políticas del aliado estratégico de EEUU, Israel, la potencia del norte vota en contra en todas las resoluciones, especialmente las que llaman a que el país firme el Tratado sobre la no proliferación de las armas nucleares.

En lo referente a control de armas y desarme, China y Ecuador coinciden de manera afirmativa en siete resoluciones referentes a la legislación nacional sobre 
la transferencia de armas, equipo militar, artículos y tecnología de doble uso, y el tráfico ilícito de armas pequeñas y ligeras en todos sus aspectos. Mientras que los tres países analizados coinciden de manera afirmativa en dos resoluciones: R/57/66 de 2002 y la R/68/43 de 2013 relacionadas con la "legislación sobre transferencia de armas", específicamente la necesidad de una nueva agenda para un mundo libre de armas nucleares y la "transparencia en la transferencia de armas". Por su parte, la única vez que EEUU y China coinciden de manera afirmativa y Ecuador se abstiene es en el tema relacionado a los "instrumentos internacionales sobre transferencia de armas", específicamente sobre el tratado sobre el comercio de armas.

Finalmente, la temática sobre desarrollo (económico), Ecuador y China coinciden en 24 resoluciones relacionadas al embargo de Cuba por parte de EEUU, comercio y desarrollo internacional; medio ambiente y desarrollo sustentable, medidas unilaterales como mecanismo de coerción política y económica. Resulta relevante recalcar que, durante el periodo analizado, en la resolución específica sobre "Tecnología agrícola para el desarrollo" R/64/197 de 2009 y R/68/209 de 2013 el Ecuador se abstiene. Esto resulta contradictorio con los objetivos planteados en cuanto a política productiva del país que planteaba la generación de fuentes alternativas de financiamiento, especialmente de sectores minoristas de la economía ecuatoriana y fue uno de los pilares más promovidos durante la presidencia del Gobierno del presidente Rafael Correa.

El análisis de las temáticas permitió observar que la temática referente a los Derechos Humanos es, por una parte, la más discutida en el seno de la AGNU, y por otra, representa un área muy sensible para EEUU y para China. Durante los 12 años analizados, de los 94 votos realizados en esta área, China votó afirmativamente en 55 oportunidades mientras que Ecuador lo hizo en 70 oportunidades, y EEUU lo hizo en 36 ocasiones (Gráfico 25). Esto se traduce en una dispersión de ciertos votos y subtemáticas específicas, donde Beijin y Quito mostrarían mayores grados de discrepancia. El análisis más detallado de los votos en esta área permite visualizar en que subtemas el Ecuador cambió de posicionamiento a lo largo del tiempo. 
Por ello, en el anexo 3, que se desplega al final de la tesis, se desglosa el posicionamiento del país andino frente a las subtemáticas que se votan en el ámbito de los DDHH desde el año 2000 al 2012 (para los cuales se encontró la disponibilidad de datos) con la finalidad de comparar el alineamiento político del Ecuador y definir el cambio de posicionamiento político frente a las dos potencias analizadas. En dicha tabla se pueden observar las votaciones en NNUU en la temática de Derechos Humanos.

Al respecto, se puede señalar que existe una tendencia clara a coincidir en los votos afirmativos del Ecuador con los de EEUU, especialmente en subtemáticas que expresan preocupación por la vulnerabilidad de los derechos humanos en zonas geográficas específicas. Desde el año 2000 al 2006 el Ecuador tiende a alinearse con la potencia del norte en temas específicos como la situación en Irán, en Iraq, la República Democrática del Congo, República Democrática de Corea, o Myanmar, coincidiendo en 15 de 17 posicionamientos de manera afirmativa; las únicas excepciones durante este período son las resoluciones R/59/205 para el caso de Belarús de 2004 y la R/61/175 para Irán de 2006. Estas resoluciones expresan preocupación por el deterioro de los derechos humanos en estos territorios.

Sin embargo, a partir del año 2006 se observa que el Ecuador modifica su postura en estas temáticas y cambia su voto a abstención o vota en contra, justamente en las resoluciones relacionadas a reportes que condenan la situación de DDHH en Irán, Myanmar Siria, Corea del Norte y Belarús. Es decir, coincidentemente con la llegada a la presidencia de Rafael Correa en el año 2006 el país sudamericano empieza a alinear sus votos con China en el área de DDHH. Esto marca un giro drástico en cuanto a la tradicional postura del país andino de condenar de manera rotunda las violaciones a los derechos humanos en estos países y a la vez da cuenta del giro que adopta la política exterior del Ecuador que buscó activamente afianzar los lazos políticos y económicos con China.

Como corolario, el posicionamiento del Ecuador en el área de Derechos Humanos refleja los nuevos lineamientos de política exterior que adoptó el 
Ecuador en la primera década del nuevo milenio que buscaron ser congruentes con el interés nacional fortaleciendo relaciones políticas y económicas con países del sur. A su vez, dado que EEUU ejerce una alta presión a la comunidad internacional para que alineen su votación en estos temas, el hecho de que Ecuador marque un posicionamiento diferente podría implicar un mayor grado de autonomía en cuanto a su postura ante la tradicional potencia hegemónica. De igual manera, implica una arista más del apoyo a la conformación de nuevos bloques geopolíticos liderados por economías emergentes como China, y cuyo peso político es muy grande en países periféricos como el Ecuador.

\section{Recapitulación}

El siglo XXI marcó un nuevo ciclo en el quehacer político latinoamericano que se manifiesta en la reconfiguración de las relaciones de poder y la transformación en la economía política nacional e internacional. La presencia cada vez más asertiva de actores hemisféricos extra regionales como China en la región implicó nuevas alternativas de relacionamiento de los países periféricos en relación a la histórica presencia que la hegemonía estadounidense ejerce en la región. Para el Ecuador, esto se convirtió en el marco internacional de relacionamiento donde el país se avocó a ejercer una política exterior reivindicativa y revitalizó el debate en torno al retorno del Estado, la política y el desarrollo.

El Ecuador enrumba su política exterior en base a posicionamientos característicos de los Estados periféricos que pueden ser analizadas en relación a variables e indicadores que aluden a su condición de Estado pequeño y débil. En este capítulo se buscó entender la política exterior del país andino enmarcándola en el contexto de las estructuras internacionales y los factores nacionales que influencian en la dinámica de la política externa de un país periférico. Esto ha determinado una serie de actuaciones que fluctúan entre lógicas de disenso y evasión hasta lógicas de complacencia para con las potencias centrales analizadas. 
Durante el período estudiado, el Ecuador optó por una política de inserción internacional "inteligente y soberana" que buscó fortalecer nuevos vínculos y concretar alianzas con países del Sur Global que no han sido tradicionalmente cercanos al Ecuador -lo que refleja la búsqueda de alternativas a la hegemonía estadounidense. Esto coincide con la inserción asertiva de China en economía global y su desembarco en la región latinoamericana, que empieza a jugar un rol cada vez más preponderante para la economía y política del Ecuador.

En el ámbito económico, el estudio de caso de caso demuestra que el gobierno ecuatoriano se avocó a fortalecer las relaciones Sur-Sur, a través de estrategias como la diversificación de socios comerciales y de productos que permitan trascender el modelo primario exportador de desarrollo y hacerlo menos dependiente de los EEUU. Se enfatiza en la relación comercial cada vez mayor con China, lo que permitió verificar la hipótesis de que la creciente presencia del país asiático en el país ha abierto oportunidades y creado ventajas para quienes persiguen formas autónomas de inserción internacional y buscan reducir la dependencia de los países centrales.

Sin embargo, los datos demuestran que la presencia de China en el país sudamericano ha aupado las dinámicas primario exportadoras, especialmente del sector extractivo del país. Se visualiza una tendencia general a reproducir las mismas prácticas dependientes de la explotación de recursos naturales y la venta de petróleo; así, si bien China aporta con la diversificación de los destinos de exportación de Ecuador, la canasta exportadora no se diversifica.

En el aspecto político, el análisis sobre el alineamiento del Ecuador en el ámbito de la AGNU revela que durante el período de sesiones analizados existe una tendencia del país andino a alinear su voto con China. Esto se hace evidente en el área de Derechos Humanos, donde se visualiza que desde el año 2006 el Ecuador tiende a votar de manera negativa o abstenerse en temáticas que tradicionalmente había optado por la postura condenatoria a las violaciones de derechos humanos. Esto da cuenta de la influencia estratégica cada vez mayor que el socio asiático desempeña con países periféricos como el Ecuador. 


\section{CAPÍTULO VI. CONCLUSIONES GENERALES}

El trabajo que se desarrolló a lo largo de estas páginas se propuso investigar el resurgimiento de la cooperación Sur-Sur en América Latina en los albores del siglo XXI y el modo en que su fortalecimiento contribuyó a establecer modelos de desarrollo más autónomos y menos dependientes de potencias centrales, tomando como caso de estudio al Ecuador desde el año 2000 al 2015. La investigación giró alrededor de tres preguntas interconectadas que guían la estructura de la tesis, a saber: ¿Cómo se explica el resurgimiento de la CSS como mecanismo de la política exterior de los países latinoamericanos durante el período 2000-2015?; ¿cómo se alinea la política exterior de los países latinoamericanos ante la creciente presencia de la potencia emergente de China y la potencia hegemónica de EEUU?; y ¿en qué medida el fortalecimiento de la CSS se ha constituido, para el país sudamericano, en un mecanismo que apuntala la consecución de mayores márgenes de autonomía y reducción de dependencia de potencias centrales?

Para el análisis se tomó como eje central el relacionamiento de los países latinoamericanos con las grandes potencias desde la perspectiva de una relación triangular: América Latina, China y Estados Unidos. A este respecto, el estudio buscó comprender, por una parte, la lógica de reconfiguración de las estructuras sistémicas internacionales y cómo la transformación de las relaciones de poder juegan un rol determinante en el surgimiento de políticas exteriores de carácter reivindicativo, especialmente en los países que experimentaron el ascenso al poder de líderes de corte progresista. Por otra parte, se contempló el análisis de factores de tipo doméstico, característicos de la política exterior en la periferia, que inciden y condicionan las propuestas de desarrollo de carácter autonómico de los países la región. Para ello, se optó por una base teórica fundamentada en el Realismo Periférico y en las contribuciones de la EPI.

Se corroboró la hipótesis general sobre la que giró la investigación: los países periféricos en América Latina optaron por fortalecer la CSS con una narrativa revisionista en el ejercicio de la política exterior cuya la finalidad fue proponer políticas alternativas de desarrollo; sin embargo, estos Estados no pudieron 
escapar a factores estructurales de asimetría política y dependencia económica característicos del sistema internacional actual. A lo largo de la investigación se demostró que, en diferente grado, los factores estructurales limitan el margen de autonomía y decisión de los países periféricos, por lo que, a pesar del fortalecimiento de lazos políticos y económicos con países del Sur Global, estos países no lograron escapar de las dinámicas de reproducción de inequidades características de las relaciones Norte-Sur.

De igual manera, las hipótesis subordinadas se corroboran total o parcialmente, a lo largo de la tesis. A continuación, se presentan las hipótesis que sirvieron de eje conceptual estructurante y algunos de hallazgos específicos que de ellas se derivan.

H1. La estructura de distribución del poder mundial, definida en periodos de unipolarismo, bipolarismo, multipolarismo, influencia en el grado de alineamiento político de los países periféricos para con las potencias dominantes.

La investigación corrobora esta hipótesis porque la emergencia de la CSS se relaciona estrechamente con los profundos cambios que se producen en las principales estructuras que componen el sistema internacional y, por ello, resulta relevante entender los tres períodos de polaridad internacional propuestos, Guerra Fría (1976-1991), unipolaridad (1992-2002) y multipolaridad (2003-2015). Estos influyen, en diverso grado, el tipo de relacionamiento de los países periféricos para con las potencias más fuertes. Históricamente, la política exterior de los países latinoamericanos ha estado transversalizada por el rol hegemónico que ejerce EEUU en la región, por lo que en una época de bipolarismo experimentada durante la época de la Guerra Fría hasta finales de los años ochenta; y, durante la época de unipolarismo hasta entrado el nuevo milenio, se esperaría que los alineamientos políticos de los países latinos converjan más con la potencia hegemónica que con otra potencia extra hemisférica.

Como hallazgo se encuentra que, durante los periodos de bipolaridad y unipolaridad, aunque los intereses de los países de América Latina convergen con los de EEUU, estos alineamientos son dispersos y tienen una tendencia a disminuir a medida que se producen trasformaciones de carácter estructural. La 
evidencia señala que la región latinoamericana encuentra de forma bastante estable, una convergencia política histórica con China, que se profundiza y se hace más evidente en el período de multipolaridad.

El razonamiento detrás de esto evidencia que la narrativa de solidaridad del Tercer Mundo, aupada en la época posterior a las guerras mundiales y que propone la horizontalidad como base del relacionamiento sur-sur, tuvo calado a lo largo del tiempo y se hizo más evidente cuando China asciende al rango de potencia emergente. Los procesos de reordenamiento del poder mundial acentuados a partir de la primera década del siglo XXI hacen que los votos de los países latinoamericanos encuentren mayor consonancia con las posiciones de China a la par de su creciente influencia política y estratégica en la región. Esto corrobora que la colaboración política entre países en desarrollo y del Sur Global ha sido relativamente estable a lo largo del período analizado.

H2. El declive relativo del poder de la potencia hegemónica disminuye el alineamiento de los votos latinoamericanos con EEUU, mientras que el aumento relativo del poder de la potencia ascendente aumenta el alineamiento de votos latinoamericanos para con China.

A lo largo de la tesis se demuestra cómo el "marco de acción" sobre el cual se lee el resurgimiento de la CSS y el ejercicio de la política exterior favorable al fortalecimiento de este tipo de relaciones está marcado por el paulatino proceso de transición hegemónica. La relevancia de China en el actual proceso de transición del Atlántico Norte al Asia Pacífico es un fenómeno geopolítico sin precedentes. El gigante asiático, como potencia emergente del Sur Global, es un país en desarrollo, pero que gracias a su crecimiento económico y proceso de trasnformación estructural es actualmente es la segunda economía mundial y disputa su rol de líder en áreas geoestratégicas a nivel regional y global. Por su parte, EEUU si bien sigue siendo la única potencia hegemónica mundial ha visto disminuida su preponderancia tras fracasos como las guerras de Irak y de Afganistán; de igual manera, ha debido sortear la crisis económica global experimentada a finales de la primera década del siglo XXI de la que ha salido muy debilitado productiva, comercial y tecnológicamente. 
La tesis encontró que la prioridad estratégica que EEUU da a la región latinoamericana varía en cada momento histórico, lo que repercute en el alineamiento político de los países. Siguiendo los postulados teóricos adoptados, el proceso de declive relativo de EEUU se evidenció desde la década de los sesenta, pero se acentuó a inicios del siglo XXI. Entrado el nuevo milenio, se experimentó el "abandono" de EEUU de la región latinoamericana que había sido zona de su influencia natural. Esto dio paso a la dispersión del alineamiento político de los países periféricos en favor de la potencia ascendente, en este caso del gigante asiático. Esto permitió no solamente evidenciar la polarización del alineamiento de votos de los países latinoamericanos en torno a estas dos potencias, sino también su flujo y reordenamiento a lo largo del periodo estudiado.

El análisis del declive relativo de poder de la hegemonía estadounidense permitió, además, colegir que China se ha mostrado coherente en cuanto a sus principios de política exterior a lo largo del periodo estudiado. El gigante asiático no ha cambiado su posicionamiento en lo referente a su compromiso con los países del Tercer Mundo y de hecho ha sostenido su posición para liderar los ideales del Sur Global.

H3. Mayor interdependencia comercial (aumento relativo del comercio bilateral) con una potencia mayor alineamiento político.

A lo largo del trabajo se estudiaron las relaciones comerciales en clave triangular: EEUU, China y América Latina. Esta variable se deriva de los postulados teóricos que señalan que la interdependencia económica puede ser un incentivo para converger en asuntos de política exterior, ya que los beneficios del comercio son más tangibles que las disputas de carácter político. Adicionalmente, en procesos de transición hegemónica la competencia por recursos naturales se intensifica y se materializa en el fortalecimiento de nuevas alianzas comerciales (Krasner 1976). Esta hipótesis se corrobora en la investigación porque uno de los hechos más sobresalientes es que el gigante asiático desembarca en la región latinoamericana enfocándose en el fortalecimiento de las relaciones comerciales, específicamente de bienes primarios e inversiones en sectores estratégicos 
como energía, infraestructura, petroquímica, alimentos. Esto dio paso al denominado boom de los commodities que hace referencia al superciclo de precios de las materias primas que se produjo por la creciente demanda de economías emergentes.

Como resultado del análisis empírico se pudo observar la correlación entre la interdependencia comercial y la convergencia con asuntos de política exterior. Los resultados muestran no solamente una relación positiva entre capacidad económica y alineamiento político, sino también dos elementos en las dinámicas de poder de los países periféricos. En un primer momento, se evidencia que los países latinoamericanos con menor PIB per cápita tienden a converger con EEUU y los países con mayor PIB per cápita tienden a alinearse con China. En segundo lugar, se puede corroborar que los países que han obtenido más apoyos económicos por parte de las potencias tienden a alinear su política exterior con el país que les proporcionó dicha ayuda; esto consolida el supuesto de que, a mayor interdependencia económica, mayor alineamiento político.

H4. Cuanto más a la izquierda se encuentre un país, menos convergencia de votos con EEUU y más con China.

En la investigación se consideró que la variable referente al posicionamiento político de las élites gobernantes es crucial para el entendimiento de la política exterior de los países latinoamericanos; por ello, otro de los factores relacionados a la agencia que se tomó en cuenta es el signo político de los gobernantes de turno en los países analizados. La literatura académica encuentra consenso al señalar que, tradicionalmente las fuerzas políticas de izquierda han buscado desafiar el statu quo y se han asociado al sentimiento antinorteamericana. Particularmente, a partir del siglo XXI, el renovado auge que adquiere la CSS y las políticas exteriores reivindicativas se encuentran estrechamente relacionados con el ascenso de líderes políticos progresistas o se ubican en la izquierda del posicionamiento ideológico.

Al respecto, el estudio demostró que el alineamiento político de los países latinoamericanos con EEUU aumenta cuando los gobiernos latinoamericanos se 
posicionan más a la derecha de la escala ideológica. Esto se hace evidente cuando se observa que una mayor convergencia política de los países latinoamericanos con EEUU se dio a finales de la década de los ochenta y durante toda la década de los noventa, cuando asumieron el poder gobiernos con proyectos neoliberales asociados a posicionamientos ideológicos de derecha y que impulsaron las medidas adoptadas tras el Consenso de Washington. En un sentido contrario, cuanto más a la izquierda se encuentran los gobiernos, se observa una mayor convergencia de votos con China, es decir, los países de tinte progresista convergen más con la potencia emergente. Esta tendencia se evidenció con mayor intensidad a principios del siglo XXI, que es cuando asumieron el poder gobiernos progresistas en América Latina, a la par del llamado Consenso de los Commodities.

H5. Un régimen político democrático tendería a optar por estrategias de inserción internacional en línea con países que mantengan el mismo régimen político.

La base teórica recogida en la investigación señala que el régimen político de un país puede ser más favorable a extender vínculos con Estados que persigan sus mismos intereses, es decir, que mientras más cercanos estén dos estados en el tipo de instituciones políticas hay más probabilidades de que tengan acciones similares en política exterior (Voeten, 2000). De esto se colige que un país democrático tendería a alinearse más con democracias consolidadas que con otros regimenes. Por ello, durante el período estudiado se observó el alineamiento político de los países latinoamericanos frente a EEUU y China.

El estudio demostró que la existencia de instituciones políticas similares y los niveles de alineamiento en política exterior no presentan un efecto estadístico muy representativo. Por lo tanto, esta hipótesis corrobora parcialmente el hecho de que las democracias latinoamericanas tiendan a alinearse con EEUU, que es la cuna de la democracia. Considerando los relacionamientos en perspectiva triangular con China, a inicios del nuevo milenio, el país asiático desembarca en el continente con una narrativa que resalta su perfil como un socio perteneciente al Sur Global, con similares problemas y condicionamientos para su desarrollo, un claro posicionamiento político de respeto de principio de independencia y la 
autodeterminación de los pueblos. Esto facilita encontrar aliados políticos con países que comparten ideales comunes y le permite llegar a acuerdos fundamentados en la base a una visión similar de mundo. En este sentido, China logra ganar aliados políticos que defienden una perspectiva similar de inserción mundial y evita oponerse de manera frontal a la nación más democrática como EEUU.

Una vez realizado el análisis de las cinco hipótesis subordinadas -que contemplan el peso de los factores estructurales y domésticos que influencian en el ejercicio de la política exterior de los países latinoamericanos- la tesis propuso la consolidación de dos modelos analíticos que permitieron observar el peso estadístico de cada una de las variables, respecto del alineamiento de los países latinoamericanos tanto con EEUU como con China. Posteriormente, se verificaron los mismos indicadores en el estudio de caso a profundidad de Ecuador.

En lo que sigue, de manera sucinta se muestran los principales hallazgos de la investigación:

En lo referente a los dos modelos analíticos que se consideran hasta el año 2015, estos evidenciaron que Brasil y México, que son las dos economías más fuertes de América Latina, muestran una tendencia a fortalecer las relaciones Sur-Sur con China, especialmente debido a la incidencia de su capacidad económica y alto poder relativo. El grupo de países andinos conformados por Venezuela, Ecuador, Bolivia, Perú y Colombia tienden a converger con el gigante asiático especialmente por la incidencia de su posicionamiento ideológico (salvo el caso de Colombia), aunque muestran niveles bajos de poder relativo y niveles mediosbajos de capacidad económica. El grupo de países conformado por Argentina, Chile, Costa Rica, República Dominicana y Uruguay manifiesta mayor nivel de convergencia con EEUU debido a al conjunto de características que se conjugan como sus niveles medios y altos de democracia, niveles medios de capacidad económica y poder relativo. Finalmente, Paraguay, El Salvador, Guatemala, Honduras, Panamá y Nicaragua tienden a converger con EEUU y manifiestan posicionamientos ideológicos inclinados a la derecha de la escala (salvo el caso de Nicaragua), con un bajo poder relativo, con bajos niveles de democracia y baja capacidad económica. 
A lo largo de la investigación se demostró que, para todos los países latinoamericanos, la CSS se reveló como una estrategia efectiva para buscar aliados en la arena internacional con la finalidad de materializar los objetivos relacionados a su interés nacional, hacer frente a las amenazas producidas por una globalización asimétrica, y buscar una mejor inserción en el sistema internacional. Al respecto, durante el período analizado se visualizó que el gigante asiático contribuyó al crecimiento de la región, que tuvo un desempeño excepcional si se compara con las etapas anteriores y especialmente con que la época del Consenso de Washington. Esto permitió tanto a los países periféricos Sudamericanos como Ecuador, como a los líderes en la CSS, como Brasil, enfocarse en prioridades de interés nacional como, por ejemplo: mermar las tasas de pobreza y desigualdad, mejorar los índices sociales de salud y educación, o proponer estrategias para la transformación de la matriz productiva.

Sin embargo, el análisis también reveló diferentes facetas de la vulnerabilidad económica y política a la que se encuentran expuestos los estados periféricos en el actual orden internacional. Específicamente para el caso del Ecuador, los resultados apuntan a que el país, al ser un estado débil y pequeño en el concierto internacional, ve condicionadas sus estrategias de política exterior a factores de tipo estructural, especialmente marcado por el rol que desempeña EEUU y los Estados más fuertes en el sistema internacional. Si bien el fortalecimiento de relaciones con China permitió al país diversificar sus relaciones exteriores en la multipolaridad e implementar un modelo de inserción basado en el interés nacional, se observó que el país sudamericano no logró capitalizar los réditos del superciclo económico.

En el caso del Ecuador se demostró que el ascenso de Rafael Correa a la presidencia de la República en el año 2006 marcó un punto de ruptura en el relacionamiento internacional del país, porque adoptó posturas reivindicativas sobre el desarrollo y el rol de la política exterior, vinculándolas con la búsqueda de la autonomía e independencia económica de potencias centrales. En este sentido, la política internacional adquirió un matiz revisionista en la medida en que buscó contrapesar el dominio hegemónico de los EEUU priorizando nuevos 
tipos de relacionamiento con socios del Sur Global, diversificando sus relaciones en la multipolaridad y fortaleciendo relacionamientos con socios del Sur, especialmente con China. Esta estrategia fue beneficiosa para el país andino porque influyó positivamente tanto en el aspecto político, al ampliar sus socios y alternativas de relacionamiento internacional; y en el ámbito económico le permitió mejorar sus índices de crecimiento.

En lo que concierne al análisis de la dependencia, relacionado con factores económicos, la vulnerabilidad del Ecuador a factores externos quedó demostrada con el análisis de las estructuras productivas y el comportamiento del comercio bilateral del país con las dos potencias analizadas. El estudio de caso concluye que el país andino percibió elevados ingresos económicos debido al aumento de precios de las exportaciones, pero no se elevó el volumen de las exportaciones; por otra parte, al aumentar el ingreso por persona se amplió el mercado doméstico y la demanda de bienes de consumo y de capital, lo que provocó un crecimiento más elevado de las importaciones de bienes manufacturados o industrializados y de tipo tecnológico. Es decir, el Ecuador en sus relaciones con China se posicionó netamente como proveedor de bienes primarios, siendo el petróleo el producto más demandado, lo que implica que las estructuras productivas del país no lograron modificarse.

Esto demuestra la vulnerabilidad del país andino a factores exógenos, debido a que el fortalecimiento de la industria extractiva en el Ecuador estuvo estrechamente relacionado con el incremento del flujo de comercio de bienes primarios demandados por economías emergentes que requirieron grandes cantidades de recursos naturales y energéticos para su crecimiento. A pesar de los grandes ingresos derivados del periodo del boom de los commodities, el Ecuador no logró poner en marcha políticas para capturar las ganancias extraordinarias derivadas de la venta de los productos básicos e invertir en la diversificación y mejora de la competitividad de su economía.

En lo referente a las estrategias de autonomía, relacionadas con el ámbito político, los resultados apuntan a que Ecuador encontró en China un socio estratégico que coincide en los principios de relacionamiento internacional que 
abandera el Ecuador: la no interferencia en asuntos internos, la no condicionalidad y el respeto a la soberanía. Esto se pudo observar con el análisis del posicionamiento político del Ecuador en las votaciones de los países en el seno de la AGNU. Al respecto, se elaboró una base de datos -tipo panel- que contempló en total 489 resoluciones, que dieron lugar a 2.916 votaciones. Los resultados apuntan a que, a partir del nuevo milenio, existe una alta coincidencia de los votos a favor entre Ecuador y China, en detrimento de EEUU; así como una alta divergencia de posicionamiento político entre las dos potencias estudiadas.

De los datos empíricos se destaca que en todas las áreas existe un posicionamiento antagónico entre EEUU y China, lo que refleja que para el Ecuador las votaciones implican declarar una preferencia política abierta para con una u otra potencia; y por ende, son indicadores de los márgenes de maniobra que tiene un país. A lo largo del estudio se observó que, a partir del año 2006, con el ascenso de Rafael Correa a la presidencia del Ecuador, el país modifica su postura en las seis áreas de la AGNU analizadas, siendo la tendencia más acentuada en al área de los $\mathrm{DDHH}$. Esto da cuenta del giro que adopta la política exterior del Ecuador que buscó actuar de acuerdo a sus objetivos de inserción internacional procurando fortalecer, no solamente las relaciones económicas con los países del Sur, sino también las relaciones de carácter político-estratégico. Esto implicó, en algunos casos, oponerse a la presión internacional y lobby político que ejerce EEUU para que los países alineen sus votaciones.

Por otra parte, cabe resaltar que el estudio propuesto abre una interesante agenda de investigación y agenda política a futuro, que se resume a continuación.

Desde los dos ámbitos, se considera relevante incorporar el rol de China, como una variable en el análisis de la gobernanza de la cooperación internacional y regional en América Latina. En el aspecto teórico-metodológico se propusieron diversas herramientas que podrían replicarse en futuras investigaciones para comprender el rol de los países periféricos ante actores internacionales, el peso 
de las estructuras de poder, el rol de la agencia y las alternativas de inserción internacional para los estados más vulnerables como el Ecuador. Una propuesta sería analizar los desafíos de una posible doble dependencia externa que genera el fortalecimiento de la presencia China en la región y entender las áreas preferentes en las que ocurre dicho alineamiento. Para ello, esta investigación revalida el uso de las resoluciones adoptadas en AGNU como variable dependiente y proxy del comportamiento de los Estados en las dinámicas internacionales. Resta que otros investigadores establezcan si las reflexiones elaboradas a lo largo de este trabajo pueden ser verificadas por otros estudios de caso o análisis de tipo comparativo.

Esta investigación convoca también a profundizar en el análisis del rol de América Latina ante la inminente reubicación del gigante asiático en el centro de las trasformaciones sistémicas del actual orden internacional. Esto especialmente a la luz de los nuevos patrones de crecimiento de China, que desde el año 2017 aproximadamente da un salto cualitativo en su transformación industrial y consolida al consumo como principal motor de su economía. En el ámbito de la cooperación, esto podría implicar el afianzamiento del patrón "difusionista del desarrollo" - a partir del cual China reasigna industrias mas intensivas en mano de obra hacia otros países en proceso de desarrollo, como la mayoría de países latinoamericanos- abriendo oportunidades para que la región se suba a la escalera del desarrollo.

Finalmente, esta tesis forma parte de una discusión más amplia y ambiciosa referente a los horizontes de desarrollo y las oportunidades de cooperación internacional que se presentan para América Latina, en el contexto de transición hegemónica y competencia entre Estados Unidos y China. El manejo acertado de las relaciones con estos dos países puede ser la clave para determinar la actuación de la región en el mundo que se va conformando, un mundo en el que el gigante asiático es un actor fundamental de una nueva cooperación que ha venido para quedarse y que, de hecho, está siendo imitada por el hegemón en declive. Recae en el pueblo latinoamericano mirar los nuevos escenarios con mente abierta, pero sobre todo desde una reflexión crítica y realista respecto de los factores de cambio y mayores conflictos del orden internacional en ciernes. 


\section{ANEXOS}

\section{Anexo 1. Sistematización del fundamento teórico}

\begin{tabular}{|l|l|}
\hline \multicolumn{2}{|l|}{ Fundamento teórico basado en el Realismo Periférico } \\
\hline Variables & Hipótesis \\
\hline $\begin{array}{l}\text { Distribución del poder } \\
\text { mundial }\end{array}$ & $\begin{array}{l}\mathrm{H} 1 \text {. La estructura de distribución del poder mundial (unipolarismo, bipolarismo, multipolarismo) influencia } \\
\text { el grado de alineamiento político de los países periféricos para con las potencias dominantes. }\end{array}$ \\
\hline Poder relativo & $\begin{array}{l}\mathrm{H} \text { 2. El declive relativo del poder de la potencia hegemónica disminuye la cohesión política de un país } \\
\text { periférico para con dicha potencia, mientras que el apoyo se traslada a la potencia emergente. }\end{array}$ \\
\hline $\begin{array}{l}\text { Interdependencia } \\
\text { económica }\end{array}$ & $\begin{array}{l}\mathrm{H} \text {. Mayor interdependencia comercial (aumento relativo del comercio bilateral) con una potencia mayor } \\
\text { alineamiento político. }\end{array}$ \\
\hline Ideología & $\begin{array}{l}\mathrm{H} \text { 4. El signo político de un Estado incide en la definición de tendencias de inserción internacional y } \\
\text { estrategias de política exterior }\end{array}$ \\
\hline Tipo de régimen político & $\begin{array}{l}\mathrm{H} \text {. Un régimen político democrático tendería a optar por estrategias de inserción internacional en línea } \\
\text { con países que mantengan el mismo régimen político. }\end{array}$
\end{tabular}

Fase I: Modelo explicativo

\begin{tabular}{|c|c|c|c|c|}
\hline \multicolumn{2}{|l|}{ Dimensión } & \multirow{2}{*}{$\begin{array}{l}\text { Variable } \\
\text { V_AgreeUS }\end{array}$} & \multirow{2}{*}{$\begin{array}{l}\begin{array}{l}\text { Observacio } \\
\text { nes }\end{array} \\
963\end{array}$} & \multirow{2}{*}{$\begin{array}{l}\text { Bases de datos } \\
\text { Votos en UNGA. Data and Analyses of } \\
\text { Voting in the UN General Assembly }\end{array}$} \\
\hline Dependientes & $\begin{array}{l}\text { Alineamiento de la } \\
\text { política exterior }\end{array}$ & & & \\
\hline & & V_AgreeChina & 943 & \\
\hline \multirow[t]{9}{*}{ Independientes } & $\begin{array}{l}\text { Política } \\
\text { interna }\end{array}$ & Ideología gobierno & 670 & $\begin{array}{l}\text { Ideología y partidos políticos de Murillo, } \\
\text { Oliveros y Vaishnav (2010) y Database of } \\
\text { Political Institutions (Beck et al 2001). }\end{array}$ \\
\hline & & Año de democracia & 578 & \multirow[t]{3}{*}{ Base de datos Polity IV. } \\
\hline & & Edad de democracia & 578 & \\
\hline & & $\begin{array}{l}\text { Cualidad democrática } \\
\text { (Polity IV) }\end{array}$ & 963 & \\
\hline & \multirow[t]{3}{*}{ Económica } & PIB Per Cápita & 916 & \multirow{2}{*}{$\begin{array}{l}\text { Base de datos del Banco Mundial } \\
\text { Base de datos de comercio bilateral } \\
\text { construidos por Barbieri y Keshk } 2012\end{array}$} \\
\hline & & $\begin{array}{l}\text { Dependencia económica con } \\
\text { EEUU / China }\end{array}$ & 818 & \\
\hline & & Índice de poder (CINC) & 902 & $\begin{array}{l}\text { Capacidades materiales nacionales } \\
\text { (CINC) del proyecto Correlates of War }\end{array}$ \\
\hline & \multirow[t]{2}{*}{ Control } & Año & 963 & \\
\hline & & País & 20 & \\
\hline
\end{tabular}

Países analizados: Brasil, México, Venezuela, Ecuador, Bolivia, Perú y Colombia, Argentina, Chile, Costa Rica, República Dominicana, Uruguay, Paraguay, El Salvador, Guatemala, Honduras, Panamá, Nicaragua, Estados Unidos, China.

Fase II: Caso de estudio único Ecuador

\begin{tabular}{|c|c|c|c|c|}
\hline \multirow{11}{*}{$\begin{array}{l}\text { CSS en la } \\
\text { política exterior } \\
\text { del Ecuador }\end{array}$} & \multirow[t]{2}{*}{$\begin{array}{l}\text { Posicionamiento } \\
\text { internacional }\end{array}$} & Índice de poder & & $\begin{array}{l}\text { Capacidades materiales nacionales } \\
\text { (CINC) del proyecto Correlates of War }\end{array}$ \\
\hline & & $\begin{array}{l}\text { Presencia global del Ecuador en } \\
\text { el mundo }\end{array}$ & & Indice Elcano de Presencia Global \\
\hline & \multirow[t]{3}{*}{$\begin{array}{l}\text { Estructuras } \\
\text { económicas }\end{array}$} & $\begin{array}{l}\text { Comercio } \quad \text { internacional } \\
\text { (exportaciones, importaciones, } \\
\text { composición, balanza comercial) }\end{array}$ & & $\begin{array}{l}\text { OEC, Universidad de Harvard. } \\
\text { Base de datos ALADI; Banco Central del } \\
\text { Ecuador }\end{array}$ \\
\hline & & Reprimarización de la economía & 194 & IVCR \\
\hline & & Ventajas comparativas & 194 & Índice Balassa \\
\hline & \multirow{6}{*}{$\begin{array}{l}\text { Alineamiento } \\
\text { político }\end{array}$} & Conflicto palestino & 129 & \multirow{6}{*}{$\begin{array}{l}\text { Votos en UNGA. Data and Analyses of } \\
\text { Voting in the UN General Assembly }\end{array}$} \\
\hline & & Armas y material nuclear & 48 & \\
\hline & & Control de armas y desarme & 57 & \\
\hline & & Colonialismo & 42 & \\
\hline & & Derechos humanos & 282 & \\
\hline & & Desarrollo económico & 84 & \\
\hline
\end{tabular}


Anexo 2. Listado de entrevistas

\section{Entrevista 1}

Nombre: Gabriela Rosero

Cargo: Ex Secretaria Técnica de Cooperación Internacional, ex Ministra de Desarrollo Social

Institución: SETECI - Ministerio Coordinador de Desarrollo Social

\section{Entrevista 2}

Nombre: Rocío Vergara

Cargo: Ex Subsecretaria de Cooperación Internacional Institución: MREMH

\section{Entrevista 3}

Nombre: Gabriela Montesdeoca

Cargo: Ex Directora de Cooperación Internacional Institución: MREMH - SETECI

\section{Entrevista 4}

Nombre: Mónica Farinango

Cargo: Ex Directora de Cooperación Internacional

Institución: MREMH - SETECI

\section{Entrevista 5}

Nombre: Tania Cueva

Cargo: Analista Cooperación Internacional

Institución: MREMH

\section{Entrevista 6}

Nombre: Omar Ñuflo

Cargo: Delegado encargado, Presidencia Pro Tempore Bolivia en UNASUR Institución: Embajada de Bolivia en Ecuador. UNASUR

\section{Entrevista 7}

Nombre: Juan Carlos Apunte

Cargo: Subsecretaría de América Latina y del Caribe, Dirección de integración regional

Institución: MREMH 
Anexo 3. Votaciones en NNUU: Temática de Derechos Humanos

\begin{tabular}{|c|c|c|c|c|c|c|c|}
\hline Sesión & Año & Resolu. & Tema & Descripción & Ecua. & EEUU & China \\
\hline 55 & 2000 & $\mathrm{R} / 55 / 114$ & Human Rights, Iran & $\begin{array}{l}\text { Situation of human rights in the } \\
\text { Islamic Republic of Iran }\end{array}$ & 1 & 1 & 3 \\
\hline 55 & 2000 & $\mathrm{R} / 55 / 115$ & Human Rights, Iraq & Human rights situation in Iraq & 1 & 1 & 2 \\
\hline 56 & 2001 & $\mathrm{R} / 56 / 171$ & Human Rights, Iran & $\begin{array}{l}\text { Situation of human rights in the } \\
\text { Islamic Republic of Iran }\end{array}$ & 1 & 1 & 3 \\
\hline 56 & 2001 & $\mathrm{R} / 56 / 173$ & $\begin{array}{l}\text { Human Rights, } \\
\text { Democratic Congo }\end{array}$ & $\begin{array}{l}\text { Situation of human rights in the } \\
\text { Democratic Republic of the Congo }\end{array}$ & 1 & 1 & 2 \\
\hline 56 & 2001 & $\mathrm{R} / 56 / 174$ & Human Rights, Iraq & Situation of human rights in Iraq & 1 & 1 & 2 \\
\hline 57 & 2002 & $\mathrm{R} / 57 / 230$ & $\begin{array}{l}\text { Human Rights, } \\
\text { Sudan }\end{array}$ & $\begin{array}{l}\text { Situation of human rights in the } \\
\text { Sudan }\end{array}$ & 1 & 1 & 3 \\
\hline 57 & 2002 & $\mathrm{R} / 57 / 232$ & Human Rights, Iraq & Situation of human rights in Iraq & 1 & 1 & 2 \\
\hline 57 & 2002 & $\mathrm{R} / 57 / 233$ & $\begin{array}{l}\text { Human Rights, } \\
\text { Democratic Congo }\end{array}$ & $\begin{array}{l}\text { Situation of human rights in the } \\
\text { Democratic Republic of the Congo }\end{array}$ & 1 & 1 & 2 \\
\hline 58 & 2003 & $\mathrm{R} / 58 / 196$ & $\begin{array}{l}\text { Situation Of Human } \\
\text { Rights In The } \\
\text { Democratic Republic }\end{array}$ & $\begin{array}{l}\text { Situation of human rights in the } \\
\text { Democratic Republic of the Congo: } \\
\text { resolution / adopted by the General } \\
\text { Assembly }\end{array}$ & 1 & 1 & 2 \\
\hline 58 & 2003 & $\mathrm{R} / 58 / 195$ & $\begin{array}{l}\text { Situation Of Human } \\
\text { Rights In The Islamic } \\
\text { Republic Of Iran }\end{array}$ & $\begin{array}{l}\text { Situation of human rights in the } \\
\text { Islamic Republic of Iran: resolution / } \\
\text { adopted by the General Assembly }\end{array}$ & 1 & 1 & 3 \\
\hline 58 & 2003 & $\mathrm{R} / 58 / 194$ & $\begin{array}{l}\text { Situation Of Human } \\
\text { Rights } \\
\text { inTurkmenistan }\end{array}$ & $\begin{array}{l}\text { Situation of human rights in } \\
\text { Turkmenistan : resolution / adopted } \\
\text { by the General Assembly }\end{array}$ & 1 & 1 & 3 \\
\hline 59 & 2004 & $\mathrm{R} / 59 / 205$ & $\begin{array}{l}\text { Situation Of Human } \\
\text { Rights In The Islamic } \\
\text { Republic Of Iran }\end{array}$ & $\begin{array}{l}\text { Situation of human rights in the } \\
\text { Islamic Republic of Iran : resolution / } \\
\text { adopted by the General Assemly }\end{array}$ & 2 & 1 & 3 \\
\hline 60 & 2005 & $\mathrm{R} / 60 / 171$ & $\begin{array}{l}\text { Situation Of Human } \\
\text { Rights In The Islamic } \\
\text { Republic Of Iran }\end{array}$ & $\begin{array}{l}\text { Situation of human rights in the } \\
\text { Islamic Republic of Iran : resolution / } \\
\text { adopted by the General Assembly }\end{array}$ & 1 & 1 & 3 \\
\hline 61 & 2006 & $\mathrm{R} / 61 / 176$ & $\begin{array}{l}\text { Situation Of Human } \\
\text { Rights In The Islamic } \\
\text { Republic Of Iran: R }\end{array}$ & $\begin{array}{l}\text { Situation of human rights in the } \\
\text { Islamic Republic of Iran: resolution / } \\
\text { adopted by the General Assembly }\end{array}$ & 1 & 1 & 3 \\
\hline 61 & 2006 & $\mathrm{R} / 61 / 175$ & $\begin{array}{l}\text { Situation Of Human } \\
\text { Rights In Belarus: } \\
\text { Resolution }\end{array}$ & $\begin{array}{l}\text { Situation of human rights in Belarus: } \\
\text { resolution / adopted by the General } \\
\text { Assembly }\end{array}$ & 2 & 1 & 3 \\
\hline 61 & 2006 & $\mathrm{R} / 61 / 174$ & $\begin{array}{l}\text { Situation Of Human } \\
\text { Rights In The } \\
\text { Democratic People's }\end{array}$ & $\begin{array}{l}\text { Situation of human rights in the } \\
\text { Democratic People's Republic of } \\
\text { Korea : resolution / adopted by the } \\
\text { General Assembly }\end{array}$ & 1 & 1 & 3 \\
\hline 61 & 2006 & $\mathrm{R} / 61 / 232$ & $\begin{array}{l}\text { Situation On Human } \\
\text { Rights In Myanmar: } \\
\text { Resolution }\end{array}$ & $\begin{array}{l}\text { Situation on human rights in } \\
\text { Myanmar: resolution / adopted by } \\
\text { the General Assemby }\end{array}$ & 1 & 1 & 3 \\
\hline 62 & 2007 & $\mathrm{R} / 62 / 169$ & $\begin{array}{l}\text { Human Rights, } \\
\text { Reports, Belarus }\end{array}$ & $\begin{array}{l}\text { Situation of the human rights in } \\
\text { Belarus : resolution / adopted by the } \\
\text { General Assembly }\end{array}$ & 2 & 1 & 3 \\
\hline 62 & 2007 & $\mathrm{R} / 62 / 167$ & $\begin{array}{lr}\text { Human } & \text { Rights, } \\
\text { Reports, Democratic } \\
\text { People's Republic Of } \\
\text { Korea }\end{array}$ & $\begin{array}{l}\text { Situation of human rights in the } \\
\text { Democratic People's Republic of } \\
\text { Korea : resolution / adopted by the } \\
\text { General Assembly }\end{array}$ & 2 & 1 & 3 \\
\hline 62 & 2007 & $\mathrm{R} / 62 / 168$ & $\begin{array}{l}\text { Human Rights, } \\
\text { Reports, Iran (Islamic } \\
\text { Republic Of) }\end{array}$ & $\begin{array}{l}\text { Situation of human rights in the } \\
\text { Islamic Republic of Iran : resolution / } \\
\text { adopted by the General Assembly }\end{array}$ & 2 & 1 & 3 \\
\hline
\end{tabular}




\begin{tabular}{|c|c|c|c|c|c|c|c|}
\hline 62 & 2007 & $\mathrm{R} / 62 / 222$ & $\begin{array}{l}\text { Human Rights, } \\
\text { Myanmar, Reports }\end{array}$ & $\begin{array}{l}\text { Situation of human rights in } \\
\text { Myanmar : resolution / adopted by } \\
\text { the General Assembly }\end{array}$ & 2 & 1 & 3 \\
\hline 63 & 2008 & $\mathrm{R} / 63 / 190$ & $\begin{array}{l}\text { Human Rights, } \\
\text { Reports }\end{array}$ & $\begin{array}{l}\text { Situation of human rights in the } \\
\text { Democratic People's Republic of } \\
\text { Korea: resolution / adopted by the } \\
\text { General Assembly }\end{array}$ & 2 & 1 & 3 \\
\hline 63 & 2008 & $\mathrm{R} / 63 / 245$ & $\begin{array}{l}\text { Human Rights, } \\
\text { Reports }\end{array}$ & $\begin{array}{l}\text { Situation of human rights in } \\
\text { Myanmar: resolution / adopted by } \\
\text { the General Assembly }\end{array}$ & 2 & 1 & 3 \\
\hline 64 & 2009 & $\mathrm{R} / 64 / 175$ & $\begin{array}{l}\text { Human Rights, } \\
\text { Reports, Democratic } \\
\text { People's Republic Of } \\
\text { Korea }\end{array}$ & $\begin{array}{l}\text { Situation of human rights in the } \\
\text { Democratic Republic of Korea : } \\
\text { resolution / adopted by the General } \\
\text { Assembly }\end{array}$ & 2 & 1 & 3 \\
\hline 64 & 2009 & $\mathrm{R} / 64 / 238$ & $\begin{array}{l}\text { Human Rights, } \\
\text { Reports, Myanmar }\end{array}$ & $\begin{array}{l}\text { Situation of human rights in } \\
\text { Myanmar: resolution / adopted by } \\
\text { the General Assembly }\end{array}$ & 2 & 1 & 3 \\
\hline 65 & 2010 & $\mathrm{R} / 65 / 208$ & $\begin{array}{l}\text { Human Rights } \\
\text { Advancement }\end{array}$ & $\begin{array}{l}\text { Extrajudicial, summary or arbitrary } \\
\text { executions: resolution / adopted by } \\
\text { the General Assembly }\end{array}$ & 1 & 2 & 2 \\
\hline 65 & 2010 & $\mathrm{R} / 65 / 225$ & $\begin{array}{l}\text { Human Rights, } \\
\text { Democratic People's } \\
\text { Republic Of Korea }\end{array}$ & $\begin{array}{l}\text { Situation of human rights in the } \\
\text { Democratic People's Republic of } \\
\text { Korea: resolution / adopted by the } \\
\text { General Assembly }\end{array}$ & 2 & 1 & 3 \\
\hline 65 & 2010 & $\mathrm{R} / 65 / 195$ & $\begin{array}{l}\text { Un. Human Rights } \\
\text { Council, Reports }\end{array}$ & $\begin{array}{l}\text { Report of the Human Rights } \\
\text { Council: resolution / adopted by the } \\
\text { General Assembly }\end{array}$ & 1 & 2 & 1 \\
\hline 66 & 2011 & $\mathrm{R} / 66 / 136$ & $\begin{array}{l}\text { Un. Human Rights } \\
\text { Council--Reports }\end{array}$ & $\begin{array}{l}\text { Report of the Human Rights } \\
\text { Council: resolution / adopted by the } \\
\text { General Assembly }\end{array}$ & 1 & 2 & 1 \\
\hline 66 & 2011 & $\mathrm{R} / 66 / 174$ & $\begin{array}{l}\text { Human } \\
\text { Reports }\end{array}$ & $\begin{array}{l}\text { Situation of human rights in the } \\
\text { Democratic People's Republic of } \\
\text { Korea: resolution / adopted by the } \\
\text { General Assembly }\end{array}$ & 2 & 1 & 3 \\
\hline 67 & 2012 & $\mathrm{R} / 67 / 183$ & $\begin{array}{l}\text { Human } \\
\text { Reports }\end{array}$ & $\begin{array}{l}\text { Situation of human rights in the } \\
\text { Syrian Arab Republic: resolution / } \\
\text { adopted by the General Assembly }\end{array}$ & 2 & 1 & 3 \\
\hline
\end{tabular}

Fuente: UNGA.

Elaboración propia en base a datos de votaciones en la UNGA. Votos: 1=si, 2=abstención, $3=$ no 
Anexo 4: IVCR normalizado en el mercado de China

\begin{tabular}{|c|c|c|c|c|c|c|c|c|c|c|c|}
\hline \multirow[t]{2}{*}{ All products } & \multicolumn{11}{|c|}{ Ecuador, IVCR Normalizado en el mercado chino (2005-2015) } \\
\hline & 2005 & 2006 & 2007 & 2008 & 2009 & 2010 & 2011 & 2012 & 2013 & 2014 & 2015 \\
\hline $\begin{array}{l}\text { Residues and waste from the } \\
\text { food industries; prepared } \\
\text { animal fodder }\end{array}$ & $\overline{1}, 00$ & 0,19 & $\overline{0}, 45$ & $\overline{-}, 94$ & $\overline{0}, 23$ & 0,27 & 0,65 & 0,53 & 0,72 & 0,43 & 0,53 \\
\hline Cocoa and cocoa preparations & $-\overline{0}, 16$ & $-\overline{1,00}$ & $\begin{array}{l}- \\
1,00\end{array}$ & $\overline{-}, 98$ & $\overline{-}, 99$ & $\overline{-}, 97$ & $\overline{-}, 13$ & 13 & $\overline{-}, 09$ & $\overline{-}, 31$ & 0,16 \\
\hline Copper and articles thereof & 0,59 & 0,76 & 0,81 & 0,30 & 0,24 & 0,63 & 0,67 & 0,57 & 0,62 & 0,41 & 0,24 \\
\hline Ores, slag and ash & 0,95 & 0,99 & 0,84 & $\overline{1}, 00$ & 0,99 & 1,00 & 0,91 & 0,04 & 0,45 & 0,56 & $\overline{0}, 80$ \\
\hline $\begin{array}{l}\text { Wood and articles of wood; } \\
\text { wood charcoal }\end{array}$ & 0,22 & $-\overline{-}, 31$ & $-\overline{0}$ & $-\overline{-}$ & 0,04 & 0,73 & 0,74 & 0,00 & 0,12 & 0,40 & 0,68 \\
\hline $\begin{array}{l}\text { Edible fruit and nuts; peel of } \\
\text { citrus fruit or melons }\end{array}$ & 17 & 0,99 & 0,91 & 0,80 & $\overline{-}-8,8$ & 0,63 & $\overline{-}, 28$ & 0,20 & 0,20 & 0,79 & 0,81 \\
\hline $\begin{array}{l}\text { Mineral fuels, mineral oils and } \\
\text { products of their distillation; } \\
\text { bituminous substances; } \\
\text { mineral }\end{array}$ & $\overline{1,00}$ & 0,98 & 0,63 & 0,92 & 0,77 & 0,95 & 1,00 & 0,87 & 0,94 & 0,61 & 0,84 \\
\hline $\begin{array}{l}\text { Fish and crustaceans, } \\
\text { molluscs and other aquatic } \\
\text { invertebrates }\end{array}$ & $\overline{0}, 60$ & $\overline{-}$ & $\overline{0}, \overline{7}$ & $\overline{-}, 98$ & $\overline{-}-51$ & 0,23 & 0,69 & 0,60 & 0,77 & 0,80 & 0,87 \\
\hline $\begin{array}{l}\text { Toys, games and } \\
\text { requisites; parts } \\
\text { accessories thereof }\end{array}$ & $\overline{1}, 00$ & $\overline{1}, 00$ & $\overline{1}, 00$ & $\overline{1}-$ & $\overline{1}, 00$ & $\overline{1}, 00$ & $\overline{1}, 00$ & $\overline{1}, 00$ & $\overline{-}, 99$ & $\overline{1}, 00$ & $-\overline{1}$ \\
\hline $\begin{array}{l}\text { Animal or vegetable fats and } \\
\text { oils and their cleavage } \\
\text { products; prepared edible fats; } \\
\text { animal }\end{array}$ & $\overline{-} 0,97$ & $-\overline{1}$ & $\overline{-}-9$ & $\overline{1}-$ & $\overline{1}$ & $\overline{-}-9$ & $\overline{-}, 96$ & $\overline{-}$ & $-\overline{1}$ & $\overline{-}-97$ & $-\overline{0}$ \\
\hline Organic chemicals & $\overline{1}, 00$ & 1,00 & 1,00 & $\overline{1}-$ & $\overline{1}-, 00$ & & $\overline{1}, 00$ & 0,98 & 0,85 & $\overline{-}, 96$ & $\overline{-}$ \\
\hline $\begin{array}{ll}\text { Miscellaneous } & \text { edible } \\
\text { preparations } & \end{array}$ & 0,87 & 0,74 & 0,98 & 0,96 & 0,99 & 0,99 & 0,93 & 0,95 & 0,98 & 1,00 & 1,00 \\
\hline Rubber and articles thereof & $\overline{-}, 95$ & 1,00 & - & 1,00 & $-\overline{1}$ & $-\overline{1}$ & 1,00 & - & 1,00 & $-1,00$ & 1,00 \\
\hline $\begin{array}{l}\text { Pulp of wood or of other fibrous } \\
\text { cellulosic material; recovered } \\
\text { (waste and scrap) paper or ... }\end{array}$ & - & $-\overline{0}, 98$ & $-\overline{0}, 99$ & $-\overline{0}, 99$ & $\overline{1}-$ & 1,00 & $-\overline{0}, 93$ & $-\overline{0}, 99$ & $\overline{1}-$ & 1,00 & - \\
\hline Man-made staple fibres & $\overline{1}-00$ & 1,00 & $\overline{1}, 00$ & $\overline{1}-00$ & $\overline{1}, 00$ & $\overline{1}-00$ & $\overline{-}, 99$ & 1,00 & $\overline{1}-00$ & $-\overline{1,00}$ & $-\overline{1}$ \\
\hline $\begin{array}{l}\text { Articles of apparel and clothing } \\
\text { accessories, knitted or } \\
\text { crocheted }\end{array}$ & 1,00 & $\overline{1}-00$ & $\overline{1}, 00$ & $\overline{1}, 00$ & 1,00 & 1,00 & $\overline{1}, 00$ & $\overline{1}, 00$ & $\overline{1}-00$ & 1,00 & 1,00 \\
\hline $\begin{array}{l}\text { Articles of apparel and clothing } \\
\text { accessories, not knitted or } \\
\text { crocheted }\end{array}$ & $\overline{-}$ & 1,00 & $\overline{1}, 00$ & $\overline{1}-$ & $\overline{1}, 00$ & $\overline{1}$ & $\overline{1}, 00$ & 1,00 & 1,00 & $-\overline{1}$ & $-\overline{1}$ \\
\hline $\begin{array}{l}\text { Footwear, gaiters and the like; } \\
\text { parts of such articles }\end{array}$ & $\overline{1}, 00$ & $\overline{1}, 00$ & $\overline{1}, 00$ & $-\overline{1,00}$ & $\overline{1}-00$ & $\overline{1}, 00$ & $\overline{1}-$ & $\overline{1}-00$ & $\overline{1}-00$ & $-\overline{1,00}$ & $\begin{array}{l}- \\
1,00\end{array}$ \\
\hline $\begin{array}{l}\text { Umbrellas, sun umbrellas, } \\
\text { walking sticks, seat-sticks, } \\
\text { whips, riding-crops and parts } \\
\text { thereof }\end{array}$ & 1,00 & 1,00 & 1,00 & 1,00 & 1,00 & 1,00 & 1,00 & 1,00 & 1,00 & 1,00 & 1,00 \\
\hline $\begin{array}{l}\text { Natural or cultured pearls, } \\
\text { precious or semi-precious } \\
\text { stones, precious metals, } \\
\text { metals clad ... }\end{array}$ & $\begin{array}{l}- \\
1,00\end{array}$ & $\begin{array}{l}- \\
1,00\end{array}$ & $\overline{1}-\overline{0}$ & $\overline{1}-\overline{0}$ & $\overline{1}-\overline{0}$ & $\overline{1}-\overline{ }$ & $\overline{1}-\overline{0}$ & $\begin{array}{l}- \\
1,00\end{array}$ & $\overline{-}$ & $\overline{0}-66$ & 0,64 \\
\hline Articles of iron or steel & $\overline{1}-\overline{0}$ & 0,9 & 1,00 & $-\overline{1,00}$ & $\overline{1}, 00$ & 1,00 & $\overline{1}-00$ & 1,00 & 1,00 & $\overline{1,00}$ & $\overline{-}, 80$ \\
\hline Iron and steel & $\overline{0,54}$ & 0,18 & 0,30 & 0,67 & 0,81 & 0,99 & 0,70 & 1,00 & 1,00 & 1,00 & 1,00 \\
\hline
\end{tabular}




\begin{tabular}{|c|c|c|c|c|c|c|c|c|c|c|c|}
\hline Glass and glassware & 1,00 & $\overline{1,00}$ & $\overline{1,00}$ & $\overline{1,00}$ & $\overline{1}-00$ & $\overline{1,00}$ & $\overline{1}, 00$ & $\overline{1,00}$ & $\overline{1,00}$ & $\overline{1,00}$ & $\begin{array}{l}- \\
1,00\end{array}$ \\
\hline $\begin{array}{l}\text { Salt; sulphur; earths and } \\
\text { stone; plastering materials, } \\
\text { lime and cement }\end{array}$ & 1,00 & 1,00 & 0,99 & 1,00 & 1,00 & 1,00 & 1,00 & 1,00 & 1,00 & 1,00 & 1,00 \\
\hline $\begin{array}{l}\text { Vehicles other than railway or } \\
\text { tramway rolling stock, and } \\
\text { parts and accessories thereof }\end{array}$ & 1,00 & 1,00 & $\overline{1}, 00$ & 1,00 & 1,00 & 1,00 & 1,00 & 1,00 & $\overline{1}, 00$ & 0,99 & 0,97 \\
\hline Beverages, spirits and vinegar & $\begin{array}{l}- \\
1,00\end{array}$ & $\overline{1,00}$ & $\overline{1,00}$ & $\overline{1}-00$ & $\begin{array}{l}- \\
1,00\end{array}$ & $\overline{-}, 99$ & $\overline{0}, 99$ & $\begin{array}{l}- \\
1,00\end{array}$ & $\overline{1}-00$ & $\overline{0}-99$ & $\begin{array}{l}- \\
1,00\end{array}$ \\
\hline $\begin{array}{l}\text { Optical, photographic, } \\
\text { cinematographic, measuring, } \\
\text { checking, precision, medical or } \\
\text { surgical }\end{array}$ & 1,00 & 0,99 & $\overline{-}-9$ & 1,00 & 0,97 & 0,99 & 0,99 & 0,99 & $-\overline{1}$ & 1,00 & 0,99 \\
\hline $\begin{array}{l}\text { Preparations of meat, of fish or } \\
\text { of crustaceans, molluscs or } \\
\text { other aquatic invertebrates }\end{array}$ & $\overline{1,00}$ & $\overline{1,00}$ & $\overline{1}$ & $\overline{1}$ & - & $\overline{1}$ & $\overline{1,00}$ & $\overline{1,00}$ & $\overline{1}$ & $\overline{1}$ & $\overline{0}-$ \\
\hline Zinc and articles thereof & $\overline{1}-\overline{0}$ & $\overline{1}-\overline{ }$ & $\overline{1}-\overline{0}$ & $\overline{-}$ & $\overline{0}, 99$ & $\overline{1}-\overline{0}$ & $\overline{0}, 94$ & $\overline{-}, 98$ & $\overline{1}-\overline{0}$ & $\overline{-}, 99$ & $\overline{1}-00$ \\
\hline $\begin{array}{l}\text { Products of animal origin, not } \\
\text { elsewhere specified or } \\
\text { included }\end{array}$ & $\overline{1}$ & $\overline{1}-$ & $\overline{1}-$ & $\overline{1}$ & - & $\overline{-}$ & $\overline{-}, 96$ & $\overline{-}, 91$ & $\overline{-}$ & $\overline{-}$ & 0,97 \\
\hline $\begin{array}{l}\text { Other vegetable textile fibres; } \\
\text { paper yarn and woven fabrics } \\
\text { of paper yarn }\end{array}$ & $\overline{-}$ & $\overline{-}$ & $\overline{1}$ & $\overline{1}$ & $\overline{-}$ & $\begin{array}{l}- \\
0,97\end{array}$ & $\overline{-}$ & $\overline{-}$ & $\overline{0}, 99$ & $\overline{-}-\overline{0}$ & $\begin{array}{l}- \\
1,00\end{array}$ \\
\hline $\begin{array}{l}\text { Vegetable plaiting materials; } \\
\text { vegetable products not } \\
\text { elsewhere specified }\end{array}$ & $\overline{1}$ & - & $\overline{1}-$ & $\overline{1}$ & $\begin{array}{l}- \\
1,00\end{array}$ & $\overline{-}$ & $\overline{-}$ & $\overline{-}$ & $\overline{-}$ & $\overline{-}-97$ & $\overline{-}$ \\
\hline $\begin{array}{l}\text { Raw hides and skins (other } \\
\text { than furskins) and leather }\end{array}$ & $\overline{0}, 96$ & $\begin{array}{l}- \\
0,55\end{array}$ & $\overline{0}, 69$ & $\overline{-}, 99$ & $\overline{1}-00$ & $\begin{array}{l}- \\
1,00\end{array}$ & 0,81 & 0,92 & $\begin{array}{l}- \\
0,74\end{array}$ & $\overline{0}, 96$ & $\overline{0}, 83$ \\
\hline $\begin{array}{l}\text { Machinery, mechanical } \\
\text { appliances, nuclear reactors, } \\
\text { boilers; parts thereof }\end{array}$ & - & - & $\overline{-}, 95$ & - & - & $\overline{-}$ & $\overline{-}, 93$ & $\overline{-}-$ & $\overline{0}-$ & $-\overline{0}, 97$ & $-\overline{0}$ \\
\hline Headgear and parts thereof & $\overline{0}, 95$ & $\overline{0}, 99$ & $\overline{0}-98$ & $\overline{-}, 99$ & $\overline{0}, 99$ & $\begin{array}{l}- \\
1,00\end{array}$ & 1,00 & $\overline{1,00}$ & $\overline{1}-00$ & $\overline{0}-99$ & $\overline{0}, 99$ \\
\hline $\begin{array}{l}\text { Miscellaneous chemical } \\
\text { products }\end{array}$ & $\overline{-}$ & $\overline{-}$ & $\overline{-}, 99$ & $\overline{-}$ & - & $\overline{1}-$ & $\overline{1}$ & $\overline{-}$ & $\overline{-}-97$ & $\overline{-}, 99$ & $\overline{0}$ \\
\hline $\begin{array}{l}\text { Miscellaneous articles of base } \\
\text { metal }\end{array}$ & 1,00 & 1,00 & 0,99 & 1,00 & 1,00 & - & 0,98 & 1,00 & - & 0,92 & 0,80 \\
\hline Coffee, tea, maté and spices & - & $\begin{array}{l}- \\
1,00\end{array}$ & - & 1,00 & $\overline{1}, 00$ & - & 1,00 & 1,00 & - & - & $\overline{0}-99$ \\
\hline $\begin{array}{l}\text { Preparations of vegetables, } \\
\text { fruit, nuts or other parts of } \\
\text { plants }\end{array}$ & 1,00 & 1,00 & - & - & - & $\overline{0}, 97$ & $\overline{0}, 95$ & $\overline{0}, 92$ & $\overline{0}, 87$ & $\overline{0}, 82$ & 0,86 \\
\hline $\begin{array}{l}\text { Electrical machinery, } \\
\text { equipment and parts; sound } \\
\text { recorders and reproducers, } \\
\text { television }\end{array}$ & 0,89 & 0,90 & 0,59 & 0,81 & 0,99 & 0,92 & 1,00 & 1,00 & 0,97 & 0,83 & 0,75 \\
\hline Aluminium and articles thereof & 0,04 & 0,23 & 0,02 & 0,56 & 0,73 & 0,39 & 0,02 & 0,22 & $\overline{-}, 20$ & 0,65 & 0,46 \\
\hline Plastics and articles thereof & 0,12 & $\overline{-}-2$ & 0,36 & 0,84 & 0,80 & - & 0,29 & 0,23 & 0,10 & - & 0,42 \\
\hline $\begin{array}{l}\text { Miscellaneous manufactured } \\
\text { articles }\end{array}$ & 0,06 & $\overline{-}, 31$ & $-\overline{0}$ & $-\overline{0}, 92$ & $\overline{-}, 95$ & - & $-\overline{-}$ & - & $-\overline{0}$ & $-\overline{0}, 78$ & $-\overline{-}$ \\
\hline $\begin{array}{l}\text { Oil seeds and oleaginous } \\
\text { fruits; miscellaneous grains, } \\
\text { seeds and fruit; industrial or } \\
\text { medicinal ... }\end{array}$ & $\overline{1}, 00$ & $\overline{1,00}$ & 1,00 & 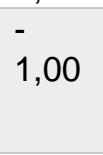 & 1,00 & $\overline{1,00}$ & 1,00 & 1,00 & $\overline{1}$ & $\overline{0}, 91$ & 0,84 \\
\hline $\begin{array}{l}\text { Live trees and other plants; } \\
\text { bulbs, roots and the like; cut } \\
\text { flowers and ornamental foliage }\end{array}$ & $\overline{0}, 97$ & 0,98 & 0,89 & 1,00 & $\overline{-}, 99$ & $\overline{-}, 99$ & 0,99 & 0,99 & $\overline{-}$ & $\overline{-}-78$ & $\overline{-}, 55$ \\
\hline
\end{tabular}


Anexo 5: IVCR Normalizado en el mercado de EEUU

\begin{tabular}{|c|c|c|c|c|c|c|c|c|c|c|c|}
\hline \multirow[t]{2}{*}{ Todos los productos } & \multicolumn{11}{|c|}{ Ecuador. IVCR Normalizado en el mercado de USA (2005-2015) } \\
\hline & 2005 & 2006 & 2007 & 2008 & 2009 & 2010 & 2011 & 2012 & 2013 & 2014 & 2015 \\
\hline $\begin{array}{l}\text { Wood and articles of wood; } \\
\text { wood charcoal }\end{array}$ & 0,11 & $\overline{-}, 03$ & 0,10 & $\overline{-}, 20$ & $\overline{-}, 02$ & $\overline{-}, 05$ & $\overline{-}, 30$ & $\overline{-}, 25$ & $\overline{0}, 39$ & $\overline{-}, 29$ & 0,02 \\
\hline $\begin{array}{l}\text { Preparations of vegetables, } \\
\text { fruit, nuts or other parts of } \\
\text { plants }\end{array}$ & $\overline{-}, 01$ & $\overline{-}, 05$ & $\overline{-}, 05$ & $\overline{-}-$ & 0,11 & $\overline{-}, 06$ & $\overline{-}-22$ & $\overline{-}-16$ & $\overline{-}, 29$ & $\overline{-}-17$ & 0,13 \\
\hline $\begin{array}{l}\text { Cocoa and cocoa } \\
\text { preparations }\end{array}$ & 0,20 & $\overline{0}, 19$ & 0,12 & 0,13 & 0,56 & 0,12 & 0,40 & 0,12 & 0,13 & 0,36 & 0,63 \\
\hline $\begin{array}{l}\text { Natural or cultured pearls, } \\
\text { precious or semi-precious } \\
\text { stones, precious metals, } \\
\text { metals clad ... }\end{array}$ & $\overline{-}$ & $\overline{-}$ & 0,01 & $-\overline{-}$ & $\overline{-}, 49$ & $\overline{-}-$ & $\overline{-}-$ & 0,47 & 0,46 & 0,76 & 0,81 \\
\hline $\begin{array}{l}\text { Preparations of meat, of fish } \\
\text { or of crustaceans, molluscs } \\
\text { or other aquatic } \\
\text { invertebrates }\end{array}$ & 0,32 & 0,34 & 0,11 & 0,25 & $\overline{0}, 07$ & $\overline{0}, 23$ & 0,03 & 0,10 & 0,00 & 0,04 & 0,31 \\
\hline $\begin{array}{l}\text { Live trees and other plants; } \\
\text { bulbs, roots and the like; cut } \\
\text { flowers and ornamental } \\
\text { foliage }\end{array}$ & 0,72 & 0,67 & 0,66 & 0,66 & 0,65 & 0,58 & 0,47 & 0,51 & 0,45 & 0,49 & 0,70 \\
\hline $\begin{array}{l}\text { Edible fruit and nuts; peel of } \\
\text { citrus fruit or melons }\end{array}$ & 0,78 & 0,76 & 0,75 & 0,62 & 0,83 & 0,75 & 0,66 & 0,62 & 0,58 & 0,60 & 0,79 \\
\hline $\begin{array}{l}\text { Fish and crustaceans, } \\
\text { molluscs and other aquatic } \\
\text { invertebrates }\end{array}$ & 0,78 & 0,77 & 0,78 & 0,67 & 0,80 & 0,75 & 0,73 & 0,75 & 0,72 & 0,78 & 0,84 \\
\hline $\begin{array}{l}\text { Mineral fuels, mineral oils } \\
\text { and products of their } \\
\text { distillation; bituminous } \\
\text { substances; mineral }\end{array}$ & 0,98 & 0,98 & 0,98 & 0,98 & 0,97 & 0,97 & 0,97 & 0,98 & 0,97 & 0,97 & 0,97 \\
\hline $\begin{array}{l}\text { Pulp of wood or of other } \\
\text { fibrous cellulosic material; } \\
\text { recovered (waste and scrap) } \\
\text { paper }\end{array}$ & $\begin{array}{l}- \\
1,00\end{array}$ & $\overline{-}$ & $\overline{-}, 99$ & $\overline{-}$ & $\overline{-}$ & $\overline{-}$ & $\overline{-}$ & $\overline{-}$ & $\overline{-}$ & $\overline{-}$ & $-1,00$ \\
\hline Cotton & $\overline{-}-9$ & $\overline{-}$ & $\overline{1}-, 00$ & $\overline{-}$ & $\overline{-}$ & $\overline{1}$ & $\overline{-}$ & $-\overline{1}$ & $\overline{1}-, 00$ & $\overline{1}-$ & $-1,00$ \\
\hline $\begin{array}{l}\text { Man-made filaments; strip } \\
\text { and the like of man-made } \\
\text { textile materials }\end{array}$ & 0,99 & 1,00 & 1,00 & 1,00 & 1,00 & 1,00 & 1,00 & 1,00 & 1,00 & 1,00 & $-1,00$ \\
\hline Man-made staple fibres & $\overline{0}, 99$ & $\overline{0}, 99$ & $\overline{-}, 99$ & $\begin{array}{l}- \\
1,00\end{array}$ & $\overline{1,00}$ & $\overline{1,00}$ & 1,00 & $\overline{1,00}$ & $\begin{array}{l}- \\
1,00\end{array}$ & $\begin{array}{l}- \\
1,00\end{array}$ & $-1,00$ \\
\hline $\begin{array}{l}\text { Other base metals; cermets; } \\
\text { articles thereof }\end{array}$ & $\overline{1}$ & - & $\overline{1}-$ & $\overline{1}$ & $-\overline{1}$ & $\overline{1}-$ & $\overline{1}$ & $\overline{1}-$ & $\overline{1}-$ & $\overline{1}-$ & $-1,00$ \\
\hline $\begin{array}{l}\text { Footwear, gaiters and the } \\
\text { like; parts of such articles }\end{array}$ & $\overline{-}$ & $\overline{-}-9$ & $\overline{-}-99$ & $\overline{-}$ & $\overline{-}$ & $\overline{-}-99$ & $\overline{-}, 99$ & $\overline{-}$ & $\overline{1}-\overline{1}$ & $\overline{1}-$ & $-1,00$ \\
\hline $\begin{array}{l}\text { Musical instruments; parts } \\
\text { and accessories of such } \\
\text { articles }\end{array}$ & 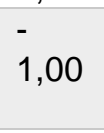 & 1,00 & 1,00 & - & 1,00 & - & 1,00 & 1,00 & - & 1,00 & $-1,00$ \\
\hline $\begin{array}{l}\text { Soap, organic surface-active } \\
\text { agents, } \quad \text { washing } \\
\text { preparations, lubricating } \\
\text { preparations, artificial }\end{array}$ & $\overline{-}-99$ & $\overline{-}$ & $\overline{-}$ & $\overline{1}-, 00$ & $\begin{array}{l}- \\
1,00\end{array}$ & $\begin{array}{l}- \\
1,00\end{array}$ & $\begin{array}{l}- \\
1,00\end{array}$ & $\begin{array}{l}- \\
1,00\end{array}$ & $\begin{array}{l}- \\
1,00\end{array}$ & $\begin{array}{l}- \\
1,00\end{array}$ & $-0,99$ \\
\hline $\begin{array}{l}\text { Wadding, felt and } \\
\text { nonwovens; special yarns; } \\
\text { twine, cordage, ropes and } \\
\text { cables and articles }\end{array}$ & $\overline{0}, 98$ & 0,99 & $\begin{array}{l}- \\
1,00\end{array}$ & 1,00 & $\begin{array}{l}- \\
1,00\end{array}$ & 1,00 & 1,00 & 1,00 & $\begin{array}{l}- \\
1,00\end{array}$ & 1,00 & $-1,00$ \\
\hline
\end{tabular}




\begin{tabular}{|c|c|c|c|c|c|c|c|c|c|c|c|}
\hline harmaceutical products & $\overline{-}, 98$ & $\overline{1}, 00$ & $\overline{1,00}$ & $\begin{array}{l}- \\
1,00\end{array}$ & $\begin{array}{l}- \\
1,00\end{array}$ & $\overline{1}-00$ & $\overline{1,00}$ & $\overline{1}, 00$ & $\begin{array}{l}- \\
1,00\end{array}$ & $\overline{1,00}$ & $-1,00$ \\
\hline $\begin{array}{l}\text { c; gums, resins and other } \\
\text { getable saps and extracts }\end{array}$ & 1,00 & - & - & $-\overline{1,00}$ & $-\overline{1,00}$ & - & 1,00 & $-\overline{1,00}$ & - & 1,00 & $-1,00$ \\
\hline $\begin{array}{l}\text { alt; sulphur; earths and } \\
\text { tone; plastering materials, } \\
\text { ne and cement }\end{array}$ & 1,00 & 1,00 & - & 1,00 & 1,00 & 0,97 & 0,99 & 0,99 & $\overline{1}$ & 1,00 & $-1,00$ \\
\hline $\begin{array}{l}\text { liscellaneous chemical } \\
\text { roducts }\end{array}$ & $\overline{0}, 98$ & $\overline{0}, 17$ & $\begin{array}{l}- \\
0,49\end{array}$ & 1,00 & 1,00 & $\overline{1}, 00$ & $\begin{array}{l}- \\
1,00\end{array}$ & $\overline{0}, 99$ & $\overline{0}$ & $\overline{-}, 96$ & $-0,98$ \\
\hline $\begin{array}{l}\text { aw hides and skins (other } \\
\text { an furskins) and leather }\end{array}$ & 0,98 & - & 1,00 & 1,00 & 1,00 & 1,00 & 1,00 & 1,00 & 1,00 & 1,00 & 0,99 \\
\hline $\begin{array}{l}\text { rticles of leather; saddlery } \\
\text { nd harness; travel goods, } \\
\text { andbags and similar } \\
\text { ontainers }\end{array}$ & 0,99 & - & - & 1,00 & 1,00 & 0,99 & 1,00 & 0,99 & 1,00 & 1,00 & $-0,99$ \\
\hline $\begin{array}{l}\text { obacco and manufactured } \\
\text { bbacco substitutes }\end{array}$ & $\overline{0}, 90$ & $\overline{0}, 95$ & $\overline{-}$ & 0,99 & 0,99 & 1,00 & 1,00 & 0,98 & $\begin{array}{l}- \\
1,00\end{array}$ & $\overline{0}, 99$ & $-0,99$ \\
\hline $\begin{array}{l}\text { hips, boats and floating } \\
\text { tructures }\end{array}$ & 0,99 & 1,00 & - & 1,00 & 1,00 & - & 1,00 & 1,00 & 1,00 & - & $-1,00$ \\
\hline $\begin{array}{l}\text { Dairy produce; birds' eggs; } \\
\text { hatural honey; edible } \\
\text { oroducts of animal origin, not } \\
\text { elsewhere }\end{array}$ & 0,99 & $\overline{0}, 99$ & 0,99 & 1,00 & 0,99 & 0,99 & 0,99 & 0,99 & 1,00 & $\overline{0}, 99$ & $-0,99$ \\
\hline $\begin{array}{l}\text { Other made-up textile } \\
\text { articles; sets; worn clothing } \\
\text { and worn textile articles; } \\
\text { rags }\end{array}$ & 0,94 & 1,00 & $\overline{1,00}$ & $\overline{0}, 99$ & 0,97 & 0,99 & 0,99 & 1,00 & 1,00 & - & $-0,99$ \\
\hline $\begin{array}{l}\text { rinted books, newspapers, } \\
\text { ictures and other products } \\
\text { f the printing industry; } \\
\text { hanuscripts }\end{array}$ & 0,96 & 0,98 & 0,97 & 0,97 & 0,98 & 0,99 & 0,99 & 0,99 & 0,99 & 0,99 & $-0,98$ \\
\hline $\begin{array}{l}\text { anning or dyeing extracts; } \\
\text { annins and their derivatives; } \\
\text { lyes, pigments and other } \\
\text { olouring ... }\end{array}$ & 0,92 & 0,92 & $\overline{0}, 96$ & 0,98 & 0,98 & 0,97 & 0,98 & 0,97 & 0,99 & $-\overline{0}$ & $-0,97$ \\
\hline $\begin{array}{l}\text { Vehicles other than railway } \\
\text { or tramway rolling stock, and } \\
\text { parts and accessories } \\
\text { thereof }\end{array}$ & 0,80 & 0,97 & $\overline{-} \mathbf{0}, 97$ & 0,99 & 1,00 & 0,96 & 0,97 & 0,92 & 0,99 & $\overline{-}, 98$ & $-0,94$ \\
\hline $\begin{array}{l}\text { odities not elsewhere } \\
\text { ed }\end{array}$ & $\begin{array}{l}- \\
1,00\end{array}$ & 1,00 & $\begin{array}{l}- \\
1,00\end{array}$ & $\begin{array}{l}- \\
1,00\end{array}$ & 0,99 & 0,99 & 0,99 & 0,99 & 0,99 & $\overline{-}, 98$ & $-0,98$ \\
\hline Copper and articles thereof & 0,98 & 0,97 & 0,94 & 0,93 & 0,89 & 0,97 & 0,94 & 0,98 & 0,97 & 0,95 & $-0,96$ \\
\hline $\begin{array}{l}\text { Toys, games and sports } \\
\text { requisites; parts and } \\
\text { accessories thereof }\end{array}$ & 0,88 & 0,90 & 1,00 & 0,97 & 0,87 & 0,91 & 0,94 & 0,93 & 0,94 & $-\overline{0}, 92$ & $-0,92$ \\
\hline $\begin{array}{l}\text { Tools, implements, cutlery, } \\
\text { spoons and forks, of base } \\
\text { metal; parts thereof of base } \\
\text { metal }\end{array}$ & 0,94 & 0,94 & $-\overline{0}$ & 0,96 & 0,90 & 0,89 & 0,93 & 0,91 & 0,94 & $\overline{-}$ & $-0,93$ \\
\hline Live animals & 0,99 & 0,98 & 0,99 & 0,99 & 0,99 & 0,99 & 0,99 & 0,99 & 0,99 & 0,99 & $-0,97$ \\
\hline $\begin{array}{l}\text { Sugars and sugar } \\
\text { confectionery }\end{array}$ & 0,64 & 0,61 & 0,64 & 0,77 & 0,70 & 0,67 & 0,74 & 0,82 & 0,99 & 0,93 & $-0,81$ \\
\hline $\begin{array}{l}\text { Articles of stone, plaster, } \\
\text { cement, asbestos, mica or } \\
\text { similar materials }\end{array}$ & $\overline{0}, 97$ & - & - & 0,99 & 0,99 & - & 0,99 & 1,00 & - & $-\overline{0}, 98$ & $-0,97$ \\
\hline $\begin{array}{l}\text { Miscellaneous articles of } \\
\text { base metal }\end{array}$ & $\begin{array}{l}- \\
0,93\end{array}$ & 0,95 & $\begin{array}{l}- \\
0,94\end{array}$ & $\overline{0}, 95$ & $\overline{0}, 92$ & $\overline{0}, 94$ & $\begin{array}{l}- \\
0,96\end{array}$ & & $\overline{0} \overline{0,97}$ & $\overline{-}$ & $-0,96$ \\
\hline
\end{tabular}




\begin{tabular}{|c|c|c|c|c|c|c|c|c|c|c|c|}
\hline $\begin{array}{l}\text { Oil seeds and oleaginous } \\
\text { fruits; miscellaneous grains, } \\
\text { seeds and fruit; industrial or } \\
\text { medicinal }\end{array}$ & 0,97 & 0,97 & 0,97 & $\overline{0}, 99$ & 0,98 & 0,97 & 0,97 & 0,95 & 0,92 & 0,93 & $-0,93$ \\
\hline ticles of iron or steel & $\overline{-}, 81$ & $\overline{0}, 91$ & $\overline{-}, 93$ & $\overline{0}, 88$ & 0,85 & 0,98 & 0,98 & 0,96 & $\overline{0}, 98$ & 0,98 & $-0,93$ \\
\hline $\begin{array}{l}\text { Paper and paperboard; } \\
\text { articles of paper pulp, of } \\
\text { paper or of paperboard }\end{array}$ & $\overline{-}-9$ & $\overline{-}, 95$ & $\overline{-}, 99$ & 1,00 & 1,00 & $\overline{1}-$ & - & - & - & 1,00 & $-1,00$ \\
\hline $\begin{array}{l}\text { Beverages, spirits and } \\
\text { vinegar }\end{array}$ & $\overline{-}, 92$ & $\overline{0}, 93$ & $\overline{-}, 94$ & 0,97 & 0,96 & 0,96 & 0,98 & 0,98 & $\overline{-}-\overline{0} 98$ & 0,98 & $-0,96$ \\
\hline $\begin{array}{l}\text { Miscellaneous } \\
\text { manufactured articles }\end{array}$ & 0,95 & 0,99 & - & 1,00 & 1,00 & 1,00 & 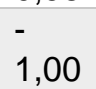 & 0,99 & - & 0,98 & $-0,97$ \\
\hline Cereals & 0,98 & 0,99 & - & 0,99 & 0,99 & - & - & 0,96 & $\overline{-}$ & $\overline{0}, 96$ & $-0,94$ \\
\hline $\begin{array}{l}\text { Articles of apparel and } \\
\text { clothing accessories, not } \\
\text { knitted or crocheted }\end{array}$ & $\overline{-}-9$ & 0,92 & 0,93 & $\overline{-}-$ & 0,94 & 0,97 & 0,98 & 0,97 & 0,98 & 0,97 & $-0,96$ \\
\hline $\begin{array}{l}\text { Products of animal origin, } \\
\text { not elsewhere specified or } \\
\text { included }\end{array}$ & $\overline{-}, 99$ & 0,99 & $\overline{0}, 98$ & 0,99 & 0,98 & 1,00 & 0,98 & 0,99 & $\overline{0}, 98$ & 0,97 & $-0,96$ \\
\hline Glass and glassware & $\overline{-}-82$ & $\overline{0}, 97$ & $\overline{-}, 98$ & $\overline{0}, 99$ & 0,98 & 0,99 & $\overline{0}, 99$ & $\overline{0}, 98$ & $\overline{0}-99$ & $\overline{-}, 99$ & $-0,98$ \\
\hline $\begin{array}{ll}\text { Miscellaneous } & \text { edible } \\
\text { preparations } & \end{array}$ & $\overline{-}-8$ & - & $\overline{-}-9$ & $\overline{0}-96$ & $-\overline{0}$ & $\overline{-}$ & $\overline{-}-96$ & $\overline{-}-9$ & $\overline{-}$ & $\overline{0}-85$ & $-0,81$ \\
\hline Headgear and parts thereof & $\overline{0}-93$ & 0,95 & 0,96 & 0,97 & 0,95 & 0,96 & 0,95 & 0,96 & 0,96 & 0,94 & $-0,86$ \\
\hline $\begin{array}{l}\text { Preparations of cereals, } \\
\text { flour, starch or milk; } \\
\text { pastrycooks' products }\end{array}$ & - & - & $\overline{0}-97$ & 0,97 & - & $\overline{0}, 97$ & $\overline{0}-97$ & - & $\overline{0}-97$ & $-\overline{0,96}$ & $-0,93$ \\
\hline $\begin{array}{l}\text { Optical, photographic, } \\
\text { cinematographic, } \\
\text { measuring, checking, } \\
\text { precision, medical or } \\
\text { surgical }\end{array}$ & $\overline{-}, 94$ & 0,96 & $\overline{-}, 94$ & 0,98 & 0,93 & 0,93 & 0,97 & 0,95 & 0,93 & $\overline{0}, 89$ & $-0,76$ \\
\hline $\begin{array}{lr}\text { Furniture; } & \text { bedding, } \\
\text { mattresses, } & \text { mattress } \\
\text { supports, cushions and } \\
\text { similar stuffed furnishings; ... }\end{array}$ & $\begin{array}{l}- \\
0,88\end{array}$ & 0,89 & $\begin{array}{l}- \\
0,90\end{array}$ & 0,94 & 0,93 & 0,95 & 0,97 & 0,96 & 0,97 & 0,97 & $-0,92$ \\
\hline $\begin{array}{l}\text { Products of the milling } \\
\text { industry; malt; starches; } \\
\text { inulin; wheat gluten }\end{array}$ & $\overline{0}-99$ & 0,99 & $\overline{-}, 99$ & 0,99 & 0,98 & 0,99 & 0,99 & 0,99 & 0,99 & $\overline{0}, 95$ & $-0,87$ \\
\hline $\begin{array}{l}\text { Essential oils and resinoids; } \\
\text { perfumery, cosmetic or toilet } \\
\text { preparations }\end{array}$ & $\overline{0}, 99$ & 0,99 & 0,99 & 1,00 & 1,00 & 1,00 & 1,00 & 1,00 & 1,00 & 0,97 & $-0,80$ \\
\hline Ceramic products & $\begin{array}{l}- \\
0,36\end{array}$ & $\begin{array}{l}- \\
0,54\end{array}$ & $\begin{array}{l}- \\
0,55\end{array}$ & $\overline{-}, 78$ & $\overline{0}, 69$ & $\overline{-}-80$ & $\begin{array}{l}- \\
0,87\end{array}$ & 90 & $\begin{array}{l}- \\
0,94\end{array}$ & $\overline{0}, 87$ & $-0,89$ \\
\hline $\begin{array}{l}\text { Articles of apparel and } \\
\text { clothing accessories, knitted } \\
\text { or crocheted }\end{array}$ & $-\overline{0,55}$ & 0,82 & 0,85 & $\overline{-}, 80$ & 0,77 & 0,84 & 0,88 & 0,91 & 0,93 & 0,93 & $-0,88$ \\
\hline $\begin{array}{l}\text { Residues and waste from } \\
\text { the food industries; prepared } \\
\text { animal fodder }\end{array}$ & $\overline{-}-98$ & 0,98 & $\begin{array}{l}- \\
1,00\end{array}$ & 0,99 & $\overline{0}, 99$ & 0,94 & 0,99 & 0,99 & 0,99 & $\overline{0}, 98$ & $-0,89$ \\
\hline $\begin{array}{l}\text { Animal or vegetable fats and } \\
\text { oils and their cleavage } \\
\text { products; prepared edible } \\
\text { fats; animal ... }\end{array}$ & $\overline{0}, 85$ & 0,96 & $\overline{0}, 87$ & 0,90 & 0,98 & 0,99 & 0,97 & 0,92 & $\overline{0}, 96$ & $\overline{0}, 93$ & $-0,88$ \\
\hline Coffee, tea, maté and spices & $\overline{-}, 57$ & $\overline{-}, 46$ & $\overline{-}, 58$ & $\overline{-}, 84$ & $\overline{-}, 65$ & $\overline{-}, 64$ & $\overline{-}, 61$ & $\overline{0}, 82$ & $\overline{0}, 85$ & $\overline{0}-76$ & $-0,58$ \\
\hline
\end{tabular}




\begin{tabular}{|c|c|c|c|c|c|c|c|c|c|c|c|}
\hline Rubber and articles thereof & $\overline{-}, 97$ & $\overline{-}, 99$ & $\overline{0}, 99$ & $\overline{-}, 99$ & $\overline{-}$ & $\overline{-}, 99$ & $\overline{-}$ & $\overline{-}, 99$ & $\overline{0}, 99$ & $\begin{array}{l}- \\
1,00\end{array}$ & $-0,99$ \\
\hline Iron and steel & - & 0,96 & - & - & 0,99 & - & - & 0,98 & 1,00 & 0,98 & $-0,99$ \\
\hline $\begin{array}{l}\text { Aircraft, spacecraft, and } \\
\text { parts thereof }\end{array}$ & $\overline{-}$ & $-\overline{0}$ & $-\overline{0}$ & $\overline{-}-9$ & 0,94 & $-\overline{0}, 56$ & $\overline{-}-9$ & 0,99 & $\overline{0}, 80$ & $-\overline{0}, 73$ & $-0,15$ \\
\hline Plastics and articles thereof & $\overline{-}, 90$ & $-\overline{0}$ & - & - & $\overline{-}$ & $-\bar{c}$ & $\overline{-}-84$ & $\overline{-}, 79$ & $\overline{0}-83$ & $\overline{-}, 73$ & $-0,63$ \\
\hline Lead and articles thereof & $\overline{1}-$ & $\overline{1}-$ & 1,00 & - & 1,00 & - & $-\overline{0}, 99$ & - & 0,86 & - & $-0,48$ \\
\hline $\begin{array}{l}\text { Aluminium and articles } \\
\text { thereof }\end{array}$ & - & 0,33 & - & - & 0,96 & 0,98 & - & - & 0,86 & 0,90 & $-0,82$ \\
\hline $\begin{array}{l}\text { Electrical machinery, } \\
\text { equipment and parts thereof; } \\
\text { sound recorders and } \\
\text { reproducers, television }\end{array}$ & $\overline{-}, 41$ & 0,52 & $\overline{-}, 72$ & $\overline{0}-$ & 0,76 & - & $-\overline{0}$ & 0,79 & $\overline{-}, 78$ & $\overline{-}, 75$ & $-0,64$ \\
\hline $\begin{array}{l}\text { Machinery, mechanical } \\
\text { appliances, } \\
\text { reactors, boilers; } \begin{array}{r}\text { nuclear } \\
\text { thereof }\end{array}\end{array}$ & $\overline{-}-37$ & $\overline{-}-45$ & $\overline{-}, 70$ & $\overline{-}-\overline{0}$ & $\overline{-}-$ & $\overline{-}, 72$ & $\overline{-}, 79$ & $\overline{-}$, & $\overline{-}, 76$ & $\overline{-}, 72$ & $-0,40$ \\
\hline $\begin{array}{l}\text { Edible vegetables and } \\
\text { certain roots and tubers }\end{array}$ & $\overline{-}, 29$ & $\overline{-}, 37$ & $\overline{0}, 18$ & $\overline{-}, 35$ & $-\overline{0}$ & $\overline{0}, 33$ & $\overline{-}, 46$ & $\overline{-}, 42$ & $\overline{0}, 45$ & $\overline{-}-4$ & $-0,06$ \\
\hline
\end{tabular}




\section{REFERENCIAS}

- Abernethy, David B. (1986). Dominant-subordinate relationships: How shall we define them? How do we compare them? En Dominant powers and subordinate states, ed. Jan F. Triska, 103-123. Durham: Duke University Press

- Acosta, A. (2012). Extractivismo y neoextractivismo: dos caras de la misma maldición. Polo Democrático.

- ADB. (2010). The rise of Asia's Middle class. Key indicators for Asia and the Pacific. Disponible en: http://www.adb.org/sites/default/files/publication/27726/ki2010special-chapter.pdf.

- Agüero J. (2016). América latina durante la Guerra Fría (1947-1989): una introducción. InterSedes. 17(35), 151-195. https://doi.org/10.15517/isucr.v17i35.25566

- ALBA-TCP. (2009). Tratado Constitutivo del Sistema Unitario de Compensación Regional de Pagos (SUCRE). Disponible en: https://www.bce.fin.ec/documents/pdf/sistema_u_compensacion/sucDoc01.pdf

- Alvarado, C. (2019). La inversión exterior de China se refugia en América Latina. Expansión. Disponible en: https://www.expansion.com/latinoamerica/2019/07/29/5d3d99c5e5fdea22398b465 d.html . 29 JUL. 2019.

- Álvarez, M., y Durán Lima, J. E. (2008). Indicadores de comercio exterior y política comercial: mediciones de posición y dinamismo comercial. Comisión Económica para América Latina y el Caribe (CEPAL). P 1-45.

- Amorim, O. (2011). De Dutra a Lula: A condução e os determinantes da política externa brasileira.

- Aponte García, M. (2014). El nuevo regionalismo estratégico. Los primeros diez años del ALBA-TCP. Buenos Aires: Consejo Latinoamericano de Ciencias Sociales (CLACSO)

- Aponte-García, M. y Amezquita P. (2015). El ALBA-TCP origen y fruto del nuevo regionalismo latinoamericano y caribeño. Buenos Aires: CLACSO

- Arne, B. (2004). Globalisation and the Asia-Pacific Revival. World Economics. Vol. 5, No. 2.

- Arreola, J. (2017). ¿Qué plan tiene China para Latinoamérica? Forbes, 7. Disponible en : https://www.forbes.com.mx/que-plan-tiene-china-paralatinoamerica/.

- Ash, T. (2017). Under President Trump, We'll Enter an Age of Global Confrontation. The Guardian. Recuperado el 21/1/2017

- Baldwin, D. A. (1985). Economic Statecraft. In Princeton University Press. https://books.google.de/books?hl=en\&lr=\&id=1tgP1Zi7kwwC\&oi=fnd\&pg=PR11\&d $\mathrm{q}=$ Baldwin,+D.+A.+(1985).+Economic+statecraft.+New+Jersey:+Princeton+Univer sity+Press.\&ots=orFdd0BMLs\&sig=8RKeAnbFWNfJ6gNd6Ncz8mTO6x8\#v=onepa ge\&q\&f=false

- Banco Mundial (2016). El ciclo de commodities en Latinoamérica: Espejismos y dilemas.

En https://openknowledge.worldbank.org/bitstream/handle/10986/24014/210914SpSu $\mathrm{m}$.pdf? sequence $=6$ \&isAllowed $=\mathrm{y}$ 
- Becerra, L. (2013). Hacia un marco constructivista realista para el análisis de las relaciones internacionales desde las periferias. Colombia Internacional78, 78, 79126. https://doi.org/10.7440/colombiaint78.2013.04

- Benzi, D. (2016). El exitoso ocaso del ALBA Réquiem para el último vals tercermundista. Nueva Sociedad. https://nuso.org/articulo/el-exitoso-ocaso-delalba/. Recuperado en enero 2020.

- Benzi, D. (2017). ALBA-TCP. Anatomía de una integración que no fue. Quito: Ediciones Imago Mundi.

- Bergamaschi, I. y Tickner, A.B. (2017). Introduction: South-South Cooperation Beyond the Myths. A Critical Analysis. En Bergamaschi et al. (eds.), South-South Cooperation Beyond the Myths. Rising Donors, New Aid Practices? Nueva York: Palgrave McMillan, 1-27.

- Bergamaschi, I., Tickner, A. B., y Durán, J. (2017). Going South to Reach the North? The Case of Colombia. In South-South Cooperation Beyond the Myths (pp. 245269). Palgrave Macmillan, London.

- Bernal, A. 2014. The Meaning and Perils of Presidential Refounding in Latin America. Constellations, 21(4), 440-457.

- Bernal-Meza, R. (2004). Política Exterior de Argentina, Brasil y Chile: Perspectiva Comparada. Political Regime and Foreign Relations. A Historical perspective, Paris, L'Harmattan, 183-212.

- Bernal-Meza, R. (2008). Argentina and Brazil in the Internacional Politics: regionalism and Mercosur (strategy, cooperation and factors of tension). Revista Brasileira de Política Internacional, 51(2), 154-178.

- Bernal-Meza, R. (2016). China Y América Latina: de la oportunidad al desafío.

- Bernal-Meza, R. y Masera, G. A. (2008). El retorno del regionalismo. Aspectos políticos y económicos en los procesos de integración internacional. Revista Aportes para la Integración Latinoamericana, (18), 1-18.

- Bernal-Meza, R., \& Lavagna, R. (2000). Sistema mundial y Mercosur: globalización, regionalismo y políticas exteriores comparadas (No. 339.923). Universidad Nacional del Centro de la Provincia de Buenos Aires

- Besharati An et al. (2015). Developing a conceptual framework for South-South Cooperation. Network of Southern Think-Tanks, Africa Chapter Working Document, septiembre.

- Bigsten, A (2004). Globalisation and the Asia-Pacific Revival, World Economics, Vol. 5, No. 2.

- Bøås, M. y McNeill, D. (2004). Global Institutions and Development: Framing the World. New York: Routledge.

- Bolinaga, L. (s.f.). Estados Unidos y China en la era del Pacífico Norte: notas para la política exterior argentina. Ediciones Conicet-Uai-Untref. 1-26.

- Bonilla, A. (2006). Política Exterior del Ecuador: 25 años de vulnerabilidad. Revista Afese, 44.

- Bonilla, A. (2008). Ecuador en la era Correa: crisis política y emergencia de liderazgo personalizado. Conferencia en el ciclo: Understanding Populism and Popular Participation: a New Look at the New Left in Latin America, Wilson Center, Marzo.

- Bonilla, A., y Álvarez, I. (2013). La Diplomacia de Cumbres frente al contexto internacional del nuevo multilateralismo político latinoamericano y del Caribe. Desafíos estratégicos del regionalismo contemporáneo: CELAC e lberoamérica, 710. 
- Borja, J. (2015). 35 años de las relaciones Ecuador-China. Discurso Inauguración del Centro Latinoamericano. Universidad de Lengua y Cultura de Beijing. China, 22 abril 2015. Recuperado el 02/05/2017 de http://china.embajada.gob.ec/wpcontent/uploads/2015/04/discurso-embajador-

- Borón, A. (2014). Atilio Borón: América Latina en la geopolítica imperial. Cubadebate. Disponible en: http://www.cubadebate.cu/opinion/2014/09/16/atilioboron-america-latina-en-la-geopolitica-imperial/

- Boutros-Ghali, B. (2006). Reinventing UNCTAD. Submitted to the Panel of Eminent.

- Bracho, G. (2018). Towards a common definition of south-south cooperation: Bringing together the spirit of bandung and the spirit of Buenos Aires. Development Cooperation Review, 1(6), 9-13

- Bräutigam, D., \& Tang, X. (2014). Going global in groups: Structural transformation and China's special economic zones overseas. World Development, 63, 78-91.

- Briceño Ruiz, J. (2014). Autonomía: genealogía y desarrollo de un concepto. Su relación con el regionalismo en América Latina. Cuadernos Sobre Relaciones Internacionales, Regionalismo y Desarrollo, 9 (18).

- Briceño, J. (2011). Los cambios en la Política Exterior de Venezuela y el giro hacia el sur de Chávez". In La Política Internacional en un mundo en mutación. Banda Oriental.

http://www.scielo.org.co/scielo.php?script=sci_nlinks\&ref=000143\&pid=S01224409201300020001300016\&lng=pt

- Briceño, J., y Simonoff, A. (2015). Integración y cooperación regional en América Latina: Una relectura a partir de la teoría de la autonomía. Estudios Internacionales (Santiago), 47(181), 135-140. Disponible en: https://doi.org/10.5354/07193769.2015.36842

- Briceño-Ruiz, J. (2013). The Andes: A Long Tradition of Thought and Practice about Regional Integration. In Resilience of Regionalism in Latin America and the Caribbean (pp. 146-179). Palgrave Macmillan UK.

- Briceño-Ruiz, J., y Simonoff, A. (2017). La Escuela de la Autonomía, América Latina y la teoría de las relaciones internacionales. Estudios Internacionales, 49(186), 3989.

- Bruckmann, M. (2012). Recursos Naturales y la Geopolítica de la Integración Sudamericana. Instituto de investigaciones sociales Perumundo. www.impsanremo.net. Buenos Aires, GEL, p. 9.

- Burbano de Lara, F. (1998). Cultura política y democracia en Ecuador: Una aproximación a nuestros vacíos. CORDES. Quito.

- Burbano de Lara, F. (2015). Todo por la patria. Refundación y retorno del estado en las revoluciones bolivarianas. Iconos. № 52. Vol. 19. Núm. 2. Mayo 19-41.

- Burges, S., y Chagas, F. (2016). Latin American Diplomacy. The SAGE Handbook of Diplomacy, Londres: Sage Publishers, 372-385.

- Bustamante, F. (2000). Los partidos como orientaciones culturales. Iconos. № 9, $88-97$.

- Cabana, S.L. (2014). Chronology and history of South-South cooperation. Working Paper

- Cabral, L. y Weinstock, J. (2010). Brazil: an emerging aid player. Disponible en : https://www.odi.org/sites/odi.org.uk/files/odi-assets/publications-opinionfiles/6295.pdf

- Camacho, C. (2010). Acuerdo Especial de Servicios número: 6778 Cooperación Sur-Sur en el Contexto de la Eficacia de la Ayuda Informe Final. Cambridge 
University Press, 2, núm. 1, marzo. Disponible en: https://repository.fedesarrollo.org.co/handle/11445/227

- Cardoso, F. (1967). Dependencia y desarrollo en América Latina. Ensayo de interpretación sociológica. No. 1; Documentos Teóricos.

- Carmody, P. (2013). The Rise of the BRICS in Africa: The Geopolitics of SouthSouth Relations, London: Zed Books

- CEPAL (1977). Cooperación entre países y regiones en desarrollo de diferentes áreas geográficas. Integración Latinoamericana, 2(16), 67-73.

- CEPAL (2012). Panorama de Inserción Internacional de América Latina y el Caribe. Santiago de Chile. Naciones Unidas.

- CEPAL (2018). Perspectivas económicas de América Latina 2018. Repensando las instituciones para el desarrollo. CEPAL-Chile. Disponible en : https://repositorio.cepal.org/bitstream/handle/11362/43513/1/LEO2018_es.pdf

- CEPAL. (2010). La República Popular China y América Latina y el Caribe: hacia una relación estratégica. Publicación de la Comisión Económica para América Latina y el Caribe. Disponible en: https://www.cepal.org/es/publicaciones/2956-larepublica-popular-china-america-latina-caribe-relacion-estrategica

- CEPAL. (2015). Latin American Economic Outlook 2016: Towards a New Partnership with China. ECLAC. Disponible en https://repositorio.cepal.org/bitstream/handle/11362/39663/S1501060_en.pdf?seq uence $=1$ \&isAllowed $=\mathrm{y}$

- Chakrabarti, M. (2018). Lexicon and Sytax of Development Cooperation. Heterogeneity Among South Does It Affect SSC? Development Cooperation Policy, 1(1), 23-24.

- Chan, G. (1998). Toward an international relations theory with Chinese characteristics? Issues \& Studies, 34(6), 1-28.

- Chaturvedi, S. (2016). The development compact: a theoretical construct for SouthSouth cooperation. International Studies, 53(1), 15-43.

- Chin, H. y He, W. (2016). The Belt and Road Initiative: 65 Countries and Beyond. Fung Business Intelligence Centre.

- Cienfuegos, M., \& Perales, Sanahuja, J. A (Eds.). (2010). Una región en construcción: UNASUR y la integración en América del Sur. Barcelona: CIDOB.

- Colacrai, M. (1992). Perspectivas teóricas en la Bibliografía de la Política Exterior Argentina en Russell, Roberto (Editor) Enfoques teóricos para el estudio de la Política Exterior. Buenos Aires: GEL.

- Colacrai, M. (2009). Los aportes de la Teoría de la Autonomía, genuina contribución sudamericana. ¿La autonomía es hoy una categoría en desuso o se enfrenta al desafío de una renovación en un contexto interdependiente y más complejo? Argentina e Brasil. Vencendo os preconceitos. As varias arestas de uma concepcao estratégica, REVAN, Rio de, 33-50.

- Comaroff, J. y Comaroff, J. (2013). Teoría desde el sur. O cómo los países centrales evolucionan hacia África, Siglo XXI Eds., Buenos Aires.

- Corrales, J., \& Feinberg, R. E. (1999). Regimes of Cooperation in the Western Hemisphere: Power, Interests, and Intellectual Traditions. International Studies Quarterly, 4(1), 1-36.

- Cox, R (1981). Social forces, states and world orders: beyond international relations theory. Millennium, 10(2), 126-155.

- Cox, R. \& Keohane, R. (1986). Neorealism and its Critics. Columbia University Press. 
- Cox, R. \& Sinclair, T. (1996). Approaches to world order (No. 40). Cambridge University Press.

- Cox, R. (1979). Ideologies and the New International Economic Order: Reflections on some Recent Literature. International Organization. No 33, p 257-302.

- Cox, R. (1981), "Social Forces, States and World Orders: Beyond International Relations Theory". Millennium: Journal of International Studies 10:2, pp. 126-155.

- Cox, R. (1983). Gramsci, hegemony and international relations: an essay in method. Millennium, 12(2), 162-175.

- Cox, R. and Sinclair. T. (eds.) (2001) Approaches to World Order. New York: Cambridge University Press

- Cox, R. W. (2013). Fuerzas sociales, estados y órdenes mundiales: Más allá de la Teoría de Relaciones Internacionales/Social Forces, States and World Orders: Beyond International Relations Theory. Relaciones Internacionales, (24), 129.

- Cox, R. W., y Schechter, M. G. (2002). The political economy of a plural world: Critical reflections on power, morals and civilization. New York: Routledge. Perspectives on Politics, 2(1), 197-198.

- Cuéllar, A., \& Bauer, S. (2019). Se desacelera la inversión extranjera directa china hacia América Latina. Diálogo Chino. Disponible en: https://dialogochino.net/es/comercio-y-inversiones-es/25775-se-desacelera-lainversion-extranjera-directa-china-hacia-america-latina/

- Dabène (O.) (2012). Explaining Latin America's Fourth Wave of Regionalism: Regional Integration of a Third Kind. Paper presented at LASA Congress. San Francisco, p 1-32.

- Dale, G. (2016). In search of Karl Polanyi's International Relations theory. Review of International Studies, 42(3), 401-424. Disponible en: https://doi.org/10.1017/S0260210515000273

- Dallanegra, L. (2008). Realismo Sistémico Estructural: Hacia una Teoría Totalizadora de las Relaciones Internacionales. Revista Reflexión Política, Instituto de Estudios Políticos, Universidad Nacional Autónoma de Bucaramanga, X (19). http://luisdallanegra.bravehost.com/reasises.htm

- De Lombaerde, P. (2016). Theorizing Latin American Regionalism in the 21st Century. Fédéralisme Régionalisme, 16, 21st.

- de Oliveira, A. (2006). China-Brasil: perspectivas de cooperación sur-sur. Nueva Sociedad, 203, 138-146.

- de Seixas Corrêa, L. F. (2013). Brazil in the United Nations, 1946-2011. Brasília: Fundação Alexandre de Gusmão.

- DeHart, M. (2012). Remodelling the global development landscape: The China model and South-South cooperation in Latin America'. Third World Quarterly 33(7): 1359-75

- Denzin, N., y Lincoln, Y. (2000). Methods of collecting and analyzing empirical materials. Handbook of Qualitative Research, 2, 632-643.

- Desai, R. (2016). South-South Co-operation. In The Palgrave encyclopedia of imperialism and anti-imperialism: Vol. II. Palgrave McMillan.

- Diálogo Chino (2019). La Franja y la ruta, la nueva cara de China en América Latina. Disponible en: https://dialogochino.net/es/infraestructura-es/26121-la-franja-y-laruta-la-nueva-cara-de-china-en-america-latina/

- Díaz Segovia, A. S. (2014). Análisis de la evolución de la Política Exterior Ecuatoriana en el marco de la Revolución Ciudadana (2007-2012) frente a Estados Unidos. Pontificia Universidad Católica del Ecuador. 
- Dicken, P. (2003). Global shift: Reshaping the global economic map in the 21st century. Sage.

- Dixon, W. (1981). The Emerging Image of U.N. Politics. World Politics, 34(1), 4761.

- Dollar, D. (2018). La inversión china en América Latina continúa creciendo. Brooklings.Edu. https://www.brookings.edu/es/research/la-inversion-china-enamerica-latina-continua-creciendo/

- Domínguez, J. (2006). China's Relations with Latin America: Shared Gains, Asymmetric Hopes. Weatherhead Center for International Affairs. Disponible en: https://wcfia.harvard.edu/publications/chinas-relations-latin-america-shared-gainsasymmetric-hopes

- Domínguez, R. (2015). El tamaño importa: la financiación reembolsable en la Cooperación Sur-Sur de China, India, Venezuela y Brasil. Documentos de trabajo sobre cooperación y desarrollo, 1.

- Domínguez, R. (2016). Cooperación financiera para el desarrollo, ADN de la Cooperación Sur-Sur. Revista iberoamericana de estudios de desarrollo= Iberoamerican journal of development studies, 5(1), 62-86.

- Domínguez, R. (2017). La Princesa y el Dragón: Cooperación China en América Latina y más allá.

- Domínguez, R. (2018). China y la construcción de un régimen internacional de Cooperación Sur-Sur. 38-72. Disponible en: https://doi.org/10.21530/ci.v13n1.2018.737

- Domínguez, R. (2019). La constelación del Sur: la Cooperación Sur-Sur en el cuarenta aniversario del Plan de Acción de Buenos Aires. En R. Domínguez, G. Lo Najam, \& J. Surasky, La constelación del sur: lecturas histórico críticas de la Cooperación Sur-Sur (págs. 13-134). Cantabria: UC Universidad de Cantabria.

- Domínguez, R. (2020). Cooperación internacional y países de renta media. Perspectiva histórica para una cooperación Sur-Sur genuina en América Latina. En Grandas Estepa, D. A. y Moreno Ojeda, C.M. (Coords.). Cooperación internacional en América Latina en clave de paz y desarrollo. Bogotá: Editorial Neogranadina.

- Domínguez, R., y Caria, S. (2016). Extractivismos andinos y limitantes del cambio estructural. In Nada dura para siempre. Neo-extractivismo tras el boom de las materias primas. http://www.burchardt.uni-kassel.de/wpcontent/uploads/2016/09/Nada-dura-para-siempre-15_septiembre_2016.pdf

- Domínguez, R., y Tezanos, S. (2012). Revista Española de Desarrollo y Cooperación no 29. 29, 119-153.

- Domínguez, R., y Caria, S. (2016). Ecuador en la trampa de la renta media. Problemas del desarrollo. 47(187), 89-112.

- Drezner, D. W. (1999). The Sanctions Paradox: Economic Statecraft and International Relations. Cambridge Studies in International Relations 65, 372. http://www.amazon.com/dp/0521644151

- Duffield, M. (2005) Global governance and the new wars: The Merging of Development and Security, London: Zed Books

- Durán, E. y Álvarez, M. 2008. Indicadores de comercio exterior y política comercial: mediciones de posición y dinamismo comercial. Documento de Proyecto. División de Comercio Internacional e Integración. Santiago de Chile: Naciones Unidas.

- Dussel, E. (2000). Europa, modernidad y eurocentrismo, en Edgardo Lander (comp.) La colonialidad del saber: eurocentrismo y ciencias sociales. Perspectivas Latinoamericanas, CLACSO: Buenos Aires 
- DW. (2019). China en América Latina: economía sí, política no. 31 de julio. Disponible en: https://www.dw.com/es/china-en-am\%C3\%A9rica-latinaeconom\%C3\%ADa-s\%C3\%AD-pol\%C3\%ADtica-no/a-49833642

- Eclac y OECD (2018). Challenges and shifting paradigms: New perspectives on international cooperation for development. Santiago de Chile: Cepal

- Embajada China (2016). Xi Jinping celebra conversaciones con presidente Rafael Correa de Ecuador. Recuperado el 15/12/2016 de http://cl.chinambassy.org/esp/zldt/t1416843.htm.

- Ernst, D. (1979). La cooperación técnica entre los países en desarrollo. Un instrumento viable para la autodeterminación colectiva. Comercio Exterior, 29(12), 1396-1403

- Erten, B., y Ocampo, J. (2012). Super-cycles of commodity prices since the midnineteenth century. Visita 13 de Marzo 2013. Disponible en: www.un.org/esa/desa/papers/2012/wp110_2012.pdf

- Escobar, A. (2012). El desarrollo y la antropología de la modernidad. En Pérez Galán, Beatriz [Ed.] (2012) Antropología y desarrollo. Discurso, prácticas y actores, IUDC-La Catarata, Madrid: 72-9

- Escudé, C. (1983). La Argentina vs las grandes potencias: el precio del desafío. Buenos Aires: Editorial de Belgrano.

- Escudé, C. (1988). Argentine territorial nationalism. Journal of Latin American Studies, 20 (01), 139-165.

- Escudé, C. (1991). La política exterior de Menem y su sustento teórico implícito. América Latina Internacional, 8(27), 349-406.

- Escudé, C. (1992). Realismo periférico: fundamentos para la nueva política exterior argentina. Planeta.

- Escudé, C. (1999). Estado del mundo: las nuevas reglas de la política internacional vistas desde el Cono Sur, Buenos Aires, Ariel.

- Escudé, C. (2009). Realismo Periférico: Una Filosofía De Política Exterior Para Estados Débiles, $s / n$

- Escudé, C. (2012). Principios del realismo periférico. Una teoría argentina y su vigencia ante el ascenso de China. Buenos Aires: Lumiere.

- Estay, J. (2018). Past and Present of Latin American Regionalisms, in the Face of Economic Reprimarization. In Regionalism, Development and the PostCommodities Boom in South America (pp. 47-76). Springer International Publishing. https://doi.org/10.1007/978-3-319-62551-5_3

- Ferguson, N. (2009). The Ascent of Money: A Financial History of the World. New York: Penguin Press.

- Ferrer, A. (1978). La crisis del sistema trilateral y América Latina. Comercio Exterior, 28(7), 787-797.

- Ferrer, A. (2006). A economia argentina: de suas origens ao início do século XXI. Rio de Janeiro.

- Ferrer, Aldo (2010). El futuro de nuestro pasado. La economía argentina en su segundo centenario. Fondo de Cultura Económica. Buenos Aires, Argentina.

- FMI (2019). Perspectivas de la economía mundial fondo monetario internacional. Desaceleración del crecimiento, precaria recuperación. Disponible en: file://C:/Users/Sandra\%20E.\%20Zapata/Downloads/texts.pdf

- Foro China-CELAC (2015). Plan de Cooperación (2015-2019). Primera Reunión Ministerial del Foro CELAC, Beijing, 23 de enero. 
http://www.chinacelacforum.org/esp/zywj_4/t1230945.htm, consultado el 26 de febrero de 2016.

- Foro China-CELAC (2015). Plan de Cooperación (2015-2019). Primera Reunión Ministerial del Foro CELAC, Beijing, 23 de enero. http://www.chinacelacforum.org/esp/zywj_4/t1230945.htm.

- Freidenberg, F. (2000). Las posiciones ideológicas programáticas en los partidos ecuatorianos. Paper presented at the seminar "Political Parties in Latin America," Institute of Latin American Studies (ILAS), London.

- Freidenberg, F. y Alcántara, M. (2001). Los dueños del poder: Partidos políticos en Ecuador, 1978 -2000. Quito: FLACSO.

- Gallagher, K. P. (2016). The China triangle: Latin America's China boom and the fate of the Washington consensus. Oxford University Press.

- Gallagher, K., Irwin, A., y Koleski, K. (2012). The New Banks in Town: Chinese Finance in Latin America. The Dialogue. February 15. Disponible en: https://www.thedialogue.org/analysis/the-new-banks-in-town-chinese-finance-inlatin-america/

- Gallagher, K.P. y Margaret, M. (2020). China-Latin America Finance Database. Washington: Inter-American Dialogue. Disponible en: https://www.thedialogue.org/map_list/

- García, A. (2006). La estructura del atraso en América Latina: hacia una teoría latinoamericana del desarrollo. Convenio Andrés Bello.

- Gardini, G. L. (2010). Proyectos de integración regional sudamericana: hacia una teoría de convergencia regional. Relaciones Internacionales, 15. https://revistas.uam.es/index.php/relacionesinternacionales/article/view/5047

- Gardini, G. L., \& Lambert, P. (2011). Latin American Foreign Policies: Between Ideology and Pragmatism. New York: Palgrave Macmillan.

- Gill, S. (1995). "Globalisation, Market Civilisation and Disciplinary Neoliberalism", Millennium - Journal of International Studies, vol. 24, n³, pp. 399-423.

- Gilpin, R. (1981) War and Change in World Politics. New York: Cambridge University Press.

- Goffman, E. (1974). Frame analysis: An essay on the organization of experience. Harvard University Press.

- González-Tablas, A. M. (1995). Visión global de la cooperación para el desarrollo: la experiencia internacional y el caso español. Icaria Editorial.

- Gosovic, B. (2016). The resurgence of South-South cooperation. Third World Quarterly, 37(4), 733-743.

- Gramsci, A., \& Hoare, Q. (1971). Selections from the prison notebooks (Vol. 294). London: Lawrence and Wishart.

- Gray, K. \& Gills, B. (2016). South-South cooperation and the rise of the Global South, Third World Quarterly, 37:4, 557-574,

- Greig, M. y Enterline A. (2017). National Material Capabilities (NMC) Data Documentation. Updated version of Correlates of Power Project. Version 5.0. University of North Texas.

- Gudynas, E. (2013). Extractivismo y neoextractivismo: dos caras de la misma maldición. Abya Yala, Fundación Rosa Luxemburgo.

- Guevara, J. (2017, Marzo 9). La quiebra de la banca y congelación de cuentas $\begin{array}{lllll}\text { costaron } \$ 8.600 & \text { millones. }\end{array}$ https://www.eltelegrafo.com.ec/noticias/economia/4/la-quiebra-de-la-banca-ycongelamiento-de-cuentas-costaron-usd-8-600- 
millones?_cf_chl_jschl_tk = $=1 \mathrm{~b} 236 \mathrm{ffe} 39 \mathrm{e} 01 \mathrm{c} 23 \mathrm{ef2f7b} 727 \mathrm{a} 510 \mathrm{f} 1 \mathrm{e} 2327 \mathrm{e} 463$ 1590402845-0-AdbP8pw0WDRFSZKarRKBO89vLSTZ3AI7IPL9vhiQ6-

SiDdG47GpEntLPudCQ_HmgTkX0qqJV63depiLVD505KOmc8jbzUjP59yWnq8OH SP3GC5H6qdxMbzgJpSqBqu5mGrNI8u8oQS-

InEW2Px0ZDDeMIDtZ4C74ueda8UkL54uT_Zz_Nm-

tjV5SPX_50vKjQZvX_Ghb6Kvoq3IEPfl1JwsQamdGua-

PP8QCZBXJ3wH2eEXb1gjZxKRnql6NaqBgkiDAcQmmsRqTYlqOUL5rqPyqxLhH

PY7otHRp1m75U4QymECHcraO9t032GvyUFVY7Yz8DgmBhuS1QaTkoSQ2FyX2 MaGCJ_m2PsUPx0v_V6NGwsoEFOxO5JNSqqGSYbJcSrM8dow4OjLlgcsAygV nEGEEfLgdAhO1CzNMgi99tdlwyZOU4K3hK2uTORTQc9hCdKNIV1RKvYI_IQrYO Gwv5E

- Gustaaf Geeraerts \& Men Jing (2001) International Relations Theory in China, Global Society, 15:3, 251-276. Disponible en: http://dx.doi.org/10.1080/13600820120066258

- Guzzini, S., \& Leander, A. (2005). Constructivism and international relations: Alexander Wendt and his critics. Routledge.

- Haocai, L. (2008). China defiende que su concepción de los "Derechos Humanos" es distinta a la de Occidente. Europa Press. Disponible en: https://www.diarioinformacion.com/sociedad/2008/04/21/china-defiendeconcepcion-derechos-humanos-distinta-occidente/746137.html

- Hardoon, D., Fuentes-Nieve, R. and Ayele, S. (2016). An Economy for the 1\%: How Privilege and Power in the Economy Drive Extreme Inequality and How This Can Be Stopped, Oxford: Oxfam International.

- Harris, R. L., \& Arias, A. A. (2016). China's South-South Cooperation with Latin America and the Caribbean. Journals.Sagepub.Com, 32(4), 508-556. https://doi.org/10.1177/0169796X16674108

- Hayek, F. A. (2001). The Road to Serfdom. Routledge Classics. Routledge. Vol. 2nd Edition.

- Hey, J. (1993). Foreign Policy Options under Dependence: A Theoretical Evaluation with Evidence from Ecuador. Journal of Latin American Studies, 25(3), 543-574. https://doi.org/10.1017/S0022216X00006660

- Hey, J. A. (1995). Theories of Dependent Foreign Policy and the Case of Ecuador in the 1980s. Ohio University Press. Vol. 23

- Hey, J. y Klak, T. 1999. From protectionism towards neoliberalism: Ecuador across four administrations (1981-1996). Studies in Comparative International Development, 34(3), 66-97.

- Hirschman, A. (1945). National Power and the Structure of Foreign Trade. Berkeley: CA: University of California Press.

- Hoffmann, S. (1963). Teorías contemporáneas sobre las relaciones internacionales (No. $327 \mathrm{HOFt}$ ).

- Hsiang, A. (2016): Power Transition: The U.S. vs. China in Latin America. Journal of China International Relations, Special Issue, 44-72

- Huntington, S. (1998). The Clash of Civilizations and the Remaking of World Order. New York: Touchstone.

- lida, K. (1988). Third World Solidarity: The Group of 77 in the UN General Assembly. International Organization.

- IMF. (2019). Growth slowdown, precarious recovery. International Monetary Fund. World economic outlook. 
- Índice Elcano de presencia global. Real Instituto Elcano de estudios internacionales y estratégicos. Disponible en: https://www.globalpresence.realinstitutoelcano.org/es/

- Insignares Cera, S. (2013). La UNASUR: ¿integración regional o cooperación política?: UNASUR: Regional Integration or political cooperation? Revista de Derecho, 40. http://www.scielo.org.co/scielo.php?script=sci_arttext\&pid=S0121 86972013000200007

- International Trade Center (ITC). Trade map. Trade statistics for international business development. Disponible en: https://www.trademap.org/countrymap/Bilateral_TS.aspx?nvpm=1\%7c842\%7c\%7 c218\%7c\%7cTOTAL\%7c\%7c\%7c2\%7c1\%7c1\%7c1\%7c2\%7c1\%7c1\%7c1\%7c1

- Jaguaribe, H. (1979). Autonomía periférica y hegemonía céntrica. Estudios Internacionales 12, no 46: 91-130.

- Jaramillo, G. (2008). Mundial, B. Política Externa Los escenarios divergentes de la inserción ecuatoriana en el mundo. FLACSO Ecuador.

- Jaramillo, G. (2011). Política externa los escenarios divergentes de la inserción ecuatoriana en el mundo.

- Johnson, Paul M. (1986). The subordinate states and their strategies. En Dominant powers and subordinate states. The United States in Latin America and the Soviet Union in eastern Europe, ed. Jan F. Triska, 285-309. Durham: Duke University Press.

- Jolly R. et al. (2004). UN Contributions to Development Thinking and Practice. Indiana University Press, Bloomington and Indianapolis.

- Kennedy, P. (1994). Auge y Caída de Grandes Poderes . Barcelona: Plaza \& Janés Editores S.A.

- Kennedy, P. (2006). The Parliament of Man: The Past, Present, and Future of the United Nations. New York: Random House.

- Keohane, R. (1984), After Hegemony. Cooperation and Discord in the World Political Economy, Princeton.

- Keohane, R. O. (1986). Neorealism and its Critics. Columbia University Press.

- King, G. (1995). The qualitative-quantitative disputation: Gary King, Robert O. Keohane, and Sidney Verba's designing social inquiry: Scientific inference in qualitative research. American Political Science Review, 89(2), 454-480.

- Kitano, N. Y Harada, Y. (2014). Estimating China's Foreign Aid 2001-2013. JICA Research Institute Working Paper 78.

- Klink, F. (1990). Rationalizing Core-Periphery Relations: The Analytical Foundations of Structural Inequality in World Politics". International Studies Quarterly. Vol. 34. № 2

- Krasner, S. (1976). State Power and the International Trade Structure. World Politics. No. 28. 317-347.

- Krasner, S. (1983). International regimes, Cornell University Press.

- Krasner, S. (1987). Asymmetries in Japanese-American Trade: The Case for Specific Reciprocity. Policy Papers in International Affairs, no. 32.

- Krippendorff, E. (1985). El Sistema Internacional como Historia, México D.F., Fondo de Cultura Económica.

- Krugman, P. (2009). The Return of Depression Economics and the Crisis of 2008. New York: Norton Company.

- Lamont, C. (2015). Research Methods in International Relations. Los Angeles: SAGE Publications. 
- Lapena-Sanz, R. y Czubala, M. (2018). La política exterior dependiente: el caso de Ecuador. OASIS, 28, pp. 171-191. Disponible en: https://doi.org/10.18601/16577558.n28.10

- Laufer, R. (2013). China: ¿'País emergente' o gran potencia del Siglo XXI? Dos décadas de expansión económica y de influencia política en el mundo. VI Jornadas de Economía Crítica, Facultad de Ciencias Económicas de la Universidad Nacional de Cuyo, Mendoza, Argentina.

- Layne, C. (2008). China's challenge to US hegemony. Current history-new york then philadelphia-, 107(705), 13.

- Lechini, G. (2009). La cooperación Sur-Sur y la búsqueda de autonomía en América Latina: ¿Mito o realidad? Relaciones Internacionales, Núm. 12, octubre de 2009. GERI - UAM

- Lechini, G., y Morasso, C. (2010). La cooperación Sur-Sur en el Siglo XXI. Reflexiones desde América Latina.

- León, J. (1994). El fin de un ciclo político electoral: El regreso de las elites tradicionales, apatía y cambio. Ecuador Debate, № 32, 76 - 89.

- Li, X. (2010). The rise of China and the capitalist world order. Ashgate Pub. Co.

- Li, X., Gu, J., Leistner, S. y Cabral, L. (2018). Perspectives on the global partnership for effective development cooperation. IDS Bulletin, 49(3), 145-165.

- Li. X. (2017). Should China join the GPEDC? The prospects for China and the Global Partnership for Effective Development Co-operation. German Development Institute. Discussion Paper, 17/2017.

- Libro Blanco (1991). Libros Blancos. Observatorio de la Política China. Disponible en: https://politica-china.org/secciones/documentacion/libros-blancos.

- Lijphart, A. (1963). The analysis of bloc voting in the General Assembly: A critique and a proposal. American Political Science Review, 57(4), 902-17.

- Lin, J. Y. (2011). Nueva economía estructural: un marco para reformular el desarrollo. The World Bank. No. WPS5197, pp. 1-42

- Lin, J.L. y Wang, Y. (2017). Going Beyond Aid. Development Cooperation for Structural Tranformation. Cambridge: Cambridge University Press.

- Lin, J.Y. (2012). New Structural Economics. A Framework for Rethinking Development and Policy. The World Bank. Washington

- Linklater, A. (2005). Marxism. En: Burchill, Scott (et. al), Theories of International Relations, Third Edition, New York: Palgrave MacMillan, pp. 110-136.

- Linklater, A., Donnelly, J. et al. (2005). Theories of International Relations. P. pp. 161-187.

- Llenderozas, E. (2012). Diálogo y concertación política en América Latina: Los alcances de las propuestas regionales. En Serbín, A., Martínez, L. y Ramanzini, HJ (coords.). El regionalismo "post-liberal" en América Latina y el Caribe: Nuevos actores, nuevos temas, nuevos desafíos. pp. 153.

- Lo Brutto, G. (2017). A propósito de la cooperación internacional y del desarrollo: una visión más realista. En Historia de la cooperación internacional desde una perspectiva crítica. Revista Internacional de Cooperación y Desarrollo, 5(1), 55-74.

- Lo Brutto, G. y Reyes, E. I. G. (2015). Regionalismo estratégico, cooperación sursur y desarrollo en América Latina en el siglo XXI. Bajo el Volcán, 15(22), 151-176.

- Lo Brutto, G., y González, C. (2015). La influencia China en la Cooperación Sur-Sur Latinoamericana, durante la segunda década del Siglo XXI. Catedra COIBA DT cooperación y desarrollo, 2, 1-15.

- Lukes, S (1974). Power: A radical view. London and New York: Macmillan. 
- Malacalza, B. (2018). China, América Latina y el hormiguero. http://www.condistintosacentos.com/china-america-latina-y-el-hormiguero/

- Malacalza, B., y Lengyel, M. (2014). Política exterior y Cooperación Sur-Sur al desarrollo. El caso argentino. Diversidad y consonancia en la cooperación Sur-Sur latinoamericana, 43-76.

- Mansfield, E. D., \& Milner, H. V. (1999). The new wave of regionalism. International organization, 53(03), 589-627.

- Marín-Bosch, M. (1998). Votes in the UN General Assembly. The Hague: Kluwer Law International.

- Marshall, M., y Jaggers, K. (2008). Polity IV Dataset, version p4v2008. Center for International Development and Conflict Management. College Park: University of Maryland.

- Marshall, M.G., Gurr, T. Jaggers, K. (2011). Center for Systemic Peace. Polity IV Project

- Martínez A., Vallejo, M., Samaniego, P. (2014). Déficit comercial y déficit físico en Sudamérica. Visita 1 de septiembre 2014. Disponible en http://www.flacsoandes.edu.ec/agora/deficit-comercial-y-deficit-fisico-ensudamerica.

- Martínez-Hernández, A. y Bohigues, A. (2019). El giro a la izquierda de los parlamentos latinoamericanos: ¿cuándo y cómo se dio? Revista Política y Gobierno, XXVI (1): 93-115.

- Martínez-Peinado, J. (1999). El capitalismo global. Límites al desarrollo y la cooperación. Barcelona: Icaria

- McCoy, A. W. (2017). In the shadows of the American century: the rise and decline of US global power.

- Mijares, V. y Detlef N. (2018). Regionalismo posthegemónico en crisis: ¿Por qué la UNASUR se desintegra?. Foreign Affairs Latinoamérica 18, no 3: 105-112.

- Milani, C. y Carvalho, T. (2014). Cooperación sur-sur y política externa: la presencia de Brasil y China en el continente africano. La cooperación Sur-Sur latinoamericana, 137.

- Minutti, E. C., y Brutto, G. L. (2018). La cooperación de China en América Latina: ¿hacia una Nueva Economía Estructural? Carta Internacional, 13 (2).

- Modelski, G. (1983). Long Cycles of World Leadership. En W. Thomson, Contending Approaches to World System Analysis. California: Sage.

- Moe Fejerskov, A. (2016). Understanding the nature of change: how institutional perspectives can inform contemporary studies of development cooperation. Third World Quarterly, https://doi.org/10.1080/01436597.2016.1159128

$37(12)$,

2176-2191.

- Morvaridi, B., y Hughes, C. (2018). South-South Cooperation and Neoliberal Hegemony in a Post-aid World. Development and Change, 49(3), 867-892. https://doi.org/10.1111/dech.12405

- MRERPC -Ministerio de Relaciones Exteriores de la República Popular China. (2016). Documento sobre la Política de China Hacia América Latina y el Caribe. Disponible en: https://www.fmprc.gov.cn/esp/wjdt/wjzc/t1418256.shtml

- Muir, T. (2016). Beyond "BRICS": ten theses on South-South cooperation in the twenty-first century. Third World Quarterly, 37(4), 630-648

- Murillo, M., Oliveros, V. y Vaishnav, M. (2010). Electoral revolution or democratic alternation? Latin American Research Review. Pp.87-114. 
- Murray, D., Brown, D. (2010), Multipolarity in the 21st Century: Contemporary Security Studies. Abingdon, Routledge.

- Myers, M., \& Gallagher, K. (2020). Could China Be a White Knight Again for Latin America? - The Dialogue. The Dialogue. https://www.thedialogue.org/analysis/could-china-be-a-white-knight-again-for-latinamerica

- Myrdal, G. (1956). Development and under-development: A note on the mechanism of national and international economic inequality. National Bank of Egypt.

- Naciones Unidas (2016). Voting Practices in the United Nations. IV General Assembly: important votes and consensus actions. file://E:/Alemania/PHD/Publicaciones/Articulo\%20votos\%20NNUU,\%20AL,\%20Ch ina,\%20USA/Bases\%20de\%20datos/NNUU/USA\%20important\%20votes\%20in\%2 0the\%20UN.pdf

- Nadal, A. (2009). La reprimarización de América Latina. La Jornada, 7(10), 2009.

- Najam, A. and Thrasher, R. (2012). The Future of South-South Economic Relations, London: Zed Books

- Nandy, A. (1992). State. En Sachs, W. (ed.) The Development Dictionary: A Guide to Knowledge as Power, pp. 264-74. London: Zed Books.

- Neto, O. A., y Malamud, A. (2015). What determines foreign policy in Latin America? Systemic versus domestic factors in Argentina, Brazil, and Mexico, 1946-2008. Latin American Politics and Society, 57(4), 1-27.

- Nieto-Pereira, L. (2015). La Ruta de la Seda en América Latina. Disponible en: https://www.lamarea.com/2015/06/05/la-ruta-de-la-seda-en-america-latina

- Nolte, D. (2006). Potencias regionales en la política internacional: conceptos y enfoques de análisis (No. 30). GIGA working papers.

- North, D. (1990). Institutions and Their Consequences for Economic Performance. En Cook, K. y Levi, M. (eds.) The Limits of Rationality. Chicago: Chicago University Press, pp.383-401.

- Noyola, A. (2015). China has become main banker in Latin America. Voltaire Network, 13 march. Disponible en: http://www.voltairenet.org/article187046.html

- Nye, J. (1965). Pan-African and the East African Integration. Cambridge: Cambridge University Press.

- Nye, J. (2005). The rise of China's soft power. Wall Street Journal Asia, 29, 6-8

- Nye, J. S. (2011). Power and foreign policy. Journal of Political Power, 4(1), 9-24.

- O'Neill, H. (1980). The Need for Economic Cooperation among Developing Countries. IDS Bulletin, 11(1), 47-54.

- OECD. (2020). Development Co-operation Directorate. Disponible en: http://www.oecd.org/dac/

- Ohmae, K. (2005). The Next Global Stage: The Challenges and Opportunities in Our Borderless World. Pennsylvania: Wharton School Publishing.

- PABA (1978). Plan de Acción de Buenos Aires para Promover e Implementar Cooperación Técnica entre Países en Desarrollo. Naciones Unidas

- Palazuelos, E. (2015). Enfoque sistémico o estructural. Disponible en: https://repensarlaeconomia.files.wordpress.com/2015/01/estructuralismopresentacic3b3n.pdf

- Park, J. (2016). Is the Chinese Government's Increase in Development Cooperation with Africa the Revival of Sinocentrism? Geopolitics, 20(3), 626-644.

- Patiño, R. (2007). Discurso de Posicionamiento del Economista Ricardo Patiño como Ministro de Relaciones Exteriores, Comercio e Integración. MRE. Disponible 
en: https://www.cancilleria.gob.ec/discurso-de-posicionamiento-del-economistaricardo-patino-como-ministro-de-relaciones-exteriores-comercio-e-integracion/

- Payne, A.; Gamble, A (1996), 'Introduction: the political economy of regionalism and world order', London: Macmillan, p. 2.

- Paz, G. S. (2012). China, United States and hegemonic challenge in Latin America: An overview and some lessons from previous instances of hegemonic challenge in the region. China Quarterly, 209(209), 18-34. https://doi.org/10.1017/S0305741011001469

- Pignatta, M. (2010). Identidad y política exterior. Explorando el caso argentino. En Anabella Busso (comp), Fuerzas profundas e identidad. Reflexiones en torno a su impacto sobre la política exterior. Rosario, Argentina, UNR Editora, E-book, t.II, pp. 139-157.

Disponible

en: http://www.cerir.com.ar/admin/_cerir/archivos/libros/0000142/Busso\%20\%20ebook\%202.pdf. Consultado: 03/03/2011.

- Planex (2020). Plan Nacional de Política Exterior 2006-2020. Ministerio de Relaciones Exteriores de la República del Ecuador. Disponible en: https://www.cancilleria.gob.ec/wp-content/uploads/2013/05/planex_2020.pdf

- Prashad, V. (2013) Las naciones pobres. Una posible historia global del Sur, Península, Barcelona

- Prebisch, R. (1963). Towards a dynamic development policy for Latin America.

- Pueblo en Línea. (2015). Se abre nueva vía de cooperación económica China América Latina. Junio. Disponible en: http://spanish.peopledaily.com.cn/n/2015/0619/c31617-8908948.html

- Puig, J. (1980). Doctrinas internacionales y autonomía latinoamericana. Caracas: Instituto de Altos Estudios de América Latina. Fundación bicentenario de Simón Bolívar.

- Puig, J. (1984) América Latina: Políticas exteriores comparadas, (Vol. 2). Grupo Editor Latinoamericano.

- Puig, J. C. (1980). Doctrinas internacionales y autonomía latinoamericana. Universidad Simón Bolívar: Instituto de Altos Estudios de América Latina. Caracas. Fundación bicentenario de Simón Bolívar .

- Puig, J.C. (1986). Integración y autonomía en América Latina en las postrimerías del siglo XX. En: Integración Latinoamericana, 11, 109, pp. 40-62.

- Quijano, A. (2003). Colonialidad del poder, eurocentrismo y América Latina. En E. Lander (comp.) La colonialidad del saber: eurocentrismo y ciencias sociales. Perspectivas latinoamericanas, Buenos Aires, CLACSO.

- Ragin, C. C. (2014). The comparative method: Moving beyond qualitative and quantitative strategies. University of California Press.

- Rahme, A. J. (2012). China irrumpe en Latinoamérica: ¿Dragón o panda? Grupo Editor Orfila Valentini.

- Rica, C., \& Lockhart, F. (2013). La identidad de UNASUR: ¿Regionalismo postneoliberal o post-hegemónico? Revista de Ciencias Sociales (Cr), II, 97-109. http://www.redalyc.org/articulo.oa?id=15329874007

- RIS. South-South Cooperation (2016). Conference Proceedings. New Delhi, Research and Information System for Developing Countries (RIS)

- Rist, G. (2008). The history of development: From western origins to global faith. Zed Books Ltd.

- Rivarola, A., \& Briceño-Ruiz, J. (2013). Resilience of Regionalism in Latin America and the Caribbean. Development and Autonomy. Nueva York: Palgrave Macmillan. 
- Rodríguez, M. (2013). La cooperación venezolana en América Latina: de la retórica a la acción. América Latina Hoy, 63, 113-137.

- Rodrik, D. (1997). Has Globalization Gone Too Far? Institute for International Economics, Washington, DC

- Roett, R., y Paz, G. (2008). China's Expansion into the Western Hemisphere. Brookings Institution Press. https://www.brookings.edu/book/chinas-expansioninto-the-western-hemisphere/

- Rosero, G. (2015). Cooperación Sur-Sur: oportunidad para el reencuentro entre América Latina y el Caribe. Cooperamos, 8: 12-16

- Russell, R y Calle, F. (2009). La "periferia turbulenta" como factor de la expansión de los intereses de seguridad de Estados Unidos en América Latina.

- Russell, R. y Tokatlian J. (2010). Autonomía y neutralidad en la globalización. Una readaptación contemporánea. Buenos Aires: Capital Intelectual.

- Russell, R. y Tokatlian, J. (2013). América Latina y su gran estrategia: entre la aquiescencia y la autonomía. CIDOB d'afers internationals, pp. 157-180.

- Russell, R., y Tokatlian, J. (2003). El lugar de Brasil en la política exterior argentina (Vol. 642). Buenos Aires: Fondo de Cultura Económica.

- Russell, R., y Tokatlian, J. (2006). Will Foreign Allies Help? Argentina's Relations with Brazil and the United States. En E. Epstein, \& D. Pion-Berlin, Broken Promises? The Argentine Crisis and Argentine Democracy (págs. 245-69). Lanham: Rowman and Littlefield Publishers.

- Russell, R., y Tokatlian, J. (2013). América Latina y su gran estrategia: entre la aquiescencia y la autonomía/Latin America and its grand strategy: between acquiescence and autonomy. Revista CIDOB d'afers internacionals, 157-180.

- Russell, R., y Tokatlian, J. G. (2001). Relaciones internacionales y política interna: Los neutrales en la Segunda Guerra Mundial, un estudio de caso. Foro Internacional, 63-103.

- Russell, R., y Tokatlian, J. G. (2002). De la autonomía antagónica a la autonomía relacional: una mirada teórica desde el Cono Sur. Perfiles latinoamericanos: revista de la Facultad Latinoamericana de Ciencias Sociales, Sede México, (21), 159-194.

- Sagasti, F. y Alcalde, G. (1999), Development Cooperation in a Fractured Global Order: An Arduous Transition. Ottawa: International Development Research Centre.

- Sanahuja, A., \& Comini, N. (2018). Unasur: ¿'Sudamexit' o la estrategia de la silla vacía? - Esglobal - Política, economía e ideas sobre el mundo en español. Esglobal. https://www.esglobal.org/unasur-sudamexit-o-la-estrategia-de-la-silla-vacia/

- Sanahuja, J. A. (2013). Las nuevas geografías de la pobreza y la desigualdad y las metas de desarrollo global post-2015. Anuario Ceipaz 2013-2014. El reto de la democracia en un mundo en cambio: respuestas políticas y sociales., 61-100.

- Sanahuja, J. A. (2014). Enfoques diferenciados y marcos comunes en el regionalismo latinoamericano: Alcance y perspectivas de UNASUR y CELAC. Pensamiento Propio, 39. www.imagentres.com

- Sanahuja, J. A. (2016). Regionalismo e integración en América Latina: de la fractura Atlántico-Pacífico a los retos de una globalización en crisis. Pensamiento propio, 21(44), 29-76.

- Sánchez Padilla, A. (2016). ¿En defensa de la Doctrina Monroe? Los desencuentros en América Latina entre España y Estados Unidos (1880-1890). Historia Crítica, No. 40, 62, 13-33. https://doi.org/10.7440/histcrit62.2016.01

- Sánchez, F. y García Montero, M. (2019). Los ciclos políticos y económicos de América Latina y el boom de las materias primas. Madrid, España. Editorial Tecnos. 
- Santana, C. y Bustamante, G. (2013). La autonomía en la política exterior latinoamericana: evolución y debates actuales. Papel político, 18(2), 719-742.

- Santander, G. (2016). La cooperación sur-sur: entre la promoción del desarrollo y la funcionalidad política: los casos de Chile, Venezuela y Brasil. Universidad Complutense de Madrid.

- Schenoni, L. (2012). Los determinantes sistémicos de la política externa brasileña en el contexto de América Latina. In 4th Uruguayan Congress of Political Science (AUCiP), Montevideo, November (pp. 14-16).

- SEGIB (2011). Informe de la Cooperación Sur-Sur en Iberoamérica 2011. Estudios Secretaría General Iberoamericana (SEGIB). N. 6

- SEGIB (2014). Programa Iberoamericano para el Fortalecimiento de la Cooperación Sur-Sur: Diagnóstico de los marcos normativos e institucionales para la gestión de la Cooperación Sur-Sur en los países de Iberoamérica. Estudios Secretaría General Iberoamericana. Documento de trabajo No. 6, año 2014

- SEGIB (2017). Informe de la Cooperación Sur-Sur en Iberoamérica. Secretaría General Iberoamericana (SEGIB) P. 1-232

- Selcher, W. (1978). Brazil's Multilateral Relations: Between First and Third Worlds. . Boulder: Westview Press.

- SENPLADES (2008). Plan Nacional de Desarrollo 2007-2010. Secretaría Nacional de Planificación y Desarrollo. República del Ecuador.

- SENPLADES (2010). República del Ecuador. Plan Nacional del Buen Vivir 20092013. Secretaría Nacional de Planificación y Desarrollo. República del Ecuador.

- SENPLADES (2013). Plan Nacional del Buen Vivir 2013-2017. Secretaría Nacional de Planificación y Desarrollo. República del Ecuador.

- Sequeiros, S., \& Redondo, M. (2003). Algunas cuestiones metodológicas sobre la medición del comercio intra industrial. Versión Online: http://gaspar. udc. es/subido/4_comercio_internacional/algunas_cuestiones_metodolgicas.pdf.

- Serbín, A (2017). China y América Latina y el Caribe frente a un cambio de ciclo: narrativas y estrategias. En La proyección de China en América Latina y el Caribe, de Eduardo Pastrana y Hubert Gehring. Pontificia Universidad Javeriana.

- Serbin, A. (2012). Déficit democrático y participación ciudadana en el marco del regionalismo post-liberal. Serbin, A., Martínez, L. y Ramanzini, HJ (coords.). El regionalismo "post-liberal" en América Latina y el Caribe: Nuevos actores, nuevos temas, nuevos desafíos, 73-128.

- Serbin, A. (2016). ¿Fin de ciclo?: Las relaciones entre Cuba y los Estados Unidos en el entorno regional y global. Anuario de Integración, Edición especial

- Serbín, A. (2017). Un triángulo escaleno América Latina y el Caribe, China y los Estados Unidos y las narrativas del nuevo ciclo. En Serbin, A.; Martínez, L.; Ramanzini Junior, H. y Serbín Pont, A. (Coords.) América Latina y el Caribe frente a la encrucijada actual de la globalización. Anuario de la integración regional de América Latina y el Caribe, (13), 31-58.

- Sevares, J. (2007). ¿Cooperación Sur-Sur o dependencia a la vieja usanza? América Latina en el comercio internacional. Nueva Sociedad, 207. www.unctad.org

- Shicheng, X. (2016). Iniciativas chinas en América Latina y el Caribe. Vanguardia Dossier China. La Nueva Ruta de la Seda, 69, 85-88.

- Shicheng, X. (2006). Las diferentes etapas de las relaciones sinolatinoamericanas. Nueva Sociedad, 203, 102-113 
- Simonoff, A. (2015). Integración y autonomía en el pensamiento de Juan Carlos Puig. En Briceño Ruiz, A. y Simonoff, A. Integración y cooperación regional en América Latina. Una relectura a partir de la teoría de la autonomía. Editorial Biblos

- Singer, J., Bremer, S. y Stuckey J. (1972). Capability distribution, uncertainty, and major power war, 1820-1965. Peace, war, and numbers 19: 48.

- Slipak, A. (2014a). América Latina y China: ¿Cooperación Sur-Sur o «Consenso de Beijing»? Nueva Sociedad, 250. https://nuso.org/articulo/america-latina-y-chinacooperacion-sur-sur-o-consenso-de-beijing/

- Slipak, A. (2014b). Un análisis del ascenso de China y sus vínculos con América a la luz de la Teoría de la Dependencia*. Transformaciones.

- Sogge, D. (2002). Give and take: what's the matter with foreign aid? Zed Books.

- Sotillo, J. (2010). La Cooperación Sur-Sur en Latinoamérica. Utopía y Realidad. Madrid: La Catarata/IUDC-UCM, pp. 11-16.

- Spence, M. (2017). China: nueva potencia reguladora de la economía global. Foro Económico Mundial. Word Economic Forum. September 11. https://es.weforum.org/agenda/2017/09/china-nueva-potencia-reguladora-de-laeconomia-global/

- State Council (2014). China's Foreign Aid (2014). Information Office of the State Council. http://news.xinhuanet.com/english/china/2014-07/10/c_133474011.htm.

- Stengel, R. (2017). The End of the American Century. The Atlantic. https://www.theatlantic.com/politics/archive/2017/01/end-of-the-americancentury $/ 514526 /$.

- Strange, S. (1983). Structure, values and risks in the study of International Political Economy. En Barry Jones, R. Perspectives in Political Economy. Londres, Pinter, p. 220

- Strange, S. (1988). States and markets: an introduction to political economy. London, Pinter.

- Strüver, G. (2014). Bereft of friends? China's rise and search for political partners in South America. Chinese Journal of International Politics, 7(1), 117-151. https://doi.org/10.1093/cjip/pot018

- Suraski, J. (2014). La Cooperación Sur-Sur en América Latina como herramienta decolonial. Congreso FLACSO-ISA, Buenos Aires.

- Svampa, M. (2012). Consenso de los Commodities, Giro Ecoterritorial y Pensamiento crítico en. CLACSO. http://biblioteca.clacso.edu.ar/clacso/osal/20120927103642/OSAL32.pdf

- Svampa, M. (2019). Las fronteras del neoextractivismo en América Latina. In Las fronteras del neoextractivismo en América Latina. transcript Verlag. https://doi.org/10.14361/9783839445266

- Svampa, M., y Slipak, A. M. (2015). China en América Latina: Del Consenso de los Commodities al Consenso de Beijing. Revista Ensambles, (3).

- Tandon, Y. (2009). ¿Quién ayuda a quién?: el efecto de la ayuda al desarrollo en el Tercer Mundo. Editorial Popular.

- Thacker, S. (1999). The High Politics of IMF Lending. World Politics, 1, 38-75.

- The Economist (2011). Rumble in the Jungle-Africa and China. 20 de abril. Disponible en: https://www.economist.com/leaders/2011/04/20/rumble-in-thejungle

- Tickner, A. (2002). Los estudios internacionales en América Latina: ¿subordinación intelectual o pensamiento emancipatorio? Bogotá: Ediciones Uniandes 
- Tickner, A. (2013). Core, periphery and (neo)imperialist International Relations. European Journal of International Relations, 19(3), 627-646.

- Tickner, A. (2015). Autonomy in Latin American International Relations thinking. En J. Domínguez, \& A. Covarrubias, Routledge Handbook of Latin America and the World. Nueva York: Routledge.

- Tokatlian, J. G. (1984). La OEA: Repensando su crisis. Nueva Sociedad. Nueva Sociedad, 72. https://nuso.org/articulo/la-oea-repensando-su-crisis/

- Tokatlian, J. G., y Carvajal H, L. (1995). Autonomía y política exterior: un debate abierto, un futuro incierto. Revista CIDOB d'afers Internacionals, 7-31

- Tolcachier, J. (2020). CELAC 2020: Nuevo impulso integrador en tiempos turbulentos. TeleSUR. Telesurtv.Net. Disponible en : https://www.telesurtv.net/bloggers/CELAC-2020-Nuevo-impulso-integrador-entiempos-turbulentos-20200109-0002.html

- Tomassini, L. (1976). El proceso de cooperación técnica entre los países en desarrollo. Integración Latinoamericana, 1(4), 28-32.

- Tomassini, L. (1977). Falencias y falacias: notas sobre el estudio de las relaciones norte-sur. Estudios Internacionales, 10(40), 111-130. https://doi.org/10.5354/REI.V10140.16563

- Tomassini, L. (1979). Los países de desarrollo intermedio en la economía mundial. El caso de América Latina. Comercio Exterior, 29(3), 303-311.

- Tomlin, B. (1985). Measurement Validation: Lessons from the Use and Misuse of UN General Assembly Roll-Call Votes. International Organization, 39(4), 189-206

- Trindade d'Ávila Magalhães, D. (2018). The globaliser dragon: how is China changing economic globalisation? Third World Quarterly, 39(9), 1727-1749. https://doi.org/10.1080/01436597.2018.1432352

- UNCTAD (2010). Economic Development in Africa Report 2010. South-South Cooperation: Africa and the New Forms of Development Partnership. Nueva York y Ginebra: United Nations

- van Bergeijk, P. (2018). China's Economic Hegemony (1-2050 AD). Working paper, The Hague: International Institute of Social Studies.

- Vázquez, C. (2019). ALBA-TCP y UNASUR como experiencias de Cooperación Sur-Sur: un abordaje desde la política. In La Constelación del Sur: lecturas histórico-críticas de la Cooperación Sur-Sur. https://www.researchgate.net/publication/339831676_ALBATCP_y_UNASUR_como_experiencias_de_Cooperacion_SurSur_un_abordaje_desde_la_politica

- Vilaro, R. (1977). El "diálogo Norte-Sur" al borde del fracaso Internacional. El Pais.https://elpais.com/diario/1977/06/01/internacional/233964005_850215.html

- Vivares, E., Lombardo, P. T., \& Cvetich, K. (2014). Enfoques y cárceles conceptuales en el entendimiento de los Nuevos Regionalismos Latinoamericanos. Desafíos estratégicos del regionalismo contemporáneo: CELAC e Iberoamérica, 21.

- Vivares, E., y Zapata, S. (2011). Hacia una economía política de la cooperación pluralista y sudamericana. Revista Cooperamos, (2), 38-44.

- Voeten, E. (2000). Clashes in the Assembly. International Organizations, 54(2), 185215.

- Voeten, E. (2015). Data and analyses of voting in the UN General Assembly. Disponible en SSRN 2111149 
- Wallerstein, I. (2004). El ascenso y futura decadencia del sistema mundo capitalista: conceptos para un análisis comparativo. En Wallerstein, Capitalismo histórico y movimientos antisistémicos, pp. 85-114. Madrid: Akal

- Wallerstein, I. (2017). China and the United States: Partners? Immanuel Wallerstein. Commentary No. 441. http://iwallerstein.com/china-and-the-unitedstates-partners/

- Weiss, L. (ed.) (2003), States in the Global Economy: Bringing Domestic Institutions Back in. Cambridge: Cambridge University Press

- Wendt, A. (1999). Social theory of international politics (Vol. 67). Cambridge University Press.

- Womack, B. (2006). China and Vietnam. The politics of asymmetry. Cambridge: Cambridge University Press.

- Xing, L. (2016). The Expansion of China's Global Hegemonic Strategy: Implications for Latin America. Journal of China International Relations. Special Issue, 1-26.

- Xinhua. (2005). Human rights can be manifested differently. Xinhuanet. December 12

https://web.archive.org/web/20071209093707/http://news.xinhuanet.com/english/2 005-12/12/content_3908887.htm

- Xinhuanet (2019). Franja y Ruta: Enfoque de China: Iniciativa de Franja y Ruta es plataforma prometedora para cooperación internacional. April 26. Disponible en http://spanish.xinhuanet.com/2019-04/26/c_138013529.htm

- Xuetong, Y. (2016). Political Leadership and Power Redistribution. Chinese Journal of International Politics, 9(1), 1-26.

- Xuetong, Y. (2014). From Keeping a Low Profile to Striving for Achievement. Chinese Journal of International Politics, 7(2), 153-184.

- Xuetong, Y. (2019). Leadership and the rise of great powers. Princeton University Press.

- Yahuda, M. (1978). The Chinese View of a New World Order, Millenium: Journal of International Studies, 7(1), 1-19.

- Yan, X. (2018). Chinese values vs. liberalism: what ideology will shape the international normative order? The Chinese Journal of International Politics, 11(1), $1-22$.

- Yaqing, Q. (2014). Continuity through Change: Background Knowledge and China's International Strategy. Chinese Journal of International Politics, 7(3), 2014, p. 285314.

- Yepe Papastamatin (2013). La CELAC y el multilateralismo regional. En Desafíos estratégicos del regionalismo contemporáneo CELAC e Iberoamérica. Editores Adrián Bonilla Soria Isabel Álvarez Echandi. Flacso.

- Yu, L. (2015). China's strategic partnership with Latin America: a fulcrum in China's rise. International Affairs, 91(5), 1047-1068.

- Zapata, S. (2017). ALBA en el turbulento escenario venezolano. Política Exterior. Política Exterior. https://www.politicaexterior.com/la-iniciativa-alba-en-el-turbulentoescenario-venezolano/

- Zapata, S. (2017). El regionalismo latinoamericano en la primera década del siglo XXI: repensando la idea de autonomía. Revista Andina de Estudios Políticos, Lima, 7(2), 67-91.

- Zapata, S. (2018). Power reconfigurations and South-South Cooperation Policies in Latin America during the first decade of the 21st century. Revista Andina de Estudios politicos, 8(1), 31-59. 
- Zepeda, B., \& Egas, M. (2011). La política exterior de la revolución ciudadana: opinión y actitudes públicas. Revista Mexicana de política exterior, 93, 95-134.

- Zhang, D. y Smith, G. (2017). China's foreign aid system: structure, agencies, and identities. Third World Quarterly, 38(10), 2330-2346.

- Zhang, Y; Gu, J; Chen, Y. (2015). China's Engagement in International Development Cooperation: The State of the Debate. IDS Evidence Report, pp. 116

- Zhimin, Y. (2015). Los actores del desembarco chino en América Latina. Nueva Sociedad, 259, 45-54. 